Illinois State University

ISU ReD: Research and eData

Theses and Dissertations

3-16-2021

\title{
Synthesis Of Oxyquinoliziniporphyrins And \\ Pyridoquinoliziniporphyrins
}

Emma Cramer

Illinois State University, emmacramer96@gmail.com

Follow this and additional works at: https://ir.library.illinoisstate.edu/etd

Part of the Chemistry Commons

\section{Recommended Citation}

Cramer, Emma, "Synthesis Of Oxyquinoliziniporphyrins And Pyridoquinoliziniporphyrins" (2021). Theses and Dissertations. 1359.

https://ir.library.illinoisstate.edu/etd/1359

This Thesis is brought to you for free and open access by ISU ReD: Research and eData. It has been accepted for inclusion in Theses and Dissertations by an authorized administrator of ISU ReD: Research and eData. For more information, please contact ISUReD@ilstu.edu. 


\section{SYNTHESIS OF OXYQUINOLIZINIPORPHYRINS AND \\ PYRIDOQUINOLIZINIPORPHYRINS}

EMMA CRAMER

\section{Pages}

$\mathrm{N}$-confused porphyrins are porphyrin analogues that introduce a nitrogen outside of the macrocyclic cavity. Two novel N-confused type porphyrins were targeted for this study. Both syntheses use the key intermediate 4-quinolizone. Previous studies of $\mathrm{N}$-confused pyriporphyrin showed that the system is nonaromatic and resembles structurally analogous benziporphyrins. However, modifications to systems of this type can introduce aromatic characteristics. The first system targeted introduced a quinolizone subunit into a porphyrin system. Quinolizone contains a thermodynamically stable amide and this unit disrupts the aromatic pathway. However, dipolar resonance contributors can potentially reinstate some aromatic character. A quinolizone dialdehyde was condensed with tripyrranes under acidic conditions, and following an oxidation step, the first example of oxyquinoliziniporphyrins were isolated. These novel structures were very stable but exhibited only weakly-aromatic properties. Protonation and metalation studies were conducted and these modifications increased the diatropic ring current.

In a related study, the introduction of an antiaromatic pyridoquinolizine unit has been investigated. A pyridoquinolizine diester was prepared from the 4-quinolizone intermediate used in the previous project. However, difficulties were encountered in converting the diester into the dialdehyde required to synthesize the macrocycle. If these problems can be overcome, it is 
anticipated that pyridoquinoliziniporphyrins will possess a significant degree of aromatic character.

KEYWORDS: carbaporphyrin, N-confused porphyrin, aromatic, antiaromatic, metalation 


\title{
SYNTHESIS OF OXYQUINOLIZINIPORPHYRINS AND \\ PYRIDOQUINOLIZINIPORPHYRINS
}

\author{
EMMA CRAMER
}

A Thesis Submitted in Partial Fulfillment of the Requirements for the Degree of

MASTER OF SCIENCE

Department of Chemistry

ILLINOIS STATE UNIVERSITY 
(C) 2021 Emma Cramer 


\section{SYNTHESIS OF OXYQUINOLIZINIPORPHYRINS AND \\ PYRIDOQUINOLIZINIPORPHYRINS}

EMMA CRAMER

COMMITTEE MEMBERS:

Timothy D. Lash, Chair

T. Andrew Mitchell

Jon A. Friesen 


\section{ACKNOWLEDGMENTS}

The author would like to acknowledge and thank the members of her research group for their support and friendship throughout her time at Illinois State University. The author also thanks Dr. Timothy D. Lash for his guidance, reassurance, and constant support throughout her years working with him. The writer acknowledges financial support from the National Science Foundation under grants no. CHE-1465049 and CHE-1855240.

The writer would also like to thank the members of her committee, Dr. Andrew Mitchell and Dr. Jon Friesen for their valuable lessons and support throughout her program. Finally, and most importantly, the author would like to thank her parents for their endless support and love throughout all her endeavors.

E. C. 


\section{CONTENTS}

Page

ACKNOWLEDGMENTS

FIGURES

iii

SCHEMES

$\mathrm{v}$

CHAPTER I: INTRODUCTION

CHAPTER II: SYNTHESIS AND CHARACTERIZATION OF

OXYQUINOLIZINIPORPHYRIN

CHAPTER III: SYNTHESIS AND PROGRESS TOWARDS

PYRIDOQUINOLIZINIPORPHYRIN

61

CHAPTER IV: CONCLUSION

69

REFERENCES

APPENDIX A: SELECTED SPECTROSCOPIC DATA FOR THE SYNTHESIS OF OXYQUINOLIZINIPORPHYRIN

APPENDIX B: SELECTED SPECTROSCOPIC DATA FOR

THE SYNTHESIS OF PYRIDOQUINOLIZINIPORPHYRIN 


\section{FIGURES}

Figure

Page

1. Porphyrin and its naturally occurring counterparts 1

2. Aromatic pathways of porphyrin and [18]annulene 2

3. Diamagnetic ring current of porphyrin 3

4. Carbaporphyrin Analogs 5

5. Benziporphyrin tautomers and resonance contributors for protonated $\begin{array}{ll}\text { benziporphyrins } & 7\end{array}$

6. Naphthiporphyrin tautomers and resonance contributors for the protonated $\begin{array}{ll}\text { naphthiporphyrin dication } & 8\end{array}$

7. Dimethoxybenziporphyrins and protonated dimethoxybenziporphyrins and their resonance contributors 11

8. Hydroxybenziporphyrins, oxybenziporphyrins, protonated oxybenziporphyrins, and a phenolic resonance contributor $\quad 13$

$\begin{array}{ll}\text { 9. N-confused pyriporphyrins } & 15\end{array}$

10. Pyriporphyrins 16

11. Phthalocyanine $\mathbf{8 0}$ and dipyriphthalocyanine $\mathbf{8 1} 28$

12. ${ }^{1} \mathrm{H}$ NMR spectrum of oxyquinolizone porphyrin $84 \mathbf{b}$ in $\mathrm{CDCl}_{3}$

13. UV-vis spectra of oxyquinoliziniporphyrin $\mathbf{8 4 a}$ in $1 \%$ triethylaminedichloromethane (free base, blue line) and 10\% TFA-dichloromethane (104a, red line) 
14. UV-vis spectra of oxyquinoliziniporphyrin $\mathbf{8 4 b}$ in $1 \%$ triethylamine dichloromethane (free base, blue) and 10\% TFA-dichloromethane

$$
\text { (104b, red line) }
$$

15. Downfield region of the ${ }^{1} \mathrm{H}$ NMR spectra for oxyquinoliziniporphyrin

$$
\text { 84b (top spectrum) and dication 104b (bottom spectrum) }
$$

16. ${ }^{1} \mathrm{H}$ NMR spectrum of protonated oxyquinoliziniporphyrin dication 104a in TFA-CDCl ${ }_{3}$

17. Downfield region of the ${ }^{1} \mathrm{H}$ NMR of palladium oxyquinoliziniporphyrin 106a (top spectrum) and nickel quinoliziniporphyrin 107a (bottom spectrum)

18. Downfield region of the ${ }^{1} \mathrm{H}$ NMR spectra for oxyquinoliziniporphyrin 84b (middle spectrum), palladium complex 106b (top spectrum), and nickel complex 107b (bottom spectrum)

19. UV-vis spectra of oxyquinoliziniporphyrin 84a (black line), palladium(II) complex 106a (red line), and nickel(II) complex 107a (blue line)

20. UV-vis spectra of oxyquinoliziniporphyrin $\mathbf{8 4 b}$ (black line), palladium(II) complex 106b (red line), and nickel(II) complex 107b (blue line)

21. Antiaromatic compounds 


\section{SCHEMES}

Scheme

Page

1. Metalation of benziporphyrin $\quad 9$

2. Metalation of naphthiporphyrin 10

3. Metalation of oxybenziporphyrin 14

4. Metalation and protonation of N-confused pyriporphyrin 15

5. Tetramerization of monopyrroles to produce porphyrins 17

6. Isomers from acid-catalyzed tetramerization $\quad 18$

7. MacDonald '2+2' condensations 19

8. '3+1' MacDonald Condensation 20

9. Synthesis of tripyrrane 21

10. Synthesis of heteroporphyrins 22

11. Metalation of tetraarylbenzocarbaporphyrin 23

12. Metalation of tetraphenylbenziporphyrin 24

13. Metalation of N-confused pyriporphyrins 25

14. Syntheses of pyriporphyrins 28

15. Retrosynthetic analysis of oxyquinoliziniporphyrins 29

16. Oxyquinoliziniporphyrins resonance contributors 29

17. Synthesis of ethyl isocyanoacetate 86

18. Preparation of acetoxy nitrohexane 89 30

19. Preparation of 3,4-diethylpyrrole 61 
20. Knorr-type synthesis of ethyl 4-ethyl-3,5-dimethyl-2-carboxylate

93a and ethyl 4-butyl-3,5-dimethyl-2-carboxylate 93b

21. Preparation of diethyl aminomalonate 94

22. Synthesis of 3-ethyl-2,4-pentadione 95a and 3-butyl-2,4-pentadione 95b

23. Synthesis of $\mathbf{6 0 a - b}$

24. Synthesis of tripyrranes 63a-b

25. Synthesis of ethyl 2-pyridyl acetate 99

26. Synthesis of 4-quinolizone $\mathbf{1 0 2}$

27. Synthesis of 4-quinolizone-1,3-dicarbaldehyde $\mathbf{8 5}$

28. Synthesis of carbaporphyrins 84a-b

29. Azuliporphyrin and its aromatic dipolar resonance contributor

30. Protonation of oxyquinoliziniporphyrins 84a-b

31. Resonance contributors for oxyquinoliziniporphyrin dications

32. Metalation of oxyquinoliziniporphyrins 84a-b

33. Retrosynthetic approach to pyridoquinoliziniporphyrin

34. Synthesis of $t$-butyl ethyl $4 \mathrm{H}$-quinolizin-4-malonate (115)

35. Synthesis of ethyl 4H-quinolizin-4-ylideneacetate (116)

36. Synthesis of diester pyrido[2,1,6-de]quinolizine-1,3-dicarboxylate (117)

37. Synthesis of 3a,4-dihydropyrido[2,1,6-de]quinolizine 118 


\section{CHAPTER I: INTRODUCTION}

Porphyrins 1 are a group of heterocycles that have been studied for many years. They are composed of four pyrrole residues linked by four methine bridges, and they are found virtually

everywhere in nature. They play crucial roles in the metabolism of living organisms. ${ }^{1,2}$ Small variations in these macrocycles give these compounds a range of functions. In nature, porphyrins are seen mainly as their metalated derivatives. A few examples include, protoporphyrin IX that binds with iron in hemoglobin and myoglobin to transport oxygen around the body. In higher plants, chlorophylls a and $\mathrm{b}(\mathbf{3})$ are dihydroporphyrins with a magnesium bound center that can capture photons to drive photosynthesis, and related structurally diverse chlorophylls are found in algae and photosynthetic bacteria. ${ }^{3}$ Tetrapyrrolic pigments have many other functions and are essential components of cytochromes, peroxidases and catalases.

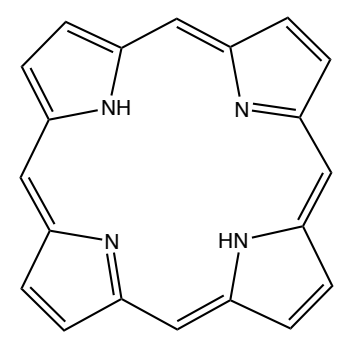

1

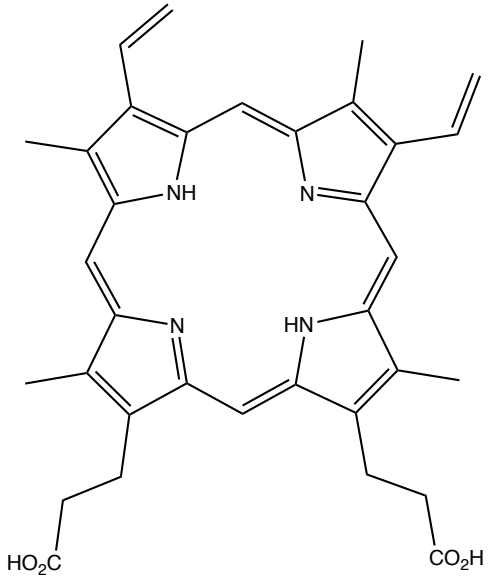

2

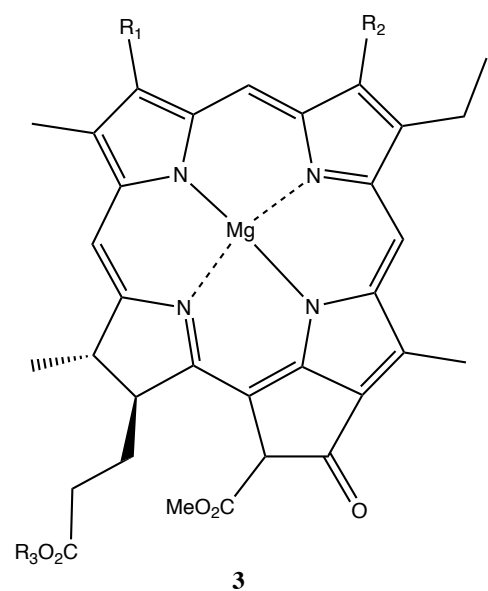

3

Figure 1. Porphyrin and its naturally occurring counterparts 
In addition to being essential to all life, porphyrins have many applications, one of which is photodynamic therapy (PDT). ${ }^{4}$ PDT uses porphyrins to act as photosensitizing agents that can produce reactive oxygen species, such as singlet oxygen, when exposed to light. As porphyrins preferentially accumulate in tumors, this therapy can be used in cancer treatment. Porphyrins contain highly conjugated pathways that allow them to absorb light in the UV-Visible region. This ability to absorb light in the near ultraviolet and visible regions also makes them potential photosensitizers for dye-sensitized solar cells (DSSC). ${ }^{5}$ DSSCs are semiconductors that use light absorbing dyes on the surface to create energy. ${ }^{6}$

Porphyrins are near planar, fully conjugated aromatic compounds. ${ }^{7}$ The global aromaticity of these macrocycles comes from the presence of an $18 \pi$ electron delocalization pathway that resembles [18]annulene (4). The delocalization pathway is also responsible for the electronic absorption spectra of porphyrins. Porphyrins are examples of nonbenzenoid aromatic systems, and many studies have been directed to understanding the aromatic properties of these molecules.

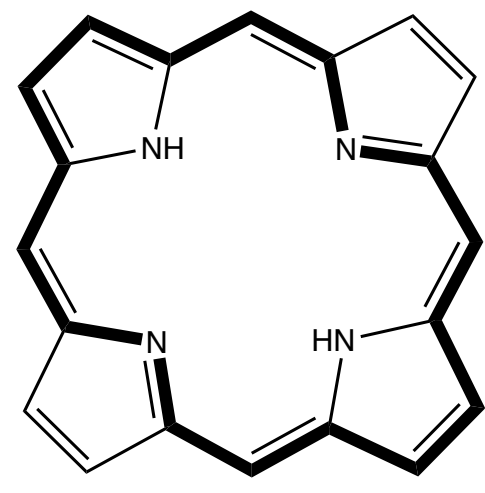

1

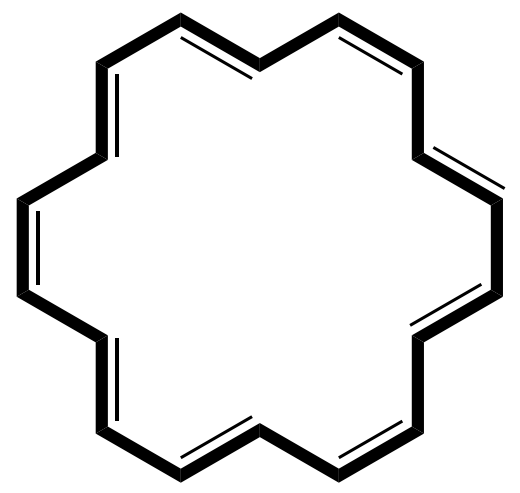

4

Figure 2. Aromatic pathways of porphyrin and [18]annulene 
The aromatic characteristics of porphyrins can be directly observed using X-ray crystallography, nuclear magnetic resonance spectroscopy (NMR), and UV-visible spectroscopy. In X-ray crystallography, the bond lengths do not alternate, which implies the presence of a conjugated pathway around the macrocycle. ${ }^{8}$ In NMR spectroscopy, the applied magnetic field induces a diamagnetic ring current over the entire macrocycle. The ring current deshields the external protons causing them to shift downfield in proton NMR spectroscopy, and the mesoprotons are commonly observed near $10 \mathrm{ppm}$. In addition, the internal protons are shielded due to the magnetic field and will therefore shift upfield in the NMR spectra (Figure 3). The internal NH peaks show up at about $-4 \mathrm{ppm} .{ }^{9}$ The degree of aromaticity in porphyrins can be determined based on the magnitude of these upfield and downfield shifts

\section{shielding}

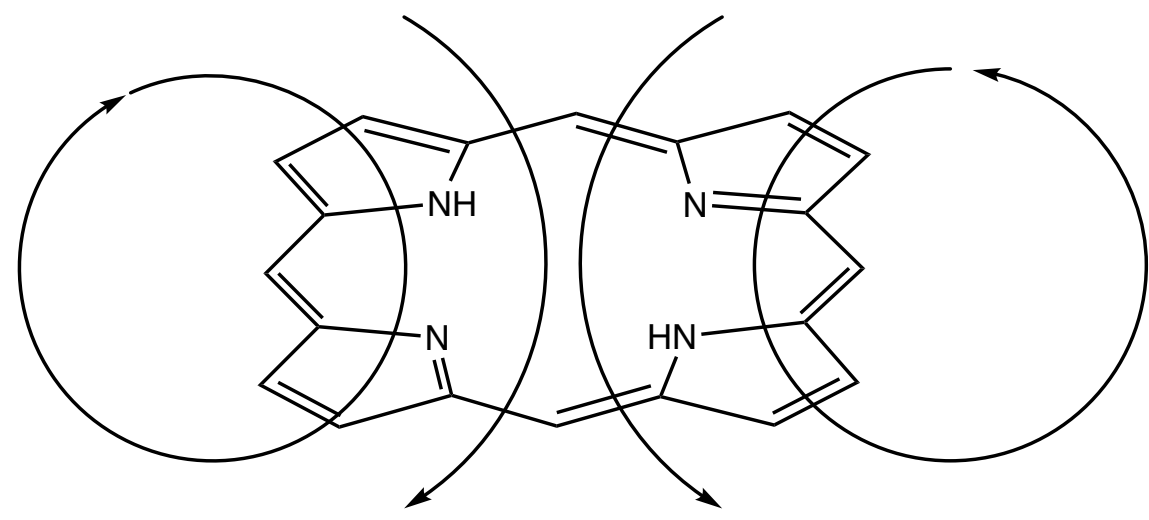

deshielding

Figure 3. Diamagnetic ring current of porphyrin 
Porphyrins exhibit strong absorptions in the near UV and visible regions. Porphyrins give a strong absorption near $400 \mathrm{~nm}$, called the Soret band, and a series of less intense absorptions between 480-700 that are known as the Q bands. As the Q bands fall into the visible region, they are responsible for the intense colors exhibited by the porphyrins. ${ }^{1} \mathrm{UV}$-visible spectroscopy is used extensively to investigate porphyrins and their analogs. Substitutions on a porphyrin system affects the number and intensity of the bands observed, and steric crowding can also modify the chromophore due to distortion of the macrocycle.

Porphyrins contain an internal cavity that possesses four nitrogen atoms, and this is key to the ability of these macrocycles to bind metal cations. Modifications of the internal cavity leads to interesting structures such as heteroporphyrins and carbaporphyrins with altered metal binding properties. Carbaporphyrins are porphyrin analogues where one or more of the nitrogens in the internal cavity have been replaced with a carbon atom. ${ }^{10}$ One way to synthesize these compounds is through the replacement of one of the pyrrole subunits. Porphyrin analogue of this type include structures the replace pyrrole with benzene $\mathbf{5}$, indene $\mathbf{6}$, and azulene $7 .{ }^{11-13}$ In addition, structures with inverted pyrrole units that place a carbon within the internal cavity and a nitrogen at the periphery, the so-called $\mathrm{N}$-confused porphyrins $\mathbf{8}$, have been widely studied. ${ }^{13}$ 

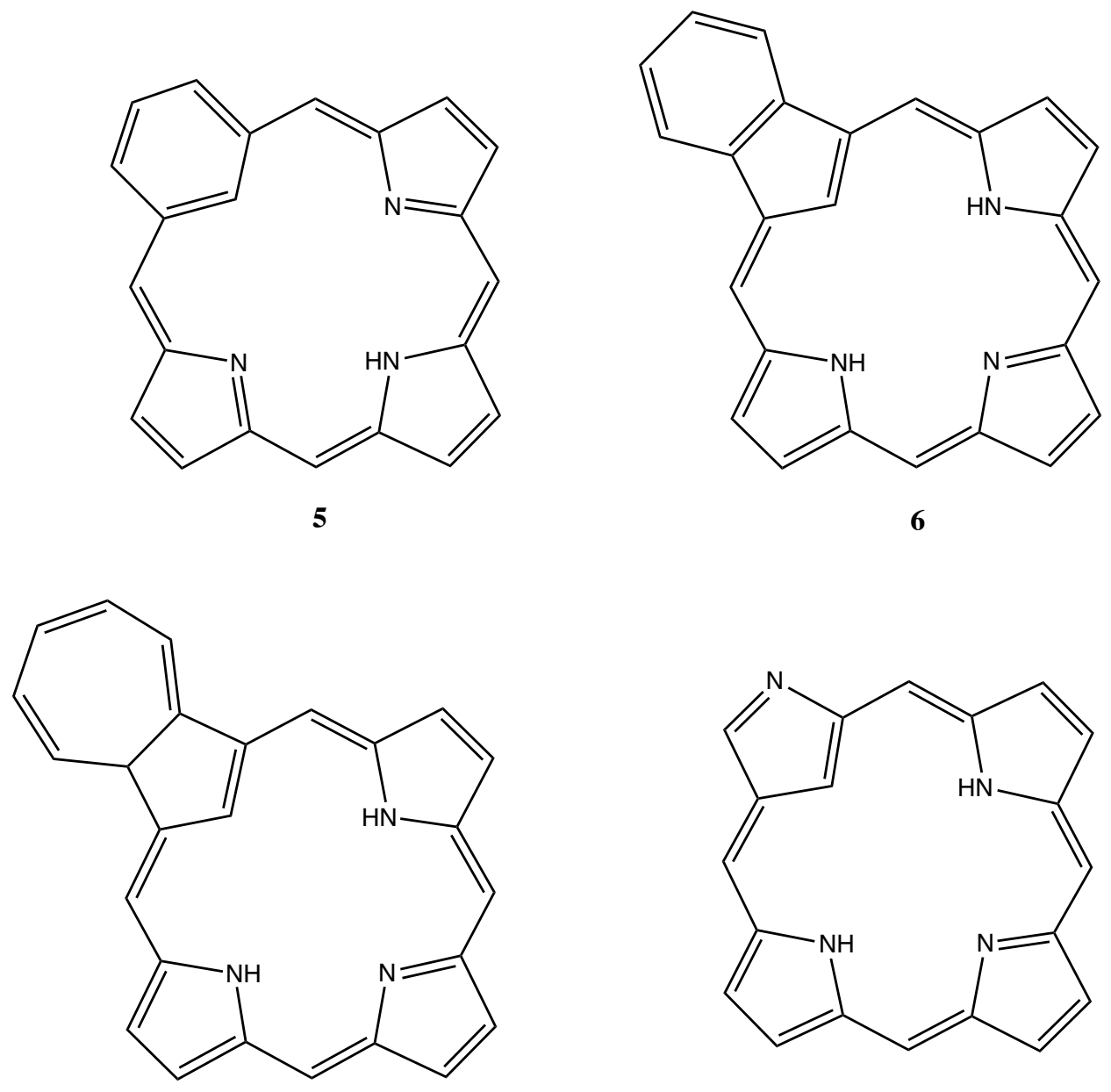

7

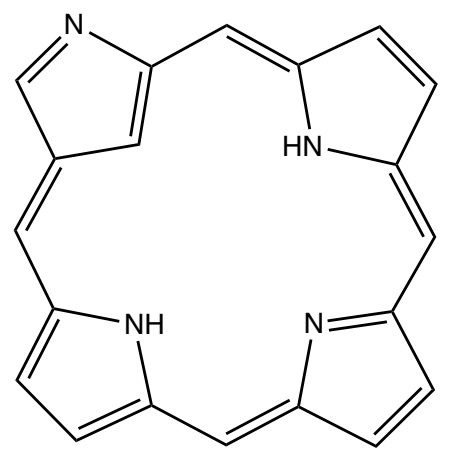

8

Figure 4. Carbaporphyrin Analogs

Carbaporphyrins have a wide range of properties and can have anything from aromatic, to nonaromatic, to even antiaromatic characteristics. ${ }^{12}$ For example, benziporphyrin could potentially exist as tautomer 9 with an $18 \pi$ electron pathway. However, synthetic samples of benziporphyrins show no indication of tautomer 9 and DFT studies indicate that it is $>40 \mathrm{kcal} / \mathrm{mol}$ higher in energy 
than the nonaromatic form. In the first synthesis of a benziporphyrins, it was suggested that tautomers $\mathbf{1 0}$ and $\mathbf{1 1}$ were formed and that these structures did not interconvert on the NMR timescale. ${ }^{14}$ Later reports showed that the original samples were impure, and better reaction conditions gave only one species $11 .{ }^{14}$ Benziporphyrin 11 showed the meso-protons at 6.57 and $7.27 \mathrm{ppm}$, while the $\mathrm{NH}$ resonance appeared downfield at $8.9 \mathrm{ppm}$, and the internal $\mathrm{CH}$ gave a broad triplet at $7.96 \mathrm{ppm}$. The outer benzene protons gave a $1 \mathrm{H}$ triplet at $7.75 \mathrm{ppm}$ and a $2 \mathrm{H}$ doublet at $7.98 \mathrm{ppm} .{ }^{14}$ These results demonstrated that the arene unit maintains its aromatic character and interrupts global conjugation pathways. The chemical shifts for the internal and external protons are very similar, confirming the absence of an overall aromatic ring current. Addition of TFA to benziporphyrin afforded a diprotonated dication 12. The proton NMR spectrum of the protonated species showed the presence of a weak diatropic ring current that shifts the internal $\mathrm{CH}$ upfield to $5 \mathrm{ppm}$, and the meso-protons downfield to give two $2 \mathrm{H}$ singlets at 6.91 and $7.94 \mathrm{ppm}$. This weak ring current was attributed to resonance contributors such as $\mathbf{1 3}$, or to a contribution from an $18 \pi$ electron species $14 .^{11,15}$ 


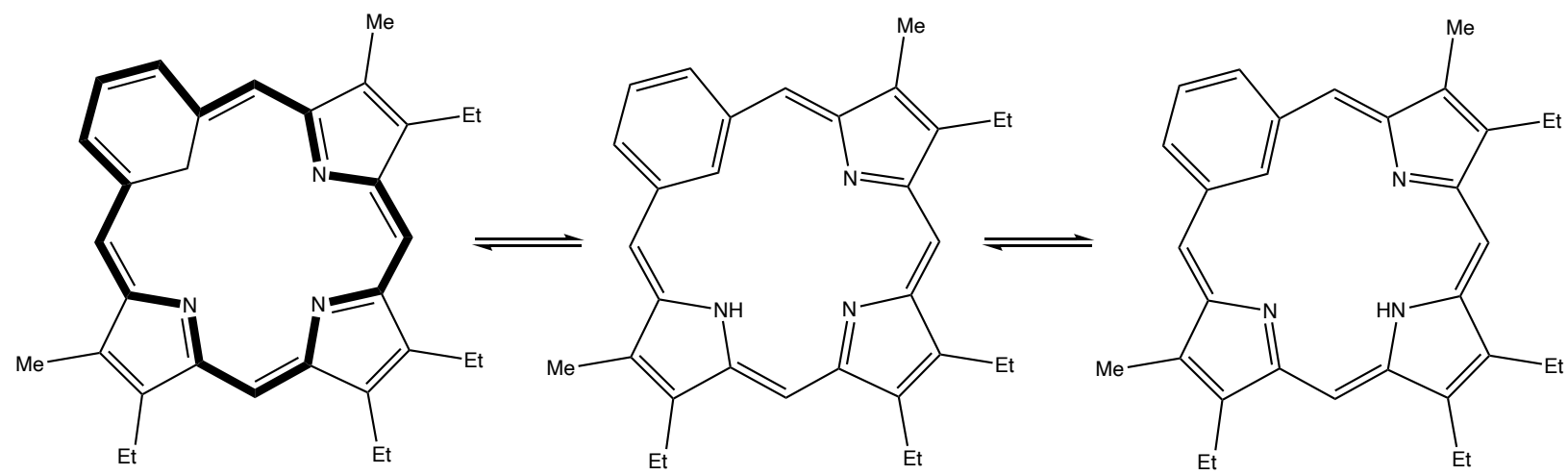

9

10

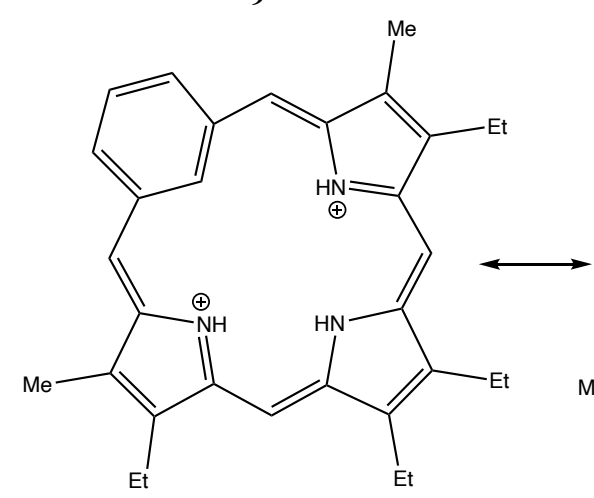

12

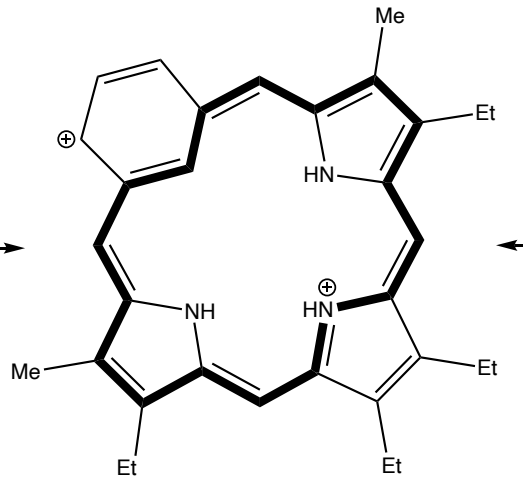

13

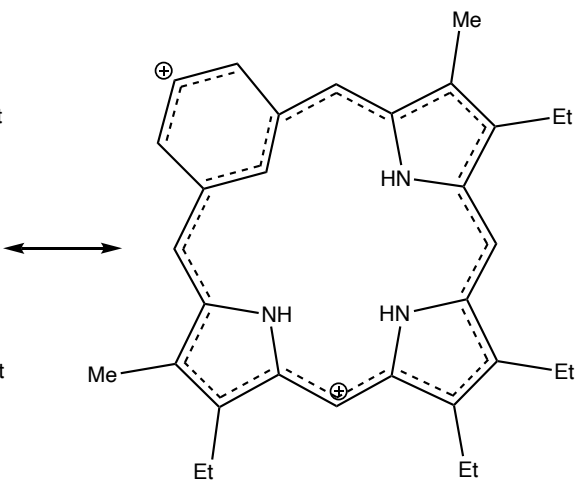

14

Figure 5. Benziporphyrin tautomers and resonance contributors for protonated benziporphyrins

Since it is energetically unfavorable for benziporphyrin to lose the aromaticity of the benzene subunit, it was speculated that naphthiporphyrin 15 might be more susceptible to taking on a global aromatic pathway because the resonance stabilization for a benzo-unit within naphthalene is reduced in comparison to benzene. However, the proton NMR spectrum of $\mathbf{1 5}$ showed no signs of a ring current. ${ }^{15}$ The internal $\mathrm{CH}$ was observed at $8.08 \mathrm{ppm}$. Napthiporphyrin was shown to favor 15 over its tautomers 16 and 17. Naphthiporphyrin could also be protonated with TFA to afford 18. This species exhibited diatropic character similar to benziporphyrin (19- 
20). The internal $\mathrm{CH}$ appeared between 4.0 and 4.6, depending on the concentration of TFA. The meso-protons appeared at 7.17, 7.20, 8.29, and $8.81 \mathrm{ppm}$, values that suggest a slightly larger ring current than protonated benziporphyrin. It was suggested that resonance contributors such as $\mathbf{1 3}$ and 19 were favored because these aid in charge delocalization.

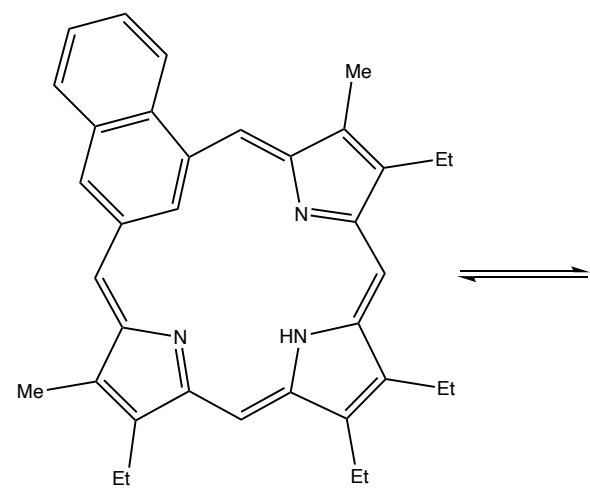

15

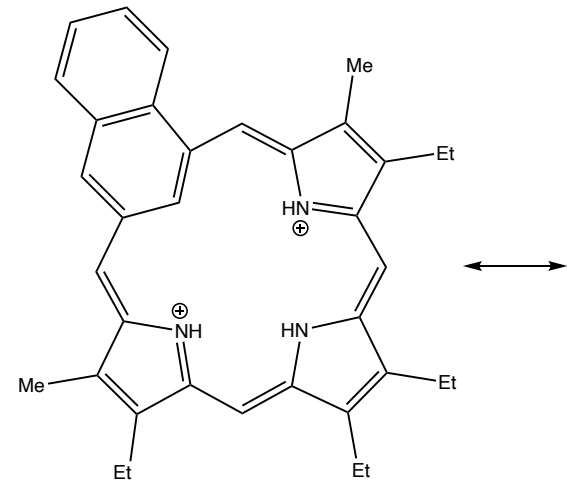

18

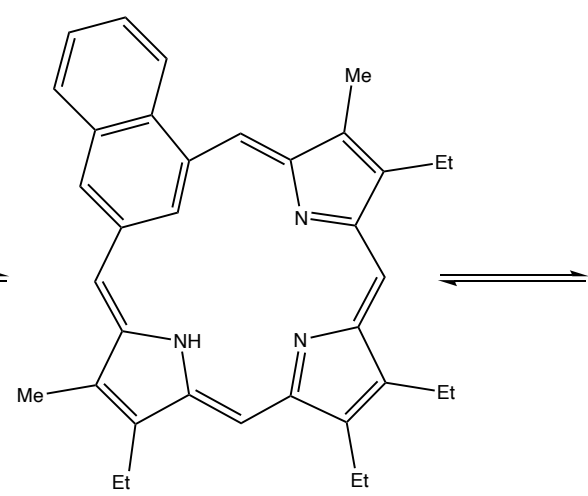

16

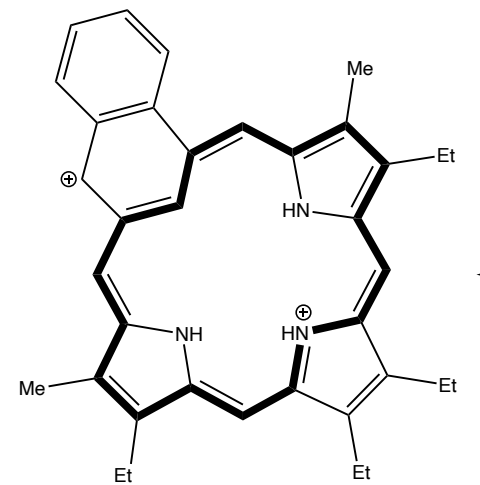

19

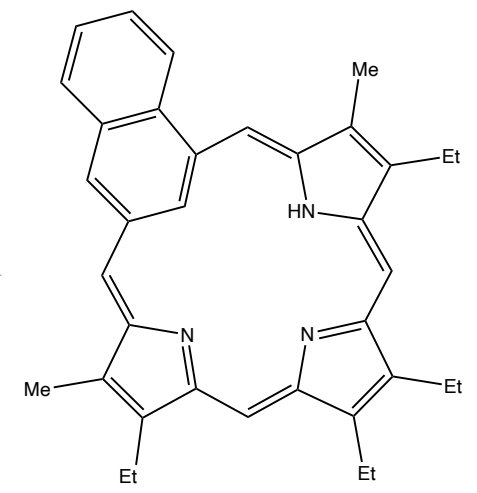

17

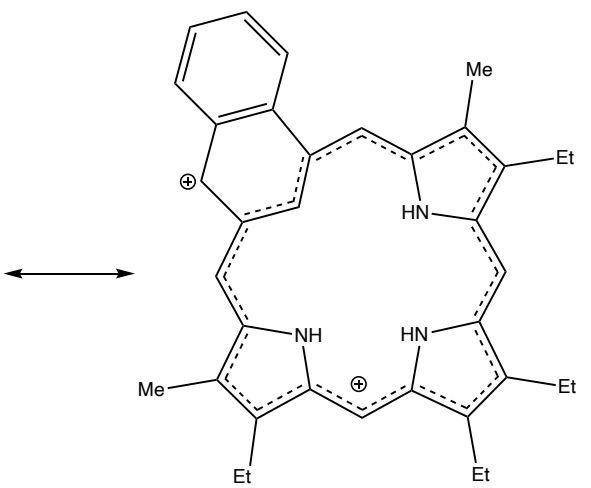

20

Figure 6. Naphthiporphyrin tautomers and resonance contributors for the protonated naphthiporphyrin dication 
Benziporphyrin reacted with nickel(II) acetate or palladium(II) acetate to give the corresponding organometallic species $\mathbf{2 1}$ and $\mathbf{2 2}$ (Scheme 1). ${ }^{15}$ The proton NMR spectrum for $\mathbf{2 1}$ showed a significant downfield shift of the meso-protons, which appeared as two $2 \mathrm{H}$ singlets at 7.16 and $7.48 \mathrm{ppm}$. The palladium complex showed a larger diatropic ring current with further downfield shifts to 7.35 and $7.72 \mathrm{ppm} .{ }^{15}$ Naphthiporphyrin was also metalated to give the corresponding palladium complex 23 (Scheme 2). The diatropic character of palladium naphthiporphyrin was similar to palladium benziporphyrin and the meso-protons appeared at 7.27, $7.39,7.64$, and $8.50 \mathrm{ppm} .{ }^{15}$ Metalation of these compounds increases the diatropicity of the system but overall, these compounds still remained only weakly aromatic.

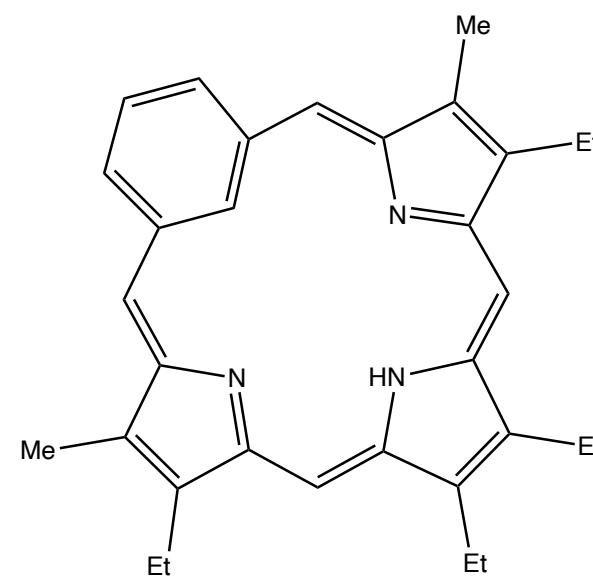

11

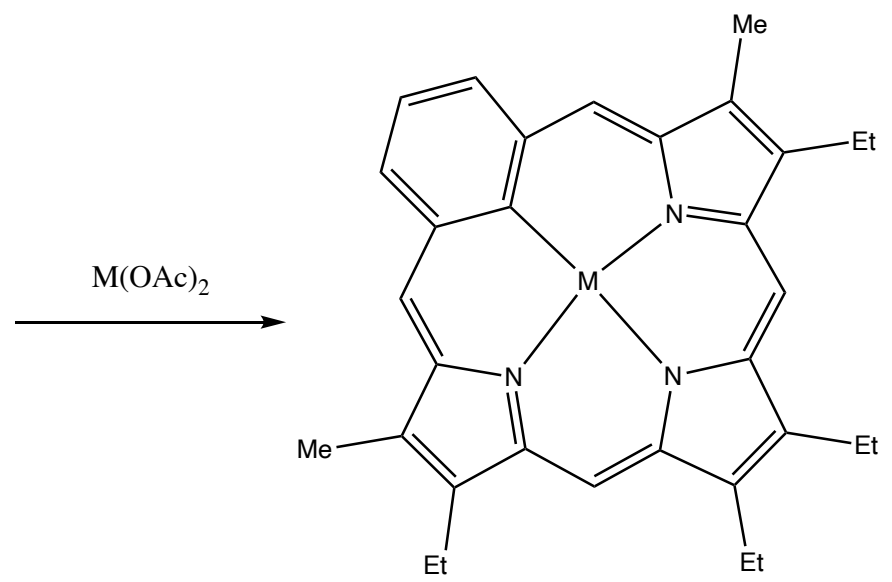

$21 \mathrm{M}=\mathrm{Ni}$

$22 \mathrm{M}=\mathrm{Pd}$

Scheme 1. Metalation of Benziporphyrin 


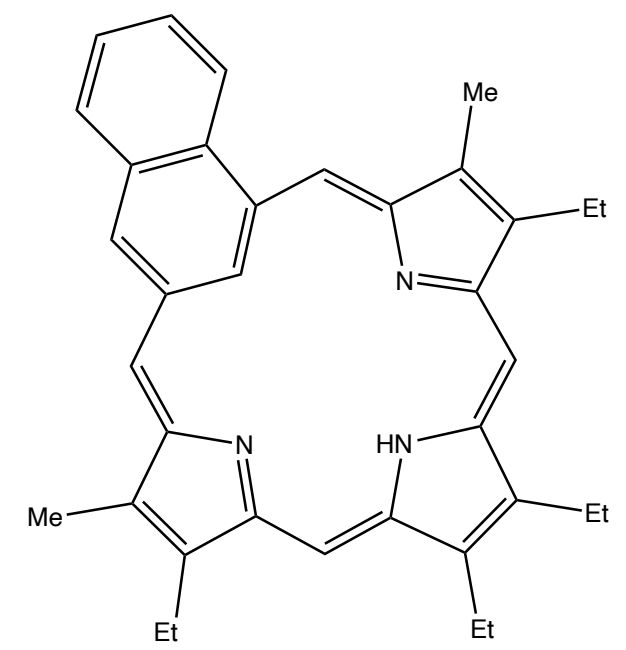

15

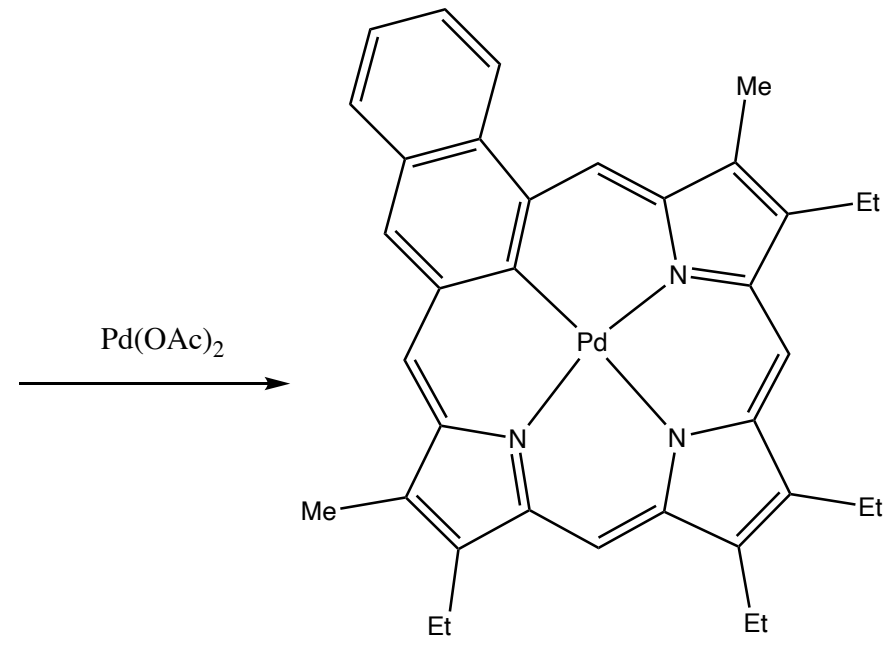

23

Scheme 2. Metalation of naphthiporphyrin

Unlike benziporphyrin and naphthiporphyrin, dimethoxybenziporphyrins $\mathbf{2 4 a - b}$ have weak diamagnetic ring currents prior to protonation. ${ }^{16}$ The proton NMR spectrum of 24a shows the meso-protons are shifted downfield to give two $2 \mathrm{H}$ singlets at 7.16 and $8.74 \mathrm{ppm}$, and the internal $\mathrm{CH}$ at a relatively upfield value at $5.07 \mathrm{ppm}$. In $\mathbf{2 4 b}$, the diamagnetic ring current is not as large, and the meso-protons showed up at 6.68 and $7.84 \mathrm{ppm} .{ }^{16}$ This aromatic character is due to electron-donating methoxy groups affording dipolar resonance contributors such as $\mathbf{2 5}$ that have $18 \pi$-electron delocalization pathways. This electronic interaction relies on the methoxy units possessing planar $\mathrm{sp}^{2}$-hybridized oxygens. Crowding due to the presence of a methyl group on the benzene in 24b inhibits this interaction, resulting in reduced diatropicity. The aromatic properties of these dimethoxybenziporphyrins are limited because of the requirement for charge separation. ${ }^{17}$ Protonation of dimethoxybenziporphyrins further enhanced the aromatic properties. Addition of TFA gave dications 26, and the proton NMR spectrum of $\mathbf{2 6 a}$ showed the internal $\mathrm{CH}$ shifted 
upfield to $-0.68 \mathrm{ppm}$, while the meso-protons moved downfield to give two $2 \mathrm{H}$ singlets at 8.44 and $9.60 \mathrm{ppm} .{ }^{16}$ The enhanced aromatic properties of protonated dimethoxybenziporphyrins are favored because they allow delocalization of positive charge in resonance contributors such as $\mathbf{2 7}$ and 28. Nevertheless, the presence of a methyl substituent between the two methoxy groups in $\mathbf{2 6 \mathbf { b }}$ reduced the aromatic ring current and the internal $\mathrm{CH}$ resonance was only shifted upfield to 4.25 ppm.
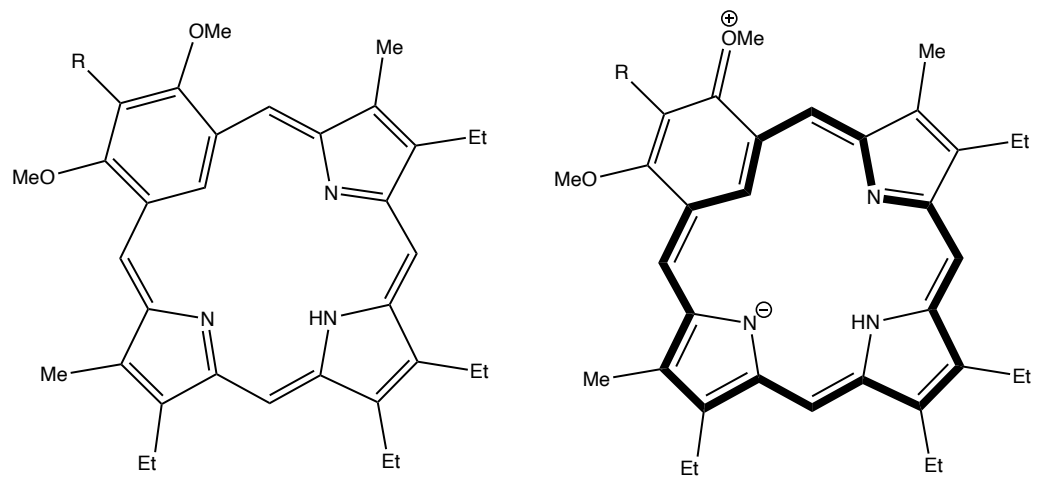

24 a. $\mathrm{R}=\mathrm{H}$; b. $\mathrm{R}=\mathrm{Me}$

25

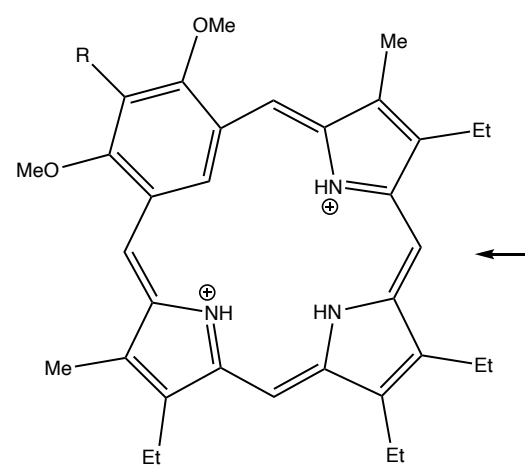

26

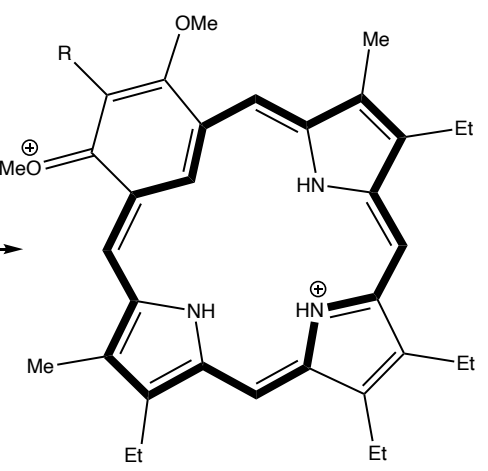

27

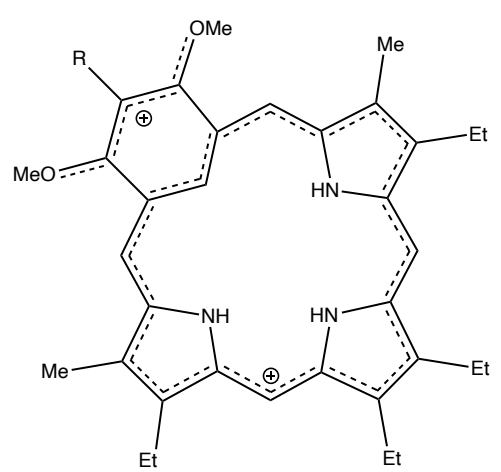

28

Figure 7. Dimethoxybenziporphyrins and protonated dimethoxybenziporphyrins and their resonance contributors 
As methoxy groups attached to the benzene increased the overall aromatic character due to the introduction of dipolar resonance contributors, a similar effect might be expected with a hydroxy substituent, e.g. structure 29. However, a hydroxy substituent on a benzene ring can also undergo a keto-enol tautomerization process that can generate a keto-unit while introducing a porphyrin-like $18 \pi$ electron delocalization pathway. Therefore, this keto-enol tautomerization can give a fully aromatic carbaporphyrin, oxybenziporphyrin $\mathbf{3 0} .^{18}$ The $6 \pi$ arene unit is lost, but $\mathbf{3 0}$ has gained a carbonyl unit and a porphyrin-like $18 \pi$-electron delocalization pathway that is thermodynamically favored. Oxybenziporphyrin exhibits strong aromatic properties, including porphyrinoid UV-vis absorptions with Soret bands at $428 \mathrm{~nm}$ and $465 \mathrm{~nm}$, and Q bands at 548, 590, 636, and $698 \mathrm{~nm}$. The proton NMR spectrum showed a strong diamagnetic ring current, and the internal $\mathrm{CH}$ is strongly shifted upfield to $-7.2 \mathrm{ppm}$. This represents an upfield shift of $15 \mathrm{ppm}$ compared to benziporphyrin. The meso-protons were observed at 8.85, 8.98, 8.99 and $10.29 \mathrm{ppm}$. Protonation of $\mathbf{3 0}$ gave a monocation $\mathbf{3 1}$ and dication $\mathbf{3 2}$ upon a titration with TFA. The second protonation occurs on the carbonyl group to give 32, a species that has significant phenolic character due to resonance contributor 33. This disrupts the aromatic conjugation pathway and drastically reduced the aromatic ring current. The proton NMR spectrum of 32 in TFA-CDCl 3 showed the internal $\mathrm{CH}$ at $+1.05 \mathrm{ppm}$, a downfield shift of 8 ppm compared to the free base form 30. ${ }^{14}$ Oxybenziporphyrin can act as a trianionic ligand and form silver (III) complexes (Scheme 3). ${ }^{19}$ 34b was soluble enough to give a proton NMR spectrum and the meso-protons were observed at $8.87,9.69,9.71$, and 10.32 , demonstrating that the complex retains a diatropic ring current 
similar to the free-base oxybenziporphyrin. The UV-Vis spectra of $\mathbf{3 4}$ was also similar to $\mathbf{3 0}$, giving a Soret band at $456 \mathrm{~nm}$ and Q bands at 524, 608, and $629 \mathrm{~nm}$.

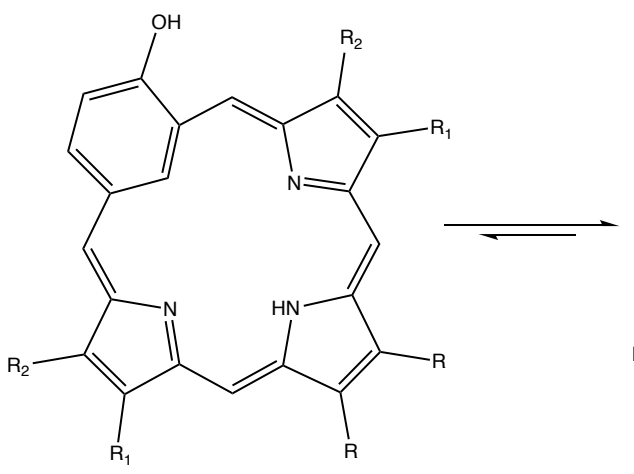

29

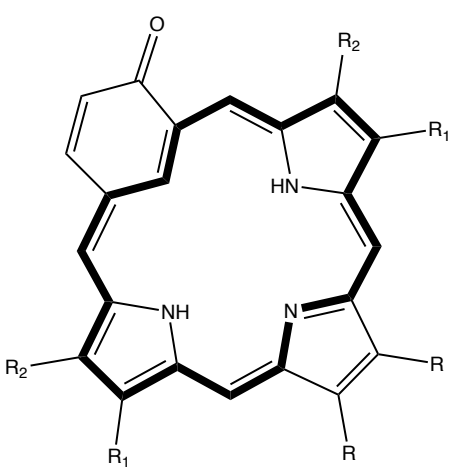

30

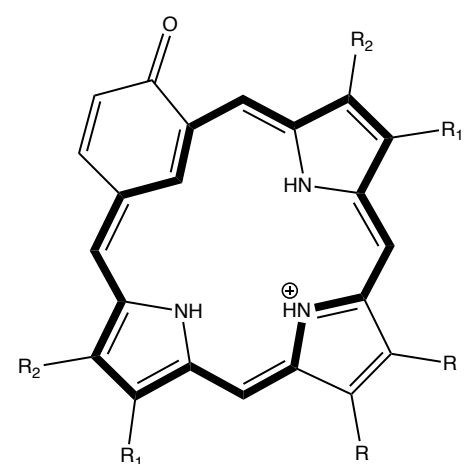

31

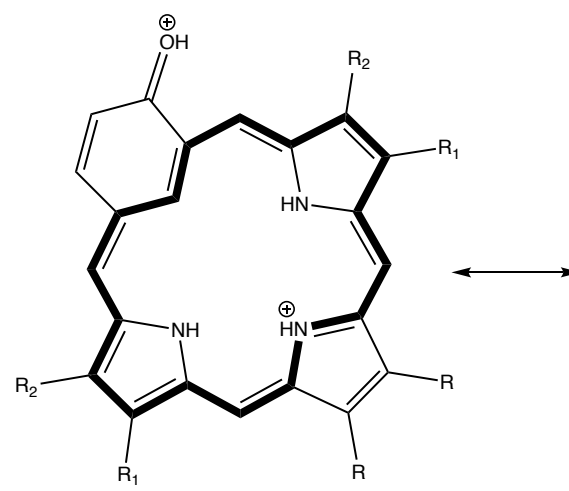

32

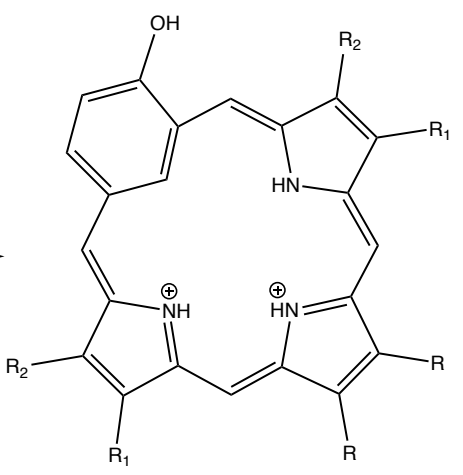

33

Figure 8. Hydroxybenziporphyrins, oxybenziporphyrins, protonated oxybenziporphyrins, and a phenolic resonance contributor. 


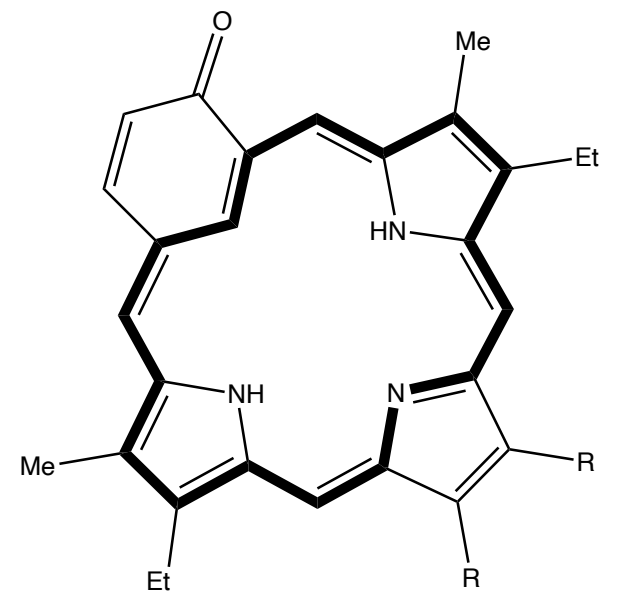

30

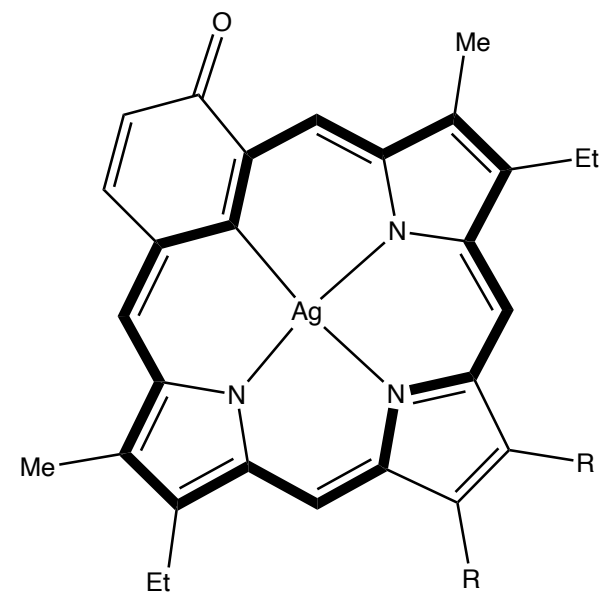

34 a. $\mathrm{R}=\mathrm{Et} ; \mathrm{b} \cdot \mathrm{R}=\mathrm{Ph}$

Scheme 3. Metalation of oxybenziporphyrin

$\mathrm{N}$-confused porphyrin $\mathbf{8}$ can be considered to be azacarbaporphyrins and can also form organometallic derivatives. An alternative family of $\mathrm{N}$-confused porphyrins are $\mathrm{N}$-confused pyriporphyrins that are structurally similar to benziporphyrins. N-confused pyriporphyrins $\mathbf{3 5}$ and 36 have been investigated where the nitrogen atom is placed at the periphery of the macrocycle. Although meso-unsubstituted pyriporphyrins are unstable, meso-substituted pyriporphyrins have been synthesized and characterized. meso-Substituted pyriporphyrin $\mathbf{3 7}$ is nonaromatic and the proton NMR spectrum showed the pyrrolic protons at 6.70 and $7.19 \mathrm{ppm}$, while the meso-protons appeared at 5.84 and $5.88 \mathrm{ppm}$, and the internal $\mathrm{CH}$ was observed at $8.98 \mathrm{ppm} .{ }^{20} 37$ underwent a metalation reaction with palladium(II) acetate to give organometallic complex 38 . The 
organometallic complex underwent a protonation with TFA to form cation 39 (Scheme 4). Even upon metalation and protonation, the palladium complex remained nonaromatic.

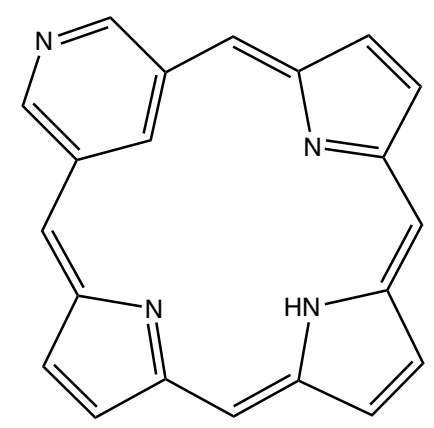

35

Figure 9. N-confused pyriporphyrins

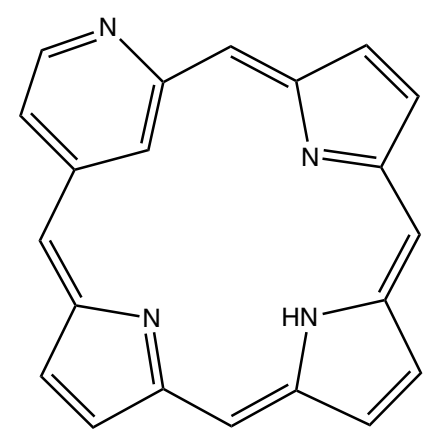

36

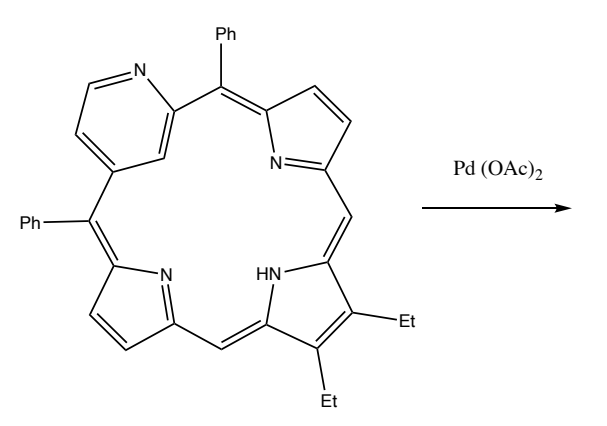

37

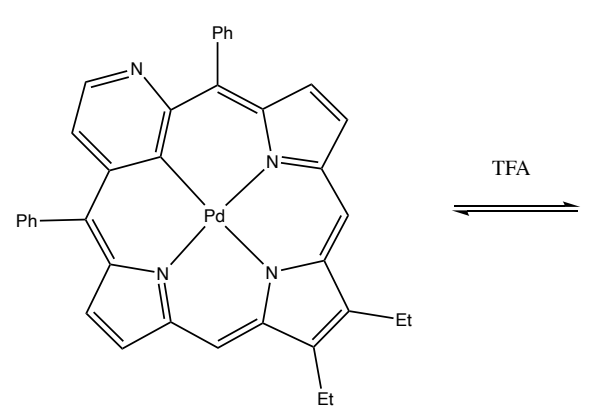

38

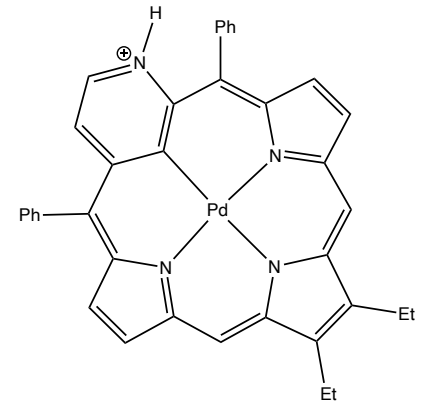

39

Scheme 4. Metalation and protonation of N-confused pyriporphyrin

Although pyriporphyrins without aryl substituents on the pyridine subunit are unstable, an attempt was made to synthesize a dihydro-N-confused pyriporphyrin by trapping it as an aromatic tautomer $40 .{ }^{20-22}$ Condensation of 2,4-pyridinedicarbaldehyde with a tripyrrane 
generated a dihydropyriporphyrin and further reaction with phenyl chloroformate afforded $\mathbf{4 2}$ as a fully aromatic compound. ${ }^{20}$ The external pyridine nitrogen reacted to form a stable carbamate structure. The UV-vis spectrum of $\mathbf{4 2}$ gave a Soret band at $420 \mathrm{~nm}$ and Q bands at 530, 567, 644, and $709 \mathrm{~nm}$. The proton NMR spectrum of $\mathbf{4 2}$ also confirmed that this species has porphyrin-like aromaticity as the internal $\mathrm{CH}$ appears at $-6.66 \mathrm{ppm}$, while the meso-protons shifted upfield to give $1 \mathrm{H}$ singlets at $8.53,9.37,9.49$, and $9.56 \mathrm{ppm}$.

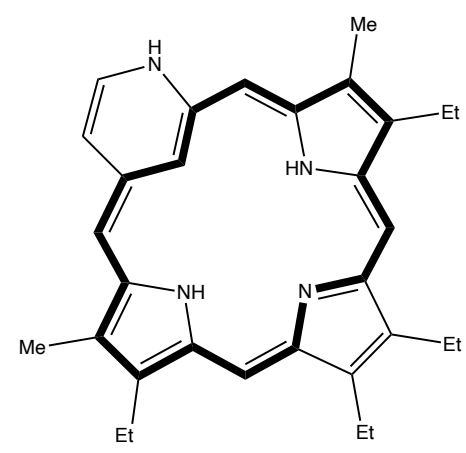

40

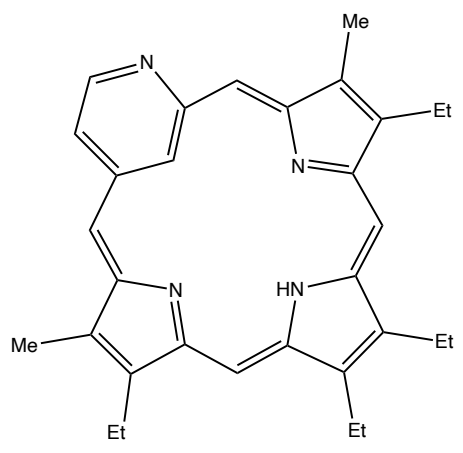

41

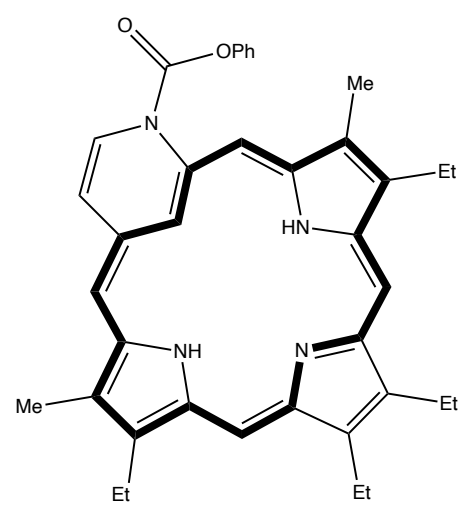

42

Figure 10. Pyriporphyrins

Many strategies have been developed for the synthesis of porphyrins and related systems. One of the first routes to be reported involved the synthesis of symmetrical porphyrins by the tetramerization of monopyrroles. This approach allows the preparation of tetraphenylporphyrin $\mathbf{4 3}$ from pyrrole (44) and benzaldehyde (Scheme 5) ${ }^{23,24}$ Similarly, reaction of 3,4-diethylpyrrole with formaldehyde produces octaethylporphyrin 45 (Scheme 5). ${ }^{25}$ 


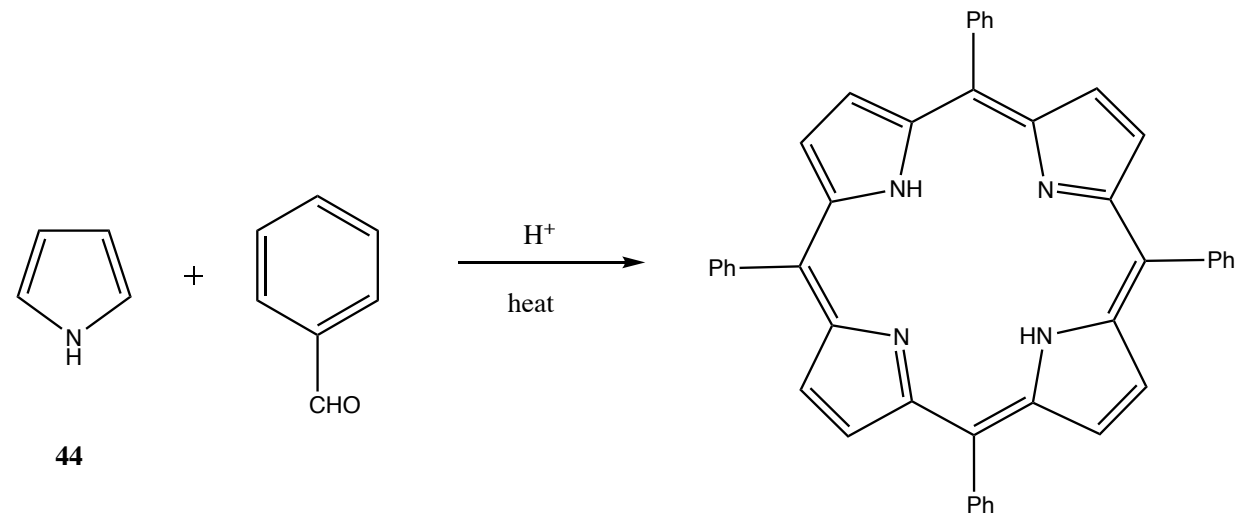

43
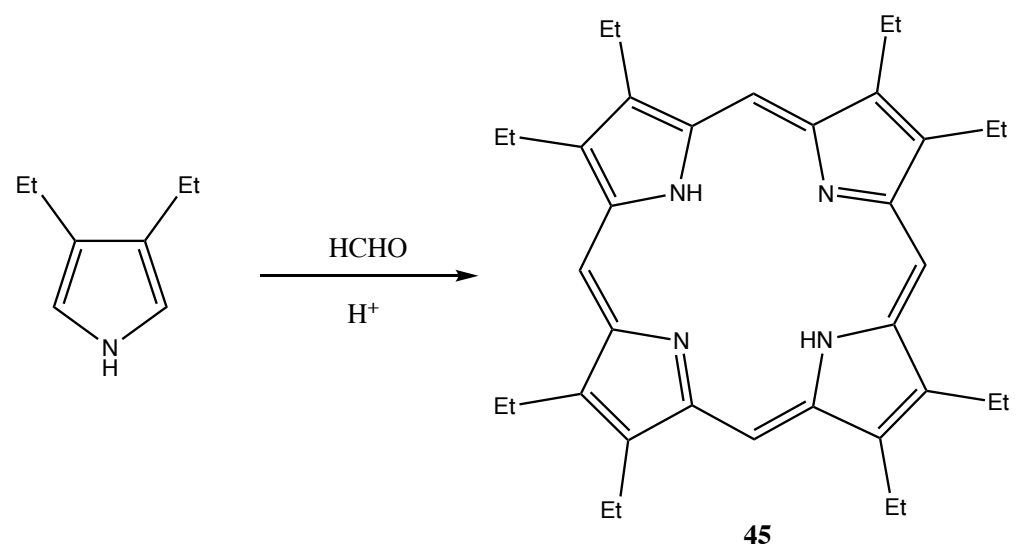

Scheme 5. Tetramerization of monopyrroles to produce porphyrins

Monopyrrole tetramerization works well with pyrroles that have identical 3-and 4- substituents because only one porphyrin product is formed. However, when two different substituents are present (eg. pyrrole 46), scrambling occurs to produce four different porphyrins 47-50 (Scheme 6). ${ }^{26-28}$. Stepwise routes are required to overcome this problem. 


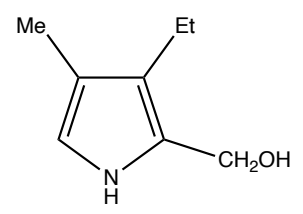

46
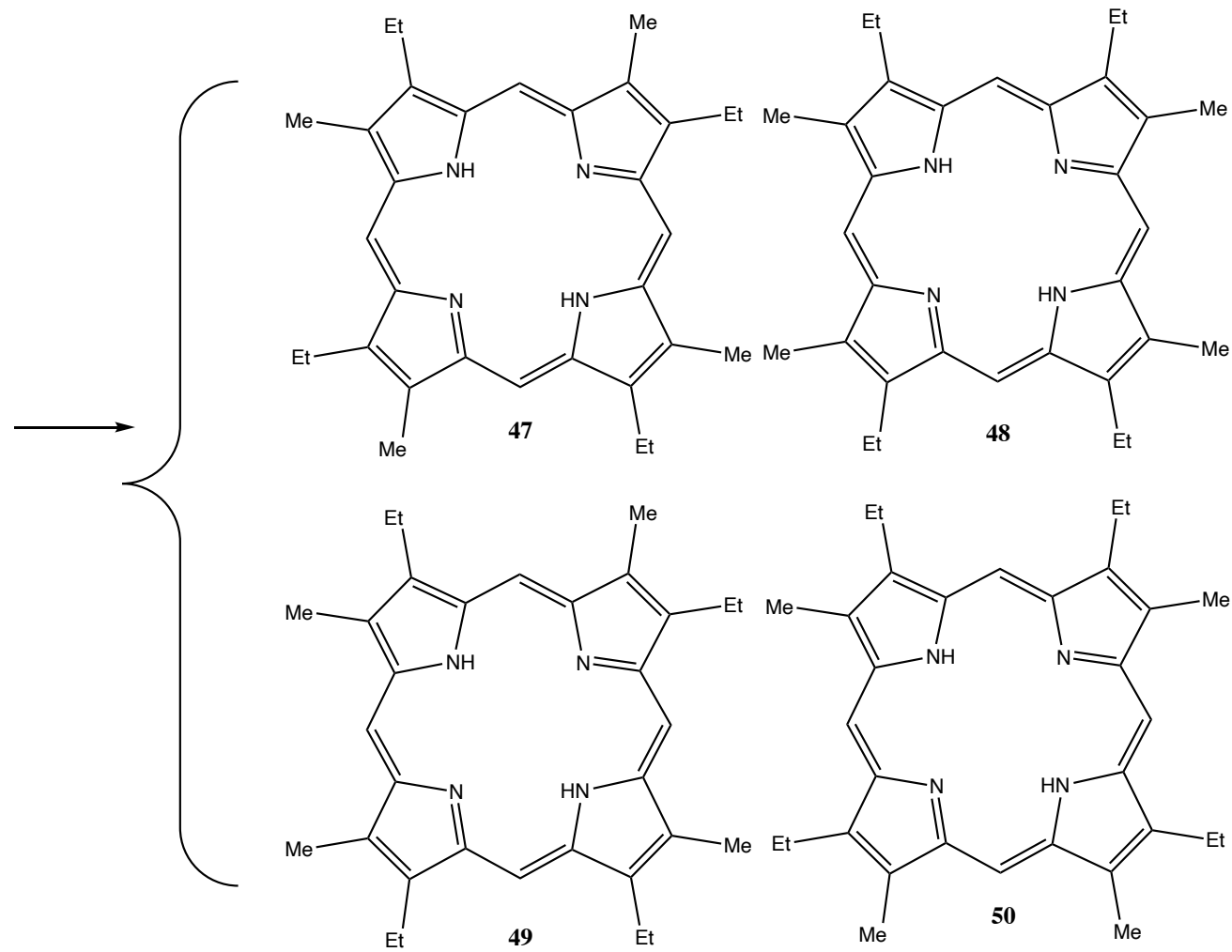

Scheme 6. Isomers from acid-catalyzed tetramerization

Pyrroles readily undergo electrophilic substitution at the $\alpha$-position, and this facilitates the formation of carbon-carbon bonds. MacDonald developed a ' $2+2$ ' condensation to prepared isomerically pure porphyrins. In this approach, dipyrrylmethane dialdehyde $\mathbf{5 1}$ and a dipyrrylmethane $\mathbf{5 2}$ are reacted in the presence of an acid catalyst to give a porphodimethene intermediate $\mathbf{5 3}$ that can be further oxidized to afford the fully aromatic porphyrin (Scheme 7). ${ }^{29}$ The main limitation to this strategy is that one of the dipyrrolic units must be symmetrical or two isomers will be formed. MacDonald and coworkers applied this route to the syntheses of naturally occurring porphyrins. For instance, reaction of 1,9-diformyldipyrrylmethane 54 with 1,9-di- 
unsubstituted dipyrrylmethane 55a, or the corresponding dicarboxylic acid 55b, under acidic conditions gave mesoporphyrin IX (56) in excellent yields (Scheme 7) ${ }^{29}$
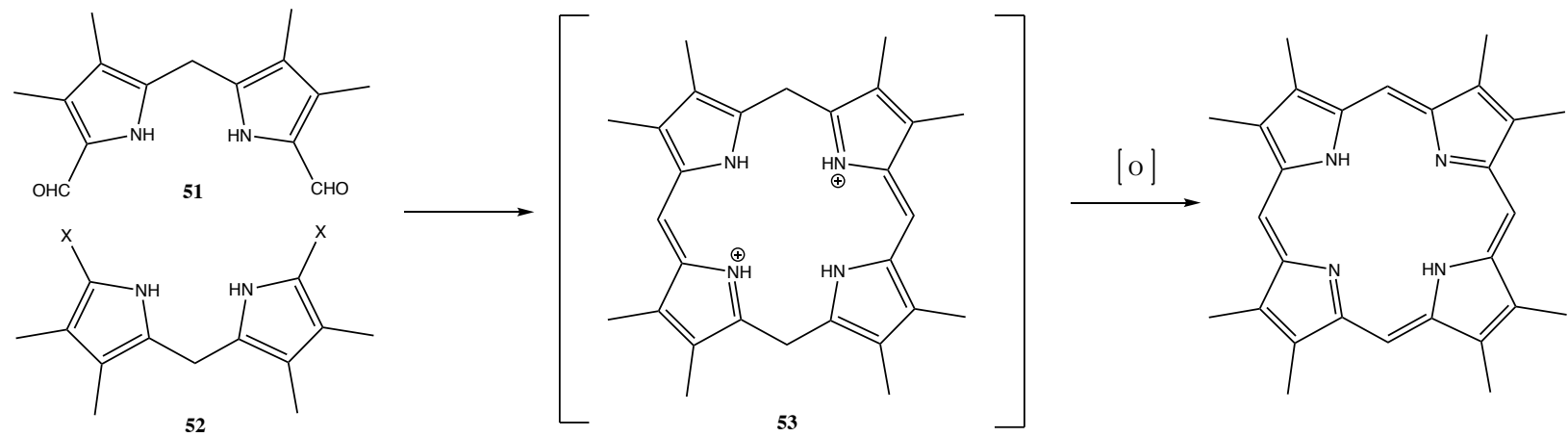

a. $\mathrm{X}=\mathrm{H}, \mathrm{b} \cdot \mathrm{X}=\mathrm{CO} 2 \mathrm{H}$
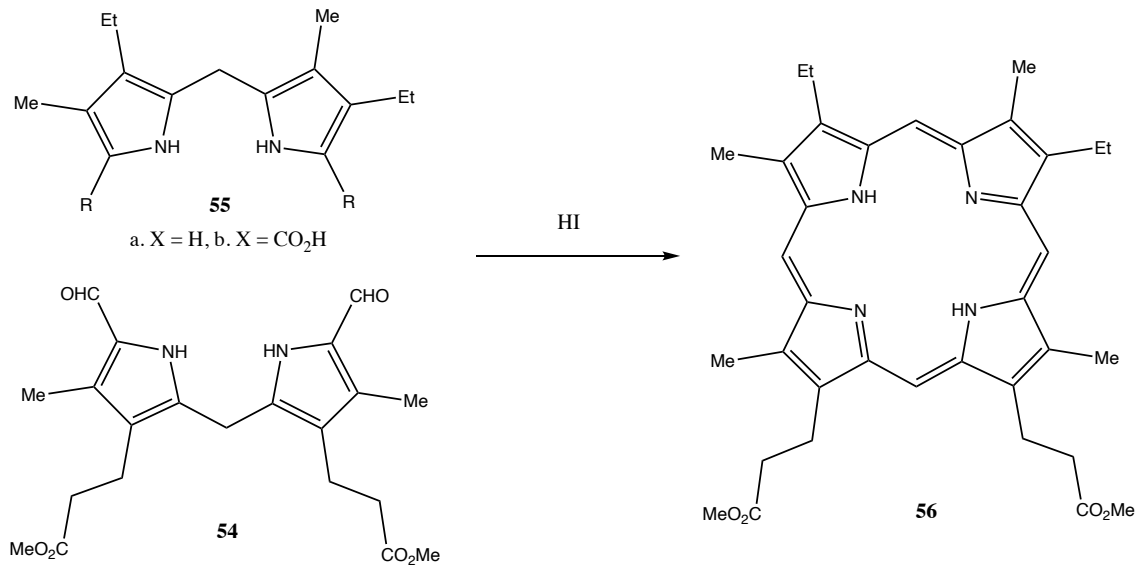

Scheme 7. MacDonald ' $2+2$ ' condensations

Johnson and coworkers developed a ' $3+1$ ' variant of the MacDonald condensation to prepare heteroporphyrins, and this methodology was later adapted for the preparation of true porphyrins. ${ }^{30}$ In this method, tripyrrane $\mathbf{5 7}$ is reacted with a pyrrole dialdehyde $\mathbf{5 8}$ to give the corresponding porphyrin 59 (Scheme 8). Although this method still requires that one of the intermediates has a plane of symmetry in order to avoid the formation of isomers, this strategy 
allows the synthesis of structures that are inaccessible by the ' $2+2$ ' route. Sessler and coworkers developed a convenient method for preparing tripyrranes in high yields that is now widely used in the synthesis of porphyrins. ${ }^{31}$

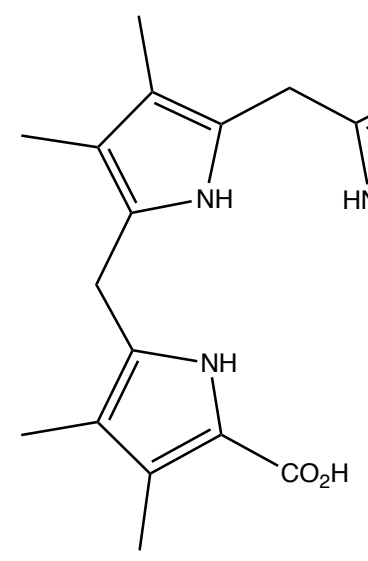

57
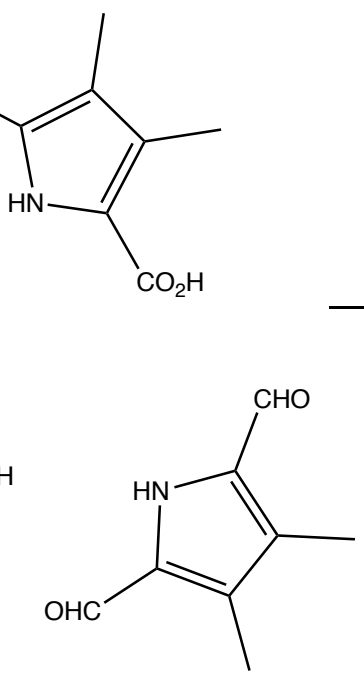

58

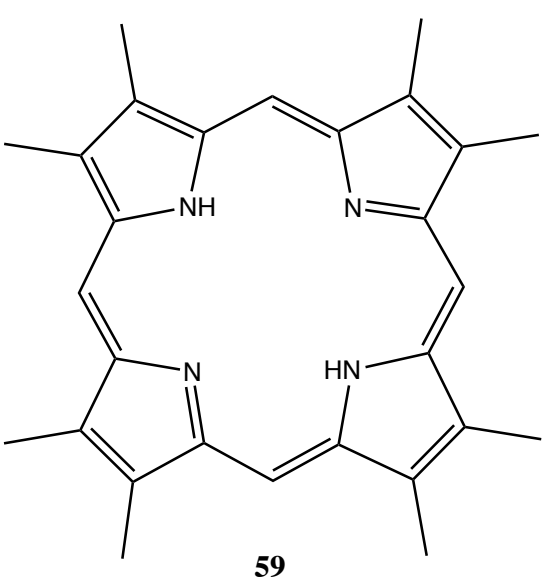

59

Scheme 8. '3+1' MacDonald Condensation

The first examples of tripyrranes were reported by Kenner and coworkers, but the initial route was ineffective and difficult to reproduce. ${ }^{32}$ Sessler and coworkers subsequently developed a practical route to symmetrical tripyrranes by reacting two equivalents of an acetoxymethylpyrrole 60 and one equivalent of pyrrole $\mathbf{6 1}$ under acidic conditions. The pure tripyrrane, 62, precipitates from solution in pure form in over $70 \%$ yield. Deprotection of the terminal benzyl ester protective groups with $\mathrm{Pd} / \mathrm{C}$ under an atmosphere of hydrogen affords the corresponding dicarboxylic acids 63 (Scheme 9). Tripyrrrane 63 is then ready for use in the ' $3+1$ ' syntheses. 

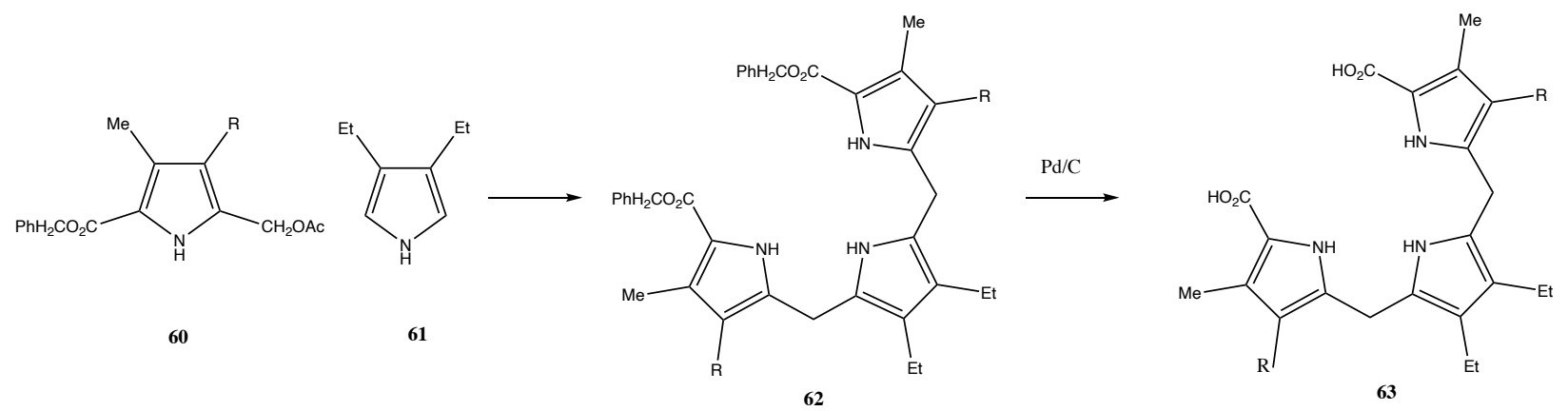

Scheme 9: Synthesis of tripyrrane

Johnson and coworkers reacted tripyrranes 64 with furan or thiophene dialdehyde 65 to give heteroporphyrins 66 (Scheme 10). ${ }^{30}$ This route is versatile because many different dialdehydes could be reacted with tripyrranes to give alternative macrocyclic systems. Although the potential for this synthetic strategy was not initially recognized, more recent studies have demonstrated that the ' $3+1$ ' approach can be applied to the synthesis of diverse porphyrin analogue structures, including carbaporphyrinoid systems. ${ }^{18}$ 


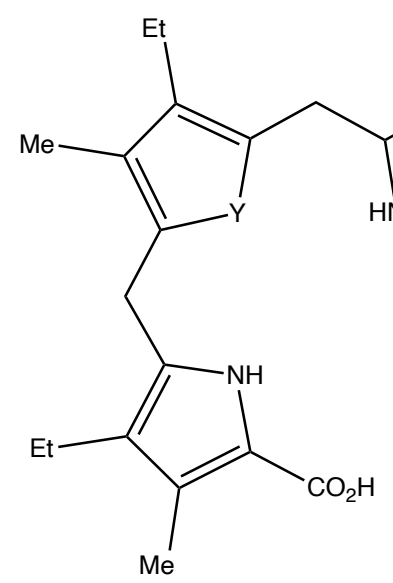

64 a. $\mathrm{Y}=\mathrm{NH}$

b. $Y=O$

c. $\mathrm{Y}=\mathrm{S}$
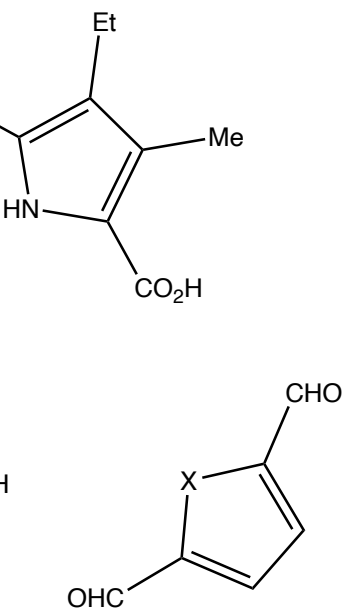

65 a. $X=O ; b \cdot X=S$

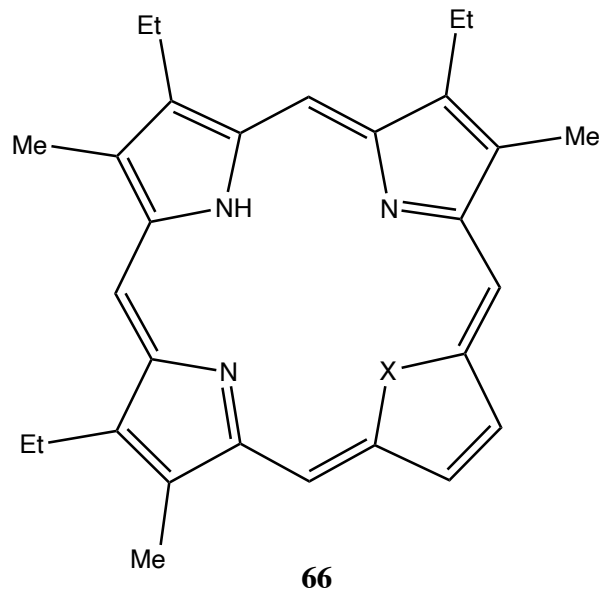

$\mathrm{Y}=\mathrm{NH}, \mathrm{O}$ or $\mathrm{S}$

$\mathrm{X}=\mathrm{O}$ or $\mathrm{S}$

Scheme 10. Synthesis of heteroporphyrins

Core modification determines how these macrocycles act as ligands.

Carbaporphyrins are capable of forming metal complexes, although these are comparatively limited compared to naturally occurring porphyrins. Initial attempts to metalate carbaporphyrins such as 67 with nickel(II), palladium(II), and copper(II) were unsuccessful. ${ }^{33,34}$ However later studies showed that benzocarbaporphyrin 67 can form organometallic silver(III) derivatives 68 when reacted with silver(I) acetate. ${ }^{35,36}$ The complexes maintain the diatropic nature of the original carbaporphyrins. In addition, reaction with gold(III) acetate gave the corresponding gold(III) derivatives 69 and these complexes also retained strongly diatropic characteristics (Scheme 11). ${ }^{36}$ True carbaporphyrins like $\mathbf{6 7}$ act as trianionic ligands, not only forming complexes with silver(III) and gold(III), but also generating organometallic derivatives with rhodium(III) and iridium(III). ${ }^{37}$ 

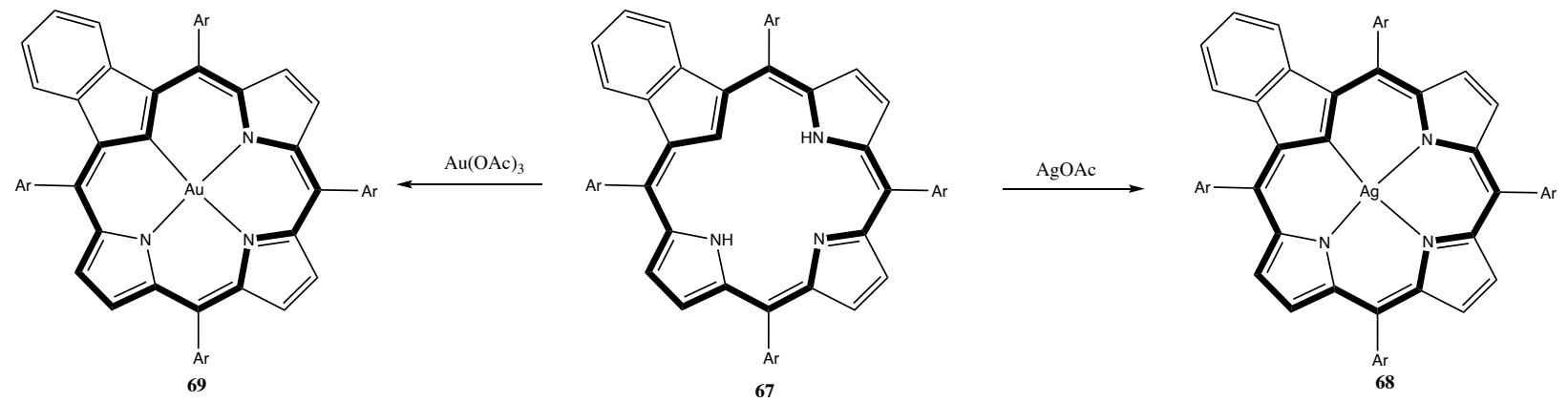

Scheme 11. Metalation of tetraarylbenzocarbaporphyrin

Benziporphyrin and naphthiporphyrin act as dianionic ligands. As mentioned before, refluxing benziporphyrin and naphthiporphyrin with nickel(II) or palladium(II) acetate affords the corresponding metalloporphyrins (Schemes 1 and 2). Metalation is associated with the emergence of a weak diatropic ring current. Platinum(II) complexes have also been described. Reaction of tetraphenylbenziporphyrin $\mathbf{7 0}$ with platinum(II) chloride in benzonitrile gave platinum(II) benziporphyrin 71 (Scheme 12) ${ }^{38}$ Benziporphyrin $\mathbf{7 0}$ was also reacted with nickel(II) chloride but initially afforded a chloronickel(II) complex 72. However, treatment with base gave the expected nickel(II) benziporphyrin. ${ }^{39}$ This chemistry is reversible and addition of $\mathrm{HCl}$ to $\mathbf{7 3}$ converted it back into $\mathbf{7 2}$.

Tetraphenylbenziporphyrin $\mathbf{7 0}$ reacted with $\left[\mathrm{Rh}(\mathrm{CO})_{2} \mathrm{Cl}\right]_{2}$ to form a six-coordinate rhodium(III) benziporphyrin $\mathbf{7 4}$. When $\mathbf{7 4}$ was dissolved in dichloromethane and placed on a silica column for 12 hours, it formed an unstable aromatic benziporphyrin $\mathbf{7 5}$. However, when $\mathbf{7 4}$ was run through an alumina column it formed rhodium(III) carbaporphyrins 76a-c instead (Scheme 12). ${ }^{40}$ These complexes were strongly aromatic in character and the chemistry demonstrates that 
the arene unit in benziporphyrin can undergo a ring contraction to form a cyclopentadiene moiety. Although these complexes were generated in low yields, and this chemistry does not provide a practical route to carbaporphyrin derivatives, important insights into the reactivity of benziporphyrins were obtained.

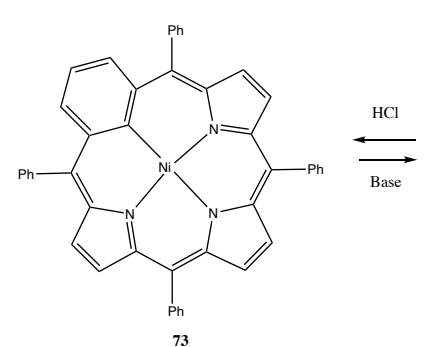

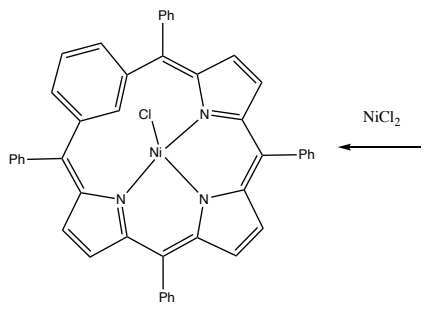

72

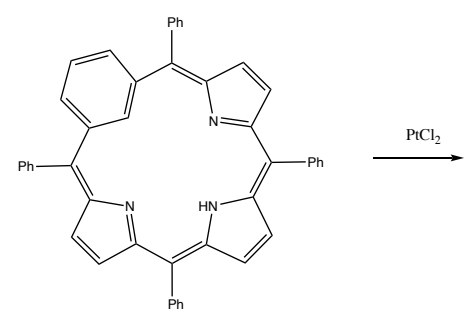

70

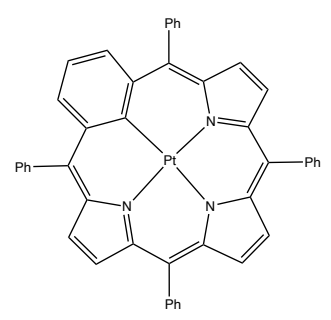

71

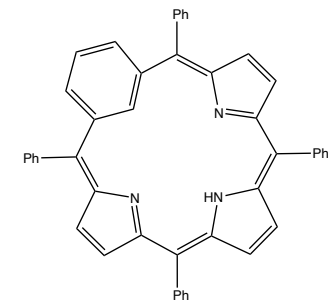

70

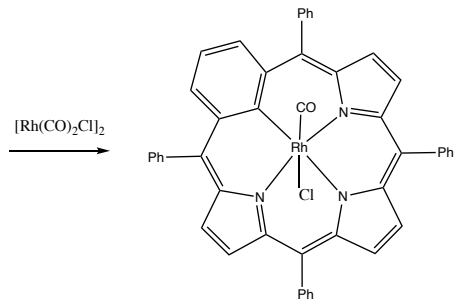

74
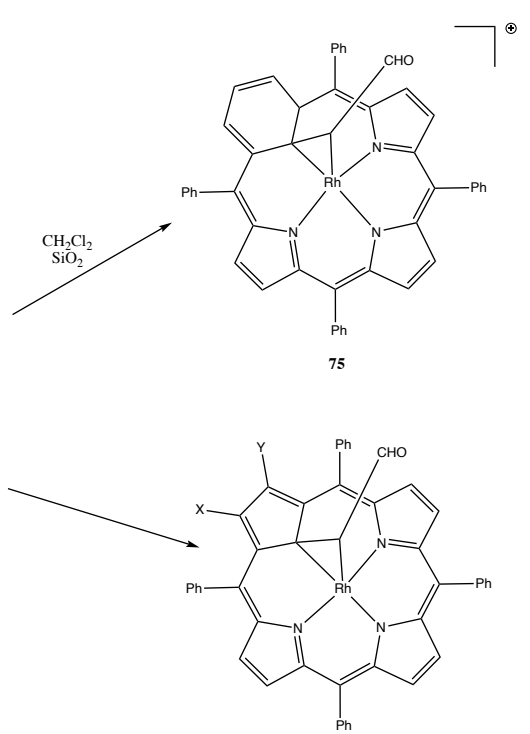

$\begin{gathered}76 . X=\mathrm{X}=\mathrm{H} \\ \mathrm{b}, \mathrm{X}=\mathrm{CHO}, \mathrm{Y}=\mathrm{H}\end{gathered}$
$\mathrm{X}=\mathrm{H}, \mathrm{Y}=\mathrm{CHO}$

Scheme 12. Metalation of tetraphenylbenziporphyrin 
$\mathrm{N}$-confused pyriporphyrins have similar coordination cavities to those found in benziporphyrins. N-confused pyriporphyrin 77 was reacted with $\mathrm{FeBr}_{2}$ and collidine in THF to give the iron(II) complex 78 (Scheme 13). ${ }^{41}$ Further reaction of $\mathbf{7 8}$ with bromine and exposure to oxygen afforded 79 with a five-coordinate iron center. Another metalation done with N-confused pyriporphyrins involved the reaction of pyriporphyrin $\mathbf{3 7}$ and palladium(II) acetate in acetonitrile to give the palladium(II) complex 38 (Scheme 4). ${ }^{20}$

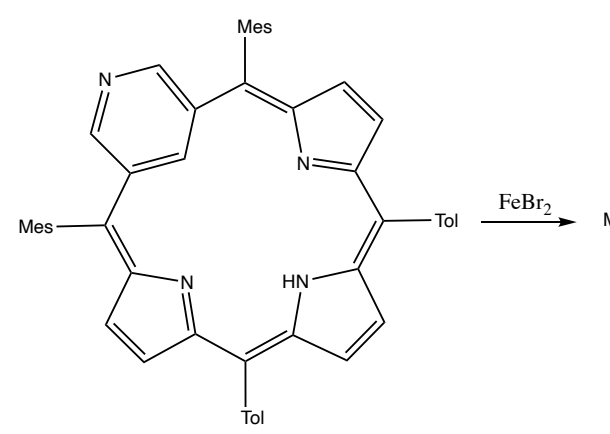

77

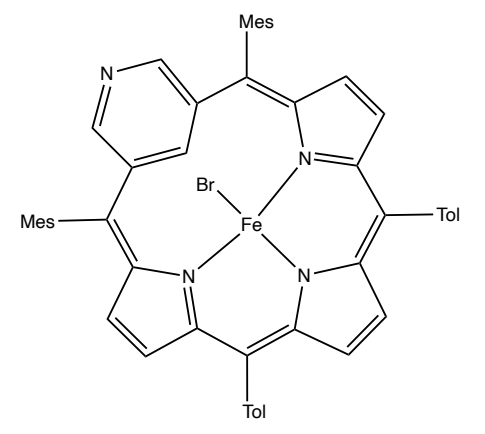

78

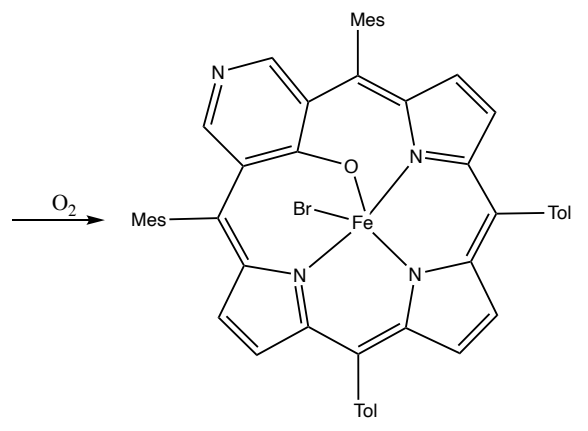

79

Scheme 13. Metalation of N-confused pyriporphyrins

Carbaporphyrinoid systems have been studied extensively over the last 25 years. The aromaticity, reactivity and spectroscopic properties of these systems vary considerably, and the availability of new structural analogues can further extend our understanding of these macrocycles. Although carbaporphyrins replace one or more of the internal nitrogens with carbon atoms, it is also possible to introduce heteroatoms at the exterior of the macrocycle. This is the 
case for N-confused porphyrins and pyriporphyrins, but few other examples of this type are currently known.

In this thesis, extended structures related to $\mathrm{N}$-confused pyriporphyrins have been explored to better understand the aromaticity and spectroscopic properties of systems of this type. Adding subunits where the heteroatom is at the exterior of the macrocycle may lead to porphyrin analogues systems with unusual properties. This approach has been applied to the introduction of a 4-quinolizone subunit to a porphyrinoid macrocycle and the aromatic properties of the new system have been assessed. Metalation and protonation of this system has also provided valuable insights. The use of 4-quinolizone to access antiaromatic pyridoquinolizones has been investigated but the formation of porphyrin analogues incorporating this antiaromatic subunit has not yet been achieved. 


\section{CHAPTER II: SYNTHESIS AND CHARACTERIZATION OF OXYQUINOLIZINIPORPHYRIN}

Pyridine analogs $\mathbf{8 1}$ of phthalocyanines $\mathbf{8 0}$ were first discovered in 1950 by Linstead (Figure 11), but the first synthesis of pyriporphyrin 82 was not attempted until 1994. ${ }^{11 \text {, }}$ ${ }^{42-45}$ Initially, 2,6-pyridinicarbaldehyde 83a was reacted with a tripyrrane 63a using the ' $3+1$ ' method in the presence of an acid catalyst, followed by an oxidation with DDQ, but the desired pyriporphyrin 82a could not be detected. Instead, several related structures were isolated. However, the related hydroxypyridine dialdehyde $\mathbf{8 3 b}$ gave excellent yields of the aromatic porphyrin $\mathbf{8 2 b}$ (Scheme 14). The ' $3+1$ ' method was also used to prepare other pyriporphyrins $\mathbf{4 2} .{ }^{20}$ Modifications to N-confused pyriporphyrin systems are of interest since these drastically alter the aromatic properties. The addition of an embedded N-confused type subunit within structure $\mathbf{8 4}$ was targeted for this investigation due to the potential for this system to exist in several tautomeric forms. In principle, this porphyrinoid may be prepared from dialdehyde 85 (Scheme 15). The thermodynamic stability of the amide component of the quinolizone unit could block the $18 \pi$ electron conjugation pathway in oxyquinoliziniporhyrins 84, but dipolar resonance contributors might reinstate a degree of macrocyclic aromaticity (Scheme 16). 

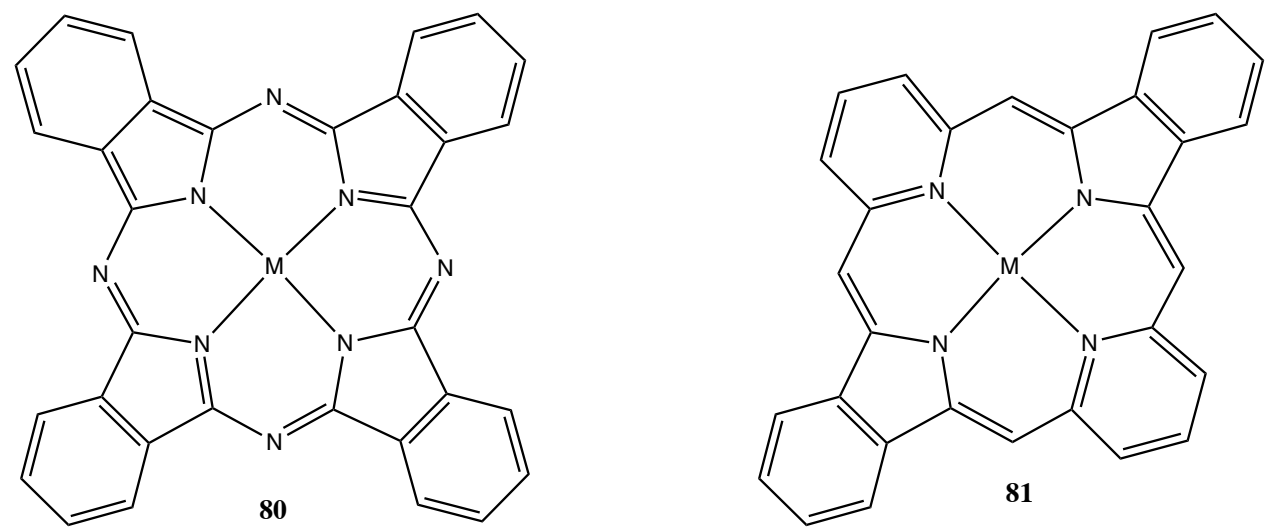

$\mathrm{M}=2 \mathrm{H}, \mathrm{Cu}, \mathrm{Ni}$

Figure 11. Phthalocyanine $\mathbf{8 0}$ and dipyriphthalocyanine $\mathbf{8 1}$
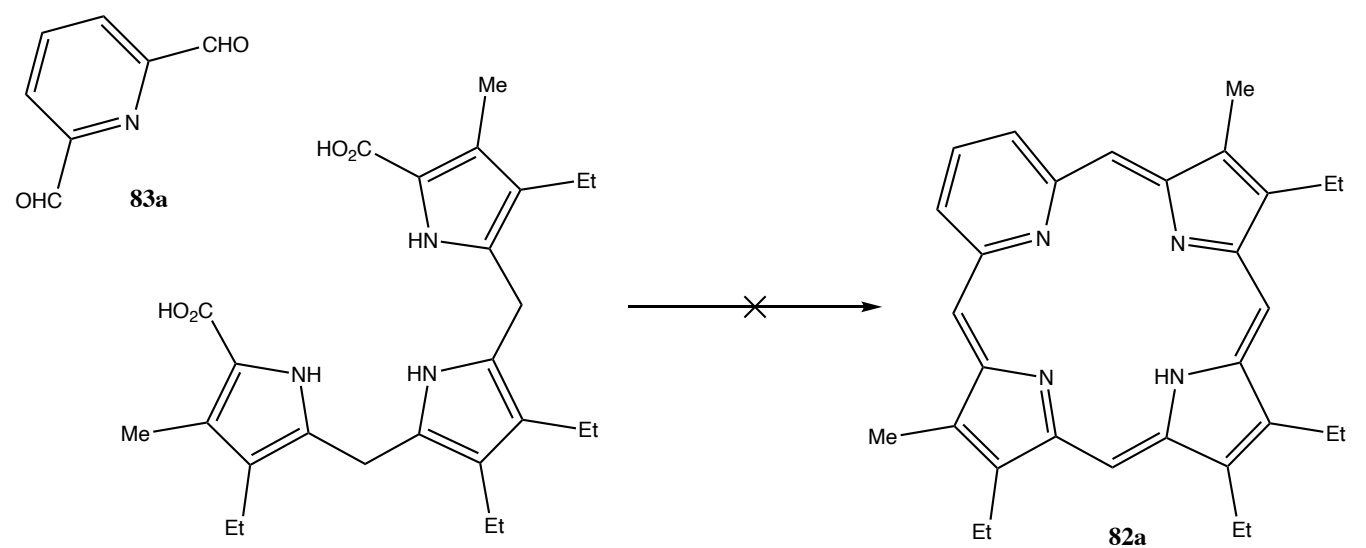

63
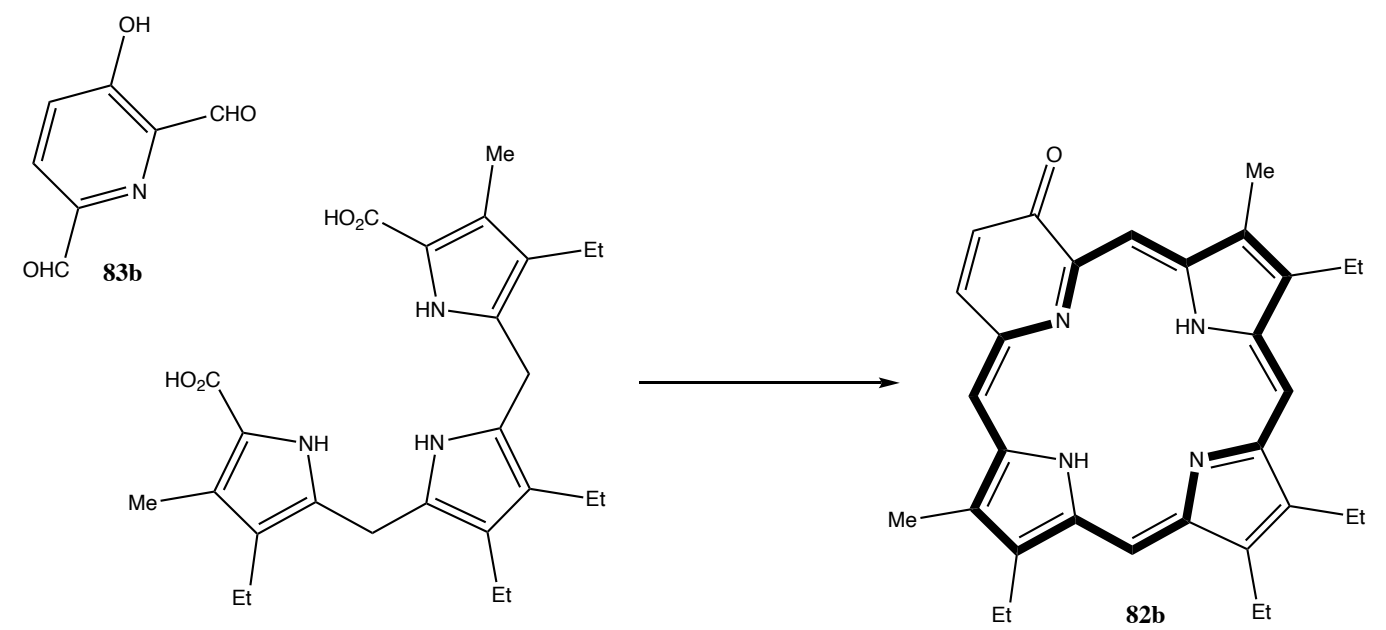

Scheme 14. Syntheses of pyriporphyrins 


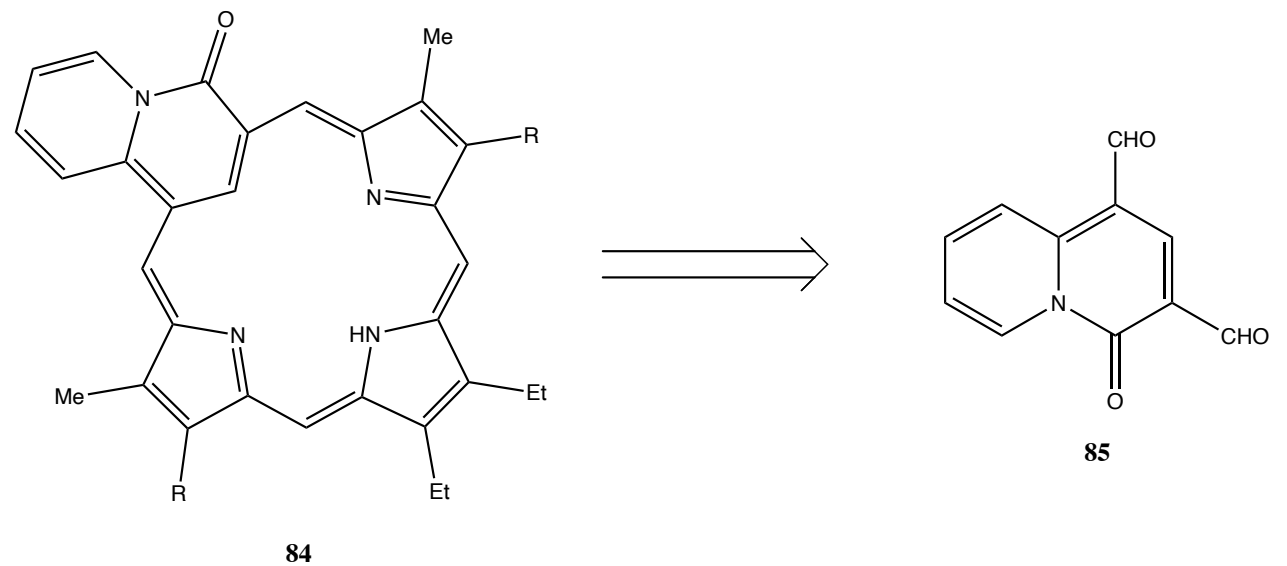

Scheme 15: Retrosynthetic analysis of oxyquinoliziniporphyrins
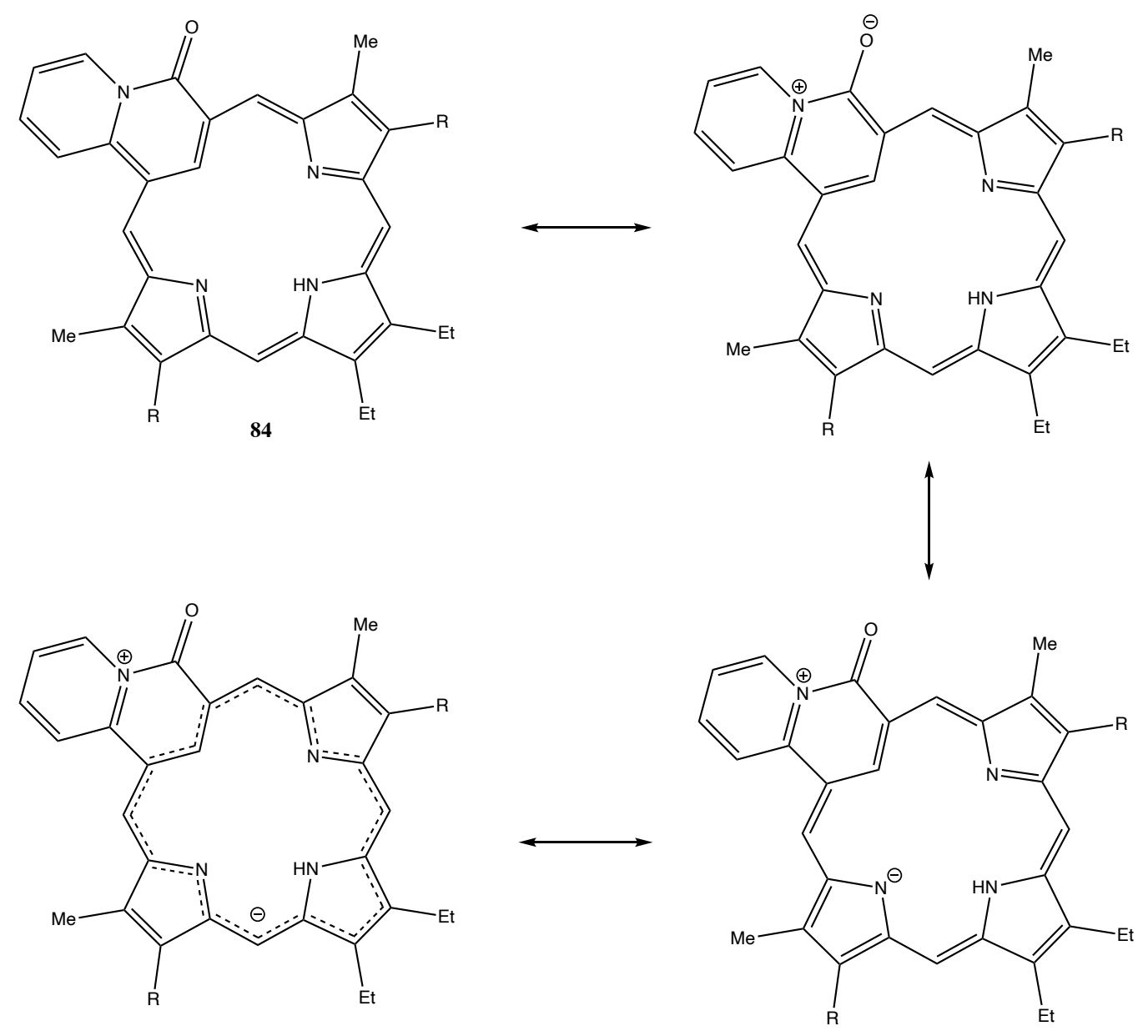

Scheme 16. Oxyquinoliziniporphyrins resonance contributors 
In addition to dialdehyde $\mathbf{8 5}$, the key intermediates for the synthesis of oxyquinoliziniporphyrins are tripyrranes (see Scheme 9). Tripyrranes can be prepared from pyrrolic precursors. The central pyrrole unit is derived from 3,4-diethylpyrrole 61. This is prepared using the Barton-Zard reaction from ethyl isocyanoacetate 86. Reaction of glycine ethyl ester hydrochloride $\mathbf{8 7}$ and triethylamine and refluxing methyl formate gave $\mathrm{N}$-formylglycinate $\mathbf{8 8}$. This was dehydrated with phosphorous oxychloride and triethylamine at $0{ }^{\circ} \mathrm{C}$ to afford the desired isocyanide 86 (Scheme 17).

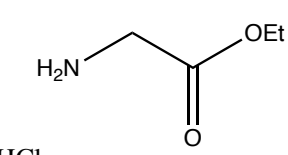

$\mathrm{HCl}$

87

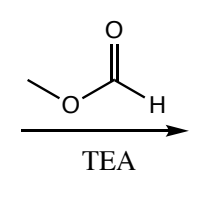<smiles>CCOC(=O)CNC=O</smiles>

88

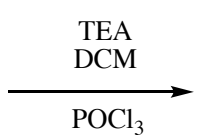

$\mathrm{POCl}_{3}$

Scheme 17. Synthesis of ethyl isocyanoacetate $\mathbf{8 6}$

The second precursor needed for the Barton Zard synthesis is acetoxy nitrohexane 89. This was prepared in two steps from propionaldehyde $\mathbf{9 0}$. Reaction of 1-nitropropane with 90 in the presence of potassium fluoride gave the corresponding nitro alcohol 91. Subsequent treatment of 91 with acetic anhydride under acidic conditions afforded the desired nitroacetate 89 (Scheme 18).

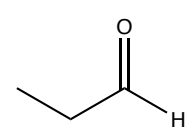

90

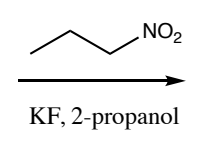

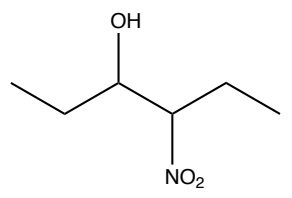

91
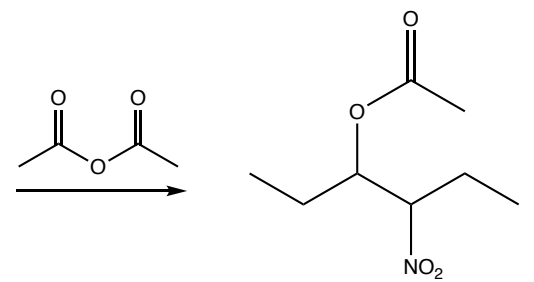

89

Scheme 18. Preparation of acetoxy nitrohexane $\mathbf{8 9}$ 
Condensation of acetoxy nitrohexane 89 and ethyl isocyanoacetate 86 in the presence of two equivalents 1,8-diazabicyclo[5.4.0]undec-7-ene (DBU) produced pyrrole ester 92. Crude 92 was then decarboxylated with sodium hydroxide in ethylene glycol at $190{ }^{\circ} \mathrm{C}$ to form diethylpyrrole 61 (Scheme 19).<smiles>CCC(OC(C)=O)C(CC)[N+](=O)[O-]</smiles>

89

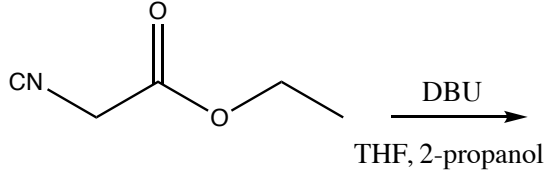

86

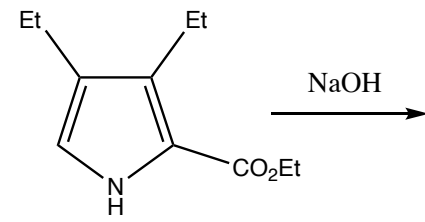

92

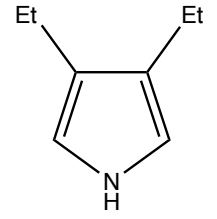

61

Scheme 19. Preparation of 3,4-diethylpyrrole 61

Two different tripyrranes were used in these studies, and these were prepared from benzyl 5-acetoxymethyl-4-ethyl-3-methylpyrrole-2-carboxylate 60a and benzyl 5-acetoxymethyl4-butyl-3-methylpyrrole-2-carboxylate $\mathbf{6 0 b}$. In order to synthesize these pyrrolic precursors, ethyl esters 93a-b were first prepared in a Knorr-type condensation of diethyl aminomalonate 94 and $\beta$ diketones 95a-b in the presence of acetic acid (Scheme 20).<smiles>CCOC(=O)C(N)C(=O)[O-]</smiles>

94

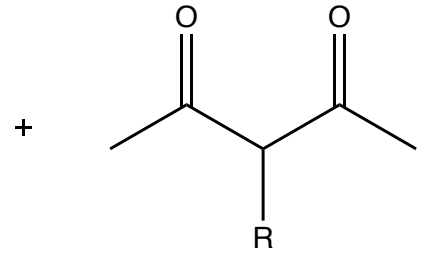

$95 \mathrm{a} \cdot \mathrm{R}=\mathrm{Et}$

b. $\mathrm{R}=\mathrm{Bu}$

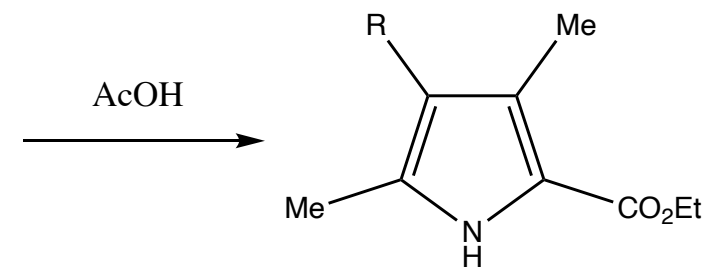

93 a. $\mathrm{R}=\mathrm{Et}$

b. $\mathrm{R}=\mathrm{Bu}$

Scheme 20. Knorr-type synthesis of ethyl 4-ethyl-3,5-dimethyl-2-carboxylate 93a and ethyl 4butyl-3,5-dimethyl-2-carboxylate 93b 
Diethyl aminomalonate $\mathbf{9 4}$ and diketones 95a-b were prepared from commercially available diethyl malonate and 2,4-pentanedione, respectively. Diethyl malonate and sodium nitrite were reacted in the presence of acetic acid to give diethyl oximinomalonate 96. Reduction with hydrogen over 10\% Pd/C then gave diethyl aminomalonate 94 (Scheme 21).<smiles>CCOC(=O)CC(=O)OCC</smiles>

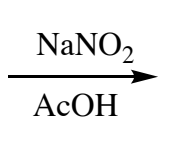<smiles>CCOC(=O)C(=NO)C(=O)OCC</smiles>

96

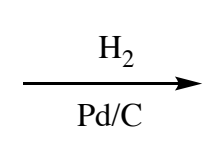

6<smiles>CCOC(=O)C(N)C(=O)OCC</smiles>

94

Scheme 21. Preparation of diethyl aminomalonate 94.

Alkylation of 2,4-pentanedione with ethyl iodide or n-butyl bromide and potassium carbonate in refluxing acetone gave the required diketones $95 \mathbf{a}$ and $95 \mathbf{b}$ (Scheme 22).<smiles>CC(=O)CC(C)=O</smiles>

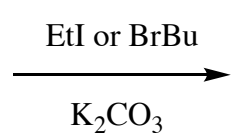<smiles>CC(=O)C(P)C(C)=O</smiles>

$$
95 \text { a. } R=E t
$$

b. $\mathrm{R}=\mathrm{Bu}$

Scheme 22. Synthesis of 3-ethyl-2,4-pentadione 95a and 3-butyl-2,4-pentadione 95b

Pyrrole 93a,b were transesterified with benzyl alcohol in the presence of sodium benzyloxide to give the corresponding benzyl esters 97a,b. Selective oxidation with lead tetraacetate in acetic acid then gave acetoxymethyl pyrroles 60a-b. (Scheme 23). 

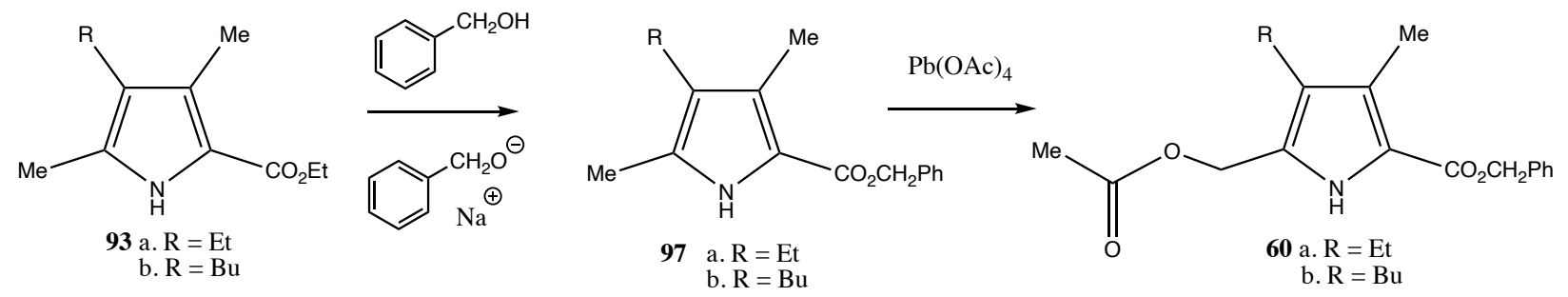

Scheme 23. Synthesis of $\mathbf{6 0 a - b}$

Two equivalents of acetoxymethylpyrroles 60a-b were reacted with 3,4diethylpyrrole (61) in refluxing ethanol with acetic acid to give the corresponding tripyrrane dibenzyl esters 62a-b. Hydrogenolysis of the benzyl esters over $\mathrm{Pd} / \mathrm{C}$ afforded the required dicarboxylic acid derivatives 63a-b (Scheme 24).
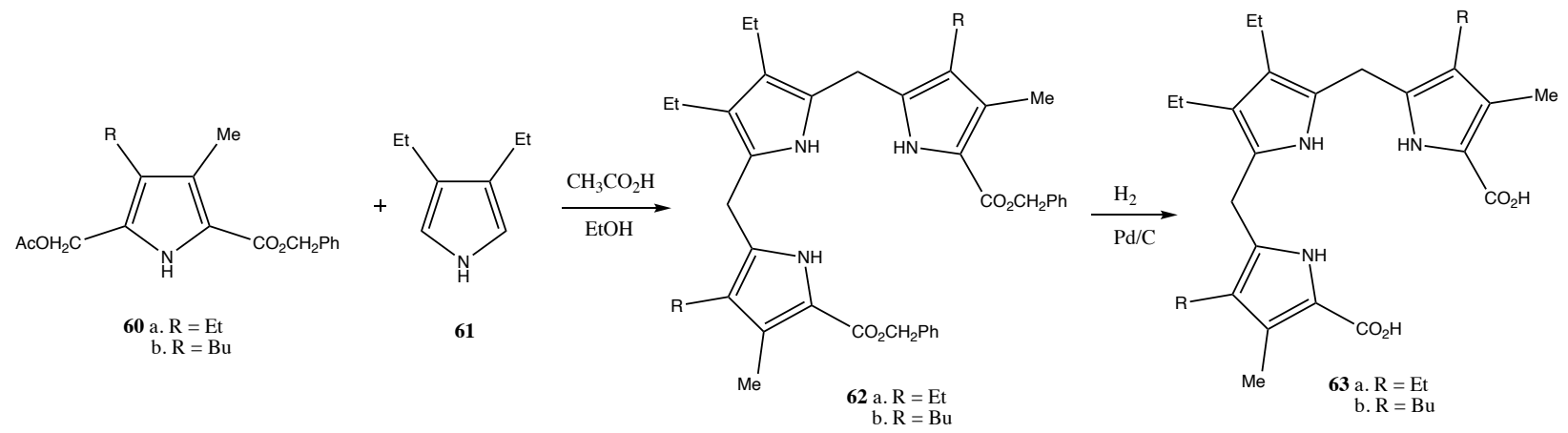

Scheme 24. Synthesis of tripyrranes 63a-b

In order to synthesize the targeted oxyquinoliziniporphyrin system, dialdehyde $\mathbf{8 5}$ was required. This was prepared in four steps from 2-picoline (98). Lithium diisopropylamide (LDA) was added to a solution of 2-picoline and diethyl carbonate in THF at $-78^{\circ} \mathrm{C}$. The reaction was quenched with saturated ammonium chloride and following workup, ethyl 2-pyridylacetate (99) was isolated (Scheme 25). ${ }^{48}$ 


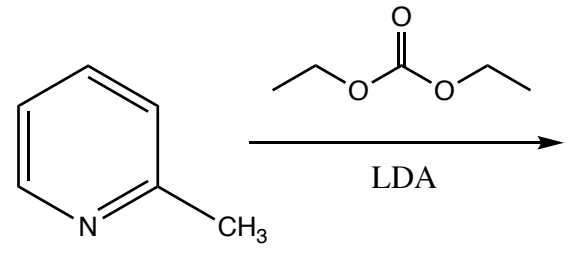

98

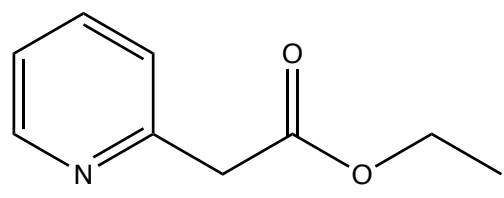

99

Scheme 25. Synthesis of ethyl 2-pyridylacetate 99

The next step in this synthesis involves the formation of the quinolizone subunit. Ethyl 2-pyridylacetate was heated with diethyl ethoxymethylene malonate $(\mathbf{1 0 0})$ at $180{ }^{\circ} \mathrm{C}$ for 8 hours to give diester 101. The esters were cleaved by refluxing $\mathbf{1 0 1}$ in $\mathrm{HCl}$ to give 4-quinolizone 102 (Scheme 26). ${ }^{46}$

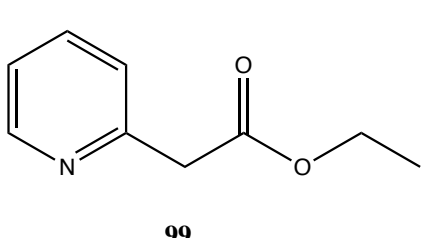

99
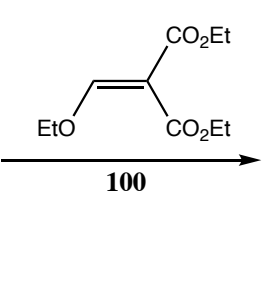

Scheme 26. Synthesis of 4-quinolizone $\mathbf{1 0 3}$ the dialdehyde units. 4-Quinolizone 102 undergoes a Vilsmeier-Haack reaction with $\mathrm{POCl}_{3}$ and DMF, and the reaction mixture was quenched with aqueous sodium carbonate to give quinolizone dialdehyde 85 (Scheme 27). ${ }^{47}$ 
<smiles>O=c1cccc2ccccn12</smiles>

102

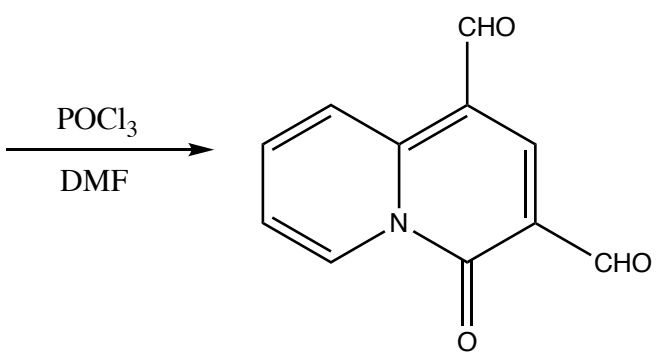

85

Scheme 27. Synthesis of 4-quinolizone-1,3-dicarbaldehyde $\mathbf{8 5}$

The ' $3+1$ ' MacDonald condensation was carried out by reacting tripyrranes 63a-b with dialdehyde $\mathbf{8 5}$ in the presence of trifluoroacetic acid under dilute conditions. The condensation was followed by an oxidation with DDQ, to give the desired porphyrin products 84ab in 36-54\% yields (Scheme 28). The porphyrins were purified by column chromatography on alumina followed by recrystallization with dichloromethane and hexanes to give dark green solids.<smiles>O=Cc1cc(C=O)c2ccccn2c1=O</smiles><smiles>[2H]c1c(C)[nH]c(C(=O)O)c1[N+](=O)[O-]</smiles><smiles>CCc1[nH]c(Cc2[nH]c(C(=O)O)c(C)c2P)c(CC)c1CC</smiles>

63 a. $\mathrm{R}=\mathrm{Et}$

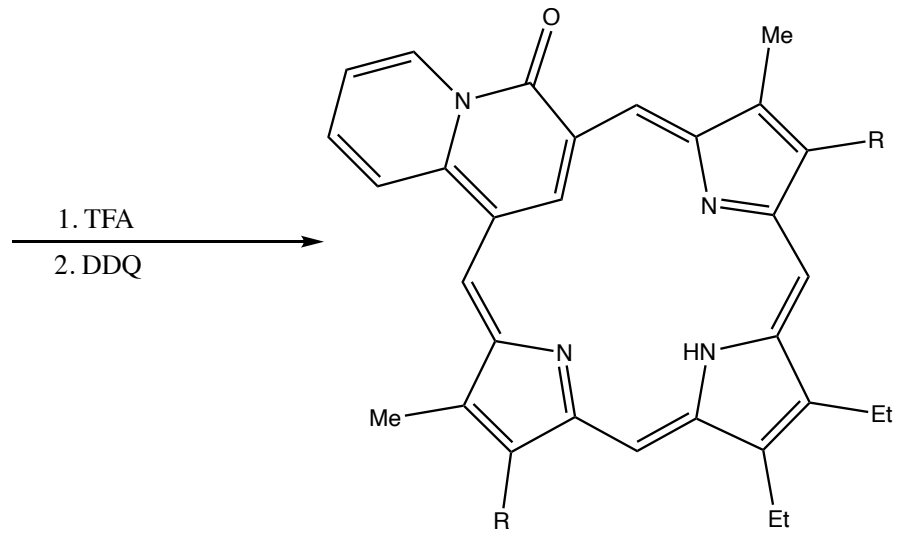

84 a. $\mathrm{R}=\mathrm{Et}$

Scheme 28. Synthesis of carbaporphyrins $\mathbf{8 4 a}, \mathbf{b}$. 
The proton NMR spectrum of the free base forms could only be obtained for $\mathbf{8 4 \mathbf { b }}$ due to the poor solubility of $\mathbf{8 4 a}$. The free base of $\mathbf{8 4 b}$ in $\mathrm{CDCl}_{3}$ showed that this species has some aromatic character and the meso-protons showed up at 7.62, 7.63, 8.13, and $9.04 \mathrm{ppm}$ (Figure 12). The internal protons of this species did not resolve in the proton NMR spectra, but the downfield shifts for the meso-protons indicate that a diatropic ring current is present. 

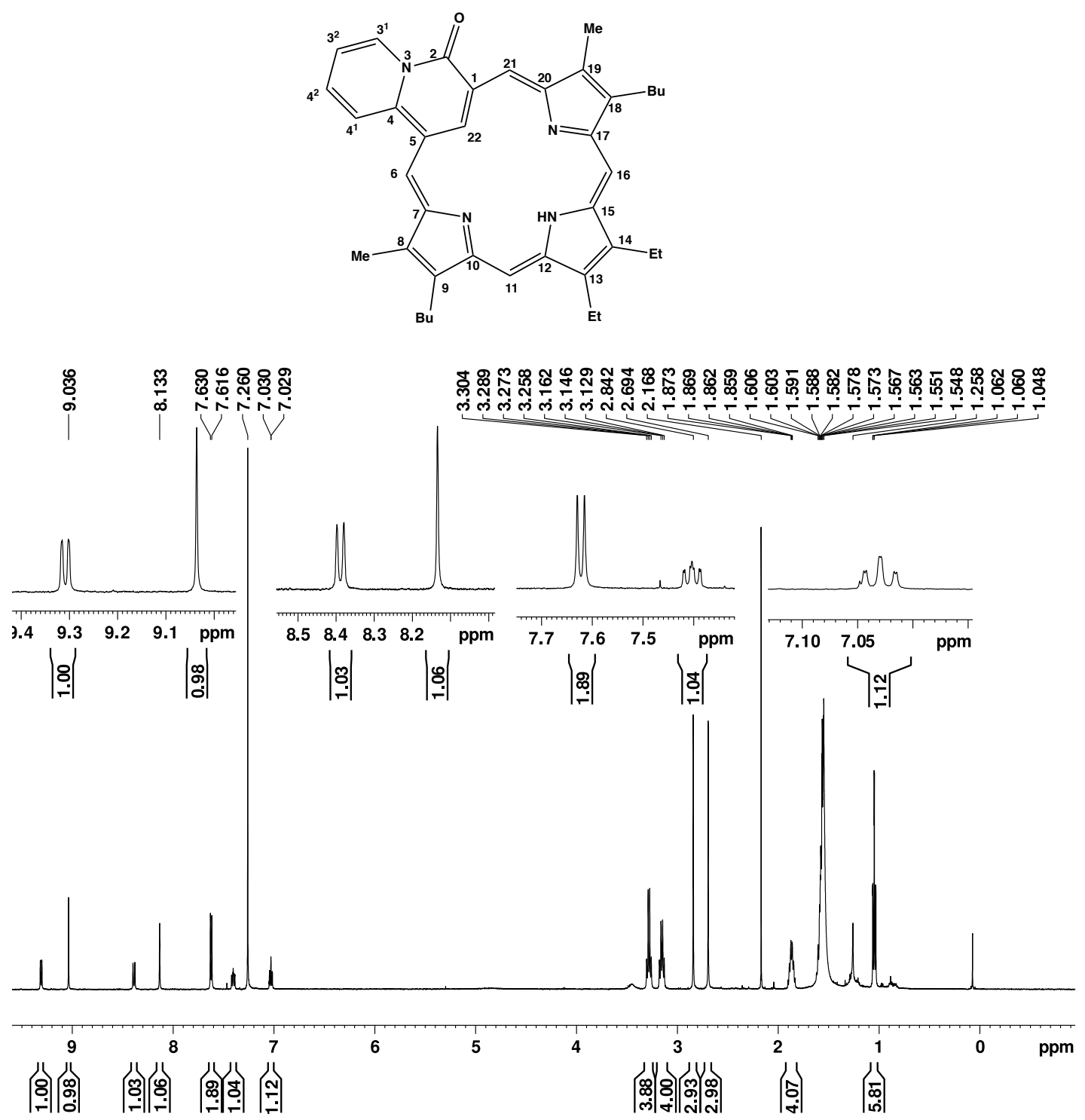

Figure 12. ${ }^{1} \mathrm{H}$ NMR spectrum of oxyquinolizone porphyrin $\mathbf{8 4} \mathbf{b}$ in $\mathrm{CDCl}_{3}$

Porphyrins 84a-b were also assessed using UV-Vis spectroscopy. In 1\% TEA 84a showed strong absorption bands at 332, 406, 462, and $489 \mathrm{~nm}$ as well as some broad bands absorption bands around 610 and $655 \mathrm{~nm}$. A similar absorption spectrum was obtained for $\mathbf{8 4 b}$. 
The spectra closely resemble the electronic absorption spectra for azuliporphyrins, a well-studied class of carbaporphyrinoids that also exhibit intermediary aromatic characteristics (Scheme 29). Addition of 1 equivalent of TFA afforded a new species that was attributed to the monoprotonated species 103a (Scheme 30). At higher concentrations of TFA, a new species corresponding to a dication 104a was formed and this gave a very strong Soret-type band at $464 \mathrm{~nm}$, and more pronounced Q bands at 638, 667, and $711 \mathrm{~nm}$ (Figure 13). This spectrum is more typical of an aromatic porphyrinoid species.

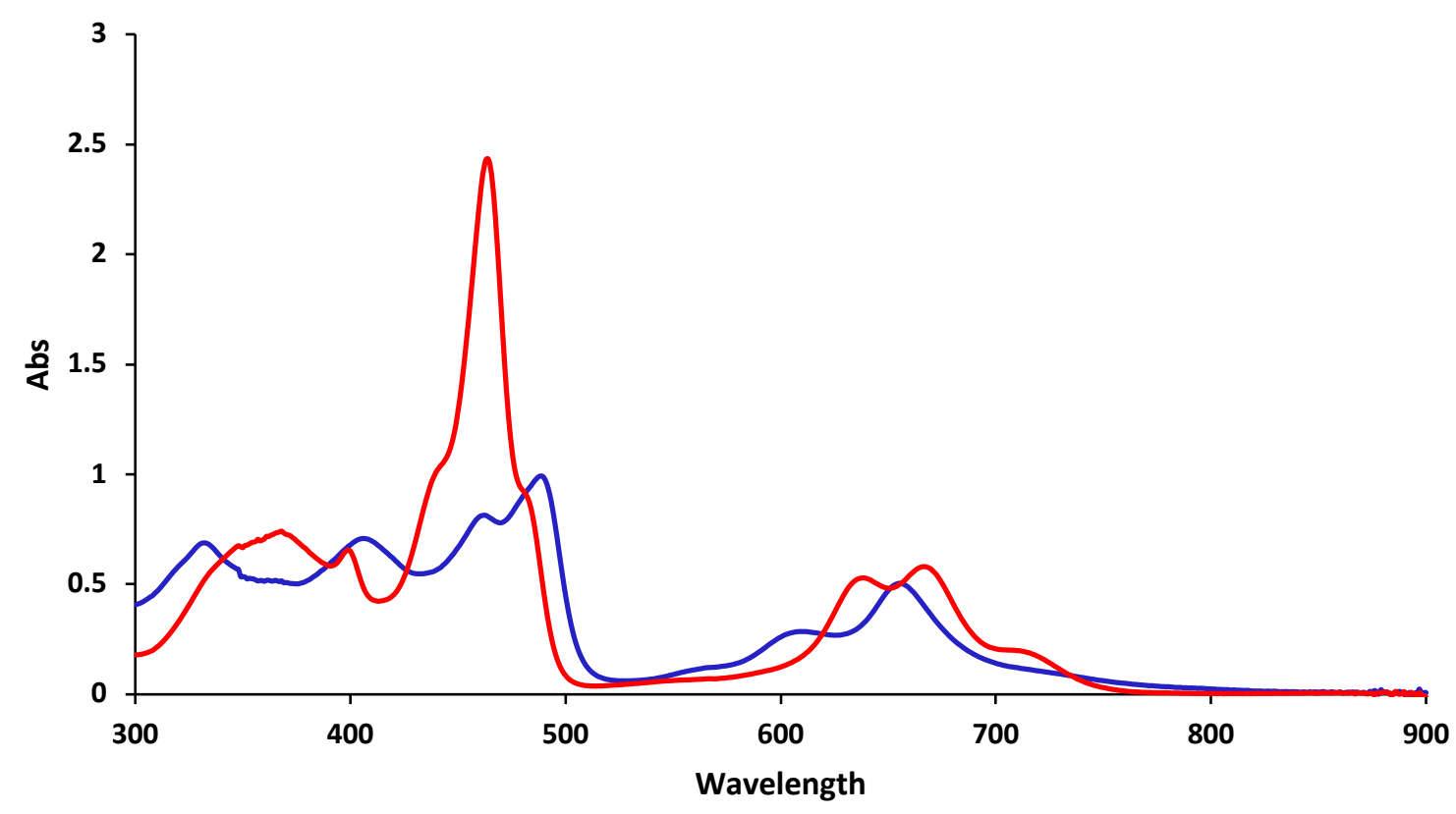

Figure 13. UV-vis spectra of oxyquinoliziniporphyrin 84a in 1\% triethylamine-dichloromethane (free base, blue line) and 10\% TFA-dichloromethane (104a, red line) 


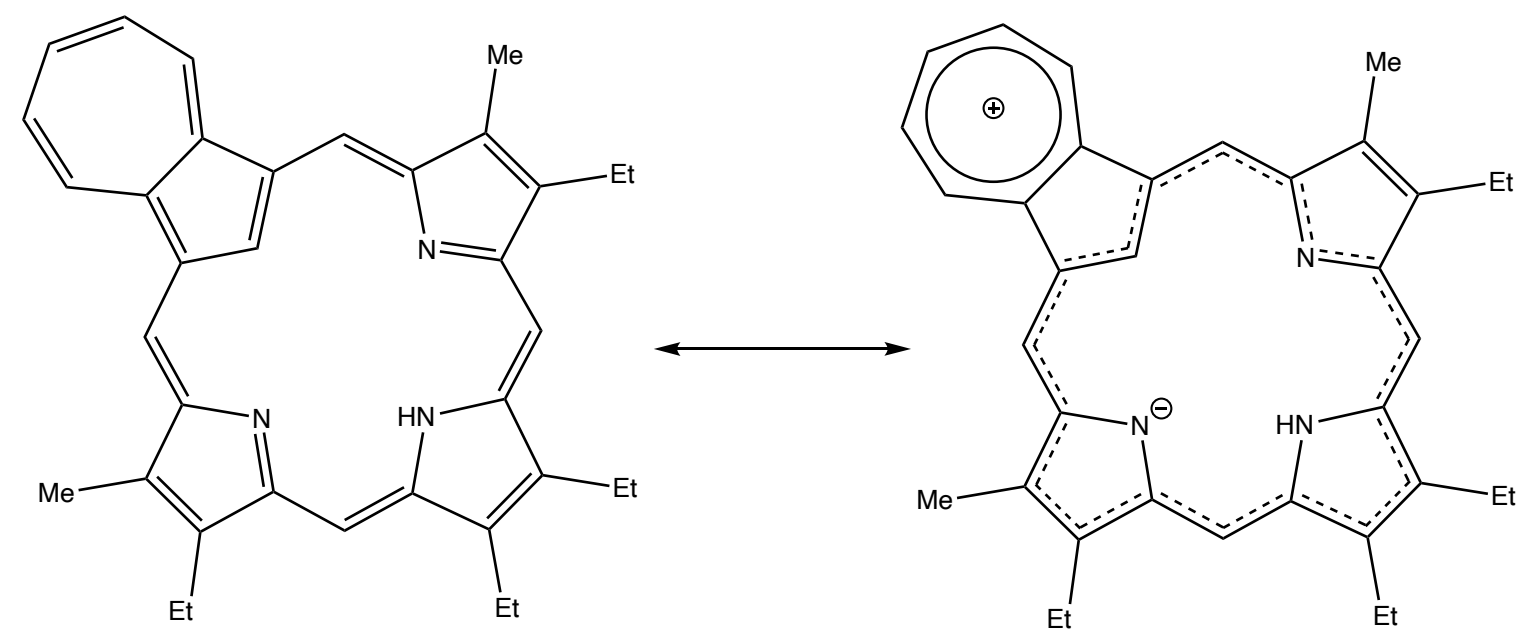

Scheme 29. Azuliporphyrin and its aromatic dipolar resonance contributor

As expected oxyquinoliziniporphyrin $\mathbf{8 4 b}$ gave a similar electronic spectra to $\mathbf{8 4 a}$.

In 1\% TEA, 84b showed strong absorption bands at 332, 409 462, and $489 \mathrm{~nm}$ and broader absorption bands at 610 and $656 \mathrm{~nm}$. Upon addition of TFA, a strong absorption emerged at 464 $\mathrm{nm}$ and Q bands appeared at 638, 667, and $713 \mathrm{~nm}$ (Figure 14). 


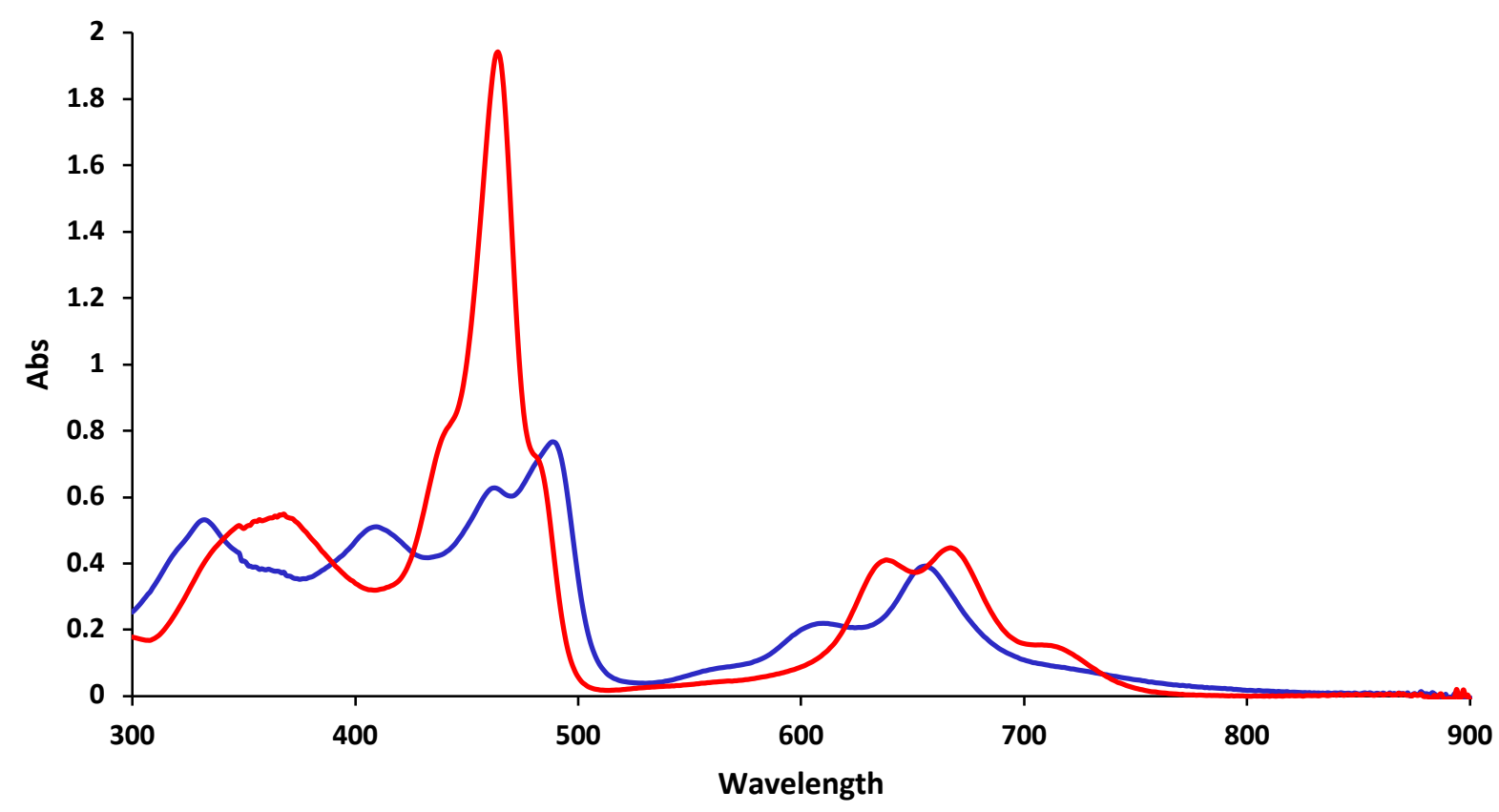

Figure 14. UV-vis spectra of oxyquinoliziniporphyrin $\mathbf{8 4 b}$ in $1 \%$ triethylamine-dichloromethane (free base, blue) and 10\% TFA-dichloromethane (104b, red line)

Protonation of benziporphyrins has been shown to give a degree of macrocyclic aromaticity. The UV-vis spectra for these carbaporphyrinoid systems indicates that this is also true for this structure. The proton NMR spectra were also consistent with the formation of a strongly aromatic structure. 

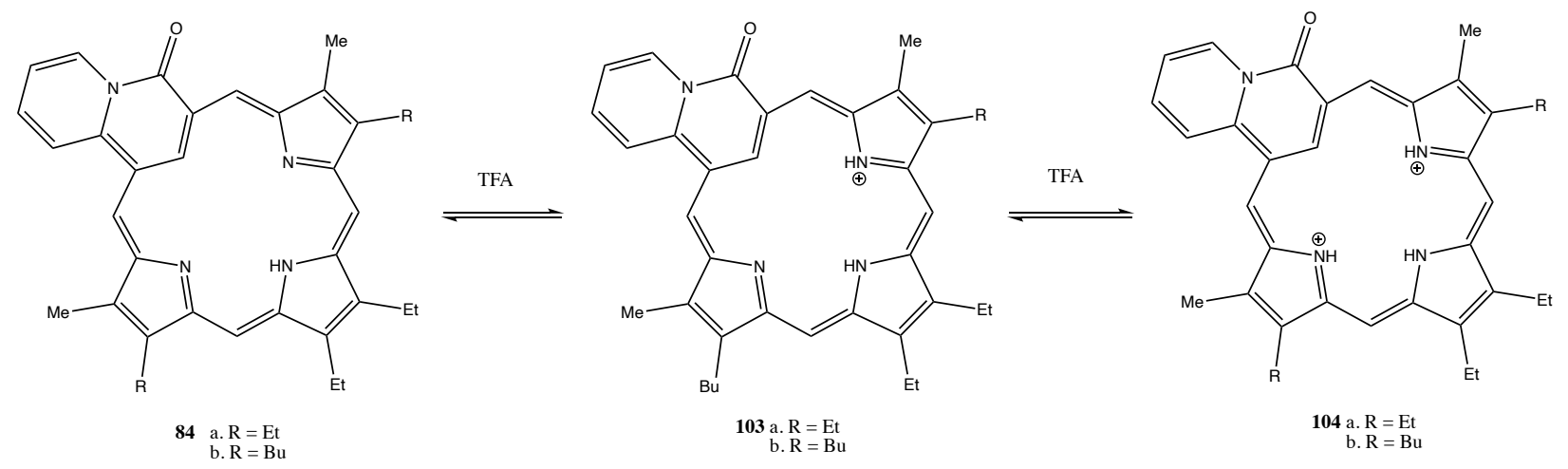

Scheme 30. Protonation of oxyquinoliziniporphyrins 84a-b

The proton NMR spectra of the protonated species $\mathbf{1 0 4 b}$ in $\mathrm{CDCl}_{3}$ with 1 drop of TFA showed the presence of a strong diatropic ring current (Figure 15). The meso-protons shifted downfield to $10.32,10.03,9.17$ and $9.14 \mathrm{ppm}$, while the internal $\mathrm{CH}$ appeared upfield at -2.82 ppm. The proton NMR spectra could also be obtained for 104a due to an increase in solubility upon protonation. This spectrum was similar to $\mathbf{1 0 4 b}$ with the meso-protons $9.18,9.21,10.05$, and $10.35 \mathrm{ppm}$, and the internal $\mathrm{CH}$ at $-2.93 \mathrm{ppm}$ (Figure 16). This increase in aromatic character can be attributed to electron-donation from the quinolizone nitrogen to give resonance contributors such as $\mathbf{1 0 5}$ with $18 \pi$ electron delocalization pathways (Scheme 31 ). 

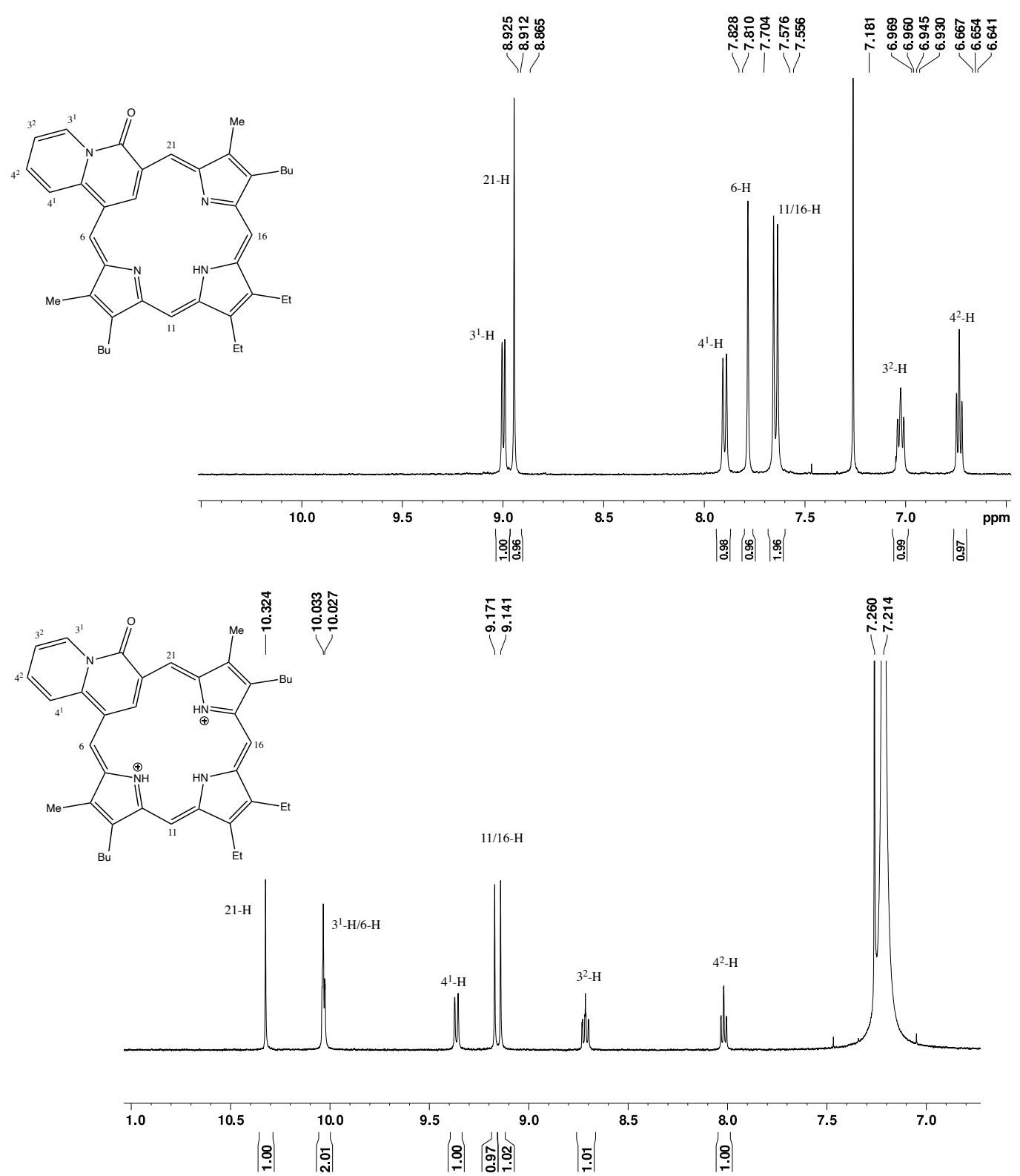

Figure 15. Downfield region of the ${ }^{1} \mathrm{H}$ NMR spectra for oxyquinoliziniporphyrin $\mathbf{8 4 b}$ (top spectrum) and dication 104b (bottom spectrum) 

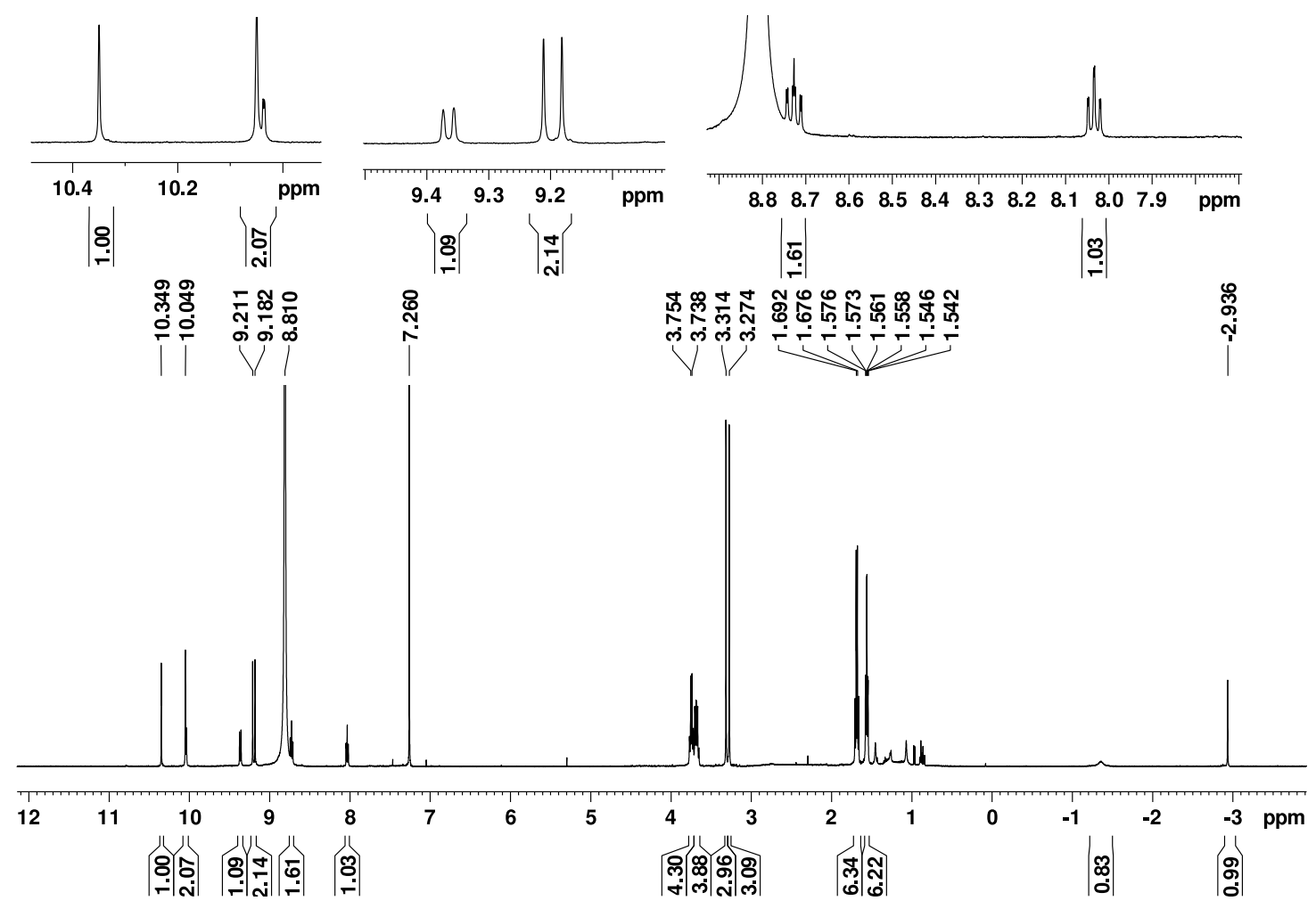

Figure 16. ${ }^{1} \mathrm{H}$ NMR spectrum of protonated oxyquinoliziniporphyrin dication 104a in TFA-CDCl 3

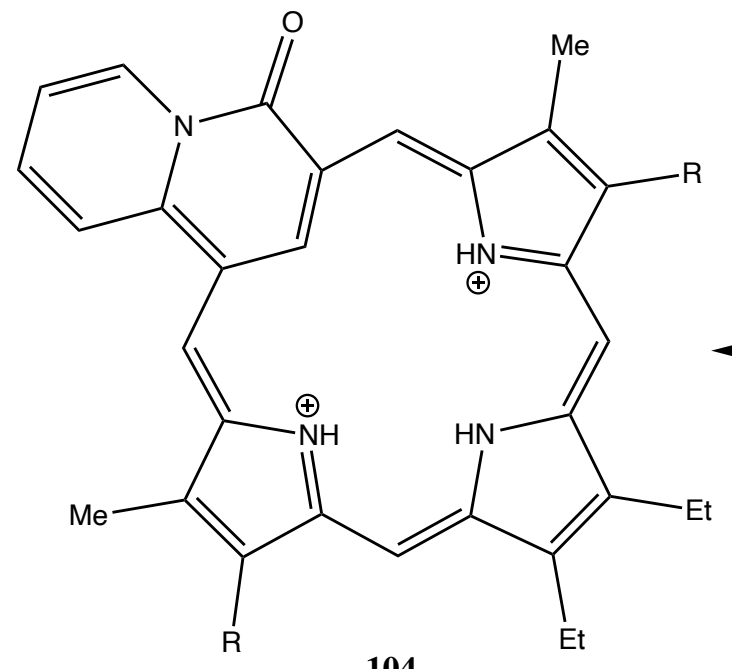

104

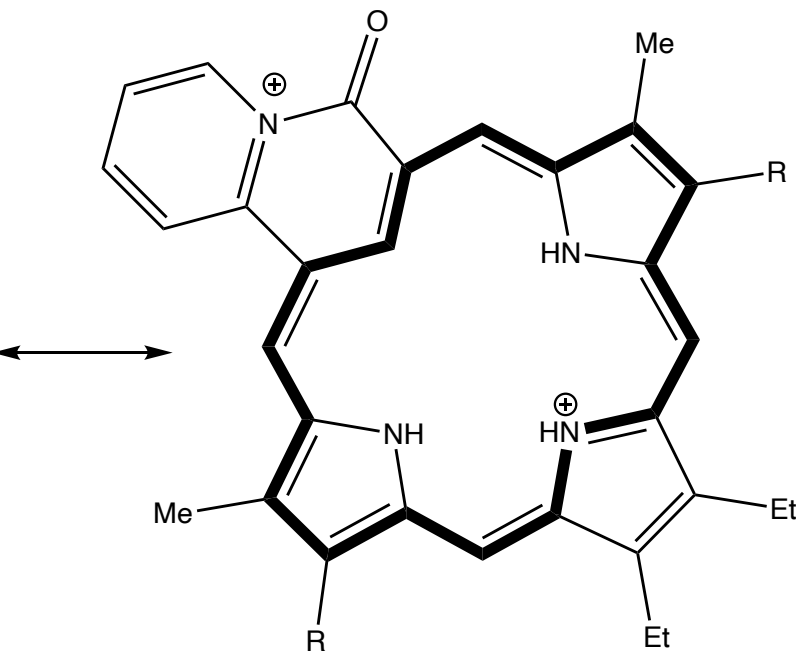
105

Scheme 31. Resonance contributors for oxyquinoliziniporphyrin dications. 
Metalation of quinoliziniporphyrins 84a-b were also investigated with palladium(II) and nickel(II) acetate. Oxyquinoliziniporphyrins 84a-b were reacted with palladium(II) acetate in acetonitrile and chloroform for 15-60 $\mathrm{min}$. The reaction mixtures were diluted with dichloromethane and washed with water. The solution was evaporated, and the residue was purified by column chromatography. Recrystallization from chloroform-hexanes gave the palladium complexes in $32 \%$ yield for $\mathbf{1 0 6 a}$ and $85 \%$ for $\mathbf{1 0 6}$. Reaction with $\mathrm{Ni}(\mathrm{OAc})_{2}$ gave the corresponding nickel complexes, and these were purified by chromatography to give $\mathbf{1 0 7 a}$ in $72 \%$ yield and 107b in a $43 \%$ yield (Scheme 32 ).
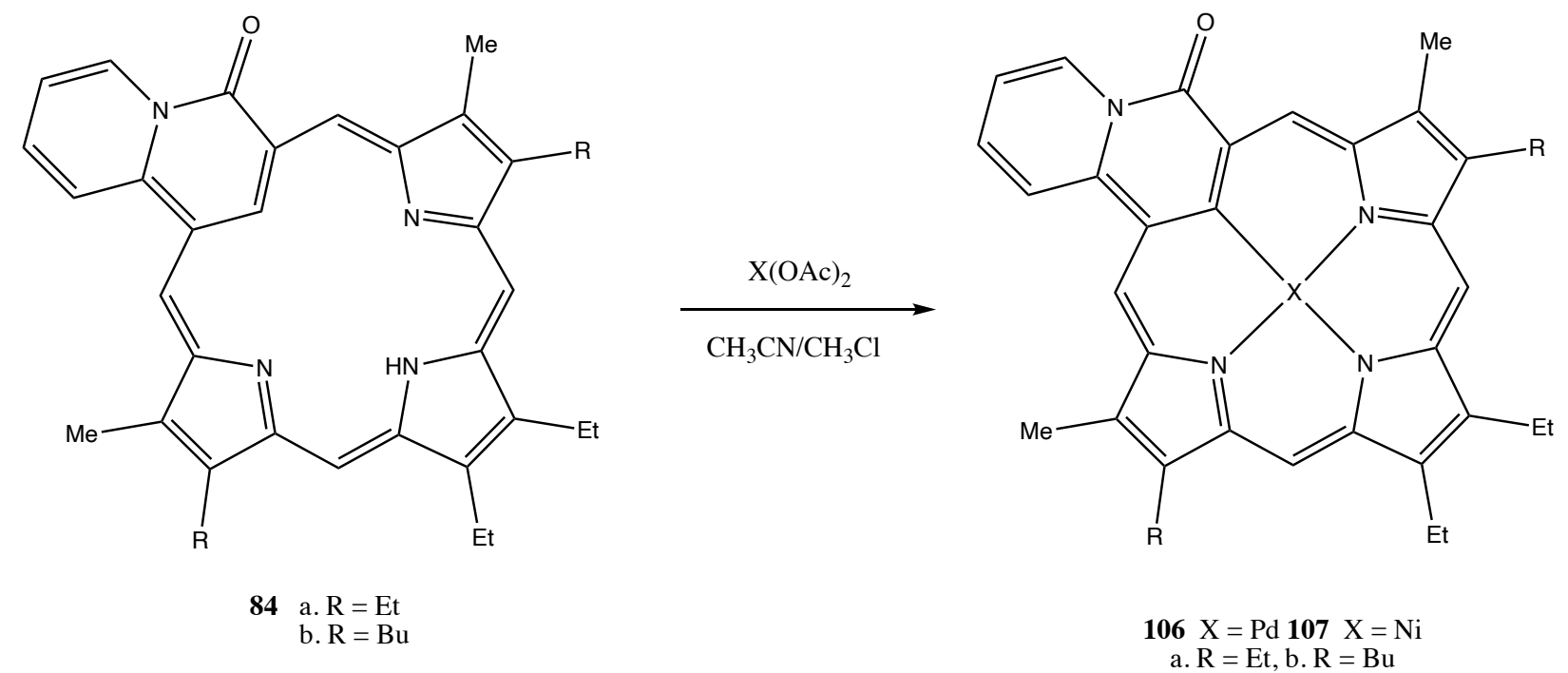

Scheme 32. Metalation of oxyquinoliziniporphyrins 84a-b

The proton NMR spectra of the palladium and nickel complexes showed that metalation effects the degree of aromaticity in these ring systems. The proton NMR spectrum of palladium(II) complex 106a showed the meso-protons at 8.29, 8.35, 8.66, and $9.62 \mathrm{ppm}$. The mesoprotons of nickel complex 107a did not shift as far downfield and showed up at 7.96, 7.98, 8.04, and $8.96 \mathrm{ppm}$ (Figure 17). 

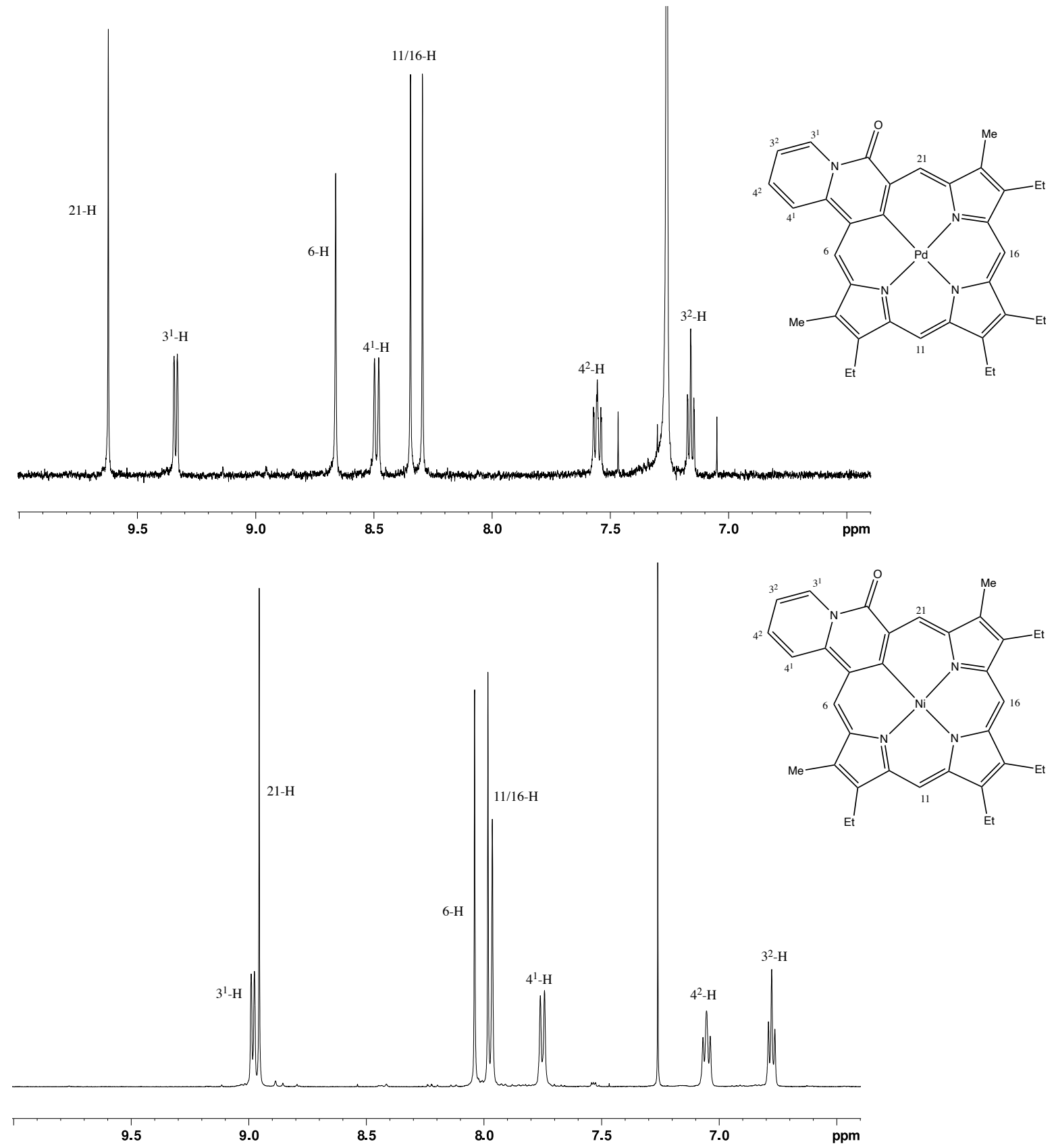

Figure 17. Downfield region of the ${ }^{1} \mathrm{H}$ NMR of palladium oxyquinoliziniporphyrin 106a (top spectrum) and nickel quinoliziniporphyrin 107a (bottom spectrum). 
The proton NMR spectra of the metal complexes of $\mathbf{8 4 b}$ gave similar results (Figure 18). In palladium complex $\mathbf{1 0 6} \mathbf{b}$, the meso-protons shifted substantially downfield compared to free base 84b appearing at 7.95, 8.25, 8.36, and 9.51 ppm. In nickel complex 107b the shifts were less drastic, and the corresponding resonances appeared at 7.97, 8.00, 8.16, and $8.96 \mathrm{ppm}$. Nevertheless, these values are still significantly downfield compared to $\mathbf{1 0 4 b}$. The enhanced aromatic character of the palladium complexes may be due to the macrocycle taking on a more planar conformation. Nickel(II) porphyrinoids are often distorted to enable coordination to the relatively small nickel(II) cation. 

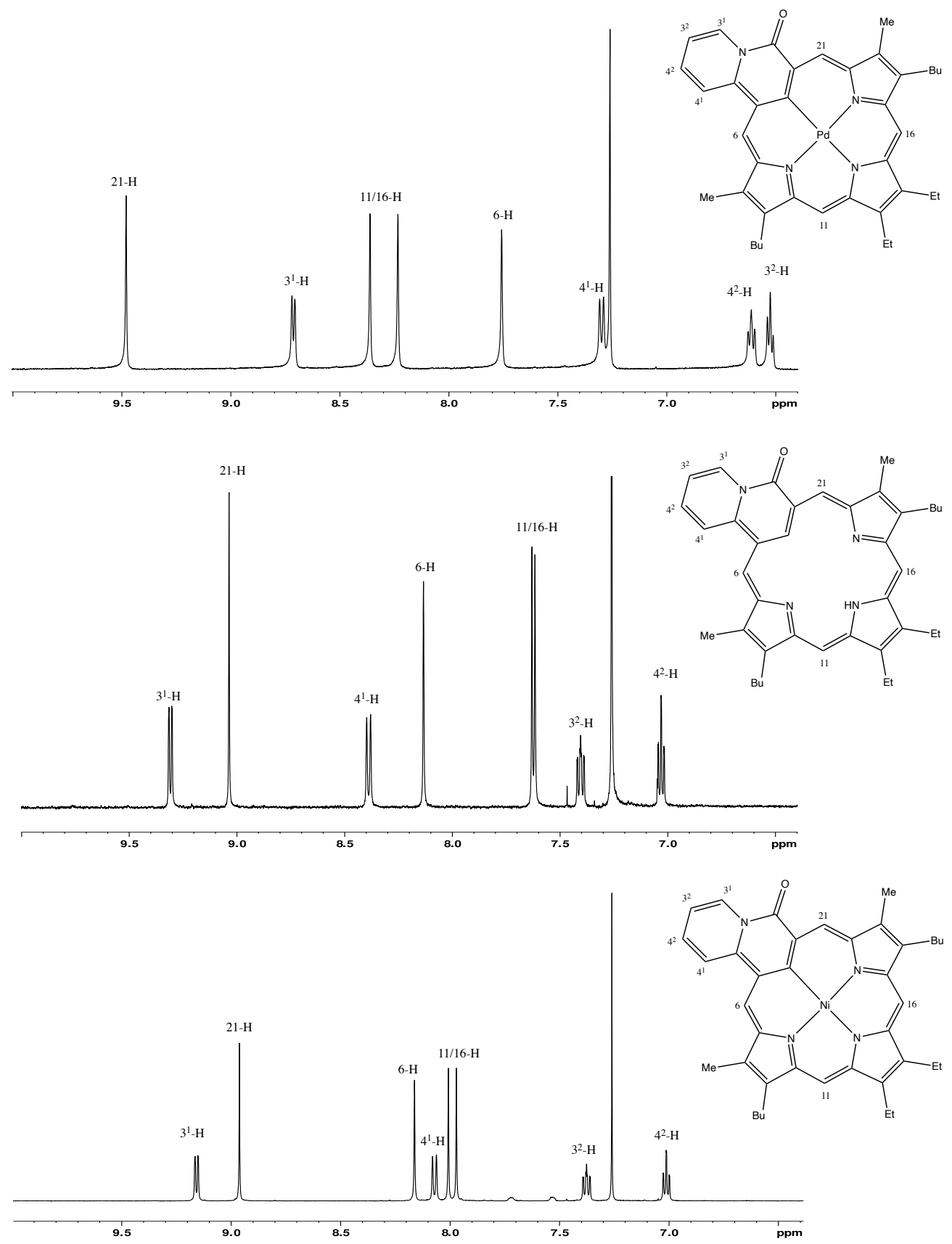

Figure 18. Downfield region of the ${ }^{1} \mathrm{H}$ NMR spectra of oxyquinoliziniporphyrin $\mathbf{8 4 b}$ (middle spectrum), palladium complex 106b (top spectrum), and nickel complex 107b (bottom spectrum) 
The metalated derivatives were also examined by UV-vis spectroscopy to further assess the changes to these systems. The $\mathrm{Ni}(\mathrm{II})$ and $\mathrm{Pd}(\mathrm{II})$ complexes of $\mathbf{8 4 a}$ show significant differences in their absorption spectra. Palladium complex 106a showed strong absorptions at 347, 409, and $465 \mathrm{~nm}$, with an equally strong broad absorption at $649 \mathrm{~nm}$. Nickel complex 107a gave strong absorptions at 359 and $411 \mathrm{~nm}$ with a shoulder at $472 \mathrm{~nm}$, and an equally strong absorption at $661 \mathrm{~nm}$ (Figure 19).

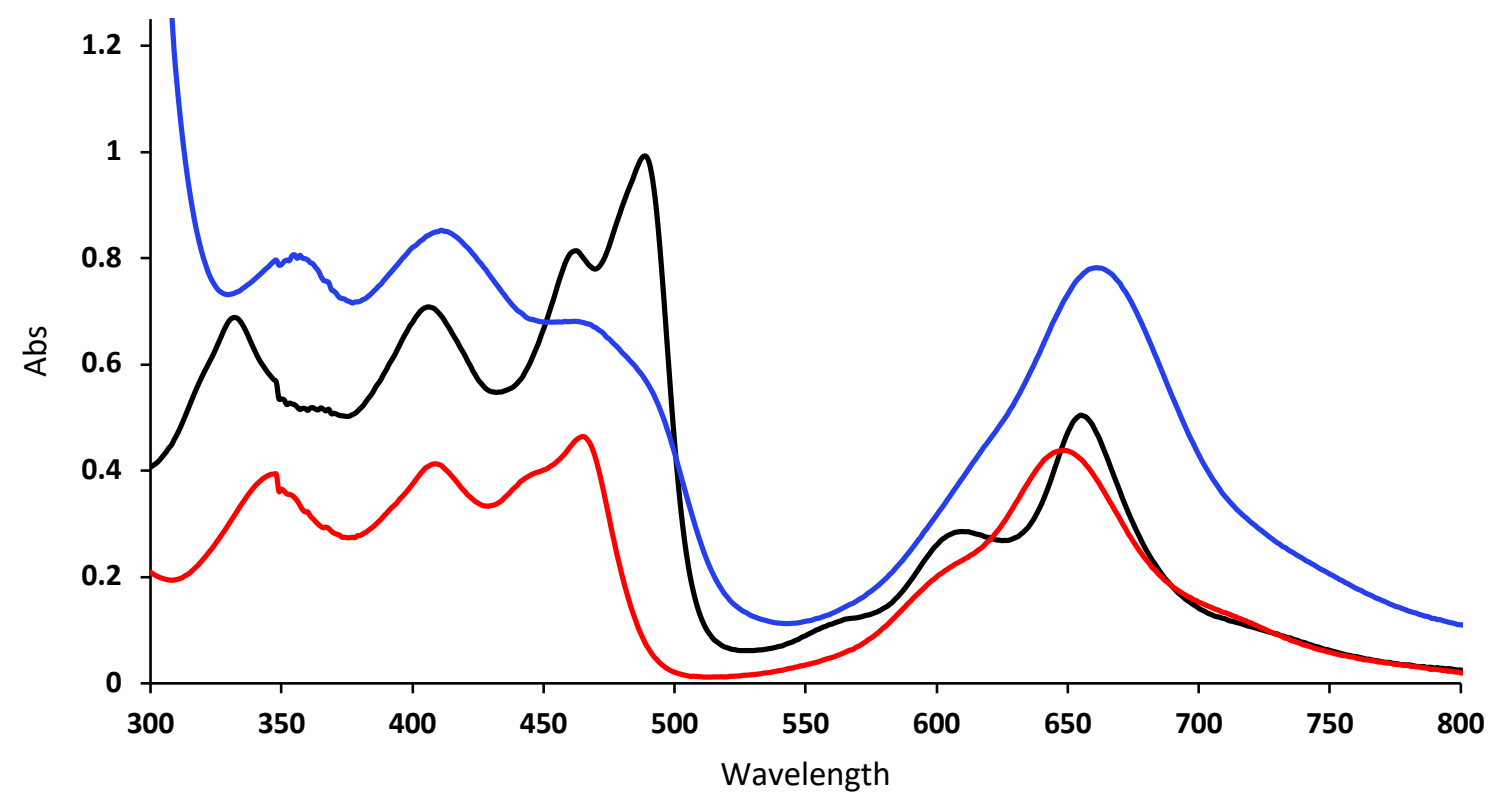

Figure 19. UV-vis spectra of oxyquinoliziniporphyrin 84a (black line), palladium(II) complex 106a (red line), and nickel(II) complex 107a (blue line)

The metal complexes of oxyquinoiliziniporphyrin $\mathbf{8 4 \mathbf { b }}$ gave similar UV-Vis spectra. Palladium(II) complex 106b showed strong absorptions at 347, 408, and $466 \mathrm{~nm}$ and an equally strong broad absorption at $648 \mathrm{~nm}$, while nickel(II) complex 107b gave strong absorptions 
at 357 and $416 \mathrm{~nm}$, with a shoulder at $454 \mathrm{~nm}$, and an equally strong broad absorptions at $660 \mathrm{~nm}$ (Figure 20).

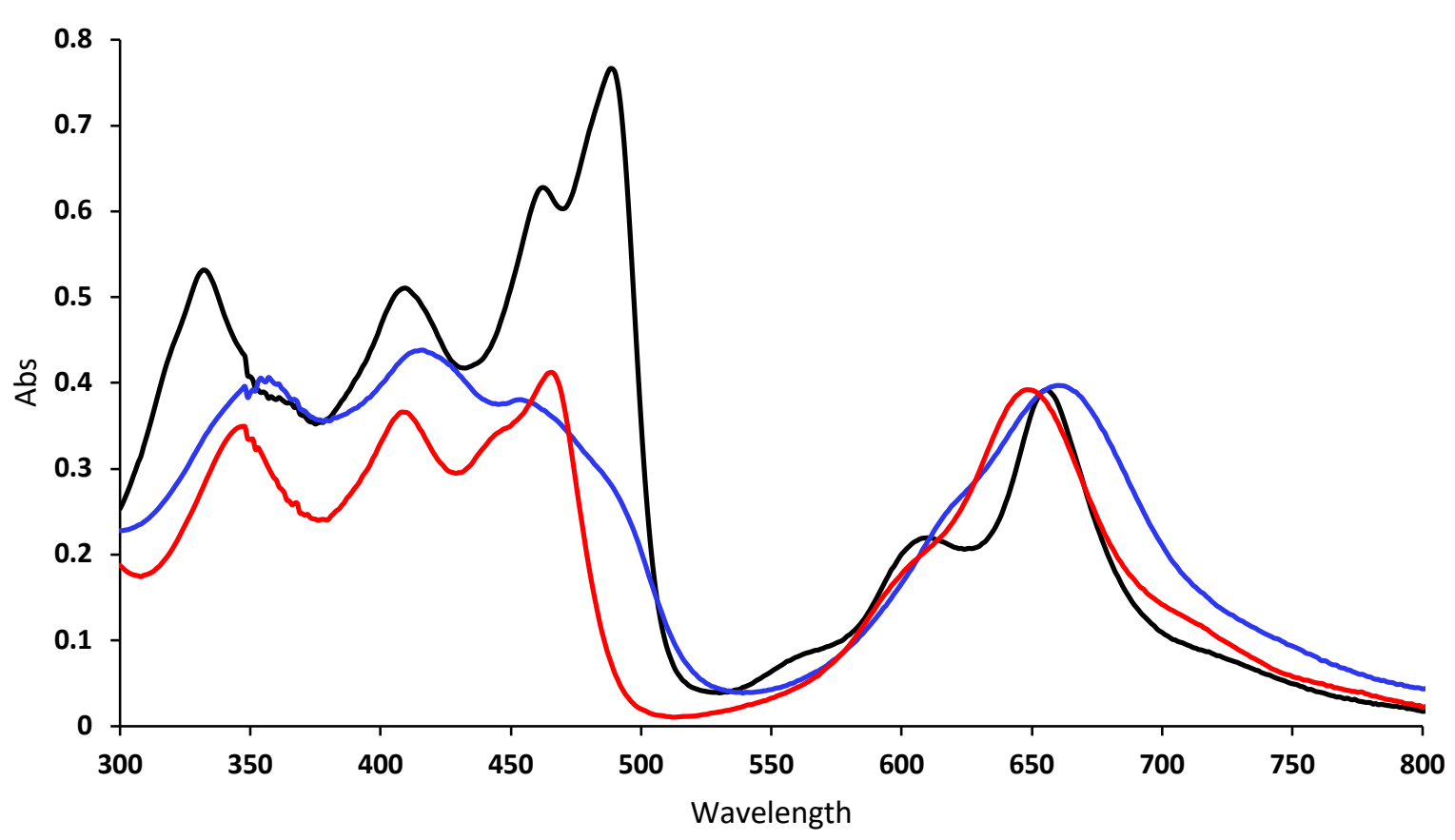

Figure 20. UV-vis spectra of oxyquinoliziniporphyrin 84b (black line), palladium(II) complex 106b (red line), and nickel(II) complex 107b (blue line)

Oxyquinoliziniporphyrins give further insights into the reactivity and aromatic properties of carbaporphyrins. Specifically, N-confused pyriporphyrins are relatively unstable and nonaromatic but the structurally related quinolizone subunit considerably alters the properties of this system. This investigation showed that structures of these types can have global aromatic character, especially upon protonation as seen in the proton NMR spectra and UV-Vis spectra. The proton NMR spectra of the protonated oxyquinoliziniporphyrins show internal $\mathrm{CH}$ peaks at ca. $2.9 \mathrm{ppm}$, and the UV-vis spectra give Soret and Q bands similar to those seen in aromatic 
porphyrinoid systems. Metalation of oxyquinoliziniporphyrins was also achieved, and the introduction of a metal cation also enhanced the aromatic characteristics of these structures. 


\section{Experimental:}

Melting points are uncorrected. NMR spectra were recorded using a 400 or $500 \mathrm{MHz}$ NMR spectrometer and were run at $302 \mathrm{~K}$ unless otherwise indicated. ${ }^{1} \mathrm{H}$ NMR values are reported as chemical shifts $\delta$, relative integral, multiplicity ( $\mathrm{s}$, singlet; $\mathrm{d}$, doublet; $\mathrm{t}$, triplet; q, quartet; $\mathrm{m}$, multiplet; br, broad peak) and coupling constant $(J)$. Chemical shifts are reported in parts per million (ppm) relative to $\mathrm{CDCl}_{3}\left({ }^{1} \mathrm{H}\right.$ residual $\mathrm{CHCl}_{3}$ singlet $\delta 7.26 \mathrm{ppm},{ }^{13} \mathrm{C} \mathrm{CDCl}_{3}$ triplet $\delta 77.23$ ppm) or $\mathrm{d}_{6}$-DMSO $\left({ }^{1} \mathrm{H}\right.$ residual $\mathrm{d}_{5}$-DMSO pentet $\delta 2.49 \mathrm{ppm},{ }^{13} \mathrm{C} \mathrm{d}_{6}$-DMSO septet $\left.\delta 39.7 \mathrm{ppm}\right)$ and coupling constants were taken directly from the spectra. NMR assignments were made with the aid of ${ }^{1} \mathrm{H}-{ }^{1} \mathrm{H}$ COSY, HSQC, DEPT-135 and nOe difference proton NMR spectroscopy. 2DNMR experiments were performed using standard software.

Ethyl 2-Pyridylacetate (99) A mixture of 2-picoline $(9.9 \mathrm{~mL})$ and diethyl carbonate $(36.3 \mathrm{~mL})$ was treated with LDA $(105 \mathrm{~mL})$ in $\mathrm{THF}(100 \mathrm{~mL})$ at $-78^{\circ} \mathrm{C}$ for 3 hours under nitrogen. The mixture was then cooled to room temperature and stirred for another $30 \mathrm{~min}$. The solution was treated with ammonium chloride $(50 \mathrm{~mL})$ in water $(200 \mathrm{~mL})$ and the aqueous layer was extracted with diethyl ether. The ether was dried with magnesium sulfate, filtered, and the filtrate was evaporated under reduced pressure to yield ethyl 2-pyridyl acetate (13.492 g, 81.7\% yield) as a dark brown liquid. ${ }^{1} \mathrm{H}$ NMR (400 MHz, $\left.\mathrm{CDCl}_{3}\right): \delta 1.12\left(3 \mathrm{H}, \mathrm{t}, J=7.1 \mathrm{~Hz}, \mathrm{OCH}_{2} \mathrm{CH}_{3},\right), 3.71\left(2 \mathrm{H}, \mathrm{s}, \mathrm{py}-\mathrm{CH}_{2}\right), 4.05$ $\left(2 \mathrm{H}, \mathrm{q}, \mathrm{J}_{\mathrm{HH}}=7.1 \mathrm{~Hz}, \mathrm{OCH}_{2} \mathrm{CH}_{3}\right), 7.00-7.05(1 \mathrm{H}, \mathrm{m}, \mathrm{py}), 7.15-7.18(1 \mathrm{H}, \mathrm{m}, \mathrm{py}), 7.47-7.53(1 \mathrm{H}, \mathrm{m}$, py), 8.39-8.43 (1H, m, 6-H). 
Diethyl 4-quinolizone-1,3-dicarboxylate (101) A mixture of ethyl 2-pyridylacetate (3.404 g, 20.0 mmol) with diethyl ethoxymethylenemalonate $(4.325 \mathrm{~g}, 20.0 \mathrm{mmol})$ was heated at $180{ }^{\circ} \mathrm{C}$ for 8 hours while distilling off ethanol. After 8 hours, a minimal amount of hot acetone was added, and the solution was allowed to cool. Recrystallization with acetone yielded the quinolizone diester $(3.691 \mathrm{~g}, 63.8 \%)$ as brown-yellow crystals, mp $123-124^{\circ} \mathrm{C}$ (lit $\left.\mathrm{mp}^{46} 123-129^{\circ} \mathrm{C}\right) .{ }^{1} \mathrm{H}$ NMR $(400$ $\left.\mathrm{MHz}, \mathrm{CDCl}_{3}\right): \delta 1.43\left(6 \mathrm{H}, \mathrm{m}, 2 \mathrm{x} \mathrm{OCH}_{2} \mathrm{CH}_{3}\right), 4.40\left(2 \mathrm{H}, \mathrm{q}, J=7.1 \mathrm{~Hz}, \mathrm{OCH}_{2} \mathrm{CH}_{3}\right), 4.44(2 \mathrm{H}, \mathrm{q}, \mathrm{J}$ $\left.=7.1 \mathrm{~Hz}, \mathrm{OCH}_{2} \mathrm{CH}_{3}\right), 7.36(1 \mathrm{H}, \mathrm{dt}, J=1.4,6.9 \mathrm{~Hz}), 7.85-7.90(1 \mathrm{H}, \mathrm{m})(7,8-\mathrm{H}), 9.17(1 \mathrm{H}, \mathrm{s}, 2-\mathrm{H})$, 9.36-9.39 (1H, m, 9-H), 9.52-9.55 (1H, m, 6-H). ${ }^{13} \mathrm{CNMR}\left(125 \mathrm{MHz}, \mathrm{CDCl}_{3}\right): \delta 14.38,14.44(2 \mathrm{x}$ $\mathrm{OCH}_{2} \mathrm{CH}_{3}$ ), 61.04, 61.18 (2 x $\left.\mathrm{OCH}_{2} \mathrm{CH}_{3}\right), 117.0$ (7 or 8-C), 124.4 (9-C), 130.4 (6-C), 136.7 (7 or 8-C), 144.4 (2-C), 147.0, 155.5, 164.8, 165.4.

4-Quinolizone (102) A solution of diethyl 4-quinolizone-1,3-dicarboxylate (2.550 g, $8.8 \mathrm{mmol})$ in $50 \mathrm{~mL}$ of concentrated hydrochloric acid was refluxed for one hour. The solution was neutralized over ice with solid potassium carbonate. The solution was extracted with ether until it was no longer colored. The ether was dried, filtered, and evaporated under reduced pressure. The residue was columned on silica with 70:30 toluene-ethyl acetate to give the product as the second broad yellow fraction $(0.787 \mathrm{~g}, 62.4 \%)$ as large yellow crystals, $\mathrm{mp} 72-73^{\circ} \mathrm{C}$ (lit $\left.\mathrm{mp}^{46} 71-72^{\circ} \mathrm{C}\right)$. ${ }^{1} \mathrm{H}$ NMR $\left(500 \mathrm{MHz}, \mathrm{CDCl}_{3}\right): \delta$ 6.57-6.62 (2H, m, 1,9-H), 6.93-6. (1H, m 7-H), 7.27-7.31 (1H, m), 7.41-7.44 (1H, m, 3-H), $7.62(1 \mathrm{H}, \mathrm{dd}, J=7.6 \mathrm{~Hz}, 2-\mathrm{H}), 9.09(1 \mathrm{H}, \mathrm{m}, 6-\mathrm{H}) .{ }^{13} \mathrm{C} \mathrm{NMR}(125 \mathrm{MHz}$, $\mathrm{CDCl}_{3}$ ): $\delta$ 103.1, 109.1 (1,9-C), 114.9 (7-C), 125.4 (3-C), 127.3 (6-C), 129.2 (8-C), 138.0 (2-C), $142.7,158.6$. 
4-Quinolizone-1,3-dicarbaldehyde (85) $\mathrm{POCl}_{3}(12 \mathrm{~mL})$ was added dropwise to DMF (12 mL) over ice and kept under $10^{\circ} \mathrm{C}$ throughout addition. 4-Quinolizone (0.700 g, $\left.4.8 \mathrm{mmol}\right)$ was added and the solution was stirred at $50{ }^{\circ} \mathrm{C}$ for three hours. After the three hours, the solution was poured over ice, and neutralized with sodium carbonate and a solid formed. The solid was filtered to afford the dialdehyde $(0.860 \mathrm{~g}, 89.1 \%)$ as a yellow powder mp $239-240{ }^{\circ} \mathrm{C}$ (lit $\left.\mathrm{mp}^{47} 231-232{ }^{\circ} \mathrm{C}\right) .{ }^{1} \mathrm{H}$ NMR (400 MHz, $\left.\mathrm{CDCl}_{3}\right): \delta 7.60(1 \mathrm{H}, \mathrm{dt}, J=1.3,7.0 \mathrm{~Hz}), 8.12-8.16(1 \mathrm{H}, \mathrm{m})(7,8-\mathrm{H}), 8.63(1 \mathrm{H}, \mathrm{s}$, 2-H), 9.58-9.60 (1H, m, 9-H), 9.62-9.65 (1H, m, 6-H), 9.93 (1H, s, 1-CHO), 10.42 (1H, s, 3-CHO). ${ }^{13} \mathrm{CNMR}\left(125 \mathrm{MHz}, \mathrm{CDCl}_{3}\right): \delta 120.1$ (7 or 8-C), 124.7 (6-C), 130.4 (9-C), 140.5 (7 or 8-C), 145.1 (2-C), 180.46, 180.56, 188.1, 188.6.

Oxyquinoliziniporphyrin (84a) In a pear-shaped flask, tripyrrane dicarboxylic acid 63 (261 mg, $0.578 \mathrm{mmol})$ was dissolved in TFA $(2 \mathrm{~mL})$ and stirred under nitrogen for 10 minutes. Dichloromethane $(200 \mathrm{~mL})$ was added followed by dialdehyde 85 (119mg, $0.591 \mathrm{mmol})$. The flask was covered in aluminum foil to protect the reactants from light, and the solution was stirred overnight under nitrogen. After stirring overnight, the solution was neutralized with triethylamine and DDQ (135 mg, $0.594 \mathrm{mmol})$ was added. After stirring for an additional hour, the resulting solution was washed with water, and the organic layer was evaporated under reduced pressure. The residue was purified by recrystallization with chloroform and hexanes to give the carbaporphyrinoid product $(165.0 \mathrm{mg}, 54.9 \%)$ as a dark green powder, $\mathrm{mp}>300^{\circ} \mathrm{C}$. UVvis $\left(1 \% \mathrm{Et}_{3} \mathrm{~N}-\mathrm{CH}_{2} \mathrm{Cl}_{2}\right): \lambda_{\max } / \mathrm{nm}(\log \varepsilon): 332$ (4.55), 406 (4.56), 462 (4.62), 489 (4.71), 565 (sh, 
3.79), 610 (4.17), 655 (4.42), 714 (sh, 3.80). UV-vis (1 eq TFA- $\left.\mathrm{CH}_{2} \mathrm{Cl}_{2}\right): \lambda_{\max } / \mathrm{nm}(\log \varepsilon): 334$ (4.54), 355 (4.52), 397 (4.47), 440 (sh, 4.63), 465 (4.95), 485 (sh, 4.39), 595 (sh, 3.96), 637 (4.62), 699 (sh, 4.16), 761 (sh, 3.84). UV-vis (10\% TFA- $\left.\mathrm{CH}_{2} \mathrm{Cl}_{2}\right): \lambda_{\max } / \mathrm{nm}(\log \varepsilon): 368$ (4.58), 399 (4.58), 440 (sh, 4.72), 464 (5.10), 482 (sh, 4.67), 638 (4.44), 667 (4.48), 711 (sh, 4.01). ${ }^{1} \mathrm{H}$ NMR (500 MHz, $\mathrm{CDCl}_{3}$-TFA): $\delta-2.93(1 \mathrm{H}, \mathrm{s}, 22-\mathrm{H}),-1.36(1 \mathrm{H}$, br s, NH), $1.55(6 \mathrm{H}, \mathrm{dt}, J=1.5$, $\left.7.7 \mathrm{~Hz}, 13,14-\mathrm{CH}_{2} \mathrm{CH}_{3}\right) 1.68\left(6 \mathrm{H}, \mathrm{q}, J=7.9 \mathrm{~Hz}, 9,18-\mathrm{CH}_{2} \mathrm{CH}_{3}\right), 3.27\left(3 \mathrm{H}, \mathrm{s}, 8-\mathrm{CH}_{3}\right), 3.31(3 \mathrm{H}$, s, 19- $\left.\mathrm{CH}_{3}\right), 3.64-3.71\left(4 \mathrm{H}, \mathrm{m}, 13,14-\mathrm{CH}_{2} \mathrm{CH}_{3}\right) 3.75\left(4 \mathrm{H}, \mathrm{q}, J=7.9 \mathrm{~Hz}, 9,18-\mathrm{CH}_{2} \mathrm{CH}_{3}\right), 8.03(1 \mathrm{H}$, dt, $\left.J=1.5,6.9 \mathrm{~Hz}, 3^{2}-\mathrm{H}\right), 8.70-8.75\left(1 \mathrm{H}, \mathrm{m}, 4^{2}-\mathrm{H}\right), 9.18(1 \mathrm{H}, \mathrm{s}), 9.21(1 \mathrm{H}, \mathrm{s})(11,16-\mathrm{H}), 9.36$ $\left(1 \mathrm{H}, \mathrm{d}, J=8.8 \mathrm{~Hz}, 4^{1}-\mathrm{H}\right), 10.03-10.04\left(1 \mathrm{H}, \mathrm{m}, 3^{1}-\mathrm{H}\right), 10.05(1 \mathrm{H}, \mathrm{s}, 6-\mathrm{H}), 10.35(1 \mathrm{H}, \mathrm{s}, 21-\mathrm{H})$. ${ }^{13} \mathrm{C}$ NMR (125 MHz, $\mathrm{CDCl}_{3}$-TFA): $\delta 10.6,10.8\left(13,14-\mathrm{CH}_{3}\right), 14.8,14.9\left(13,14-\mathrm{CH}_{2} \mathrm{CH}_{3}\right), 15.9$ $\left(9,18 \mathrm{CH}_{2} \mathrm{CH}_{3}\right) 18.50,18.54,18.59,18.60\left(9,13,14,18-\mathrm{CH}_{2} \mathrm{CH}_{3}\right)$, 92.6, 93.2 (11,16-C), 110.0, 110.2, 111.5 (6-C), 112.4, 112.5, 114.74 (21-C), 115.0, 117.0, 118.3 (22-C), 122.3 (3²-C), 126.4 (4 $\left.{ }^{1}-\mathrm{C}\right), 134.4\left(3^{1}-\mathrm{C}\right), 138.2,139.0,140.0,144.3\left(4^{2}-\mathrm{C}\right), 147.42,147.44,151.0,159.8 . \mathrm{HRMS}$ (ESI) m/z: $[\mathrm{M}+\mathrm{H}]^{+}$calcd for $\mathrm{C}_{35} \mathrm{H}_{36} \mathrm{~N}_{4} \mathrm{O} 529.2967$; found 529.2958.

Palladium(II) Complex 106a. Oxyquinoliziniporphyrin 84a (10.2 mg, $0.019 \mathrm{mmol})$ and palladium(II) acetate $(11.2 \mathrm{mg}, 0.050 \mathrm{mmol})$ in chloroform $(5 \mathrm{~mL})$ and acetonitrile $(5 \mathrm{~mL})$ were refluxed for 2 hours. The residue was cooled, chloroform $(20 \mathrm{~mL})$ was added, and the mixture was washed with water and evaporated under reduced pressure. The residue was columned on grade 3 neutral alumina and the product eluted with dichloromethane. A dark green band was collected and recrystallized with dichloromethane and hexanes to give the palladium complex as a dark 
green solid (3.9 mg, 32.0\%), mp $>300^{\circ} \mathrm{C}$. UV-vis $\left(\mathrm{CH}_{2} \mathrm{Cl}_{2}\right): \lambda_{\max } / \mathrm{nm}(\log \varepsilon): 347$ (4.39), 409 (4.41), 444 (sh, 438), 465 (4.46), 605 (sh, 4.13), 649 (4.43), 705 (sh, 3.93). ${ }^{1} \mathrm{H}$ NMR (500 MHz, $\left.\mathrm{CDCl}_{3}\right): 1.56-1.67\left(12 \mathrm{H}, \mathrm{m}, 9,13,14,18-\mathrm{CH}_{2} \mathrm{CH}_{3}\right), 2.87(3 \mathrm{H}, \mathrm{s}), 3.13(3 \mathrm{H}, \mathrm{s})\left(11,16-\mathrm{CH}_{3}\right), 3.35-$ $3.45\left(8 \mathrm{H}, \mathrm{m}, 9,13,14,18-\mathrm{CH}_{2} \mathrm{CH}_{3}\right), 7.14-7.18\left(1 \mathrm{H}, \mathrm{m}, 3^{2}-\mathrm{H}\right), 7.53-7.57\left(1 \mathrm{H}, \mathrm{m}, 4^{2}-\mathrm{H}\right), 8.29(1 \mathrm{H}$, s), $8.35(1 \mathrm{H}, \mathrm{s})(11,16-\mathrm{H}), 8.47-8.51\left(1 \mathrm{H}, \mathrm{m}, 4^{1}-\mathrm{H}\right), 8.66(1 \mathrm{H}, \mathrm{s}, 6-\mathrm{H}), 9.32-9.35\left(1 \mathrm{H}, \mathrm{m}, 3^{1}-\mathrm{H}\right)$, $9.62(1 \mathrm{H}, \mathrm{s}, 21-\mathrm{H}) .{ }^{13} \mathrm{C}$ NMR (partial data from HSQC, $\left.\mathrm{CDCl}_{3}\right): 11.1\left(8,19-\mathrm{CH}_{3}\right), 16.1,17.4$ (9,13,14,18- $\left.\mathrm{CH}_{2} \mathrm{CH}_{3}\right), 19.4\left(9,13,14,18-\mathrm{CH}_{2} \mathrm{CH}_{3}\right), 95.9$ (11,16-C), 113.3 (6-C), 116.0 (32-C), 118.4 (21-C), 123.7 (41-C), 130.9 ( $\left.3^{1}-\mathrm{C}\right), 135.3\left(4^{2}-\mathrm{C}\right)$. HRMS (ESI) m/z: [M] $]^{+}$calcd for $\mathrm{C}_{35} \mathrm{H}_{34} \mathrm{~N}_{4} \mathrm{OPd}$ 632.1767; found 632.1741 .

Nickel (II) complex (107a) Oxyquinoliziniporphyrin 84a (25.0 mg, $0.047 \mathrm{mmol})$ and nickel(II) acetate $(25.5 \mathrm{mg}, 0.102 \mathrm{mmol})$ in chloroform $(12 \mathrm{~mL})$ and acetonitrile $(12 \mathrm{~mL})$ were refluxed for 1 hour. The residue was cooled, chloroform $(20 \mathrm{~mL})$ was added, and the mixture was washed with water and evaporated under reduced pressure. The residue was columned on grade 3 neutral alumina, eluting dichloromethane. A dark green band was collected and evaporated down to give the nickel complex as a dark green solid $(20.0 \mathrm{~g}, 72.2 \%), \mathrm{mp}>300^{\circ} \mathrm{C}$. UV-vis $\left(\mathrm{CH}_{2} \mathrm{Cl}_{2}\right): \lambda_{\max } / \mathrm{nm}$ (log ع): 359 (4.33), 411 (4.43), 472 (sh, 4.33), 620 (sh, 4.18), 661 (4.40). ${ }^{1} \mathrm{H}$ NMR (500 MHz, $\left.\mathrm{CDCl}_{3}\right): 1.44-1.52\left(6 \mathrm{H}, \mathrm{m}, 9,13,14,18-\mathrm{CH}_{2} \mathrm{CH}_{3}\right), 1.54-1.60\left(6 \mathrm{H}, \mathrm{m}, 9,18-\mathrm{CH}_{2} \mathrm{CH}_{3}\right.$ or $13,14-$ $\left.\mathrm{CH}_{2} \mathrm{CH}_{3}\right), 2.60\left(3 \mathrm{H}, \mathrm{s}, 8-\mathrm{CH}_{3}\right), 2.85\left(3 \mathrm{H}, \mathrm{s}, 19-\mathrm{CH}_{3}\right), 3.18-3.34\left(8 \mathrm{H}, \mathrm{m}, 9,18-\mathrm{CH}_{2} \mathrm{CH}_{3}\right.$ and 13,14$\left.\mathrm{CH}_{2} \mathrm{CH}_{3}\right), 6.75-6.80\left(1 \mathrm{H}, \mathrm{m}, 3^{2}-\mathrm{H}\right), 7.03-7.08\left(1 \mathrm{H}, \mathrm{m}, 4^{2}-\mathrm{H}\right), 7.73-7.77\left(1 \mathrm{H}, \mathrm{m}, 4^{1}-\mathrm{H}\right), 7.96(1 \mathrm{H}$, s), $7.98(1 \mathrm{H}, \mathrm{s})(11,16-\mathrm{H}), 8.04(1 \mathrm{H}, \mathrm{s}, 6-\mathrm{H}), 8.96(1 \mathrm{H}, \mathrm{s}, 21-\mathrm{H}), 8.97-9.00\left(1 \mathrm{H}, \mathrm{m}, 3^{1}-\mathrm{H}\right) .{ }^{13} \mathrm{C}$ 
NMR (125 MHz, $\mathrm{CDCl}_{3}$-TFA): $\delta 10.7,11.0\left(8,19-\mathrm{CH}_{3}\right), 16.30,16.35,17.25,17.31(9,13,14,18-$ $\left.\mathrm{CH}_{2} \mathrm{CH}_{3}\right), 18.98,19.02,19.08,19.14\left(9,13,14,18-\mathrm{CH}_{2} \mathrm{CH}_{3}\right), 94.9,95.1$ (11,16-C), 111.4 (6-C), 113.7, 114.7 (21-C), 123.3 (41'-C), 129.8 (3 $-\mathrm{C}), 134.4$ (4²-C), 137.6, 139.0, 140.9, 141.49, 141.55, 142.9, 143.6, 143.9, 147.9, 148.1, 149.9, 151.1, 151.3, 162.0. HRMS (ESI) m/z: [M] ${ }^{+}$calcd for $\mathrm{C}_{35} \mathrm{H}_{34} \mathrm{~N}_{4} \mathrm{ONi}$ 584.2086; found 584.2072.

Oxyquinoliziniporphyrin (84b) In a pear-shaped flask, tripyrrane dicarboxylic acid 63b (103 mg, $0.202 \mathrm{mmol})$ was dissolved in TFA $(1 \mathrm{~mL})$ and stirred under nitrogen for 10 minutes. Dichloromethane (100 mL) was added, followed by dialdehyde 85 (50 mg, $0.249 \mathrm{mmol})$ The flask was covered in aluminum foil to protect the solution from light, and the mixture stirred overnight under nitrogen. The solution was neutralized with triethylamine and DDQ (70 $\mathrm{mg}, 0.308 \mathrm{~mol})$ was added and the mixture stirred for an additional hour. The resulting solution was washed with water and the organic layer evaporated under reduced pressure. The residue was purified on a grade 3 neutral alumina column, eluting with a 70:30 mixture of toluene and acetone. The product was collected as a dark green band. Recrystallization with acetone and hexanes gave the oxyquinoliziniporphyrin ( $43 \mathrm{mg}, 0.074 \mathrm{mmol}, 36.4 \%$ ) as a dark green powder, $\mathrm{mp}>300^{\circ} \mathrm{C}$. UVvis (1\% $\left.\mathrm{Et}_{3} \mathrm{~N}-\mathrm{CH}_{2} \mathrm{Cl}_{2}\right): \lambda_{\max } / \mathrm{nm}$ (log $\left.\varepsilon\right): 332$ (4.60), 364 (sh, 4.45), 409 (4.58), 462 (4.67), 489 (4.76), 558 (sh, 3.76), 610 (4.21), 656 (4.47). UV-vis (5 eq TFA- $\left.\mathrm{CH}_{2} \mathrm{Cl}_{2}\right): \lambda_{\max } / \mathrm{nm}(\log \varepsilon): 348$ (4.58), 361 (4.59), 440 (sh, 4.71), 465 (5.07), 484 (sh, 4.62), 640 (4.57), 670 (4.47). UV-vis (10\% TFA- $\mathrm{CH}_{2} \mathrm{Cl}_{2}$ ): $\lambda_{\max } / \mathrm{nm}(\log \varepsilon): 368$ (4.61), 439 (sh, 4.77), 464 (5.16), 482 (sh, 4.72), 638 (4.48), 667 (4.52), 713 (sh, 4.05). ${ }^{1} \mathrm{H}$ NMR (500 MHz, $\mathrm{CDCl}_{3}$ ): $\delta$ 1.02-1.06 (6H, m, 2 x $\mathrm{CH}_{2} \mathrm{CH}_{2} \mathrm{CH}_{2} \mathrm{CH}_{3}$ ), 
1.51-1.62 (10H, m, 2 x $\mathrm{CH}_{2} \mathrm{CH}_{2} \mathrm{CH}_{2} \mathrm{CH}_{3}$ and 13,14- $\left.\mathrm{CH}_{2} \mathrm{CH}_{3}\right), 1.82-1.91$ (4H, m, $2 \mathrm{x}$ $\left.\mathrm{CH}_{2} \mathrm{CH}_{2} \mathrm{CH}_{2} \mathrm{CH}_{3}\right), 2.69\left(3 \mathrm{H}, \mathrm{s}, 8-\mathrm{CH}_{3}\right), 2.84\left(3 \mathrm{H}, \mathrm{s}, 19-\mathrm{CH}_{3}\right), 3.15(4 \mathrm{H}, \mathrm{q}, J=8.0 \mathrm{~Hz}, 2 \mathrm{x}$ $\mathrm{CH}_{2} \mathrm{CH}_{2} \mathrm{CH}_{2} \mathrm{CH}_{3}$ ), 3.28 (4H, q, $\left.J=7.6 \mathrm{~Hz}, 13,14-\mathrm{CH}_{2} \mathrm{CH}_{3}\right), 7.00-7.05\left(1 \mathrm{H}, \mathrm{m}, 3^{2}-\mathrm{H}\right), 7.38-7.42$ (1H, m, $\left.4^{2}-\mathrm{H}\right), 7.62(1 \mathrm{H}, \mathrm{s}), 7.63(1 \mathrm{H}, \mathrm{s})(11,16-\mathrm{H}), 8.13(1 \mathrm{H}, \mathrm{s}, 6-\mathrm{H}), 8.39\left(1 \mathrm{H}, \mathrm{d}, J=9.1 \mathrm{~Hz}, 4^{1}-\right.$ H), $9.04(1 \mathrm{H}, \mathrm{s}, 21-\mathrm{H}), 9.29-9.32\left(1 \mathrm{H}, \mathrm{m}, 3^{1}-\mathrm{H}\right) .{ }^{13} \mathrm{C} \mathrm{NMR}\left(125 \mathrm{MHz}, \mathrm{CDCl}_{3}\right): \delta 11.1(\mathrm{C}-8), 11.2$ (C-19), 14.13, $14.14\left(2 \times \mathrm{CH}_{2} \mathrm{CH}_{2} \mathrm{CH}_{2} \mathrm{CH}_{3}\right), 16.67,16.69$ (2 x 13,14- $\left.\mathrm{CH}_{2} \mathrm{CH}_{3}\right), 18.55$ (2 x 13,14$\left.\mathrm{CH}_{2} \mathrm{CH}_{3}\right), 22.80,22.84\left(2 \times \mathrm{CH}_{2} \mathrm{CH}_{2} \mathrm{CH}_{2} \mathrm{CH}_{3}\right), 25.27,25.29$ (2 x $\left.\mathrm{CH}_{2} \mathrm{CH}_{2} \mathrm{CH}_{2} \mathrm{CH}_{3}\right), 33.81,33.85$ (2 x $\left.\mathrm{CH}_{2} \mathrm{CH}_{2} \mathrm{CH}_{2} \mathrm{CH}_{3}\right), 93.0,93.2$ (11,16-H), 109.8 (6-C), 114.2 (21-C), 117.4 (32-C), 122.5 (4C), 130.6 (3 $\left.3^{1}-\mathrm{C}\right), 134.8$ (4²-C), 139.1, 139.4, 139.7, 139.8, 141.0, 142.0, 147.4, 160.7. ${ }^{1} \mathrm{H}$ NMR (500 MHz, $\left.\mathrm{CDCl}_{3}-\mathrm{TFA}\right): \delta-2.82(1 \mathrm{H}, \mathrm{s}, 22-\mathrm{H}),-1.12(1 \mathrm{H}$, br s, NH), $1.03(6 \mathrm{H}$, overlapping triplets, $\left.2 \times \mathrm{CH}_{2} \mathrm{CH}_{2} \mathrm{CH}_{2} \mathrm{CH}_{3}\right), 1.51-1.60\left(4 \mathrm{H}, \mathrm{m}, 2 \times \mathrm{CH}_{2} \mathrm{CH}_{2} \mathrm{CH}_{2} \mathrm{CH}_{3}\right), 1.69$ (6H, overlapping triplets, 13,14- $\left.\mathrm{CH}_{2} \mathrm{CH}_{3}\right), 1.86-1.94\left(4 \mathrm{H}, \mathrm{m}, 2 \times \mathrm{CH}_{2} \mathrm{CH}_{2} \mathrm{CH}_{2} \mathrm{CH}_{3}\right), 3.26(3 \mathrm{H}, \mathrm{s}), 3.30(3 \mathrm{H}, \mathrm{s})(8,19-$ $\mathrm{CH}_{3}$ ), 3.61-3.68 (4H, m, 13,14- $\left.\mathrm{CH}_{2} \mathrm{CH}_{3}\right) 3.72$ (4H, overlapping quartets, $2 \times \mathrm{CH}_{2} \mathrm{CH}_{2} \mathrm{CH}_{2} \mathrm{CH}_{3}$ ), 8.00-8.04 (1H, m, $\left.4^{2}\right), 8.69-8.74\left(1 \mathrm{H}, \mathrm{m}, 3^{2}-\mathrm{H}\right), 9.14(1 \mathrm{H}, \mathrm{s}),, 9.17(1 \mathrm{H}, \mathrm{s})(11 / 16-\mathrm{H}), 9.36(1 \mathrm{H}, \mathrm{d}$, $\left.J=8.5 \mathrm{~Hz}, 4^{1}-\mathrm{H}\right), 10.01-10.05\left(2 \mathrm{H}, \mathrm{m}, 3^{1}-\mathrm{H} / 6-\mathrm{H}\right), 10.32(1 \mathrm{H}, \mathrm{s}, 21-\mathrm{H}) .{ }^{13} \mathrm{C}$ NMR $(125 \mathrm{MHz}$ $\left.\mathrm{CDCl}_{3}\right): \delta 11.79,11.97\left(8,9-\mathrm{CH}_{3}\right), 14.00,14.02\left(2 \times \mathrm{CH}_{2} \mathrm{CH}_{2} \mathrm{CH}_{2} \mathrm{CH}_{3}\right), 16.8\left(13,14-\mathrm{CH}_{2} \mathrm{CH}_{3}\right)$, $19.6\left(2 \times \mathrm{CH}_{2} \mathrm{CH}_{2} \mathrm{CH}_{2} \mathrm{CH}_{3}\right), 22.98,23.00\left(2 \times \mathrm{CH}_{2} \mathrm{CH}_{2} \mathrm{CH}_{2} \mathrm{CH}_{3}\right), 25.9\left(13,14-\mathrm{CH}_{2} \mathrm{CH}_{3}\right)$, 33.67, $33.71\left(2 \mathrm{x} \mathrm{CH}_{2} \mathrm{CH}_{2} \mathrm{CH}_{2} \mathrm{CH}_{3}\right), 93.8,94.3$ (11,16-C), 112.6 (6-C), 113.3, 113.5, 115.8 (21-C), 116.1, 119.6 (22-C), 123.1 (4²-C), 127.4 (41'-C), 135.3 (3'-C), 139.3, 139.50, 139.55, 140.0, 143.2, 143.8 , 144.3, 144.5, 144.7, $145.1\left(3^{2}-\mathrm{C}\right), 152.0,160.9$. HRMS (ESI) m/z: $[\mathrm{M}+\mathrm{H}]^{+}$calcd for $\mathrm{C}_{39} \mathrm{H}_{44} \mathrm{~N}_{4} \mathrm{O}$ 585.3593; found 585.3571. 
Palladium (II) Complex (106b) Oxyquinoliziniporphyrin 84b (10.1 mg, $0.017 \mathrm{mmol})$ and palladium(II) acetate $(10.2 \mathrm{mg}, 0.045 \mathrm{mmol})$ in chloroform $(5 \mathrm{~mL})$ and acetonitrile $(5 \mathrm{~mL})$ were stirred for $10 \mathrm{~min}$ at room temperature. Chloroform was added $(20 \mathrm{~mL})$ and solution washed with water and evaporated under reduced pressure. The residue was columned on a grade 3 neutral alumina column, eluting with dichloromethane. A dark green band was collected and recrystallized with dichloromethane and hexanes to give the palladium complex as a dark green solid (11.8 $\mathrm{mg}$, 84.9\%), mp $>300^{\circ} \mathrm{C}$. UV-vis $\left(\mathrm{CH}_{2} \mathrm{Cl}_{2}\right): \lambda_{\max }(\log \varepsilon): 347$ (4.60), 408 (4.62), 445 (sh, 4.59), 466 (4.67), 602 (sh, 4.32), 648 (4.65), 708 (sh, 4.16). ${ }^{1} \mathrm{H}$ NMR (500 MHz, CDCl3): 1.07 (3H, t, $J=7.5$ $\mathrm{Hz}), 1.11(3 \mathrm{H}, \mathrm{t}, J=7.4 \mathrm{~Hz})\left(2 \mathrm{x} \mathrm{CH}_{2} \mathrm{CH}_{2} \mathrm{CH}_{2} \mathrm{CH}_{3}\right), 1.57-1.64\left(2 \mathrm{H}, \mathrm{m}, \mathrm{CH}_{2} \mathrm{CH}_{2} \mathrm{CH}_{2} \mathrm{CH}_{3}\right), 1.64-$ $1.72\left(8 \mathrm{H}, \mathrm{m}, \mathrm{CH}_{2} \mathrm{CH}_{2} \mathrm{CH}_{2} \mathrm{CH}_{3}\right.$ and 13,14- $\left.\mathrm{CH}_{2} \mathrm{CH}_{3}\right), 1.93(2 \mathrm{H}, \mathrm{p}, J=7.4 \mathrm{~Hz}), 2.03$ ( $2 \mathrm{H}, \mathrm{p}, J=7.5$ $\mathrm{Hz})\left(2 \mathrm{x} \mathrm{CH}_{2} \mathrm{CH}_{2} \mathrm{CH}_{2} \mathrm{CH}_{3}\right), 2.52\left(3 \mathrm{H}, \mathrm{s}, 8-\mathrm{CH}_{3}\right), 3.05\left(3 \mathrm{H}, \mathrm{s}, 19-\mathrm{CH}_{3}\right), 3.29(2 \mathrm{H}, \mathrm{t}, J=7.7 \mathrm{~Hz}$, $\left.\mathrm{CH}_{2} \mathrm{CH}_{2} \mathrm{CH}_{2} \mathrm{CH}_{3}\right), 3.38-3.47\left(6 \mathrm{H}, \mathrm{m}, \mathrm{CH}_{2} \mathrm{CH}_{2} \mathrm{CH}_{2} \mathrm{CH}_{3}\right.$ and $\left.13,14-\mathrm{CH}_{2} \mathrm{CH}_{3}\right), 6.64-6.70\left(1 \mathrm{H}, \mathrm{m}, 3^{2}-\right.$ H), 6.79-6.85 (1H, m, $\left.4^{1}-\mathrm{H}\right), 7.53-7.58\left(1 \mathrm{H}, \mathrm{m}, 4^{1}-\mathrm{H}\right), 7.95(1 \mathrm{H}, \mathrm{s}, 6-\mathrm{H}), 8.25(1 \mathrm{H}, \mathrm{s}), 8.36(1 \mathrm{H}, \mathrm{s})$ (11/16-H), 8.83-8.87 (1H, m, $\left.3^{1}-\mathrm{H}\right), 9.51(1 \mathrm{H}, \mathrm{s}, 21-\mathrm{H}) .{ }^{13} \mathrm{C} \mathrm{NMR}\left(125 \mathrm{MHz}, \mathrm{CDCl}_{3}\right): 10.8,11.5$ (8,19-C), 14.34, $14.40\left(2 \times \mathrm{CH}_{2} \mathrm{CH}_{2} \mathrm{CH}_{2} \mathrm{CH}_{3}\right), 17.50,17.55\left(13,14-\mathrm{CH}_{2} \mathrm{CH}_{3}\right), 19.24,19.28(13,14-$ $\left.\mathrm{CH}_{2} \mathrm{CH}_{3}\right), 23.14,23.17$ (2 x $\left.\mathrm{CH}_{2} \mathrm{CH}_{2} \mathrm{CH}_{2} \mathrm{CH}_{3}\right), 25.74,25.91\left(2 \times \mathrm{CH}_{2} \mathrm{CH}_{2} \mathrm{CH}_{2} \mathrm{CH}_{3}\right), 34.10,34.26$ (2 x CH $\left.\mathrm{CH}_{2} \mathrm{CH}_{2} \mathrm{CH}_{3}\right), 95.7,96.3$ (11,16-C), 109.8, 113.5 (6-C), 114.6, 116.6 (32-C), 118.3 (21C), 122.7 (4 $\left.{ }^{1}-\mathrm{C}\right), 129.9$ (3 $\left.{ }^{1}-\mathrm{C}\right), 135.0$ (4²-C), 136.8, 137.7, 138.1, 139.0, 140.1, 141.7, 142.48, 142.56, 147.3, 147.5, 148.08, 148.20, 149.2, 149.4, 160.2. HRMS (ESI) m/z: $[\mathrm{M}]^{+}$calcd for $\mathrm{C}_{39} \mathrm{H}_{44} \mathrm{~N}_{4} \mathrm{OPd}$ 688.2393; found 688.2379. 
Nickel(II) Complex (107b) Oxyquinoliziniporphyrin 84b (11.2 mg, $0.019 \mathrm{mmol})$ and nickel(II) acetate $(13.8 \mathrm{mg} 0.055 \mathrm{mmol})$, in chloroform $(5 \mathrm{~mL})$ and acetonitrile $(5 \mathrm{~mL})$ were refluxed for 1 hour. The solution was cooled to room temperature and diluted with chloroform $(20 \mathrm{~mL})$. The solution was washed with water and solvent evaporated under reduced pressure. The residue was run through a grade 3 neutral alumina column eluting with dichloromethane. A dark green band was collected and evaporated under reduced pressure to give the nickel complex (5.6 $\mathrm{mg}, 42.7 \%$ ) as a dark green solid, $\mathrm{mp}>300{ }^{\circ} \mathrm{C}$. UV-vis $\left(\mathrm{CH}_{2} \mathrm{Cl}_{2}\right): \lambda_{\max }(\log \varepsilon): 357$ (4.32), 416 (4.39), 454 (sh, 4.32), 620 (sh, 4.15), 660 (4.34). ${ }^{1} \mathrm{H}$ NMR (500 MHz, $\left.\mathrm{CDCl}_{3}\right): 1.00-1.05(6 \mathrm{H}, \mathrm{m}, 2 \mathrm{x}$ $\left.\mathrm{CH}_{2} \mathrm{CH}_{2} \mathrm{CH}_{2} \mathrm{CH}_{3}\right), 1.52-1.59\left(10 \mathrm{H}, \mathrm{m}, 2 \times \mathrm{CH}_{2} \mathrm{CH}_{2} \mathrm{CH}_{2} \mathrm{CH}_{3}\right.$ and $\left.13,14-\mathrm{CH}_{2} \mathrm{CH}_{3}\right), 1.81-1.90(4 \mathrm{H}$, m, $\left.2 \times \mathrm{CH}_{2} \mathrm{CH}_{2} \mathrm{CH}_{2} \mathrm{CH}_{3}\right), 2.68\left(3 \mathrm{H}, \mathrm{s}, 19-\mathrm{CH}_{3}\right), 2.82\left(3 \mathrm{H}, \mathrm{s}, 8-\mathrm{CH}_{3}\right), 3.16-3.24(4 \mathrm{H}, \mathrm{m}, 13,14-$ $\left.\mathrm{CH}_{2} \mathrm{CH}_{3}\right), 3.24-3.31\left(4 \mathrm{H}, \mathrm{m}, 2 \times \mathrm{CH}_{2} \mathrm{CH}_{2} \mathrm{CH}_{2} \mathrm{CH}_{3}\right), 6.99-7.03\left(1 \mathrm{H}, \mathrm{m}, 4^{2}-\mathrm{H}\right), 7.35-7.40(1 \mathrm{H}, \mathrm{m}$, $\left.3^{2}-\mathrm{H}\right), 7.97(1 \mathrm{H}, \mathrm{s}), 8.00(1 \mathrm{H}, \mathrm{s})(11,16-\mathrm{H}), 8.05-8.09\left(1 \mathrm{H}, \mathrm{m}, 4^{1}-\mathrm{H}\right), 8.16(1 \mathrm{H}, \mathrm{s}, 6-\mathrm{H}), 8.96(1 \mathrm{H}$, s, 21-H), 9.14-9.17 (1H, m, $\left.3{ }^{1}-\mathrm{H}\right) .{ }^{13} \mathrm{C}$ NMR $\left(125 \mathrm{MHz}, \mathrm{CDCl}_{3}\right): 11.0\left(8-\mathrm{CH}_{3}\right), 11.2\left(19-\mathrm{CH}_{3}\right)$, $14.3\left(2 \times \mathrm{CH}_{2} \mathrm{CH}_{2} \mathrm{CH}_{2} \mathrm{CH}_{3}\right), 17.16,17.21\left(13,14-\mathrm{CH}_{2} \mathrm{CH}_{3}\right), 19.00,19.03\left(2 \times \mathrm{CH}_{2} \mathrm{CH}_{2} \mathrm{CH}_{2} \mathrm{CH}_{3}\right)$, 23.05, 23.07(2 x $\left.\mathrm{CH}_{2} \mathrm{CH}_{2} \mathrm{CH}_{2} \mathrm{CH}_{3}\right), 25.48,25.53\left(13,14-\mathrm{CH}_{2} \mathrm{CH}_{3}\right)$ 29.9, 33.92, $33.97(2 \mathrm{x}$ $\mathrm{CH}_{2} \mathrm{CH}_{2} \mathrm{CH}_{2} \mathrm{CH}_{3}$ ), 95.27, 95.39 (11,16-C), 111.3 (6-C), 113.9, 114.7 (21-C), 117.1 (42-C), 123.6 (32-C), 130.1 (3'-C), 134.4 (41-C), 138.1, 139.7, 139.8, 140.2, 141.9, 143.0, 143.9, 148.1, 148.3, 150.0, 151.4, 151.8, 152.0, 162.1. HRMS (ESI) m/z: [M] calcd for $\mathrm{C}_{39} \mathrm{H}_{44} \mathrm{~N}_{4} \mathrm{ONi}$ 640.2712; found 640.2684 . 


\section{CHAPTER III: SYNTHESIS AND PROGRESS TOWARDS PYRIDOQUINOLIZINIPORPHYRIN}

Porphyrins are important examples of nonbenzenoid aromatic compounds. German chemist Erich Hückel proposed a theory to predict when a compound is aromatic. This stated that a cyclic structure must be continuously conjugated, planar, and have $4 n+2 \pi$ electrons, in order for it to be considered aromatic. Aromatic compounds are generally very stable compounds and possess diamagnetic ring currents that can be observed in proton NMR spectroscopy. In addition, Huckel determined that antiaromatic systems also need to be planar and continuously conjugated, but possess $4 \mathrm{n} \pi$ electrons (in both cases, $\mathrm{n}$ is an integer). Antiaromatic compounds are known to be relatively unstable and include cyclobutadiene (108), the cyclopentadienyl cation (109), pentalene (110), and pyridoquinoline (111) (Figure 21). Unlike the diamagnetic ring current seen in aromatic compounds, antiaromatic compounds have a paramagnetic ring current, which may be observed by proton NMR spectroscopy, where the external protons will be shifted upfield and the internal protons will be shifted downfield. This is the reverse of what is seen in aromatic compounds. Antiaromatic systems are intriguing and the effect of incorporating a subunit of this type into a porphyrin-like framework would provide insights into the properties of porphyrinoid structures. Antiaromatic tricycle 111 can be synthesized from the common intermediate 4quinolizone (102) and its incorporation into a porphyrinoid system has been investigated. 


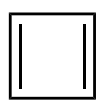

108

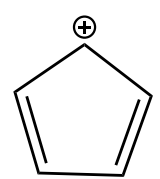

109

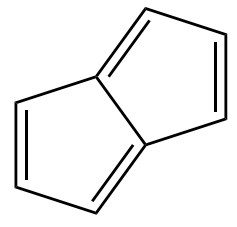

110<smiles>C1=CC2=CC=CC3=CC=CC(=C1)N23</smiles>

111

Figure 21. Antiaromatic compounds

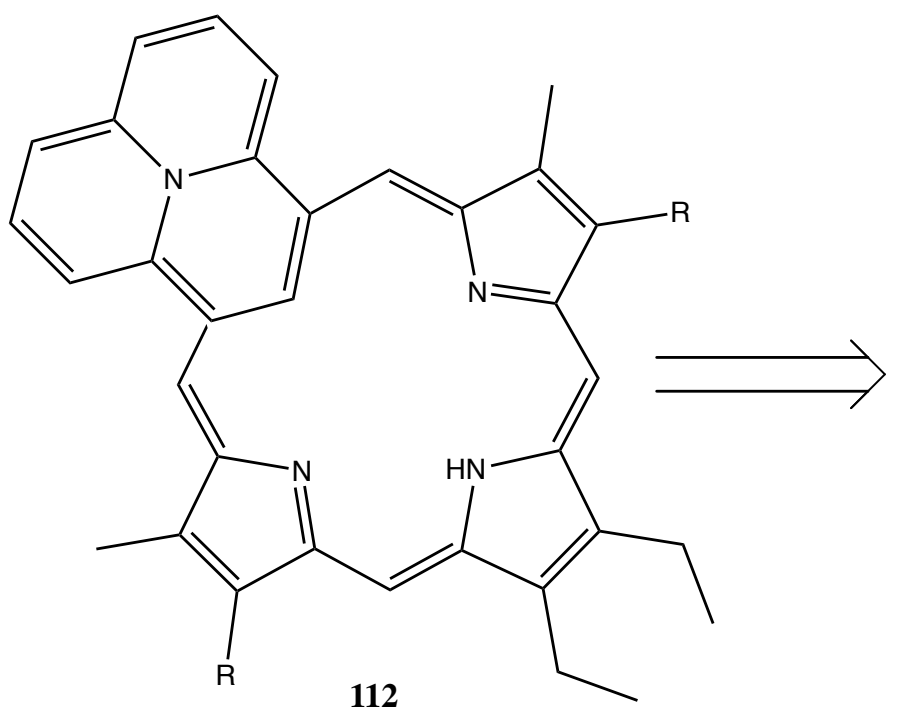<smiles></smiles>

113

Scheme 33. Retrosynthetic approach to pyridoquinoliziniporphyrin

In order to synthesize a porphyrin-like system 112 that incorporates 111 using the ' $3+1$ ' method, a related dialdehyde intermediate $\mathbf{1 1 3}$ is required. The synthesis of this key intermediate might be possible starting with quinolizone 102. Initially, 4-quinolizone was refluxed in phosphorus oxychloride for 30 minutes. The resulting solid was dissolved in water, perchloric acid was added, and the perchloric acid salt 114 was obtained. The chloroquinolizinium cation is prone to nucleophilic aromatic substitution reactions, including with malonate derived enolate ions. Treatments of perchloric salt with the tert-butyl ethyl malonate and sodium hydride resulted in 
nucleophilic addition and loss of chloride to give $t$-butyl ethyl 4H-quinolizin-4-malonate (115) (Scheme 34). ${ }^{49}$<smiles>O=C1CCC=C2C=CC=CN12</smiles>

102

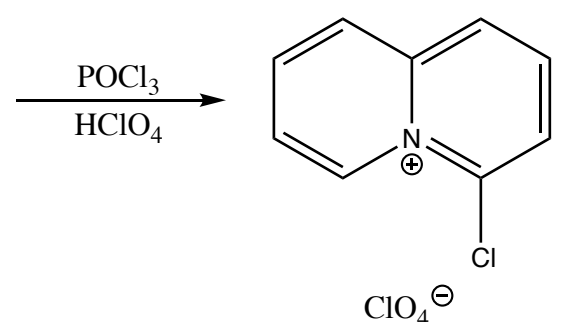

114
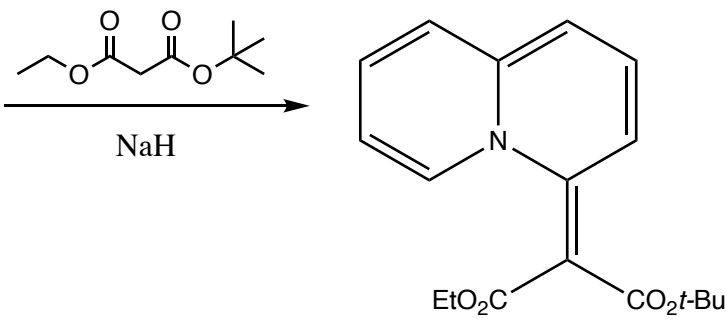

115

Scheme 34. Synthesis of $t$-butyl ethyl 4H-quinolizin-4-malonate (115)

Compound 115 was reacted with hydrogen chloride gas in toluene to cleave the tert-butyl group and this gave ethyl 4H-quinolizin-4-ylideneacetate (116) (Scheme 35).

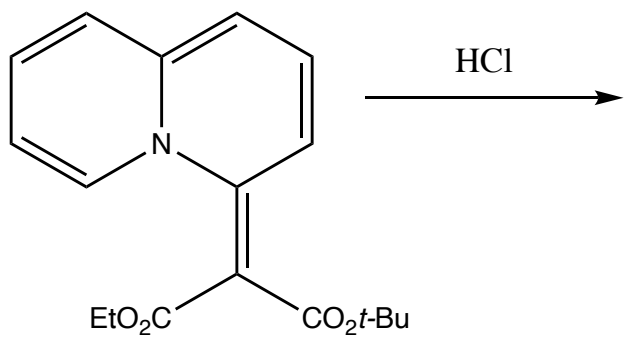

115<smiles>CCOC(=O)C=C1C=CC=C2C=CC=CN21</smiles>

116

Scheme 35. Synthesis of ethyl 4H-quinolizin-4-ylideneacetate (116)

In order to construct the tricyclic pyridoquinolizine system, 116 was refluxed with ethyl propiolate and potassium carbonate in nitrobenzene for 8 minutes. This involves a cycloaddition, followed by an oxidation to give the fully conjugated ring system. Purification by column chromatography on grade 3 neutral alumina, eluting with 80:20 toluene-hexanes, diethyl pyrido[2,1,6-de]quinolizine-1,3-dicarboxylate (117) was isolated in 42\% yield (Scheme 36) 


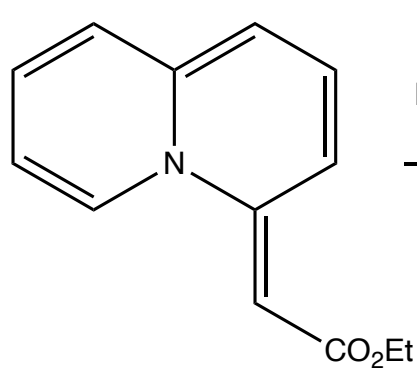

116

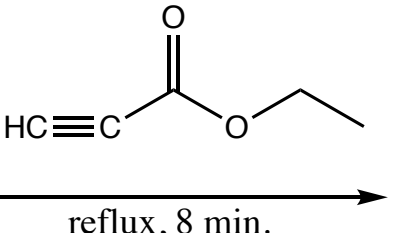

reflux, 8 min.

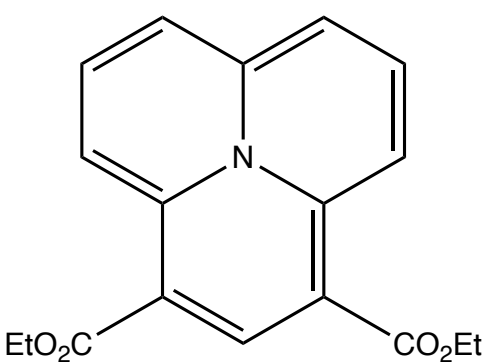

117

Scheme 36. Synthesis of diethyl pyrido[2,1,6-de]quinolizine-1,3-dicarboxylate (117)

Now that $\mathbf{1 1 7}$ was available, it is necessary to convert the ester units into aldehydes. A one step reaction was attempted using DIBAL-H but this proved to be unsuccessful. When the reaction was conducted at low temperatures or even room temperature, no conversion was observed and starting material was isolated. The low reactivity of the ester moieties can be attributed to the electron donating nitrogen atom. Attempts to fully reduce the esters to the alcohols with lithium aluminum hydride $\left(\mathrm{LiAlH}_{4}\right)$, followed by an oxidation with pyridinium chlorochromate, also proved to be unsuccessful due to the instability of the dialcohol species. In fact, the presence of electron withdrawing carbonyl groups appear to be essential for stabilizing the antiaromatic system. Hence, an alternative route was explored using the nonaromatic dihydro species $\mathbf{1 1 8}$. This can be prepared from 116 and ethyl propiolate when the reaction is carried out at $160{ }^{\circ} \mathrm{C}$ for one minute (Scheme 37). 


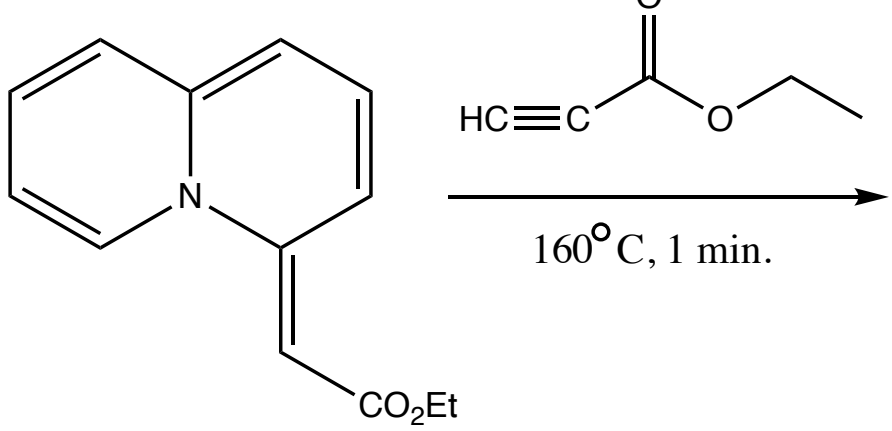

116

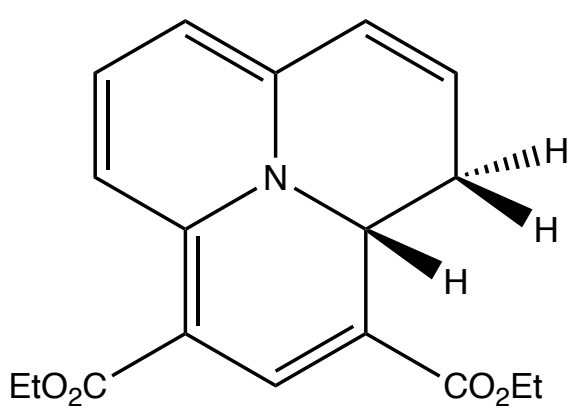

118

Scheme 37. Synthesis of 3a,4-dihydropyrido[2,1,6-de]quinolizine 118

It had been hoped that 118 would be more stable than 117. However, all attempts to convert 118 into a dialdehyde species were unsuccessful. Direct conversion of $\mathbf{1 1 8}$ to dialdehyde species 113 with DIBAL-H failed. Similar to what was seen with 117, at low temperatures and room temperature there was no reaction and starting material was collected. Attempts to reduce $\mathbf{1 1 8}$ with $\mathrm{LiAlH}_{4}$, followed by an oxidation with PCC, were also unsuccessful and led to decomposition. Further attempts to prepare dialdehyde $\mathbf{1 1 3}$ from $\mathbf{1 1 6}$ are currently under investigation. 


\section{Experimental:}

Melting points are uncorrected. NMR spectra were recorded using a 400 or $500 \mathrm{MHz}$ NMR spectrometer and were run at $302 \mathrm{~K}$ unless otherwise indicated. ${ }^{1} \mathrm{H}$ NMR values are reported as chemical shifts $\delta$, relative integral, multiplicity ( $\mathrm{s}$, singlet; $\mathrm{d}$, doublet; $\mathrm{t}$, triplet; q, quartet; $\mathrm{m}$, multiplet; br, broad peak) and coupling constant $(J)$. Chemical shifts are reported in parts per million (ppm) relative to $\mathrm{CDCl}_{3}\left({ }^{1} \mathrm{H}\right.$ residual $\mathrm{CHCl}_{3}$ singlet $\delta 7.26 \mathrm{ppm},{ }^{13} \mathrm{C} \mathrm{CDCl}_{3}$ triplet $\delta 77.23$ ppm) or $\mathrm{d}_{6}$-DMSO $\left({ }^{1} \mathrm{H}\right.$ residual $\mathrm{d}_{5}$-DMSO pentet $\delta 2.49 \mathrm{ppm},{ }^{13} \mathrm{C} \mathrm{d}_{6}$-DMSO septet $\left.\delta 39.7 \mathrm{ppm}\right)$ and coupling constants were taken directly from the spectra. NMR assignments were made with the aid of ${ }^{1} \mathrm{H}-{ }^{1} \mathrm{H}$ COSY, HSQC, DEPT-135 and nOe difference proton NMR spectroscopy. 2DNMR experiments were performed using standard software.

4-Chloroquinolizinylium Perchlorate (114) 4-Quinolizone (102) (1.995 g, $0.014 \mathrm{~mol}$ ) in phosphorus oxychloride $(4 \mathrm{ml})$ was stirred on a steam bath for 1 hour. The solid was filtered off and dissolved in water. Perchloric acid was added to the ice-cold solution until the perchlorate salt fully precipitated. The precipitate was suction filtered and vacuum dried overnight to give bright yellow crystals.

tert-Butyl ethyl 4H-quinolizin-4-ylidenemalonate (115) tert-Buyl ethyl malonate (3.420 g, 0.018 mol) in distilled THF $(30 \mathrm{~mL})$ was stirred under nitrogen, powdered sodium hydride $(1.089 \mathrm{~g}$ in mineral oil) was added in portions, and the mixture heated at $50{ }^{\circ} \mathrm{C}$ for 3 hours. 4Chloroquinolizinium perchlorate (114) (2.396 g $0.009 \mathrm{~mol}$ ) was added in small portions to the ice 
cooled solution, keeping the temperature below $20{ }^{\circ} \mathrm{C}$, and the resulting solution was refluxed overnight. The solvent was evaporated under reduced pressure. The residue was dissolved in chloroform and filtered. Any remaining solid was unreacted perchlorate. The filtrate was concentrated and loaded onto a grade 3 alumina column. An orange band eluted with chloroform, the solvent evaporated and the residue recrystallized from acetone to give tert-butyl ethyl 4quinolizin-4-ylidenemalonate as an orange powder $(1.581 \mathrm{~g}, 55.0 \%), \mathrm{mp} 171-172{ }^{\circ} \mathrm{C}\left(\mathrm{lit} . \mathrm{mp}^{49} 187\right.$ $\left.188^{\circ} \mathrm{C}\right) .{ }^{1} \mathrm{H}$ NMR $\left(500 \mathrm{MHz}, \mathrm{CDCl}_{3}\right): 1.25\left(3 \mathrm{H}, \mathrm{t}, J=7.1 \mathrm{~Hz} \mathrm{OCH}_{2} \mathrm{CH}_{3}\right), 1.40\left(9 \mathrm{H}, \mathrm{s}, \mathrm{OCCH}_{3}\right)$, $4.16\left(2 \mathrm{H}, \mathrm{q}, J=7.1 \mathrm{~Hz}, \mathrm{OCH}_{2} \mathrm{CH}_{3}\right), 7.46(1 \mathrm{H}, \mathrm{dt}, J=1.6,7.0 \mathrm{~Hz}, 7-\mathrm{H}), 7.64-7.68(1 \mathrm{H}, \mathrm{m}, 3-\mathrm{H})$, 7.76-7.81 (1H, m, 8-H), 7.88-7.92 (1H, m, 2-H), 7.93-7.97 (1H, m, 2-H), $8.10(1 \mathrm{H}, \mathrm{dd}, J=1.5,8.0$ $\mathrm{Hz}, 1-\mathrm{H}), 9.01-9.04(1 \mathrm{H}, \mathrm{m}, 6-\mathrm{H}) .{ }^{13} \mathrm{C} \mathrm{NMR}\left(125 \mathrm{MHz}, \mathrm{CDCl}_{3}\right): 15.1\left(\mathrm{OCH}_{2} \mathrm{CH}_{3}\right), 29.1\left(\mathrm{OCCH}_{3}\right)$, $58.7\left(\mathrm{OCH}_{2} \mathrm{CH}_{3}\right), 77.6,119.3$ (7-C), 119.8 (3-C), 126.3 (9-C), 129.2 (1-C), 132.3 (8-C), 135.3 (2C), 142.9, 155.1, 167.2, 168.2.

Ethyl 4H-quinolizin-4-ylideneacetate (116) Hydrogen chloride gas was passed through a rapidly stirring solution of tert-butyl ethyl 4H-quinolizin-4-ylideneacetate $(1.081 \mathrm{~g}, 3.45 \mathrm{mmol})$ in toluene $\left(40 \mathrm{~mL}\right.$ ) for 30 minutes. The gas flow was stopped, and the solution was heated at $50{ }^{\circ} \mathrm{C}$ until the reaction no longer produced $\mathrm{CO}_{2}$ gas $\left(50 \mathrm{~min}\right.$.) The mixture was cooled to $0{ }^{\circ} \mathrm{C}$, the toluene was decanted off and dichloromethane $(40 \mathrm{~mL})$ was added. The mixture was added to an ice salt bath and $6 \mathrm{M} \mathrm{NaOH}$ was added $(2 \mathrm{~mL})$ slowly. The organic layer was separated, and the water was extracted with more dichloromethane $(20 \mathrm{~mL})$. The combined organic layers were evaporated down to give a bright red residue $(0.670 \mathrm{~g}, 91 \%)$ that formed crystals with refrigeration, $\mathrm{mp} 45$ - 
$46{ }^{\circ} \mathrm{C}$ (Lit. m. p. $\left.{ }^{49} 80-81^{\circ} \mathrm{C}\right) .{ }^{1} \mathrm{H}$ NMR $\left(500 \mathrm{MHz}, \mathrm{CDCl}_{3}\right): 1.30\left(3 \mathrm{H}, \mathrm{t}, J=7.2 \mathrm{~Hz}, \mathrm{OCH}_{2} \mathrm{CH}_{3}\right)$, $4.18\left(2 \mathrm{H}, \mathrm{q}, J=7.2 \mathrm{~Hz}, \mathrm{OCH}_{2} \mathrm{CH}_{3}\right), 4.96\left(1 \mathrm{H}, \mathrm{s}, 4^{1}-\mathrm{H}\right), 6.40-6.46(1 \mathrm{H}, \mathrm{m}, 3-\mathrm{H}), 6.75-6.81(1 \mathrm{H}, \mathrm{m}$, 8-H), 7.03-7.08 (1H, m, 1-H), 7.22-7.29 (overlapping $\mathrm{CDCl}_{3}, \mathrm{~m}, 2-\mathrm{H}$ and 7-H), 7.91-7.95 (1H, m, 9-H), 8.57-8.66 (1H, m, 5-H). ${ }^{13} \mathrm{C}$ NMR (partial data from $\left.\mathrm{HSQC}, \mathrm{CDCl}_{3}\right): 14.4\left(\mathrm{OCH}_{2} \mathrm{CH}_{3}\right), 57.5$ $\left(\mathrm{OCH}_{2} \mathrm{CH}_{3}\right), 74.5$ (4'-C), 105.9 (3-C), 114.9 (8-C), 115.9 (6-C), 126.2 (1-C), 126.8 (2-C or 7-C), $128.1(9-\mathrm{C}), 131.3(2-\mathrm{C}$ or $7-\mathrm{C})$.

Diethyl Pyrido[2,1,6-de]quinolizine-1,3-dicarboxylate (117) Ethyl 4H-quinolizin-4-ylidene acetate 116 (0.696 g, $3.236 \mathrm{mmol})$ was dissolved in nitrobenzene $(25 \mathrm{~mL})$. The solution was purged with nitrogen, and ethyl propiolate $(0.400 \mathrm{~g}, 4.077 \mathrm{mmol})$ and potassium carbonate $(0.500$ $\mathrm{g}, 3.618 \mathrm{mmol}$ ) were added. The solution was stirred under reflux for 8 minutes under nitrogen. After 6 minutes the nitrobenzene was removed using a steam distillation, the remaining water was extracted with chloroform and the residue was dried on a vacuum pump overnight to remove traces of nitrobenzene. The residue was first run through a neutral alumina column, eluting with chloroform to remove any tarry biproduct. The product was further purified on neutral alumina eluting with 80:20 toluene-hexanes. A bright yellow band was collected and this gave the pyridoquinoline product 117 (0.276 g, $41.9 \%) .{ }^{1} \mathrm{H}$ NMR (500 MHz, CDCl3): 1.20 (6H, t, $J=7.2$ $\left.\mathrm{Hz}, 2 \times \mathrm{OCH}_{2} \mathrm{CH}_{3}\right), 4.01\left(4 \mathrm{H}, \mathrm{q}, J=7.2 \mathrm{~Hz}, 2 \times \mathrm{OCH}_{2} \mathrm{CH}_{3}\right), 5.19-5.22(2 \mathrm{H}, \mathrm{m}, 5,8-\mathrm{H}), 6.08(2 \mathrm{H}$, $\mathrm{t}, J=8.3 \mathrm{~Hz}, 7,6-\mathrm{H}), 6.65-6.68(2 \mathrm{H}, \mathrm{m}, 4,9-\mathrm{H})$. 


\section{CHAPTER IV: CONCLUSION}

Modifications to porphyrinoid systems allows the effects this has on the macrocycle to be investigated. Each new system can potentially alter the degree of aromaticity that is observed. Changes to the internal cavity, achieved by inserting different rings into the system, provide valuable insights. Furthermore, metalation or protonation can further influence the degree of aromatic character. Carbaporphyrinoids are common porphyrin analogues that replace one of the internal nitrogen atoms with a carbon atom. One type of carbaporphyrin that has been extensively studied is benziporphyrin. Benziporphyrin replaces one pyrrole subunit with a benzene subunit. This system is nonaromatic and has no diatropic ring current present. Likewise, N-confused pyriporphyrin, which is structurally similar to benziporphyrin, replaces a pyrrole subunit with a pyridine moiety where the nitrogen is on the exterior of the macrocycle instead of the internal cavity. N-confused pyriporphyrins are also nonaromatic, although certain modifications to this system can reinstate some of the aromatic properties.

The work reported in this thesis explored the effects of inserting an N-confused-type structure, 4-quinolizone, into a porphyrin system. Quinolizone contains a thermodynamically stable amide, and this unit disrupts the aromatic pathway. However, the proton NMR spectra, along with its UV-Vis data, showed a degree of global aromaticity that can be attributed to dipolar

resonance contributors that possess $18 \pi$ electron delocalization pathways. Metalation and protonation studies were also conducted on this system, and these resulted in significant increases to the diatropic ring current. 
Preliminary investigations into the synthesis of a porphyrin analogue incorporating an antiaromatic pyridoquinolizine unit are also reported. Pyridoquinolizine introduces another Nconfused type unit that is likely to have a profound effect on the resulting porphyrinoid system. Specifically, electron-donation from the antiaromatic unit is expected to lead to enhanced macrocyclic aromaticity. However, difficulties have been encountered in converting a pyridoquinolizine diester into the key dialdehyde intermediate required for the synthesis. Alternative routes to the dialdehyde are currently under investigation. Access to new porphyrinoid systems of these types gives insights into the aromatic properties of macrocyclic structures and provides access to novel organometallic derivatives. 


\section{REFERENCES}

1. Milgrom, L. R. The Colours of Life: An Introduction to the Chemistry of Porphyrins and Related Compounds; Oxford University Press, 1997.

2. Biesaga, M.; Pyrzyńska, K.; Trojanowicz, M. Porphyrins in analytical chemistry, A review. Talenta 2000, 51, 209-224.

3. Wasielewski, M. R. Photoinduced electron transfer in supramolecular systems for artificial photosynthesis. Chem. Rev. 1992, 92, 435-461.

4. Brown, S. B.; Truscott, T. G. New light on cancer therapy. Chem. Br. 1993, 29, 955

5. Hagerfeldt, A.; Boschloo, G.; Sun, L.; Kloo, L.; Pettersson, H. Dye-Sensitized Solar Cells. Chem. Rev. 2010, 110, 6595-6663

6. Higashino, T.; Imahori, H. Porphyrins as Excellent Dyes for Dye-

Sensitized Solar Cells: Recent Developments and Insights. Dalton Trans.2015, 44, 448463

7. Lash, T.D. Benziporphyrins, a unique platform for exploring the aromatic characteristics of porphyrinoid systems. Org. Biomol. Chem. 2015, 13, 7846-7878.

8. Smith, K. M. Porphyrins and Metalloporphyrins: A New Edition Based on the Original Volume by J. E. Falk, Elsevier, 1975.

9. Medforth, C. J. NMR Spectroscopy of Diamagnetic Porphyrins. In The Porphyrin Handbook, Kadish K. M., Smith, K. M., Guilard, R., Eds.; Academic Press: New York, 2000; Vol. 5, pp 1-80.

10. Lash, T.D. Carbaporphyrinoid Systems. Chem. Rev. 2017, 117, 2313-2446. 
11. Berlin, K.; Breitmaier, E. Benziporphyrin, a Benzene-Containing Nonaromatic Porphyrin Analogue. Angew. Chem., Int. Ed.Engl. 1994, 33, 1246-1247.

12. Lash, T.D.; Hayes, M.J. Carbaporphyrins. Angew. Chem. Int. Ed. Engl. 1997, 36, 840842.

13. Lash, T.D. Out of the Blue! Azuliporphyrins and Related Carbaporphyrin Systems. Acc. Chem. Res. 2016, 49, 471-482.

14. Lash, T.D.; Chaney, S.T.; Richter, D.T. Conjugated Macrocycles Related to the Porphyrins. Part 12. Oxybenzi- and Oxypyriporphyrins: Aromaticity and Conjugation in Highly Modified Porphyrinoid Structures. J. Org. Chem. 1998, 63, 9076-9088.

15. Lash, T.D.; Young, A.M.; Rasmussen, J.M.; Ferrence, G. M. Napthiporphyrins. J. Org. Chem. 2011, 76, 5636-5651.

16. Richter, D.T.; Lash, T.D. Conjugated Macrocycles Related to the Porphyrins. Part 18. Synthesis and Spectroscopic Characterization of Electron-rich Benzi- and Oxybenziporphyrins: Influence of Steric and Electronic Factors on Porphyrinoid Aromaticity. Tetrahedron. 2001, 57, 3657-3671.

17. AbuSalim, D.I.; Lash, T.D. Relative Stability of Benziporphyrin and Napthiporphyrin Tautomers and the Emergence of Macrocyclic Diatropicity. Org. Biomol. Chem. 2014, $12,8719-8736$.

18. Lash, T.D. Oxybenziporphyrin, an Aromatic Semiquinone Porphyrin analog with Pathways for $18 \pi$ electron Delocalization. Angew. Chem., Int. Ed.Engl. 1995, 34, 25332535. 
19. Lash, T.D.; Rasmussen, J.M.; Bergman, K.M.; Colby, D.A. Carbaporphyrinoid Chemistry has a Silver Lining! Silver (III) Oxybenzi-, Oxynaphthi-, Tropi- and Benzocarbaporphyrins. Org, Lett. 2004, 6, 549-552.

20. Lash, T.D.; Pokharel, K.; Serling, J.M.; Yant, V.R.; Ferrence, G. M. Aromatic and Nonaromatic Pyriporphyrins. Org. Lett. 2004, 9, 2863-2866.

21. Berlin, K.; Breitmaier, E. New Porphyrinoid Macrocycles Containing Pyridine. Angew. Chem., Int. Ed. Engl. 1994. 33, 219-220.

22. Young, A.M.; Lash, T.D. 6-Oxopyriphlorins. Org. Biomol. Chem. 2013. 11. 6841-6848.

23. Rothemund, P.; Menotti, A. R. The synthesis of $\alpha, \beta, \gamma, \delta$-tetraphenylporphine. J. Am. Chem. Soc. 1941, 63, 267-270

24. Rothemund, P. Formation of porphyrins from pyrrole and aldehydes. J. Am. Chem. Soc. 1935, 57, 2010-2011

25. Sessler, J. L.; Mozaffari, A.; Johnson, M. R. 3,4-Diethylpyrrole and 2,3,7,8,12,13,17,18octaethylporphyrin. Org. Synth. 1991, 70, 68-77.

26. Taniguchi, M.; Lindsey, J. S. Enumeration of isomers of substituted tetrapyrrole macrocycles: from classical problems in biology to modern combinatorial libraries. In Handbook of Porphyrin Science; Kadish, K. M, Smith, K. M, Guilard R., Eds.; World Scientific Press; Singapore, 2012; Vol. 23, pp 3-80.

27. Mauzerall, D. The thermodynamic stability of porphyrinogens. J. Am. Chem. Soc. 1960, $82,2601-2603$. 
28. Vicente, M. D.; Smith, K. M. Syntheses and Functionalizations of Porphyrin Macrocycles. Curr. Org. Synth. 2014, 11, 3-28.

29. Arsenault, G. P.; Bullock, E.; MacDonald, S.F. Pyrromethanes and Porphyrins Therefrom. J. Am. Chem. Soc. 1970, 92, 4992-4993.

30. Broadhurst, M. J.; Grigg, R.; Johnson, A. W. Synthesis of Porphin Analogues Containing Furan and/or Thiophen Rings. J. Chem. Soc. C 1971, 0, 3681-3690.

31. (a) Sessler, J. L.; Lynch, V.; Johnson, M. R. Synthesis and crystal structure of a novel tripyrrane-containing porphyrinogen-like macrocycle. J. Org. Chem. 1987, 52, 43944397. (b) Sessler, J.L.; Cyr, M. J.; Lynch, V. Synthetic and structural studies of sapphyrin, a $22 \pi$ - electron pentapyrrolic "expanded porphyrin". J. Am. Chem. Soc. 1990, $112,2810-2813$.

32. Cavaliero, J.A.S.; Gonsalves, A.M. d'A.R.; Kenner, G.W.; Smith, K.M. Pyrroles and Related Compounds. Part XXII. Syntheses of Pyrromethanes and a Tripyrrane. J. Chem. Soc. Perkin. Trans. 1973. 1, 2471-2478.

33. Lash, T.D. Metalation of Carbaporphyrinoid Systems. Makrogeterotsikly. 2008, 1, 9-20

34. Lash, T.D. Metal Complexes of Carbaporphyrinoid Systems.Chem, Asian J. 2014, 9, $682-705$.

35. Muckey, M.A.; Szczepura, L.F.; Ferrence, G.M.; Lash, T.D. Silver (III) Carbaporphyrins: The First Organometallic Complexes of True Carbaporphyrins. Inorg. Chem. 2002, 41, 4840-4842. 
36. Lash, T.D.; Colby, D. A.; Szczepura, L. F. New Riches in Carbaporphyrin Chemistry: Silver and Gold Organometallic Complexes of Benzocarbaporphyrins. Inorg. Chem. 2004, 43, 5258-5267.

37. Adiraju, V. A. K.; Ferrence, G.M.; Lash, T.D. Rhodium (I), Rhodium(III) and Iridium(III) Carbaporphyrins. Dalton Trans. 2016, 45, 13691-13694.

38. Stepien, M.; Latos-Grazynski, L. Tetraphenylbenziporphyrin-A Ligand for Organometallic Chemistry. Chem. Eur. J. 2001, 7, 5113-5117

39. Stepien, M.; Latos-Grazynski, L.; Szterenberg, L.; Panek, J.; Latajka, Z. Cadmium(II) and Nickel(II) Complexes of Benziporphyrins. A Study of Weak Intramolecular MetalArene Interactions. J. Am. Chem. Soc. 2004, 126, 4566-4580.

40. Hurjel, K.; Pawlicki, M.; Szterenberg, L.; Latos-Grażyński, L. A. Rhodium-Mediated Contraction of Benzene to Cyclopentadiene: Transformations of Rhodium(III) $\mathrm{m}$ Benziporphyrin. Angew. Chem. Int. Ed. 2016, 55, 1427-143

41. (a) Myśliborski, R.; Latos-Grażyński, L.; Pyriporphyrin-A Porphyrin Homologue Containing A Built-in Pyridine Moiety. Eur. J. Org. Chem. 2005, 5039 - 5048;

(b) Myśliborski, R.; Rachlewicz, K.; Latos-Grażyński, L. Iron Complexes of N-Confused Pyriporphyrin: NMR Studies. Inorg. Chem. 2006, 45, 7828 - 7834.

42. Linstead, R. P. Discoveries among Conjugated Macrocyclic Compounds. J. Chem. Soc. 1953, 2873. 
43. (a) Callot, H. J.; Schaeffer, E. Direct Approval of the Porphyrin Cycle by Diazoalkanes. Tetrahedron 1978, 34, 2295-2300.

(b) Carre, F. H.; Corriu, R. J. P.; Bolin, B.; Moreau J. J. E.; Vernhet, C. Aminosilanes in organic synthesis. Preparation of New Expanded Porphyrin Ligands and Bimetallic Transition-Metal Complexed. Crystal Structure of a Tetrapyrrole Macrocycle Dirhodium Complex. Organometallics 1993. 12, 2478-2486

(c) Adams, K. R.; Bonnett, R.; Burke, P. J.; Salgado, A; Vallés, M. A. Cleavage of (octaethyl-2,3-dihydroxychlorinato)nickel(II) to give the novel 2,3-dioxo-2,3-secochlorin system. J. Chem. Soc., Perkin Trans. 1 1997, 1769-1772

(d) Liu, D.; Ferrence, G. M.; Lash, T.D. Oxybenziporphyrins, Oxypyriporphyrins, Benzocarbaporphyrins, and Their 23-Oxa and 23-Thia Analogues: Synthesis, Spectroscopic Characterization of a Palladium (II) Organometallic Derivative. J. Org. Chem. 2004, 6079-6093

(e) Sim, E.-K.; Jeong, S.-D.; Yoon, D.-W.; Hong, S.-J.; Kang, Y.; Lee, C.-H. Porphyrins Bearing Stable meso-Alkylidenyl Double Bonds. A New Family of Nonplanar Porphyrinoids. Org. Lett. 2006, 8, 3355-3358.

44. Chaney, S. T.; Lash, T. D. Oxypyriporphyrin, the First Fully Aromatic Porphyrinoid Macrocycle with a Pyridine Subunit. 1996, 2, 944-948. 
45. Myśliborski, R.; Latos-Grażyński, L.; Szterenberg, L.; Pyriporphyrin - A Porphyrin Homologue Containing A Built-in Pyridine Moiety. Eur. J. Org. Chem. 2006, 3064.

46. Boekelheide, V.; Lodge, J.P. A Study of Quinolizone Derivatives. J. Am. Chem. Soc. 1951, $73,3681-3674$

47. Thyagarajan, B.S.; Gopalakrishnan, P.V. Studies on Quinolizones-IV: Formylation of 4H-quinolizini-4-one and some selective cationoid displacements. Tetrahedron 1967, 23, 3851-3858.

48. Yang, D.; Yu, Y.; Wu, Y.; Feng, H.; Li, X; Cao, H. One Pot Regiospecific Synthesis of Indolizines: A solvent-Free, Metal-Free, Three-Component Reaction of 2-(Pyridin-2yl)acetates, Ynals, and Alcohols or Thiols. Org. Lett. 2018, 20, 2477-2480.

49. Farquhar, D.; Gough, T. T.; Leaver, D. Heterocyclic Compounds with Bridgehead Nitrogen atoms. Part V. Pyrido[2,1,6-de] quinolizines (Cycl[3.3.3]azines). J. Chem. Soc., Perkin Trans. 1 1976, 3, 341-355. 


\section{APPENDIX A: SELECTED SPECTROSCOPIC DATA FOR THE SYNTHESIS OF OXYQUINOLIZINIPORPHYRIN}

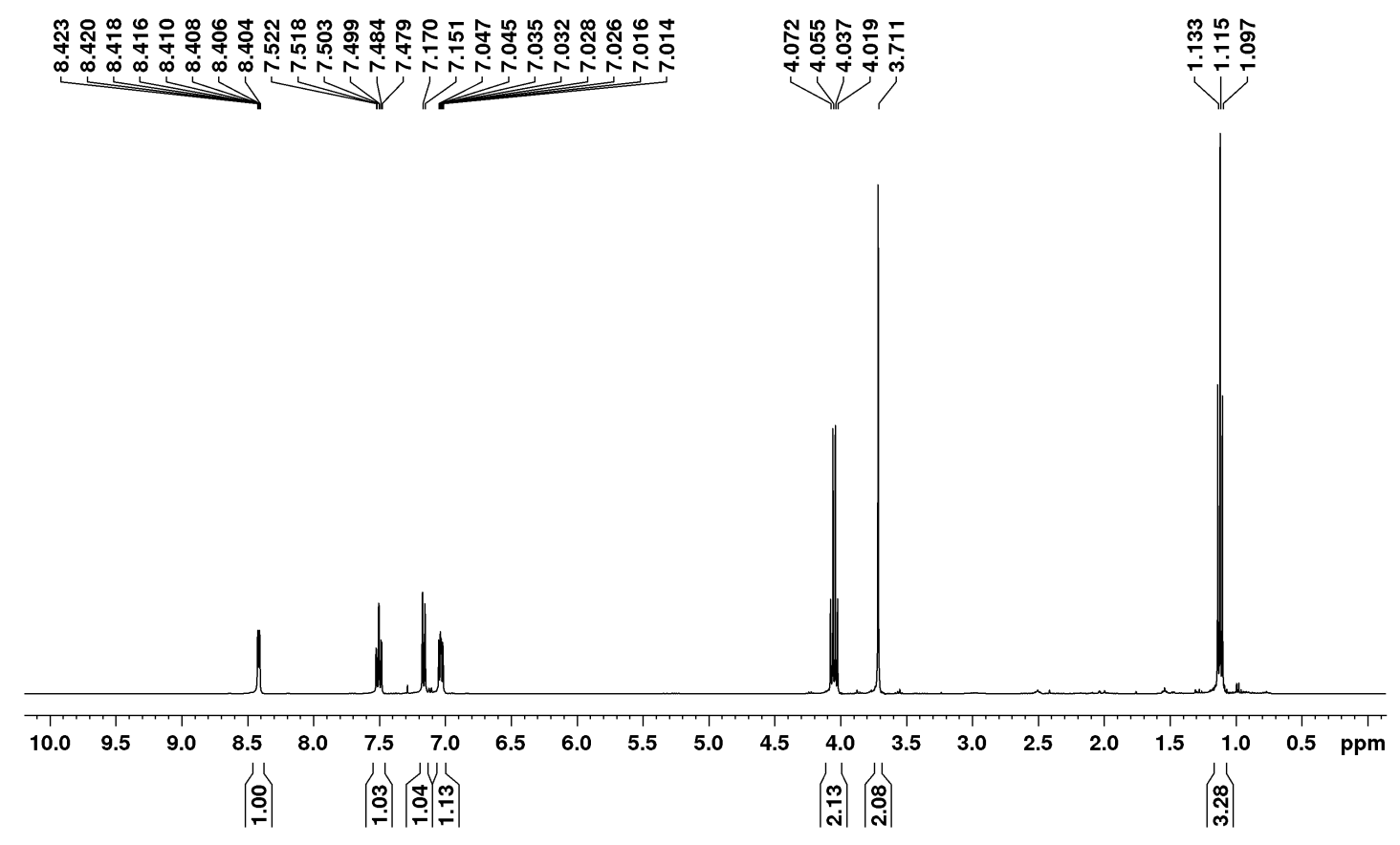

Figure A-1. $400 \mathrm{MHz}{ }^{1} \mathrm{H}$ NMR spectrum of ethyl 2-pyridylacetate 99 in $\mathrm{CDCl}_{3}$ 


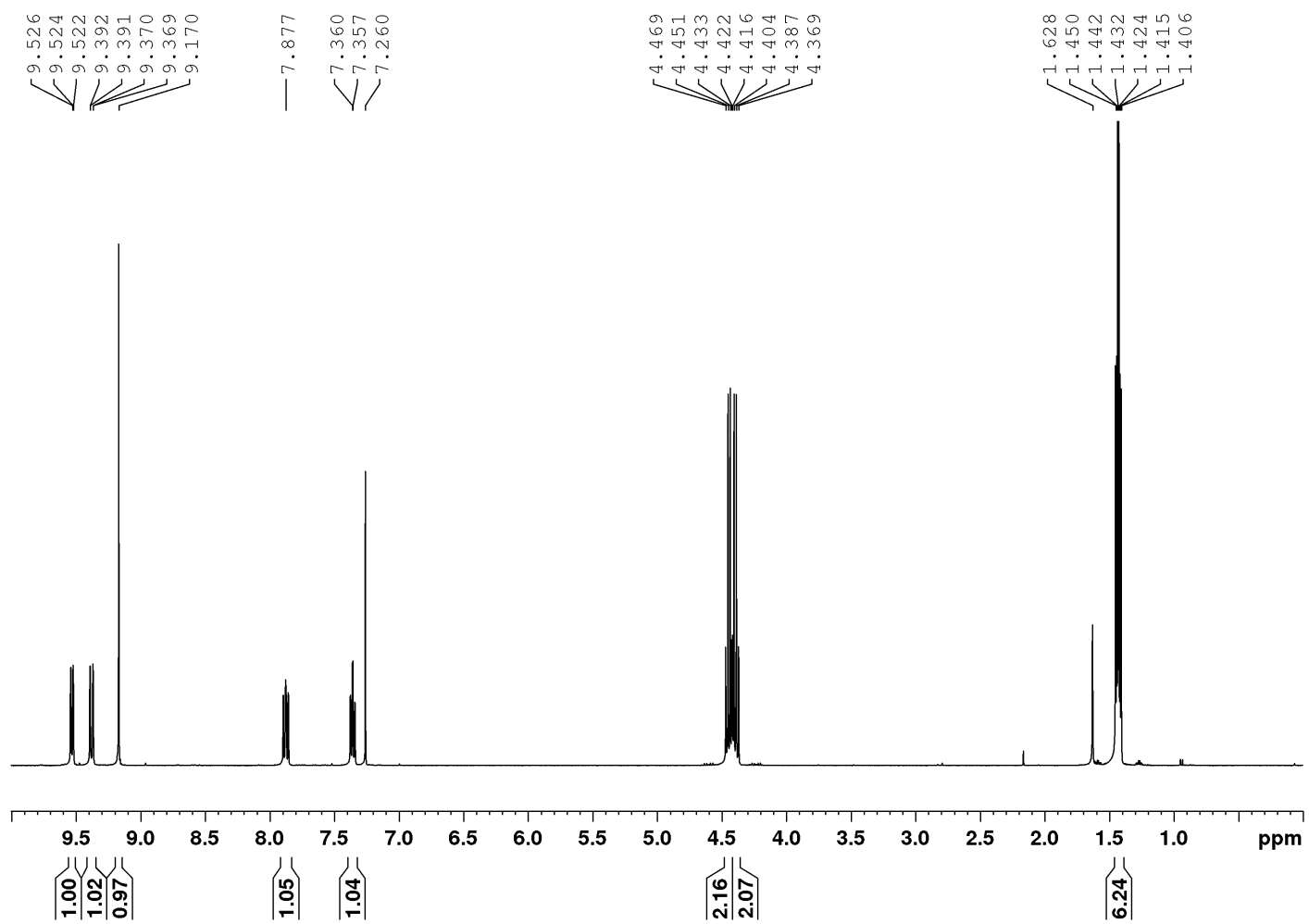

Figure A-2. $500 \mathrm{MHz}{ }^{1} \mathrm{H}$ NMR spectrum of diethyl 4-quinolizone-1,3-dicarboxylate $\mathbf{1 0 1}$ in $\mathrm{CDCl}_{3}$ 


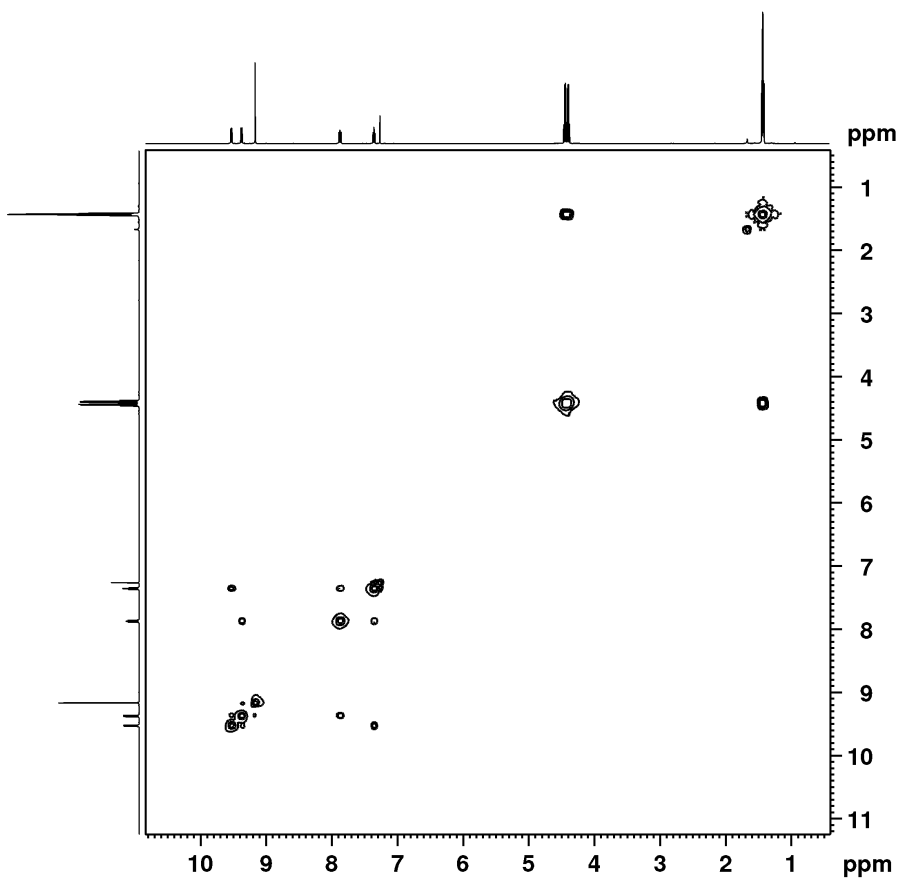

Figure A-3. ${ }^{1} \mathrm{H}-{ }^{1} \mathrm{H}$ COSY NMR spectrum of diethyl 4-quinolizone-1,3-dicarboxylate 101 in $\mathrm{CDCl}_{3}$ 


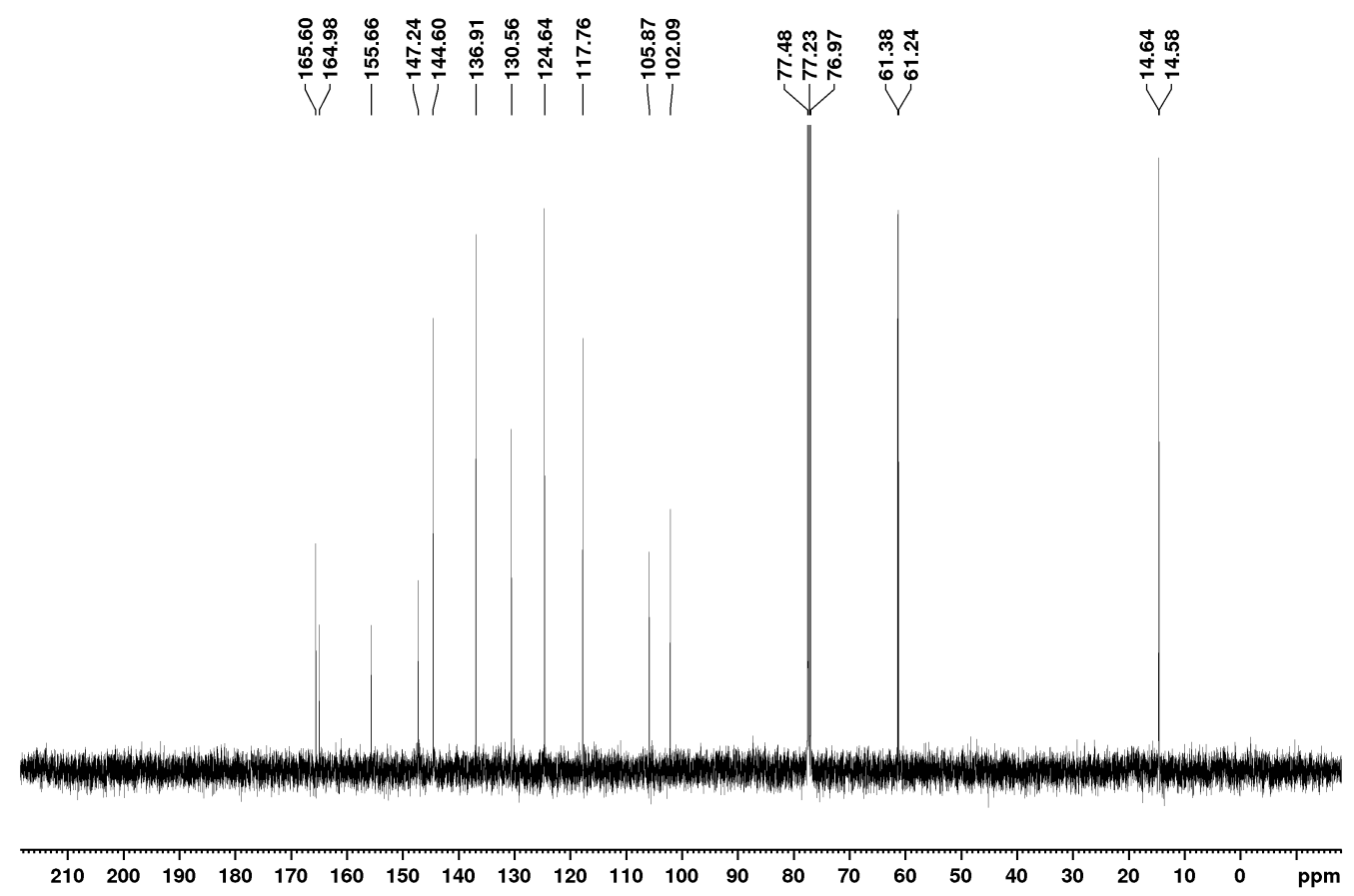

Figure A-4. $125 \mathrm{MHz}{ }^{13} \mathrm{C}$ NMR spectrum of diethyl 4-quinolizone-1,3-dicarboxylate $\mathbf{1 0 1}$ in $\mathrm{CDCl}_{3}$ 


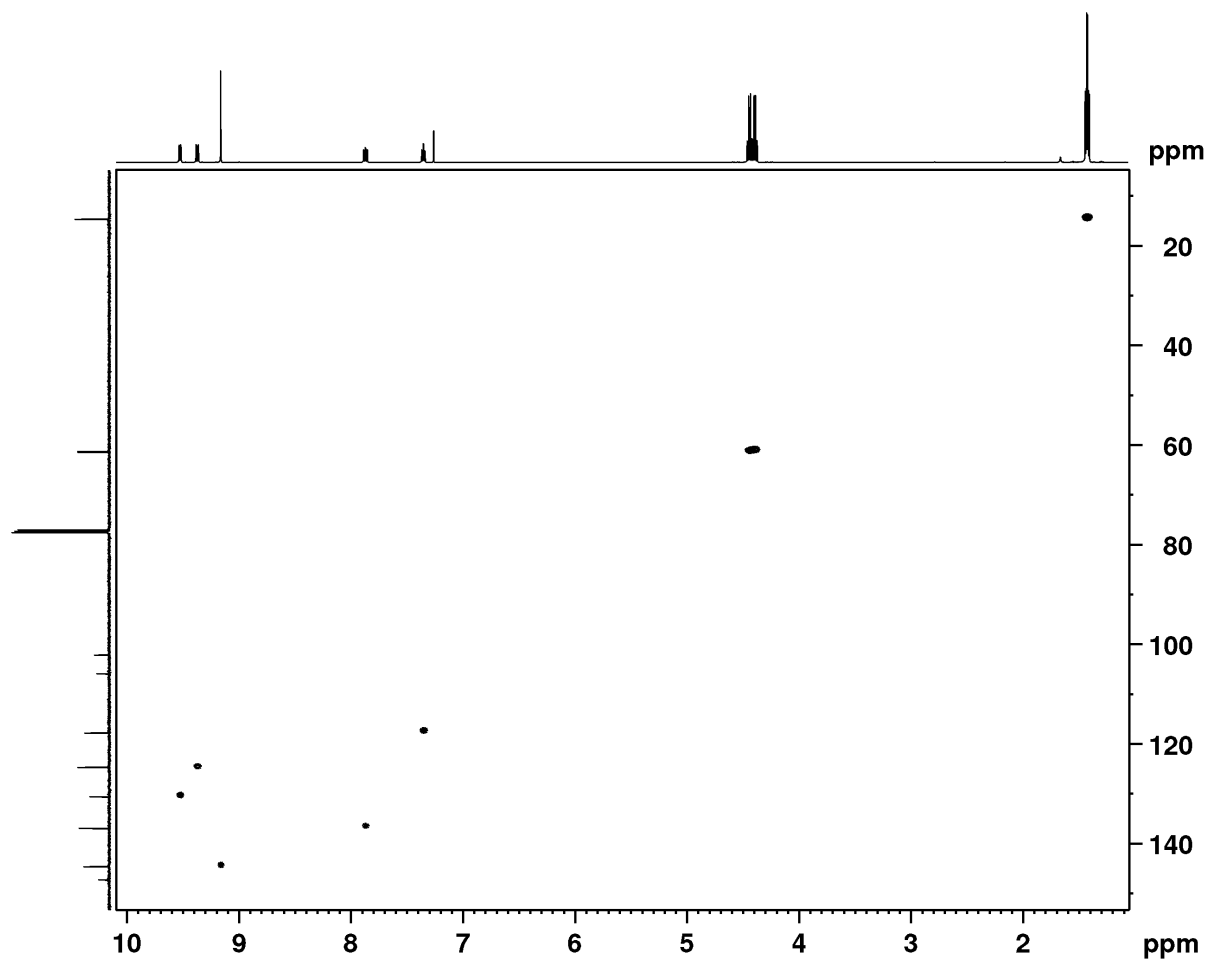

Figure A-5. HSQC NMR spectrum of diethyl 4-quinolizone-1,3-dicarboxylate 101 in $\mathrm{CDCl}_{3}$ 


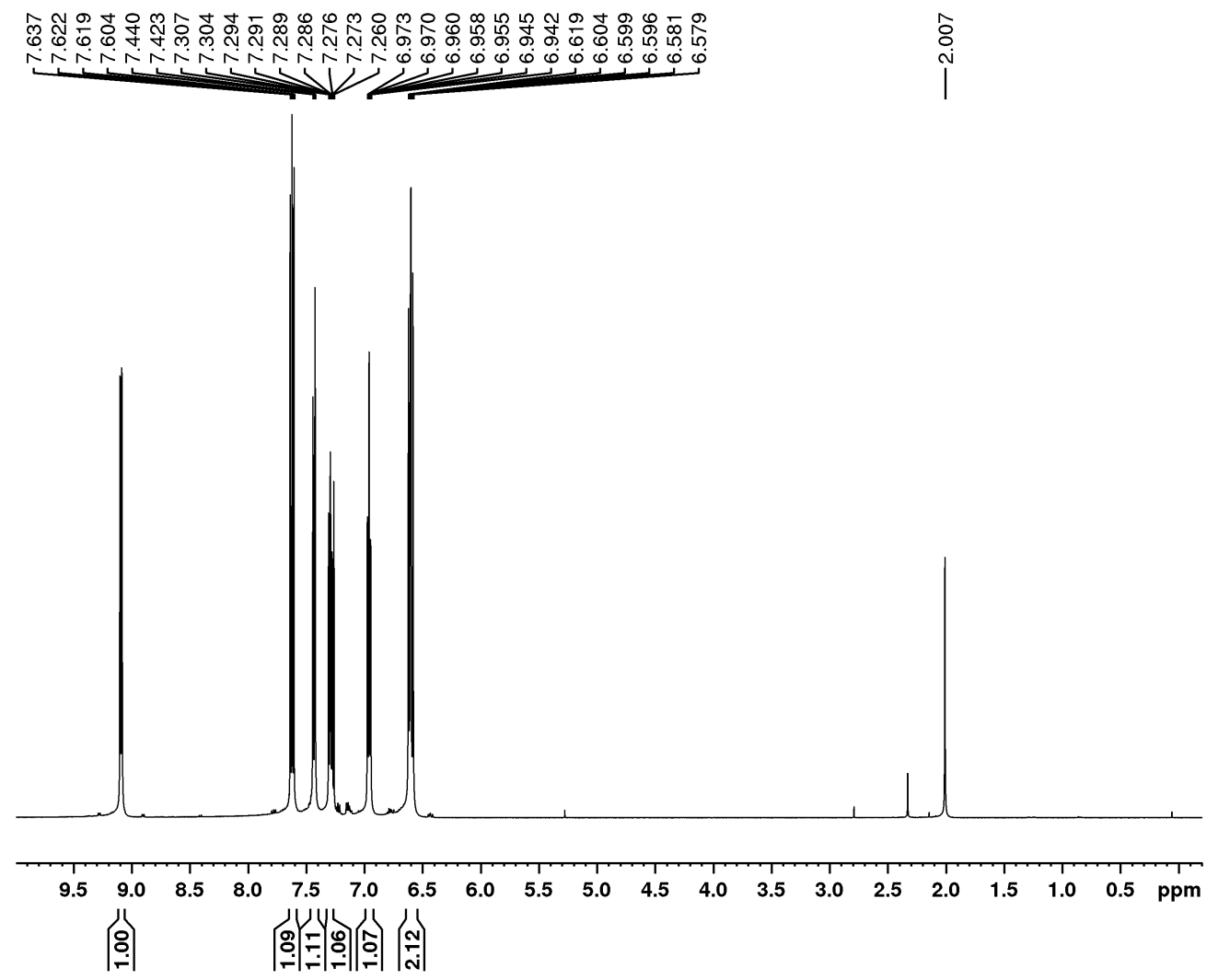

Figure A-6. $500 \mathrm{MHz}{ }^{1} \mathrm{H} \mathrm{NMR}$ spectrum of 4-quinolizone in $102 \mathrm{CDCl}_{3}$ 


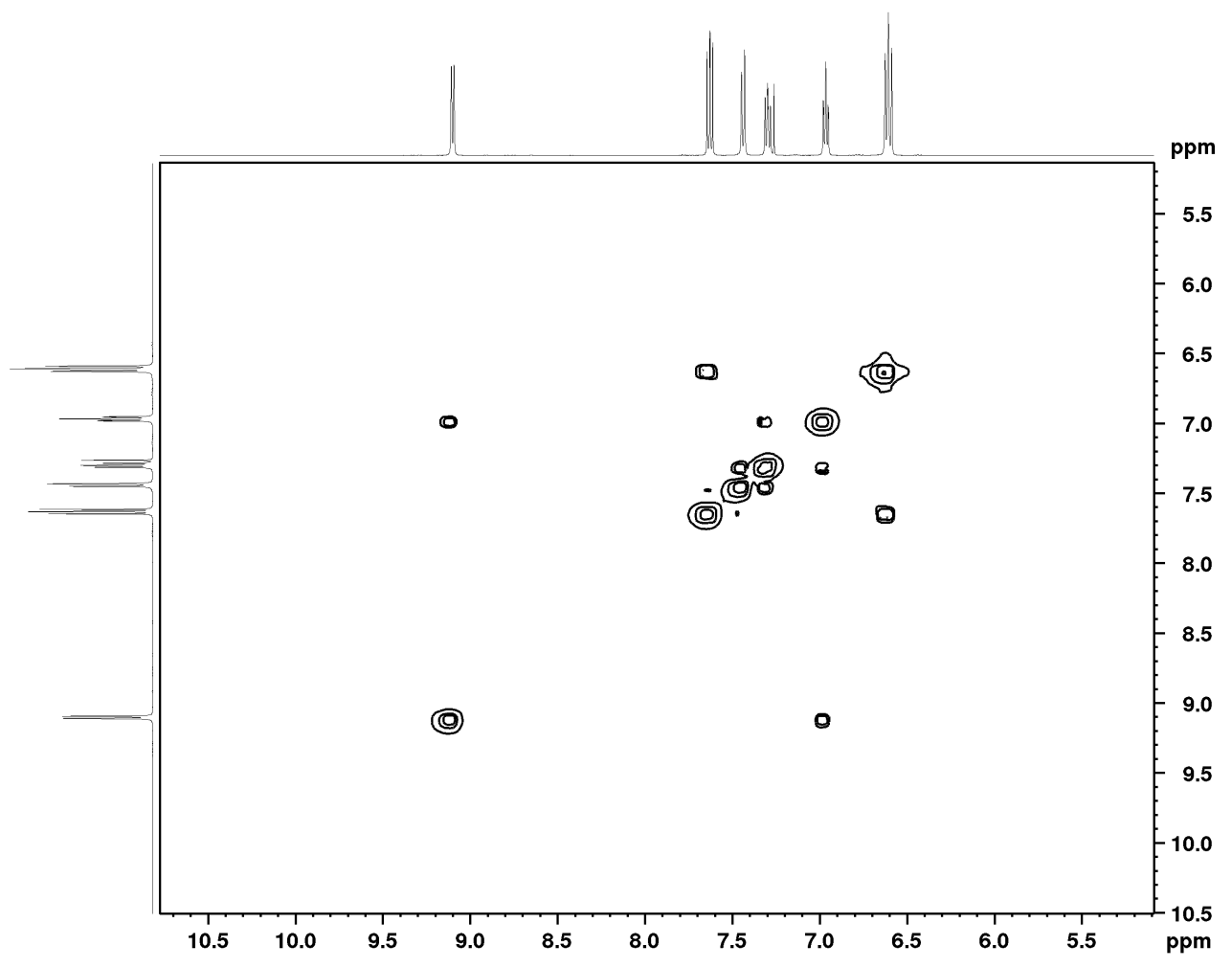

Figure A-7. ${ }^{1} \mathrm{H}-{ }^{1} \mathrm{H}$ COSY NMR spectrum of 4-quinolizone 102 in $\mathrm{CDCl}_{3}$ 


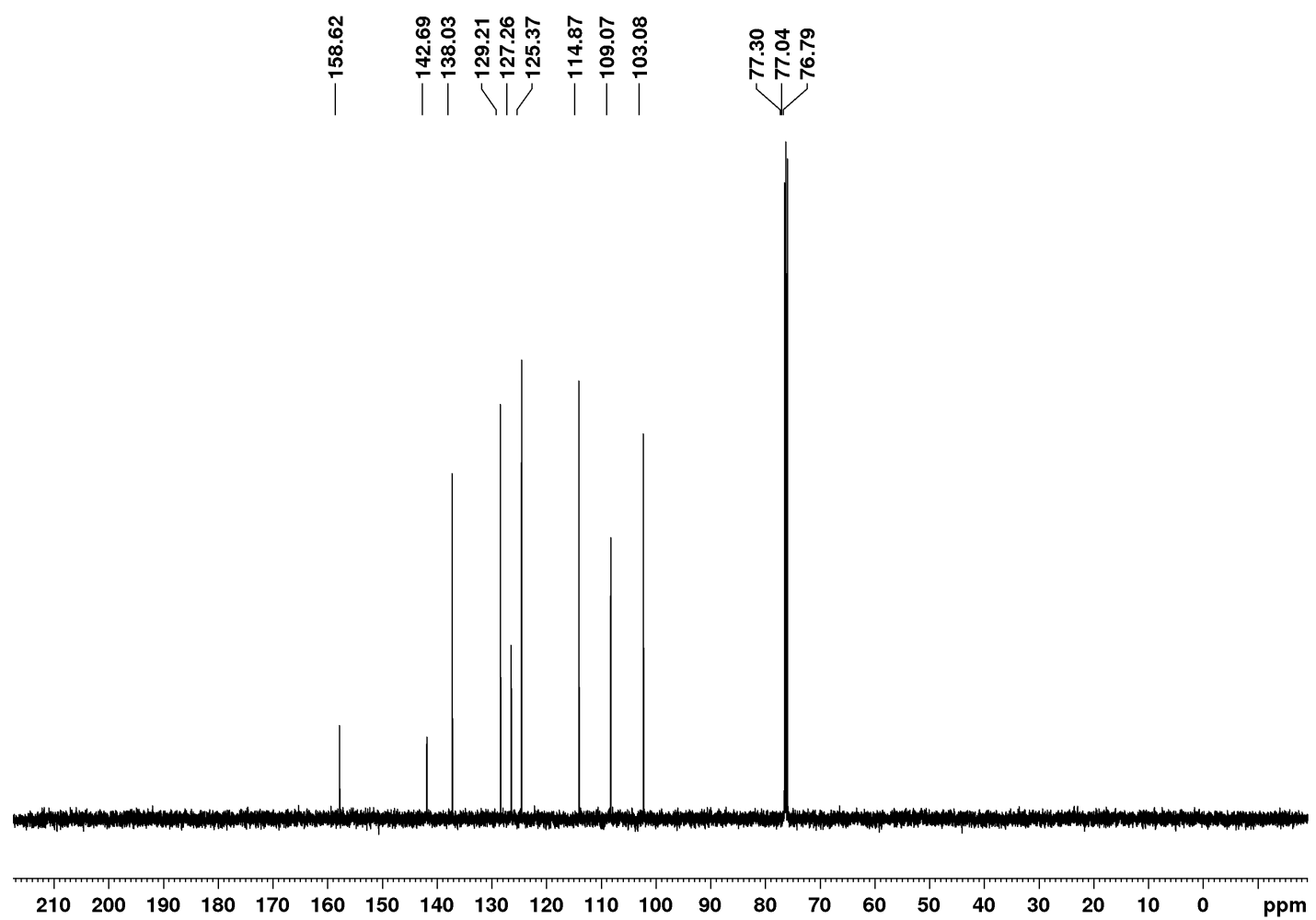

Figure A-8. $125 \mathrm{MHz}{ }^{13} \mathrm{C}$ NMR spectrum of 4-quinolizone 102 in $\mathrm{CDCl}_{3}$ 


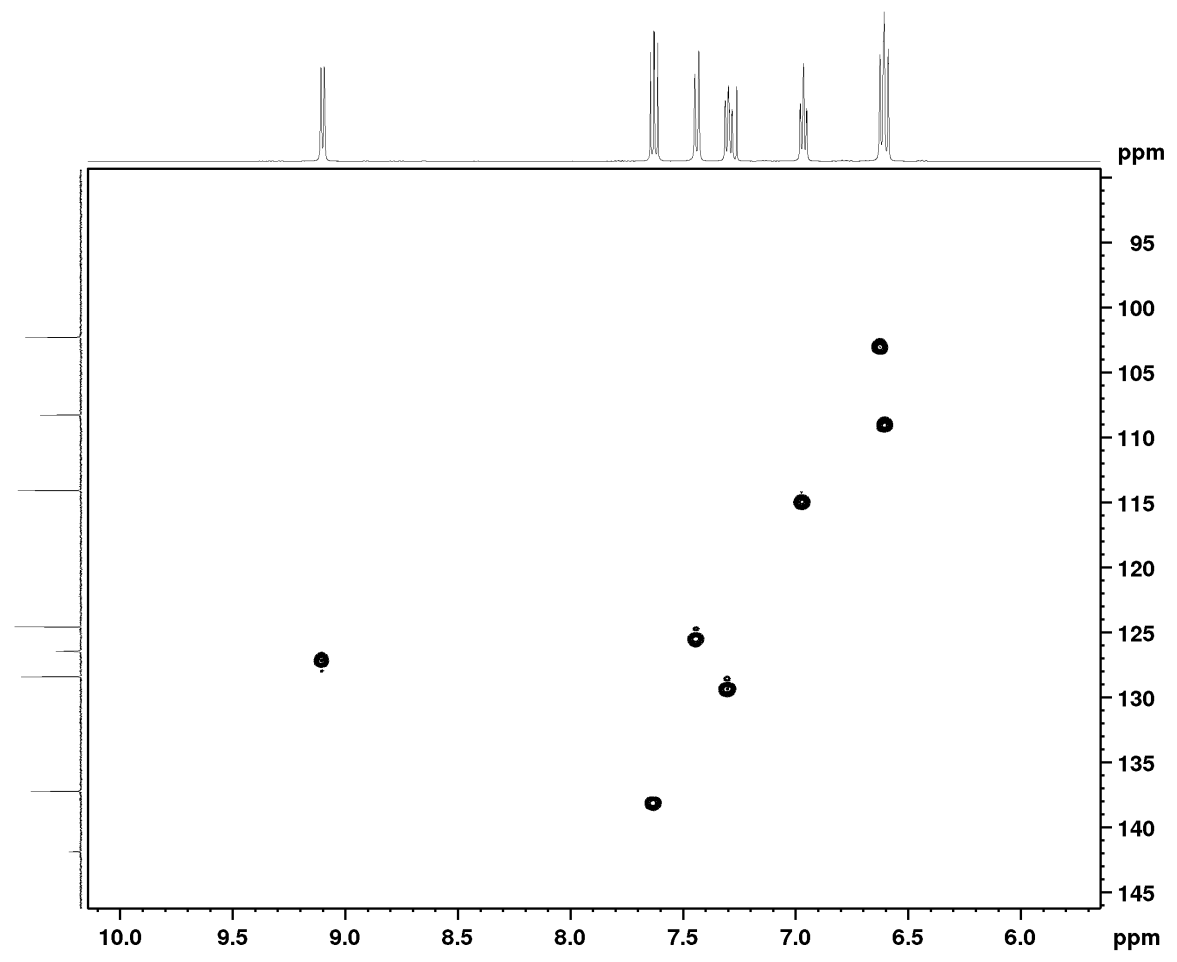

Figure A-9. HSQC NMR spectrum of 4-quinolizone 102 in $\mathrm{CDCl}_{3}$ 


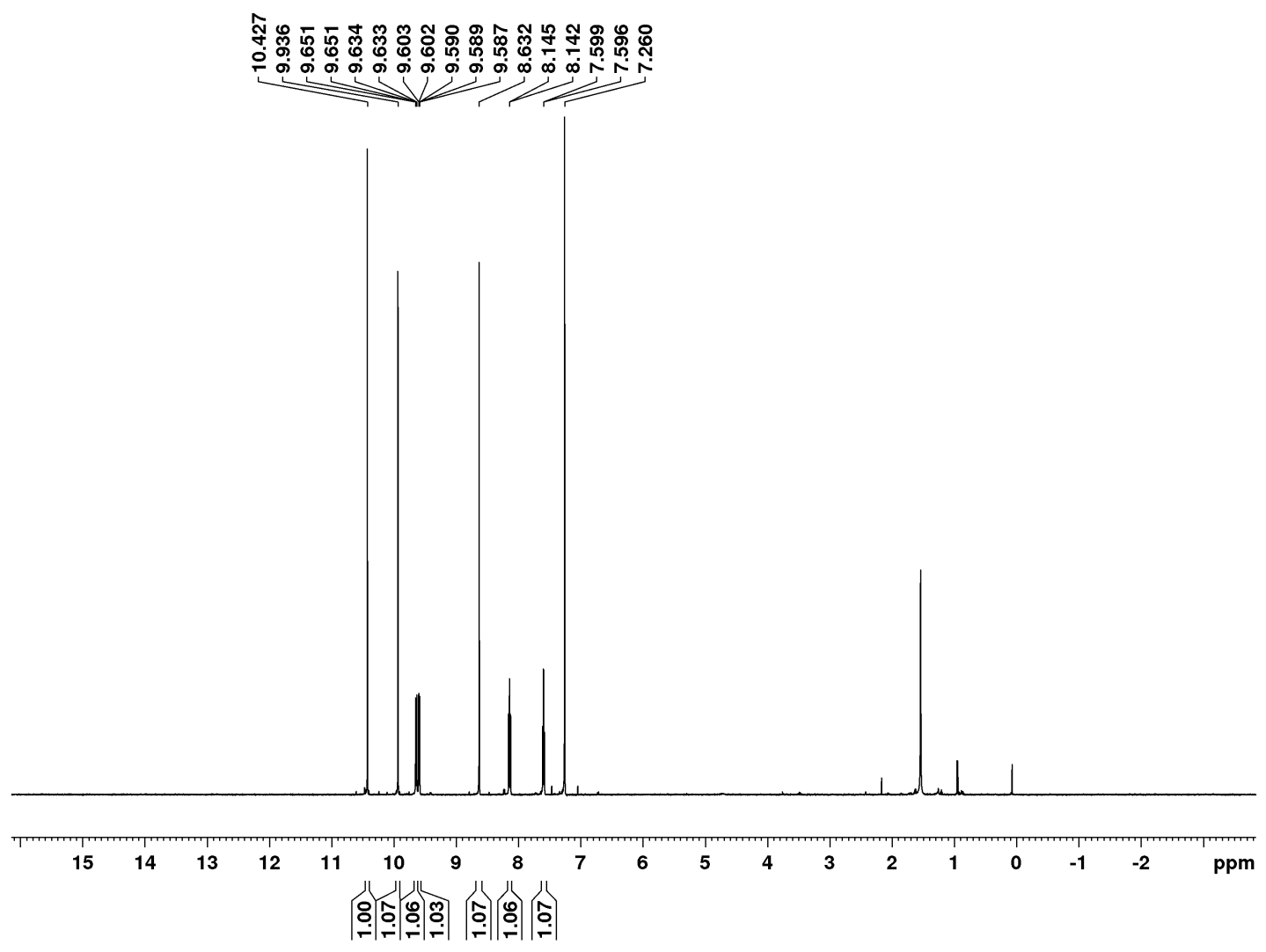

Figure A-10. $500 \mathrm{MHz}{ }^{1} \mathrm{H}$ NMR spectrum of 4-quinolizone-1,3-dicarbaldehyde 85 in $\mathrm{CDCl}_{3}$ 


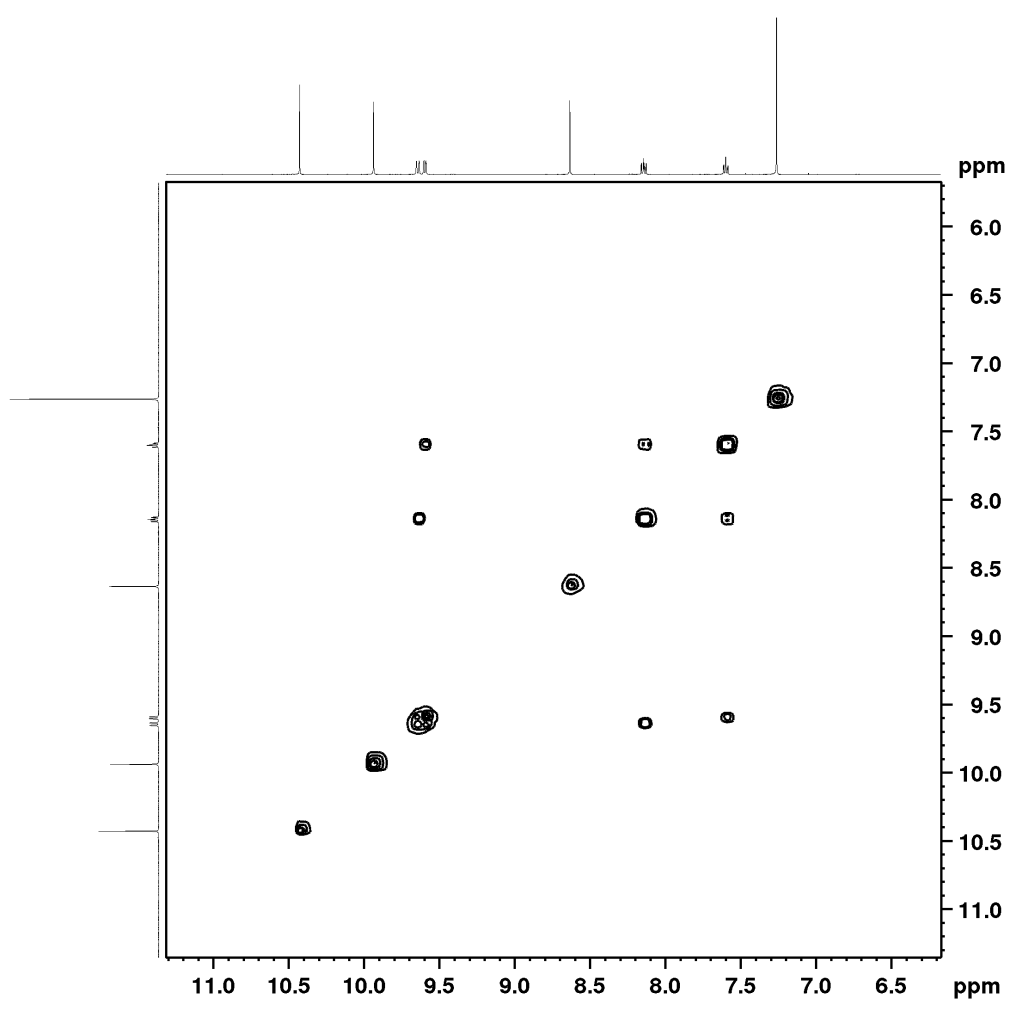

Figure A-11. ${ }^{1} \mathrm{H}-{ }^{1} \mathrm{H}$ COSY NMR spectrum of 4-quinolizone-1,3-dicarbaldehyde 85 in $\mathrm{CDCl}_{3}$ 


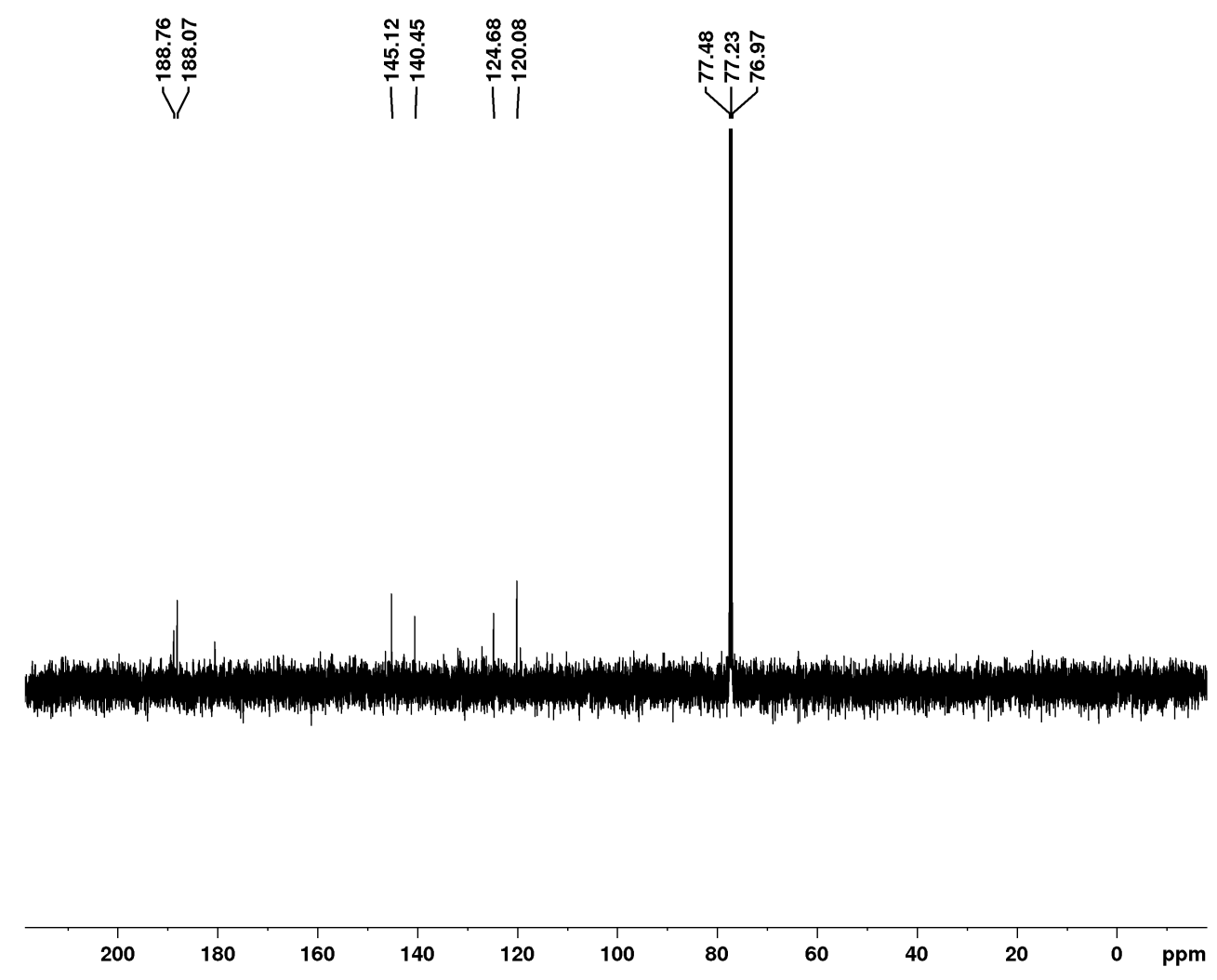

Figure A-12. $125 \mathrm{MHz}{ }^{13} \mathrm{C}$ NMR spectrum of 4-quinolizone-1,3-dicarbaldehyde 85 in $\mathrm{CDCl}_{3}$ 


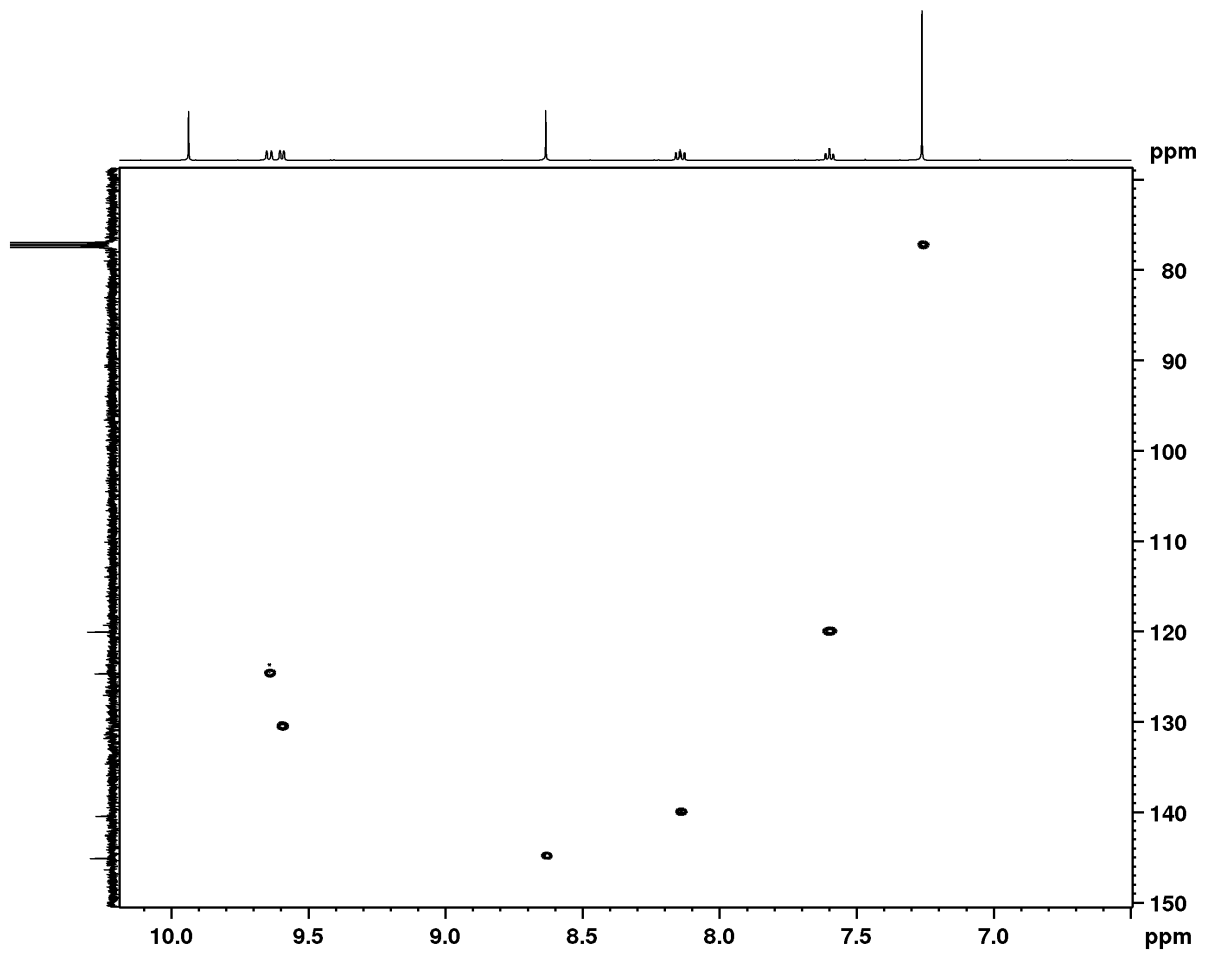

Figure A-13. HSQC NMR spectrum of 4-quinolizone-1,3-dicarbaldehyde $\mathbf{8 5}$ in $\mathrm{CDCl}_{3}$ 


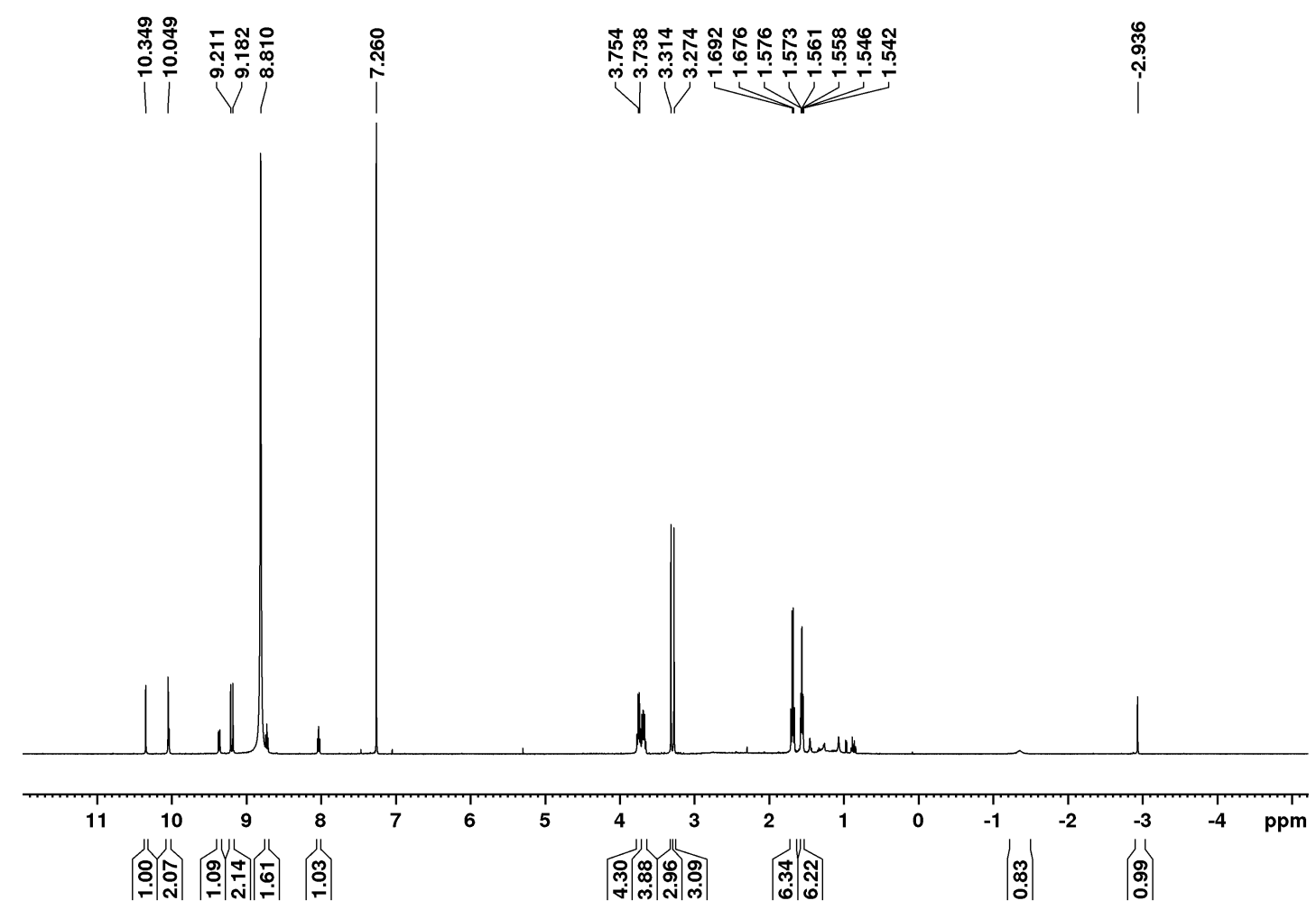

Figure A-14. $500 \mathrm{MHz}{ }^{1} \mathrm{H}$ NMR spectrum of oxyquinoliziniporphyrin 84a in $\mathrm{CDCl}_{3}$-TFA 


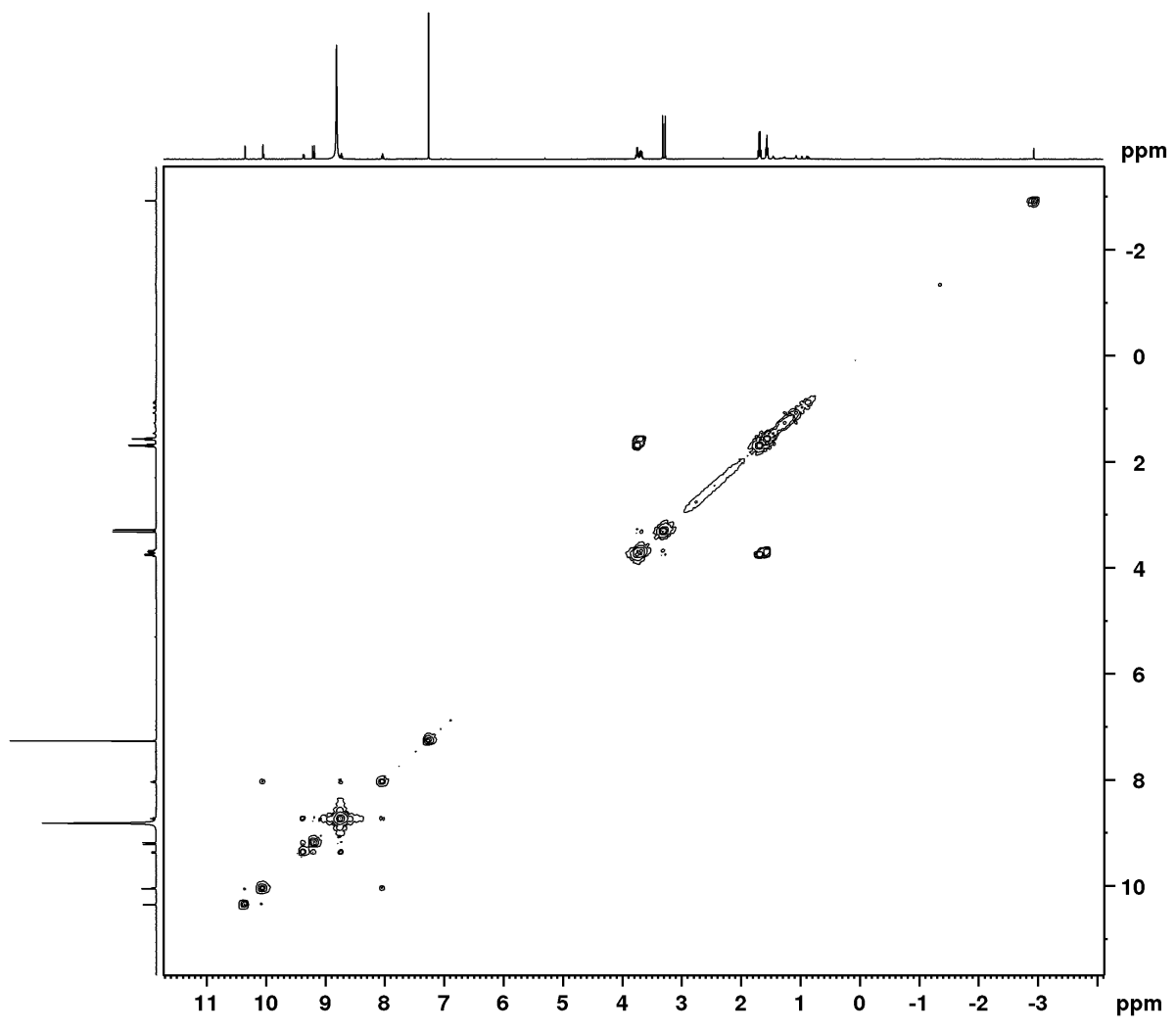

Figure A-15. ${ }^{1} \mathrm{H}-{ }^{1} \mathrm{H}$ COSY NMR spectrum of oxyquinoliziniporphyrin 84a in $\mathrm{CDCl}_{3}$-TFA 


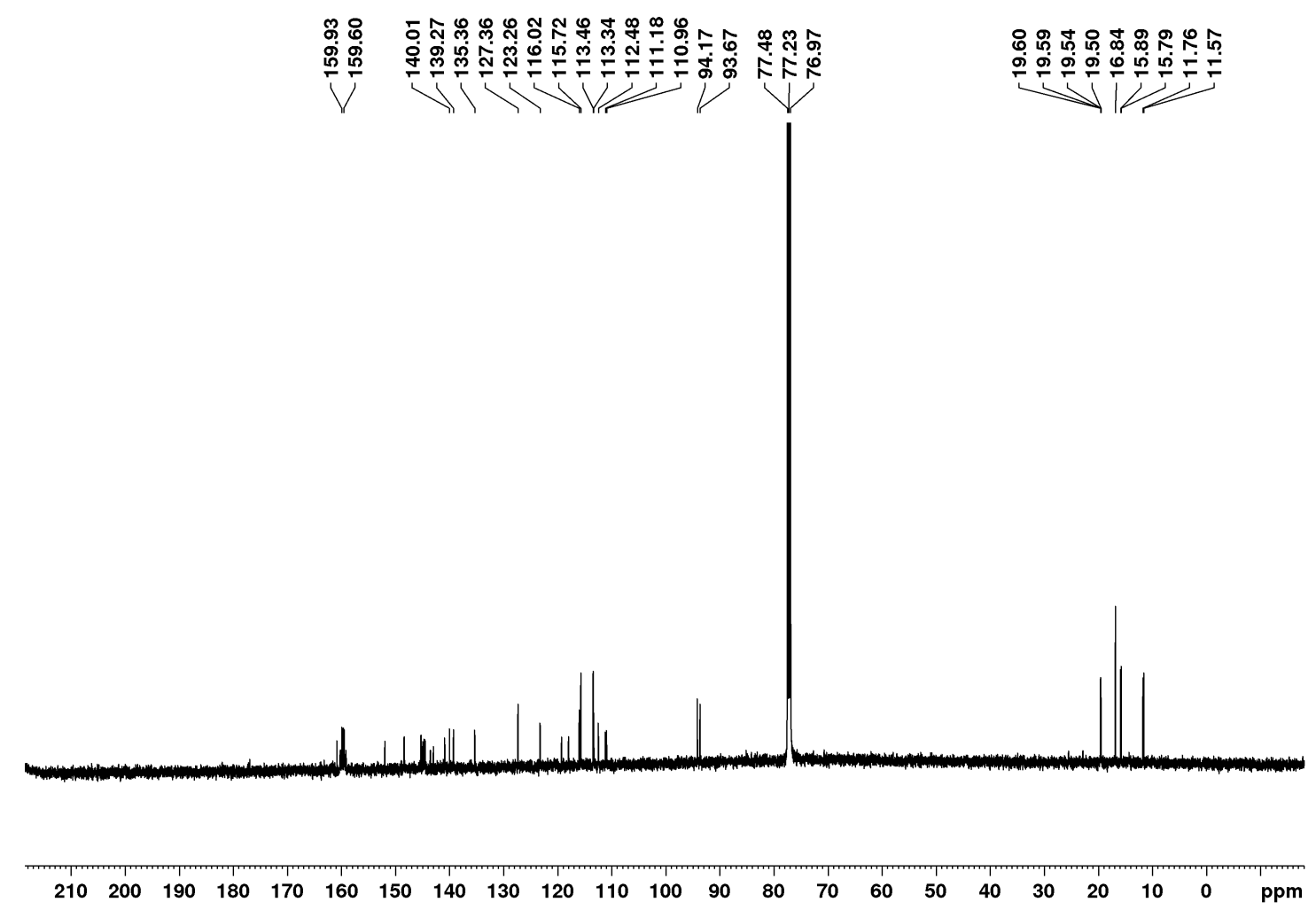

Figure A-16. $125 \mathrm{MHz}{ }^{13} \mathrm{C}$ NMR spectrum of oxyquinoliziniporphyrin 84a in $\mathrm{CDCl}_{3}$-TFA 


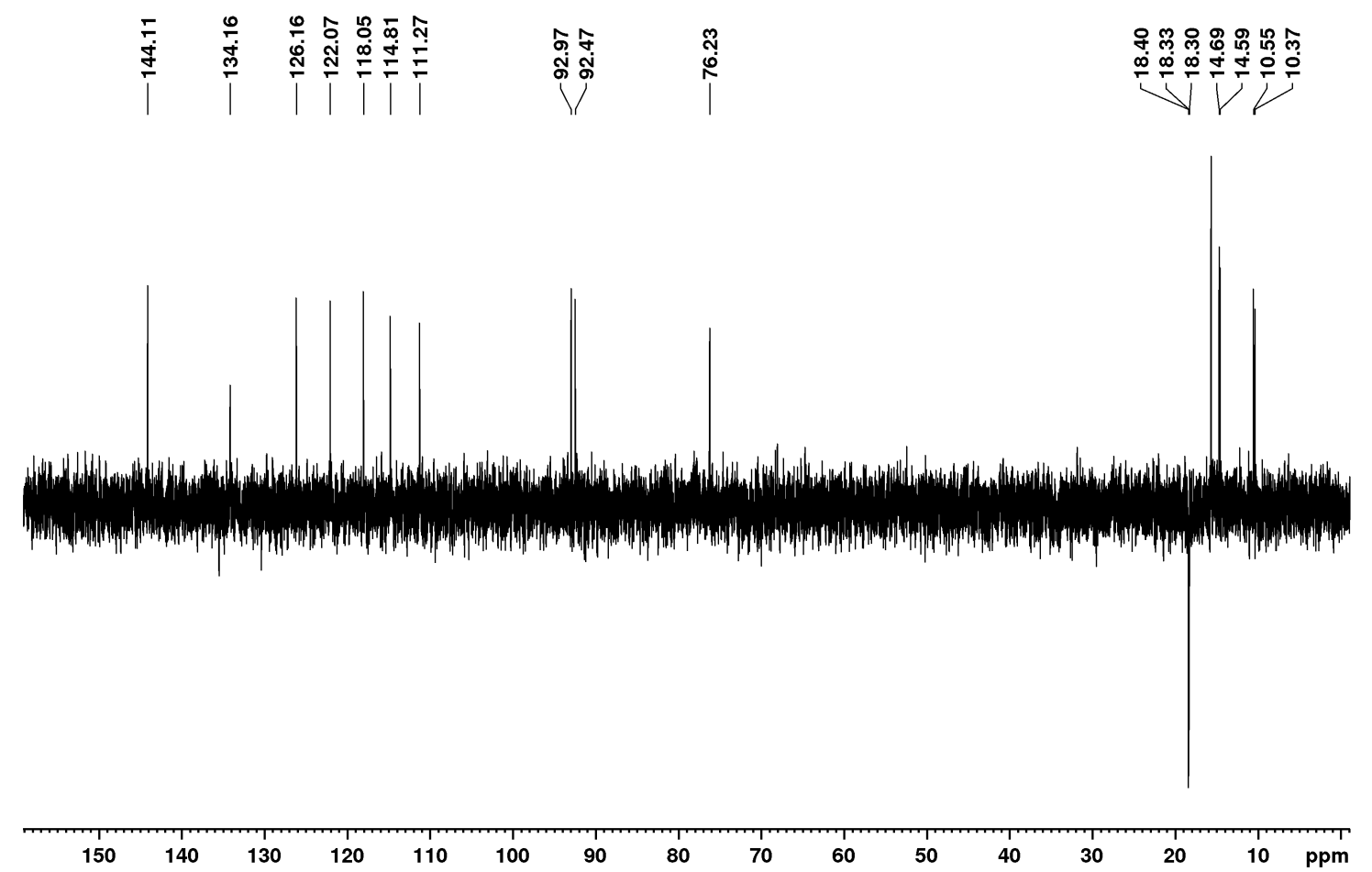

Figure A-17. DEPT-135 NMR spectrum of oxyquinoliziniporphyrin 84a in $\mathrm{CDCl}_{3}$-TFA 


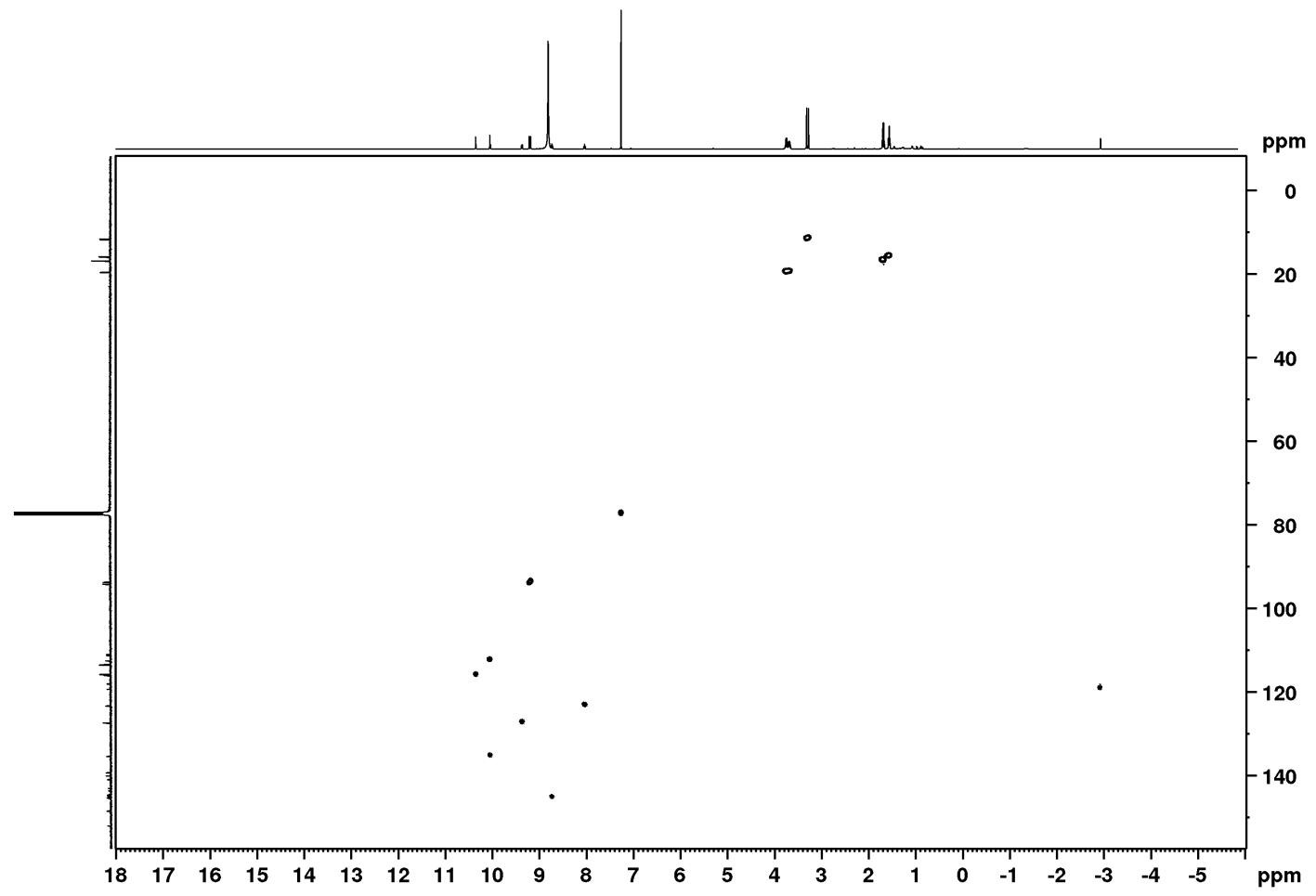

Figure A-18. HSQC NMR spectrum of oxyquinoliziniporphyin 84a in $\mathrm{CDCl}_{3}$-TFA 


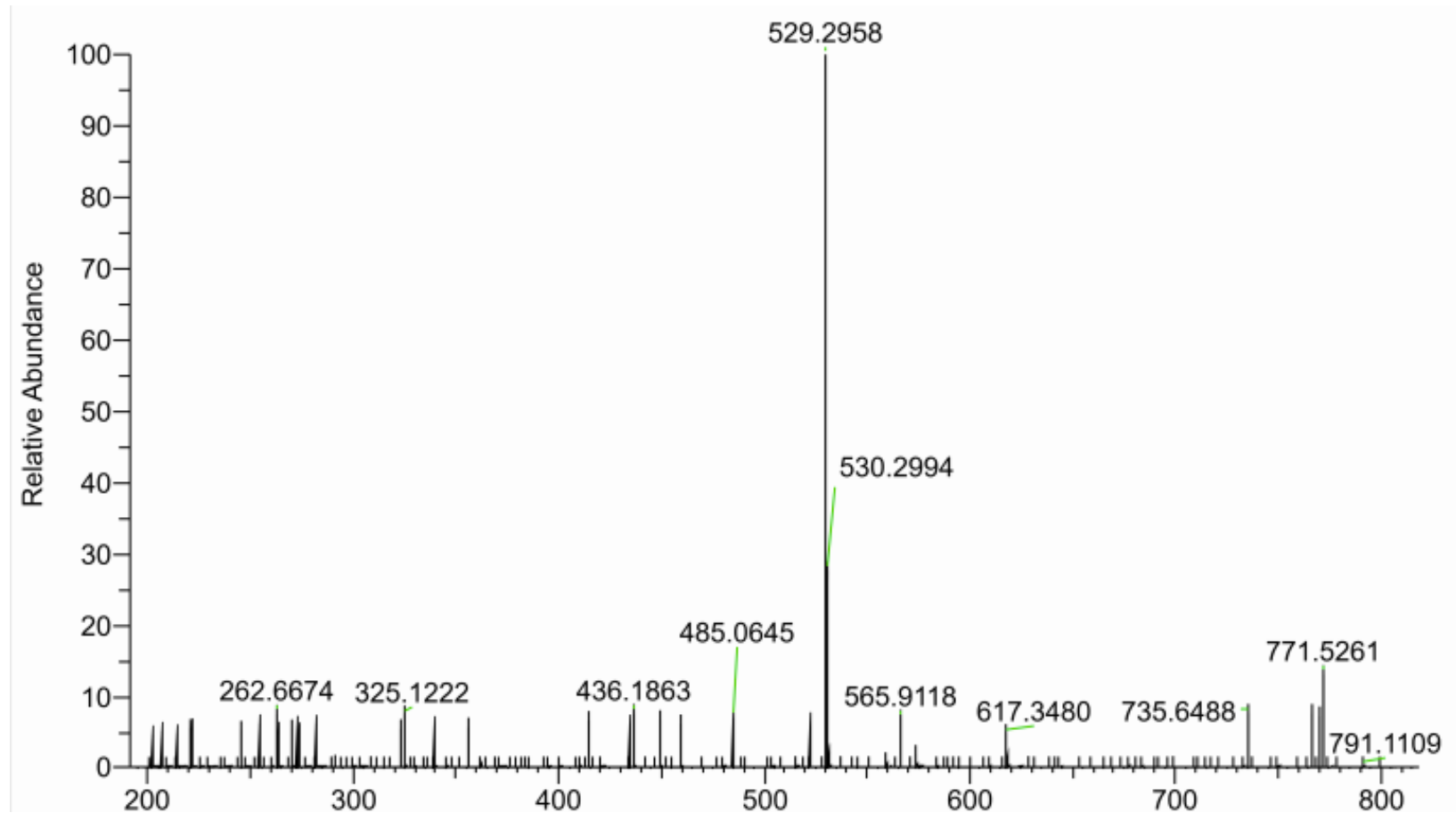

Figure A-18. ESI Mass Spectrum of oxyquinoliziniporphyrin $84 \mathbf{a} \mathrm{CHCl}_{3}$

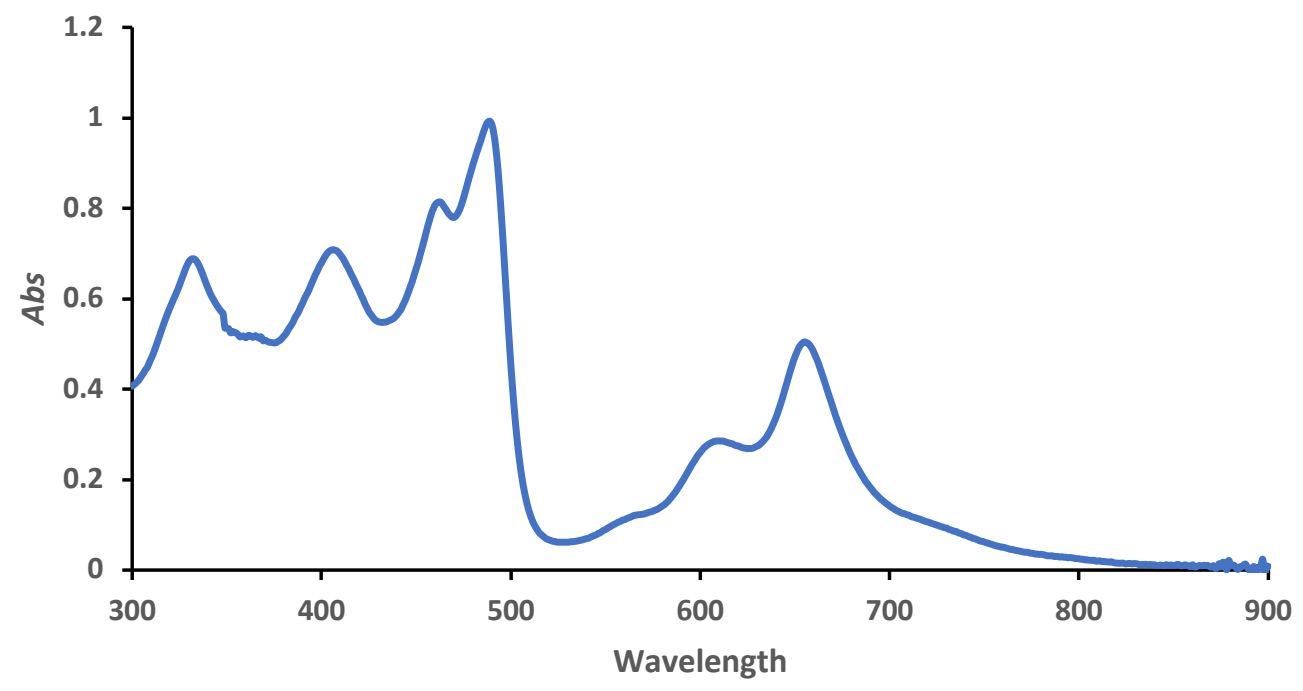

Figure A-19. UV-Vis Spectra of oxyquinoliziniporphyrin 84a $1 \% \mathrm{TEA}-\mathrm{CH}_{2} \mathrm{Cl}_{2}$ 


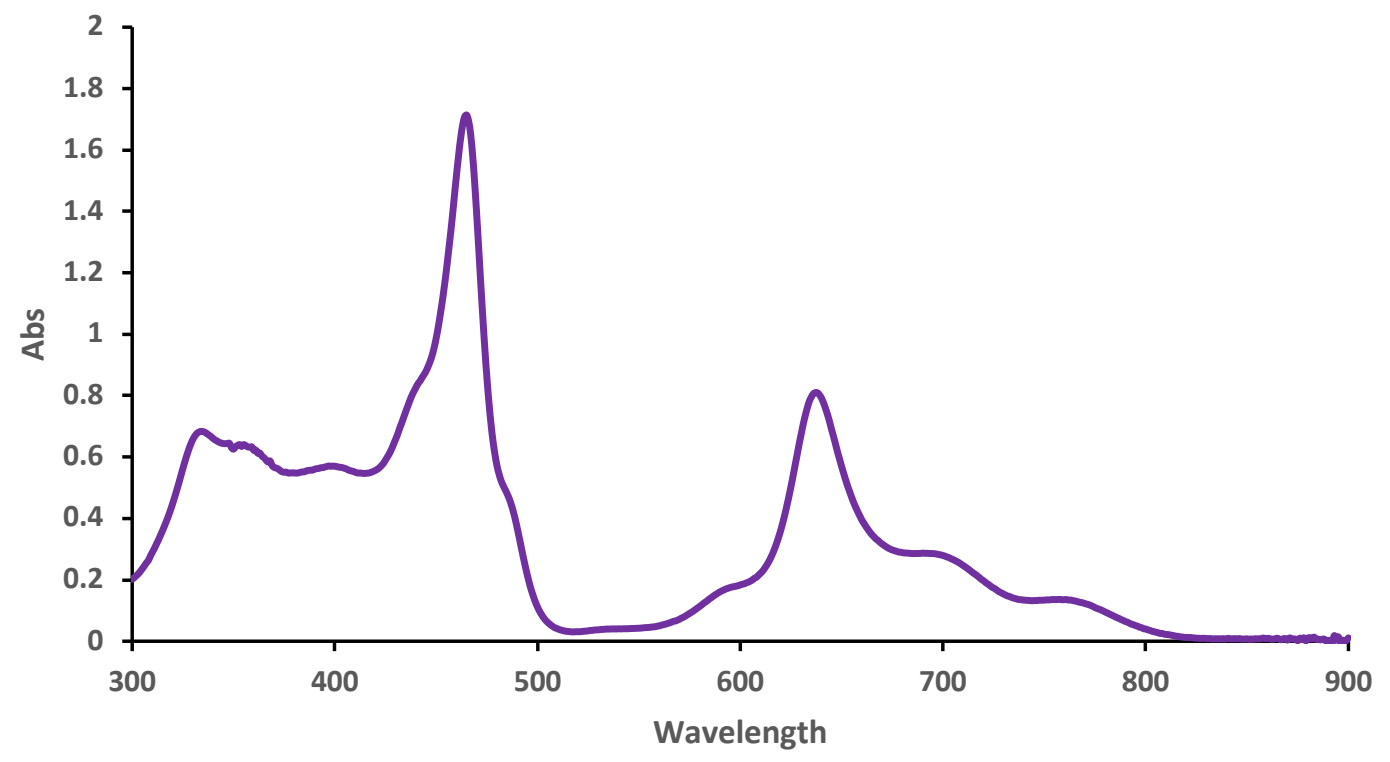

Figure A-20. UV-Vis Spectra of oxyquinoliziniporphyrin 84a 1 eq TFA- $\mathrm{CH}_{2} \mathrm{Cl}_{2}$

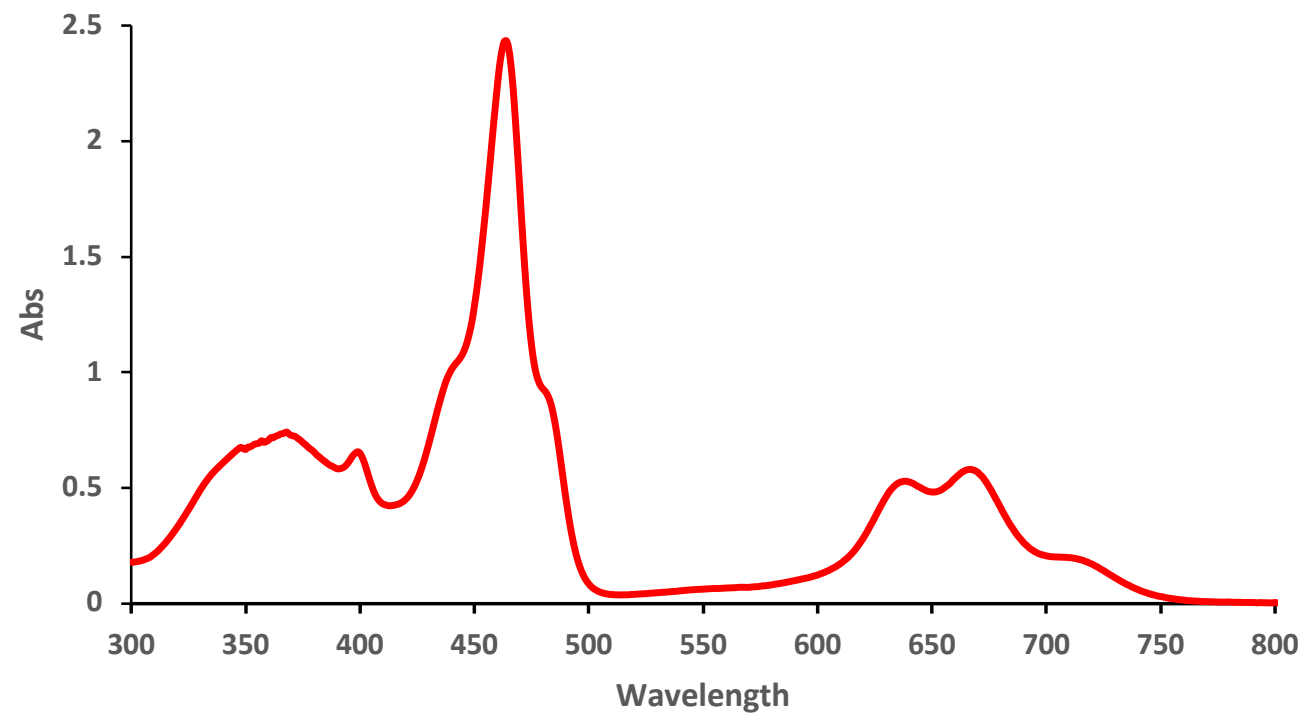

Figure A-21. UV-Vis Spectra of oxyquinoliziniporphyrin 84a 10\% TFA- $\mathrm{CH}_{2} \mathrm{Cl}_{2}$ 


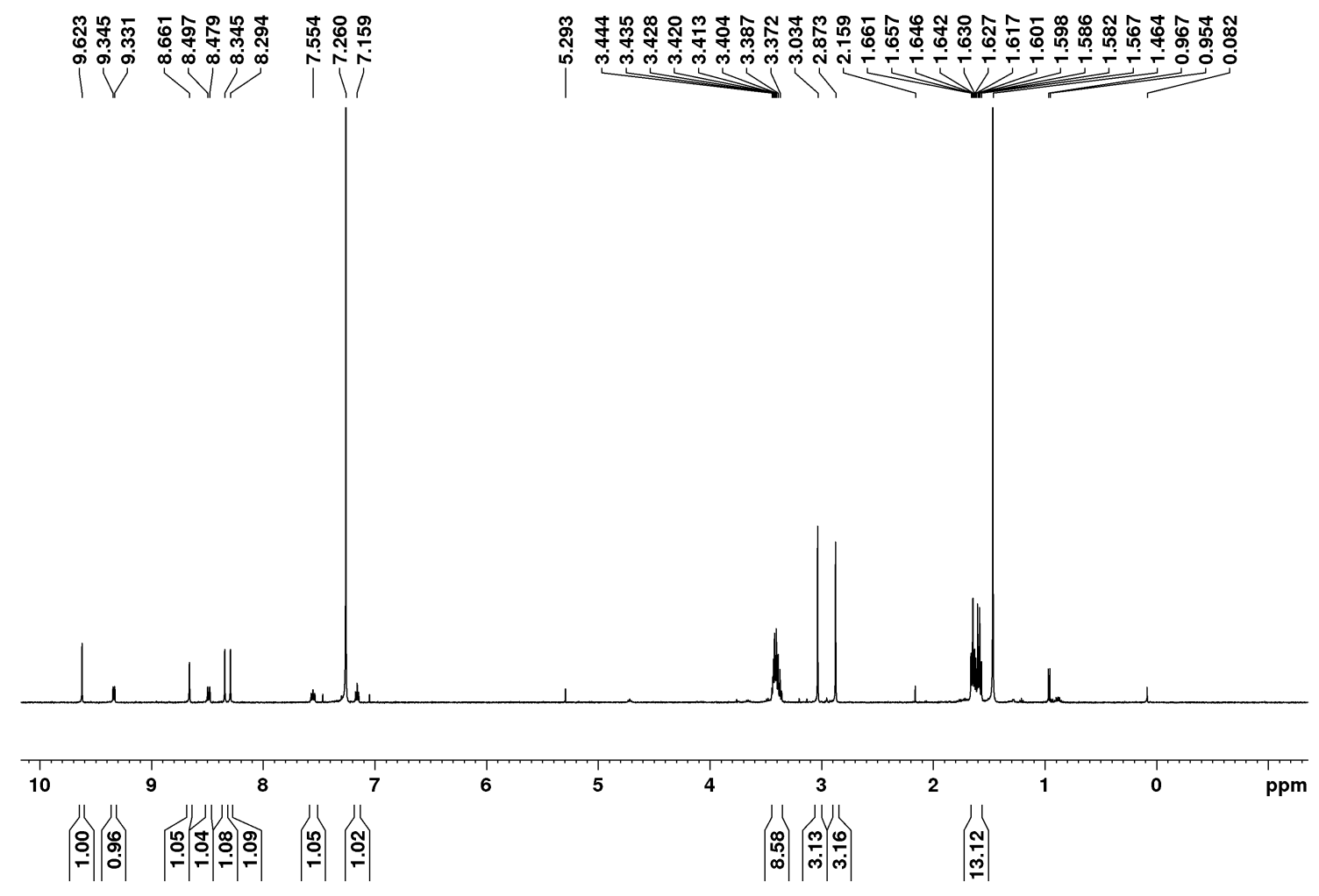

Figure A-22. $500 \mathrm{MHz}{ }^{1} \mathrm{HNMR}$ spectrum of palladium(II) complex $106 \mathbf{a}$ in $\mathrm{CHCl}_{3}$ 


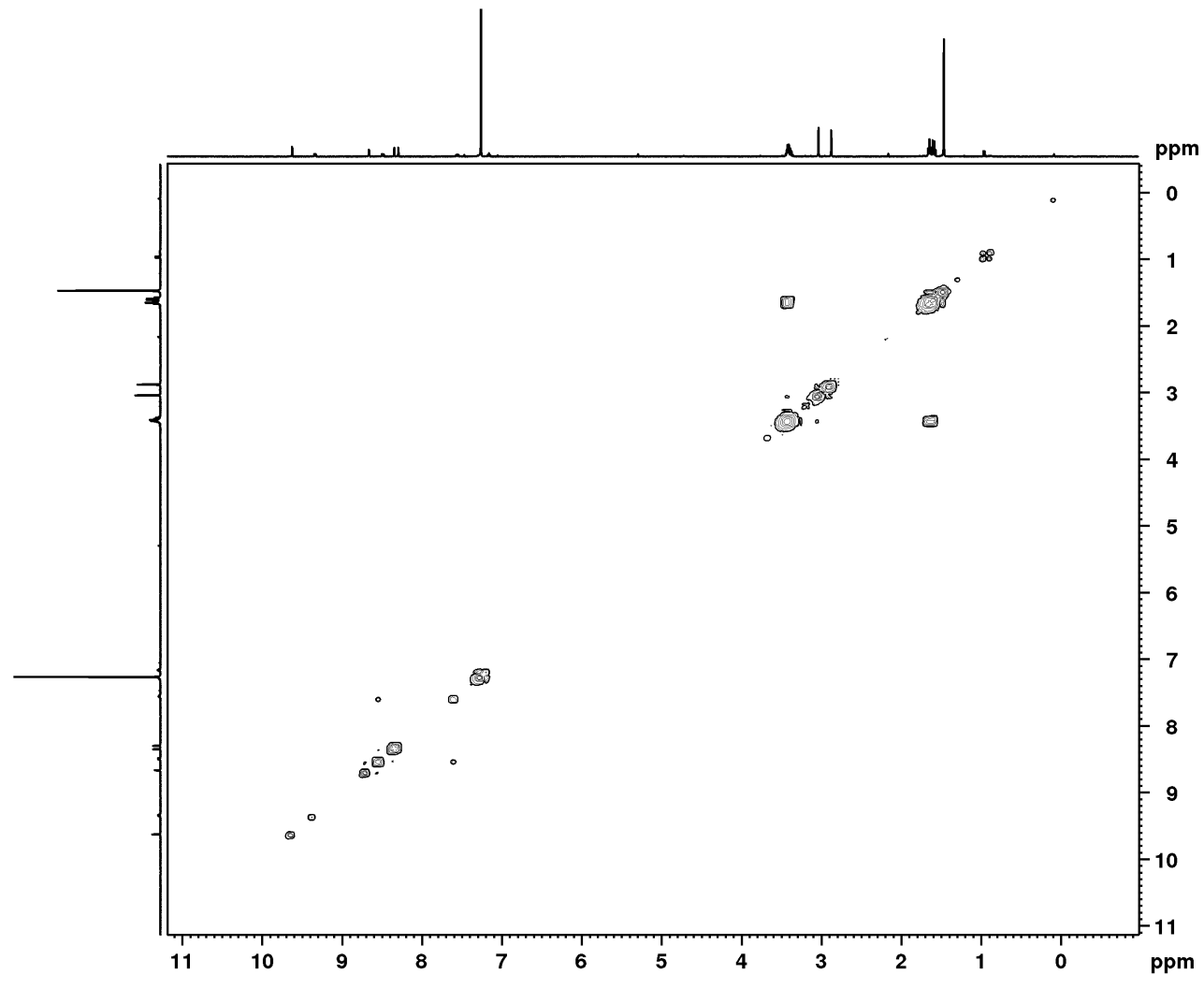

Figure A-23. ${ }^{1} \mathrm{H}-{ }^{1} \mathrm{H}$ COSY NMR spectrum of palladium(II) complex 106a in $\mathrm{CDCl}_{3}$ 


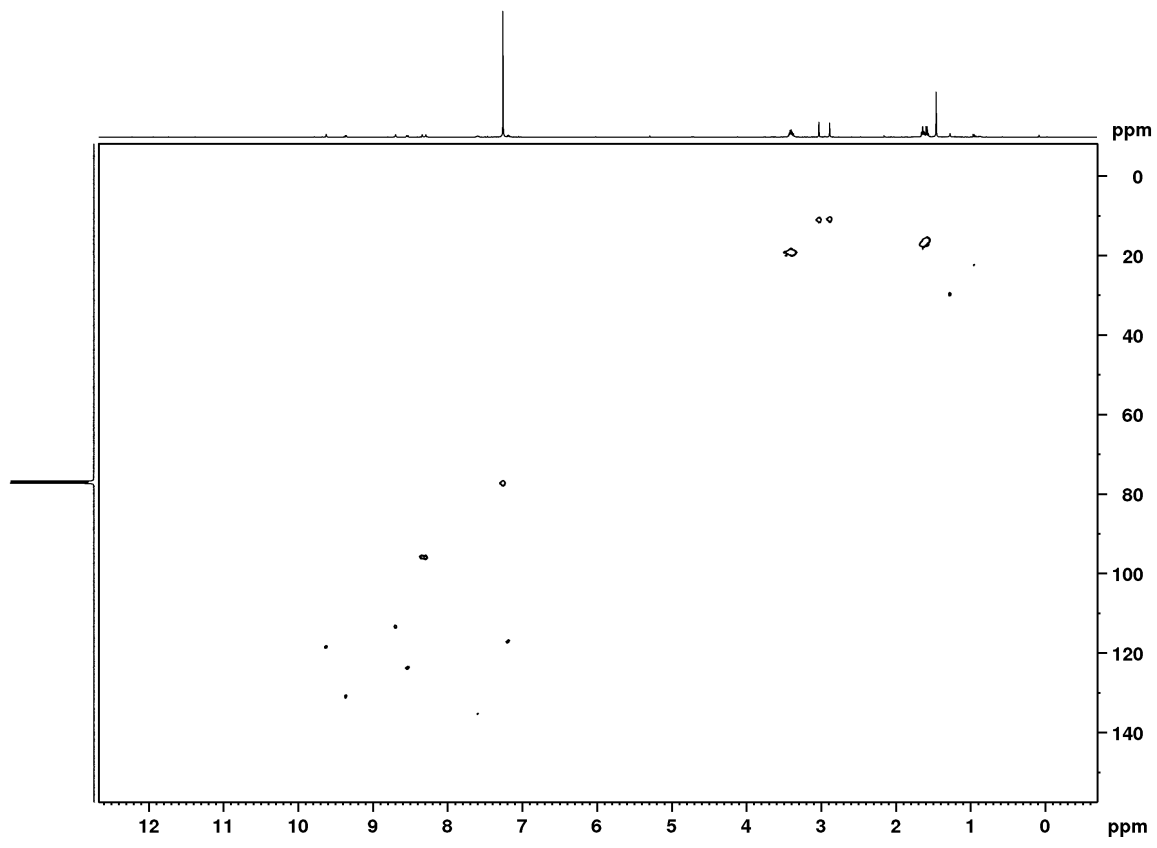

Figure A-24. HSQC NMR spectrum of palladium(II) complex 106a in $\mathrm{CDCl}_{3}$

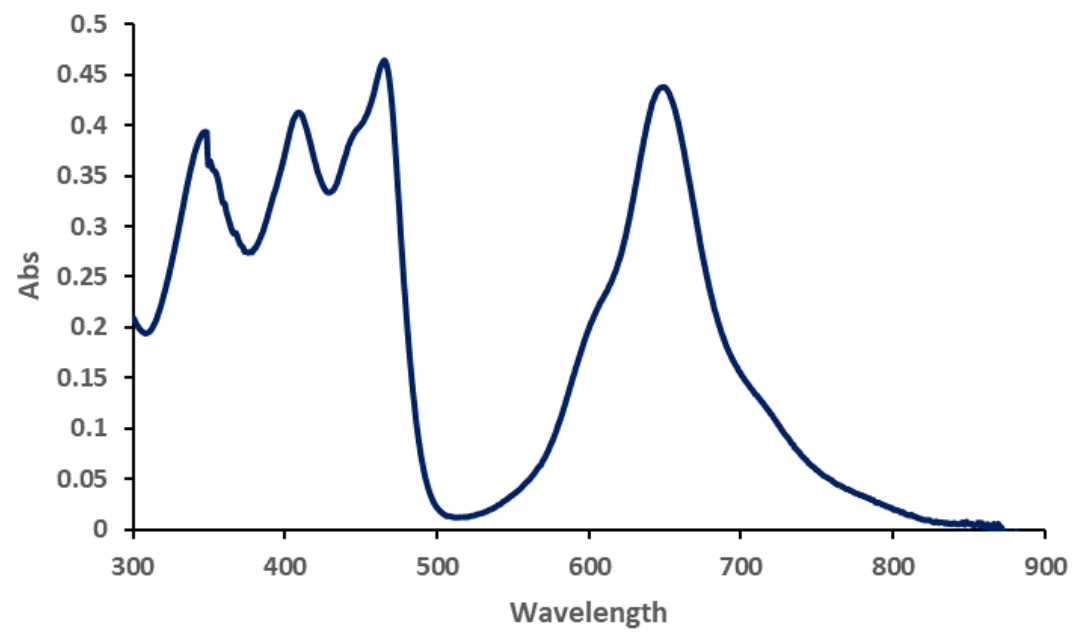

Figure A-25. UV-Vis Spectra of palladium(II) complex 106a in $\mathrm{CH}_{2} \mathrm{Cl}_{2}$ 


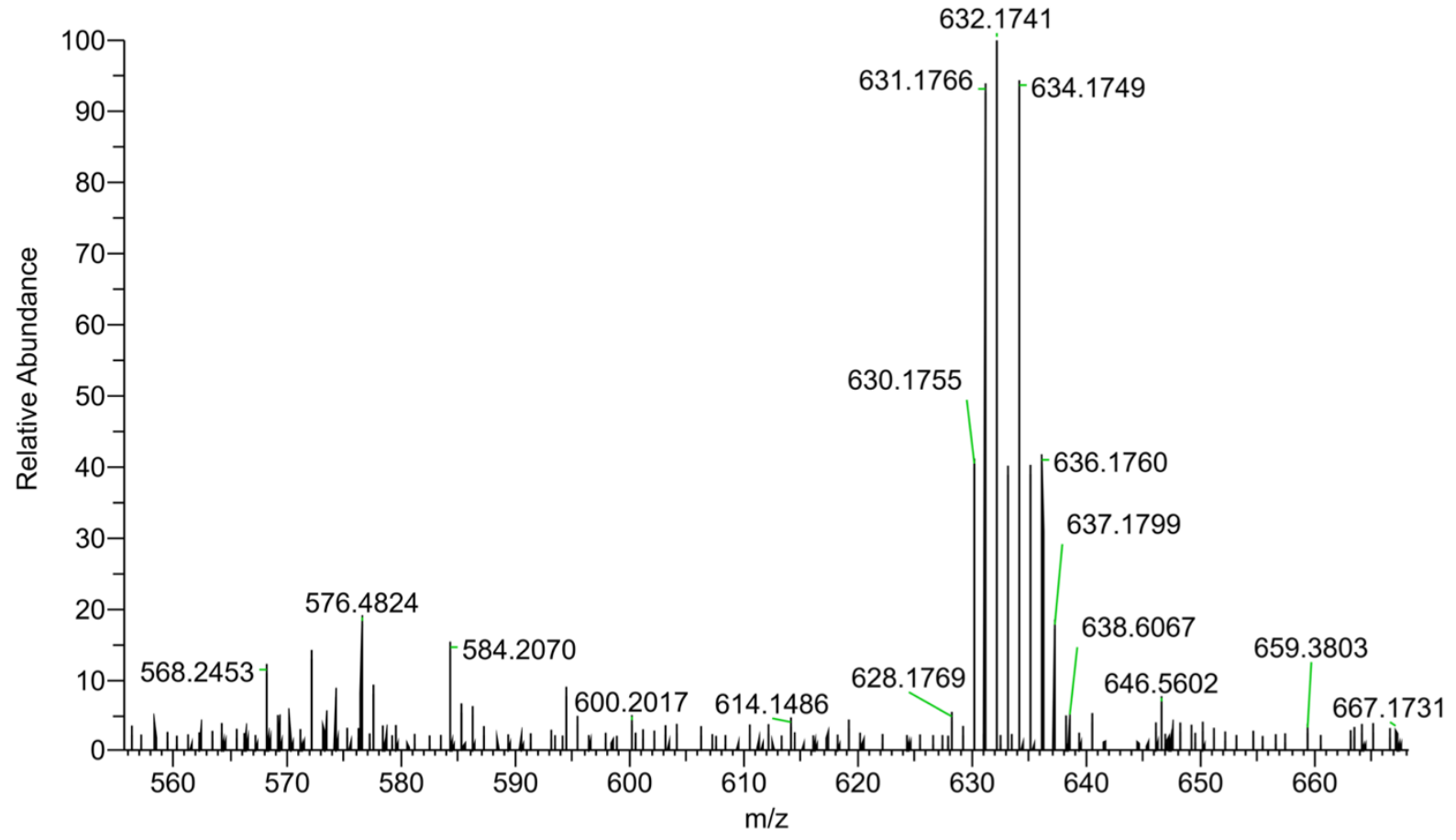

Figure A-26. ESI Mass spectrum of palladium(II) complex $\mathbf{1 0 6 a}$ in $\mathrm{CHCl}_{3}$ 


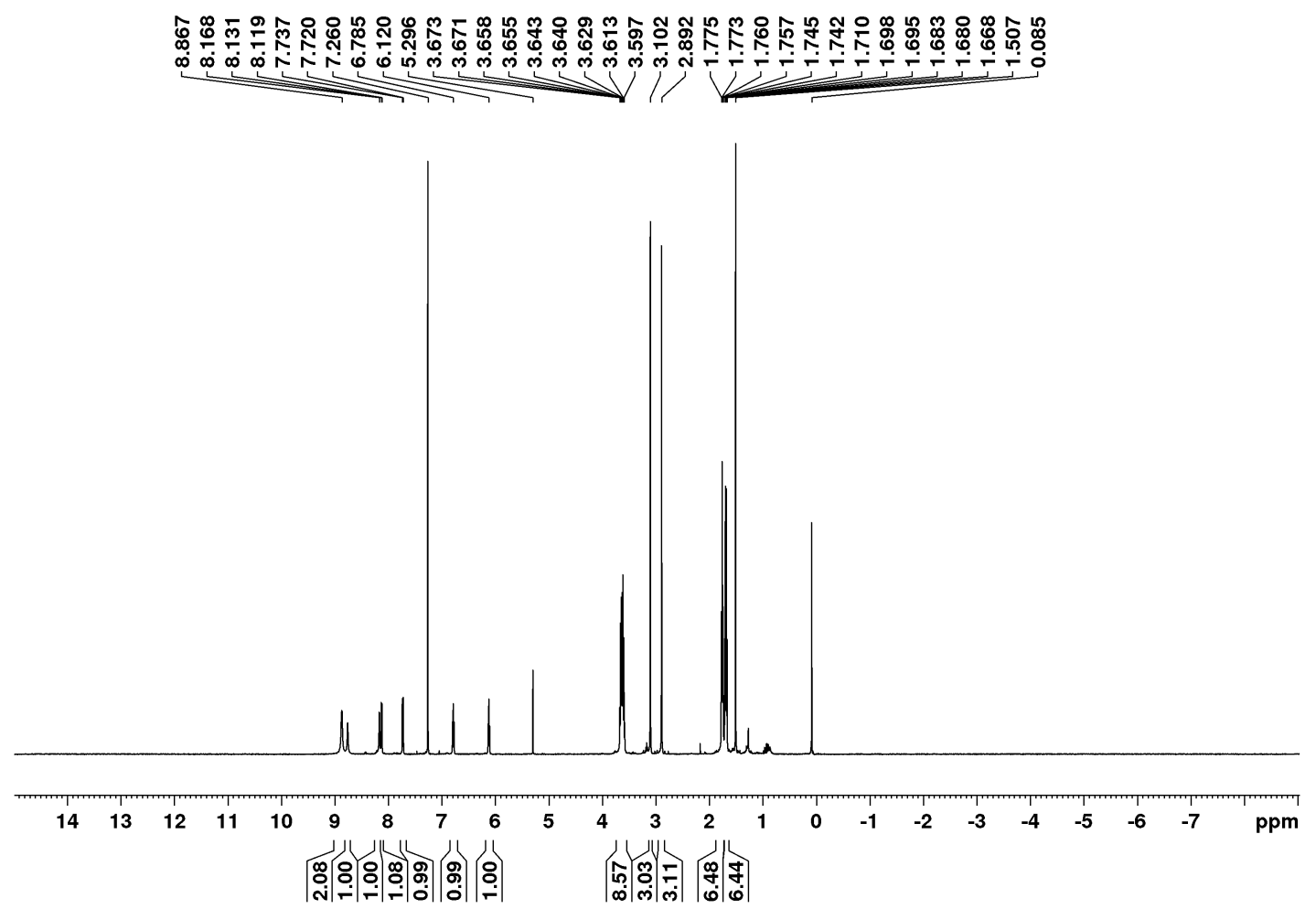

Figure A-27. $500 \mathrm{MHz}{ }^{1} \mathrm{H}$ NMR spectrum of nickel(II) complex 107a in $\mathrm{CHCl}_{3}$ 


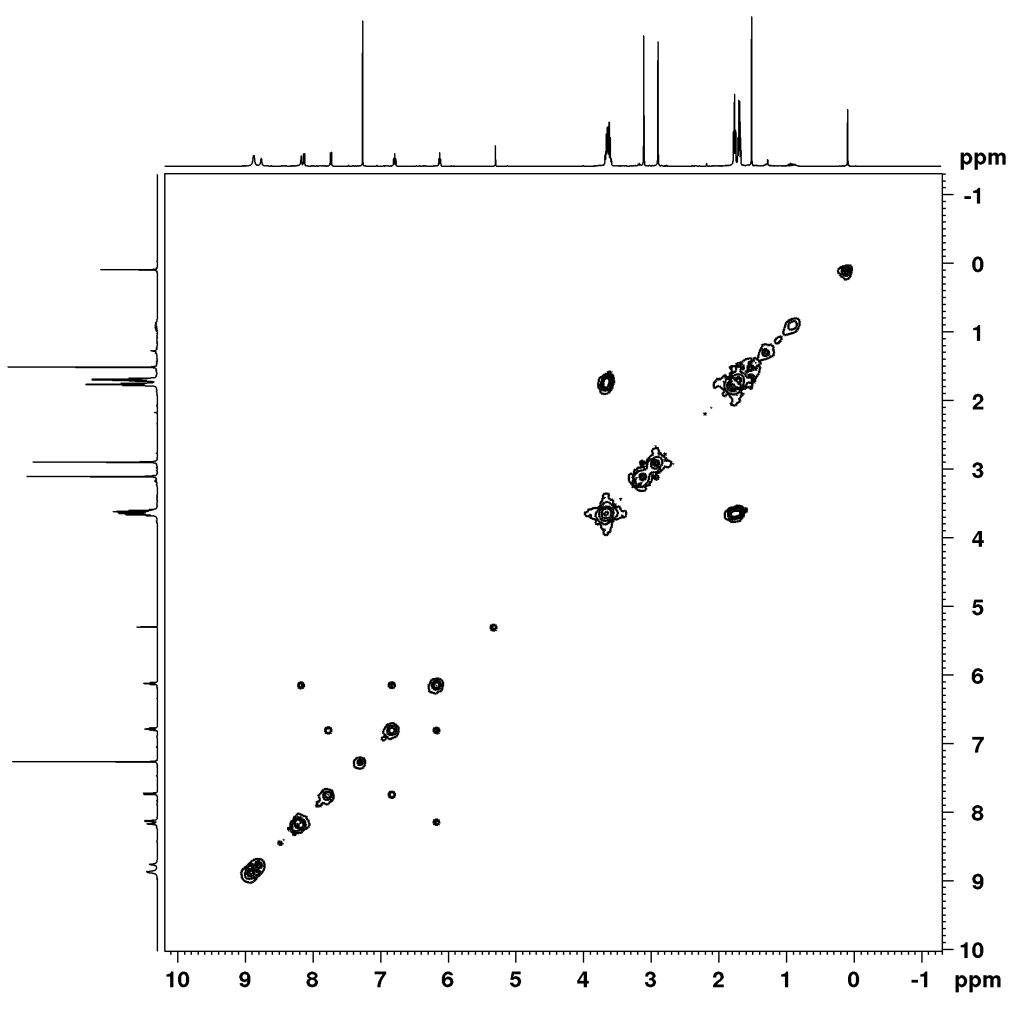

Figure A-28. ${ }^{1} \mathrm{H}-{ }^{1} \mathrm{H}$ COSY NMR spectrum of nickel(II) complex $107 \mathbf{a}$ in $\mathrm{CDCl}_{3}$ 

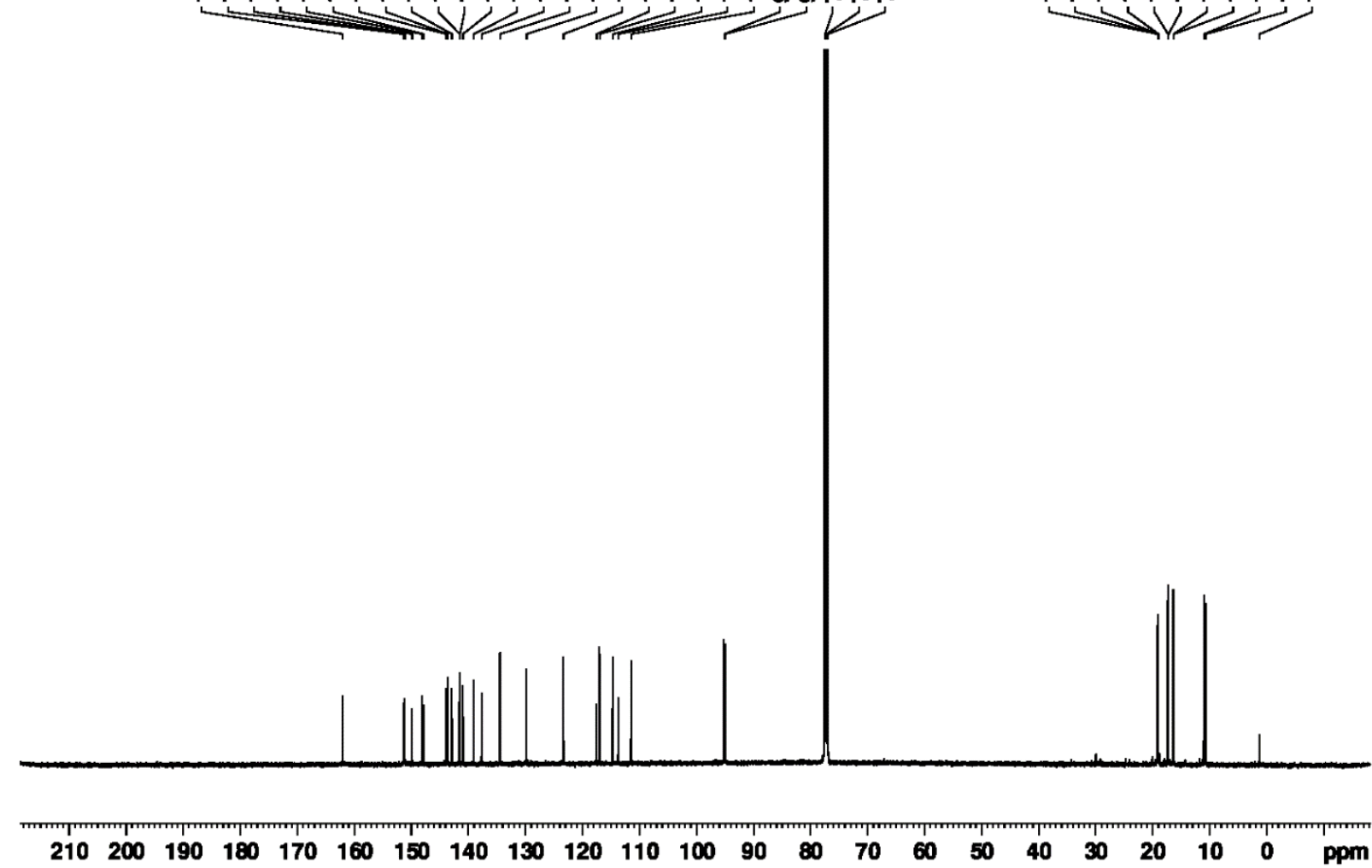

Figure A-29. $125 \mathrm{MHz}{ }^{13} \mathrm{C}$ NMR spectrum of nickel(II) complex 107a in $\mathrm{CDCl}_{3}$ 


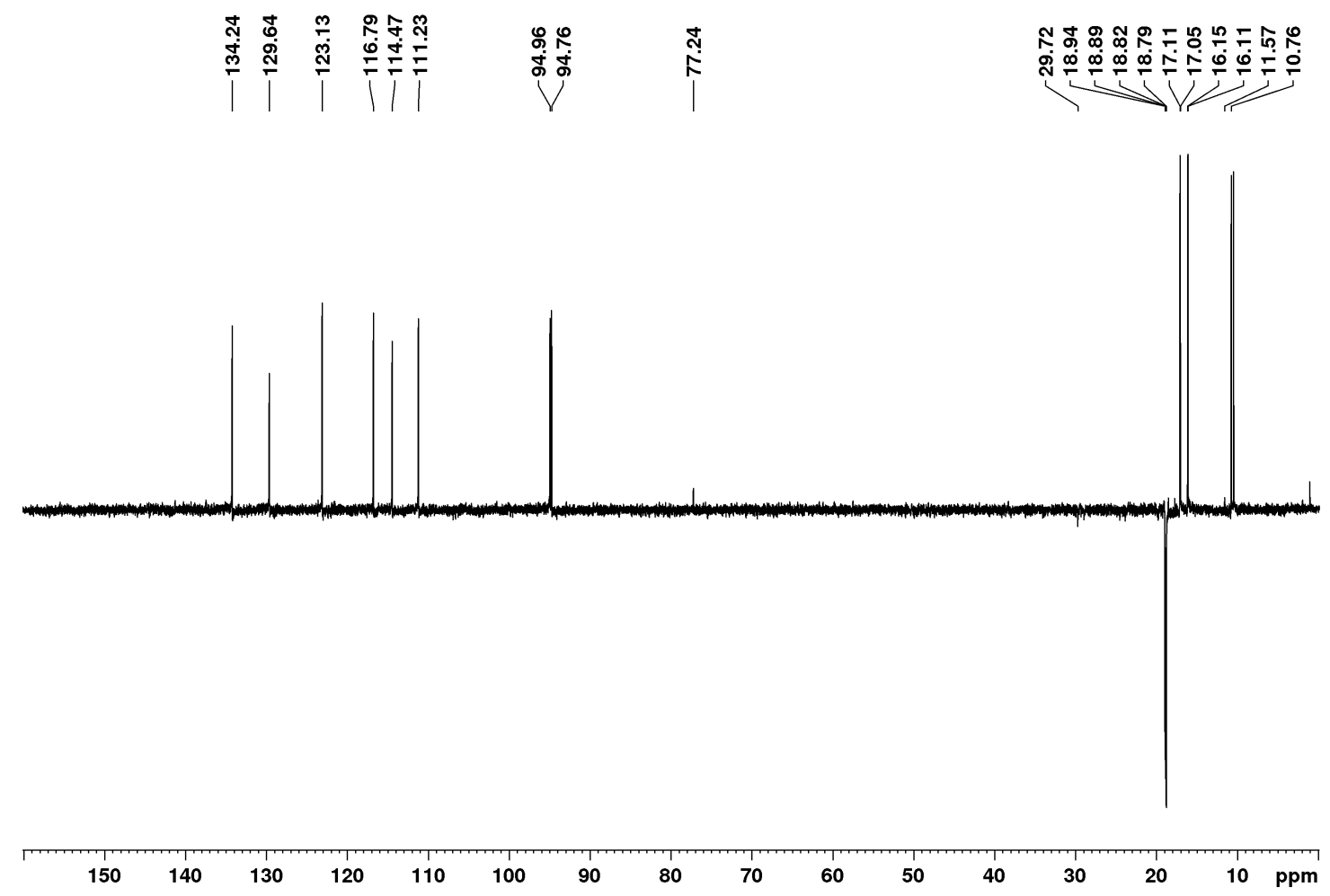

Figure A-30. DEPT-135 NMR spectrum of nickel(II) complex 107a in $\mathrm{CDCl}_{3}$ 


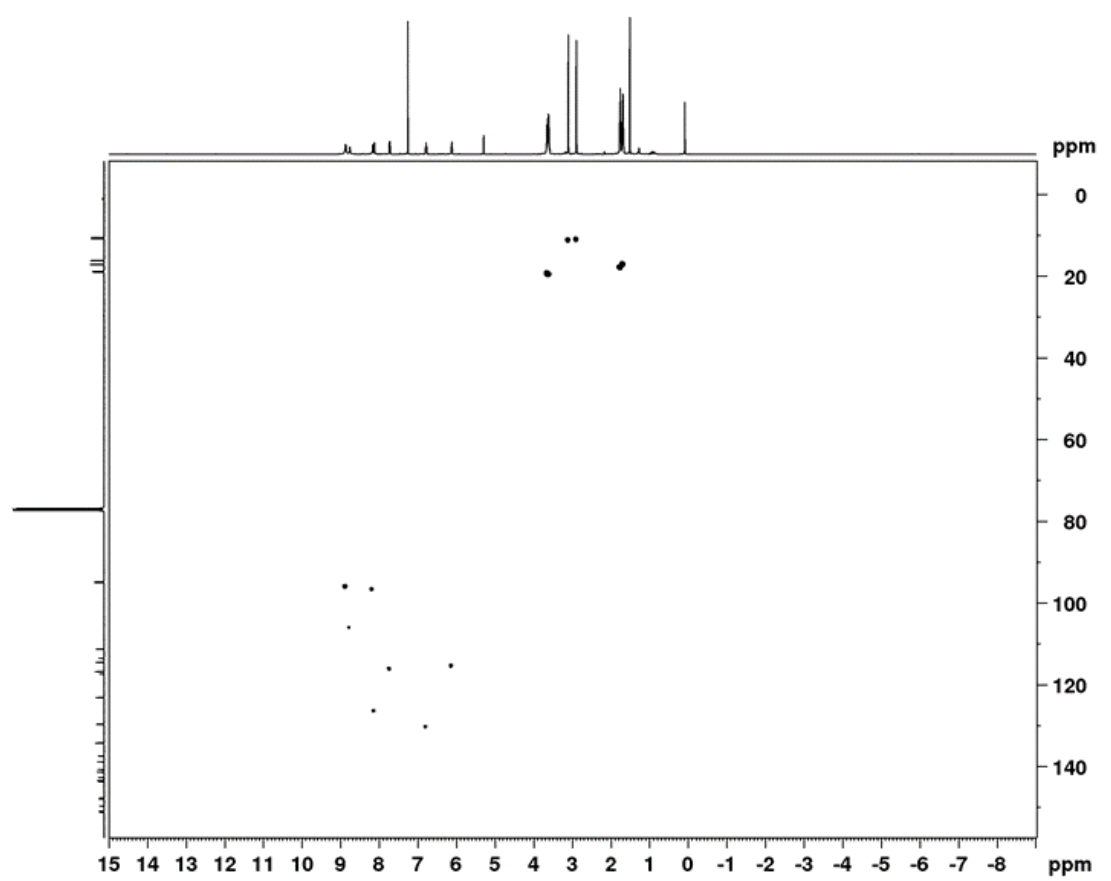

Figure A-31. HSQC NMR spectrum of nickel(II) complex 107a in $\mathrm{CDCl}_{3}$

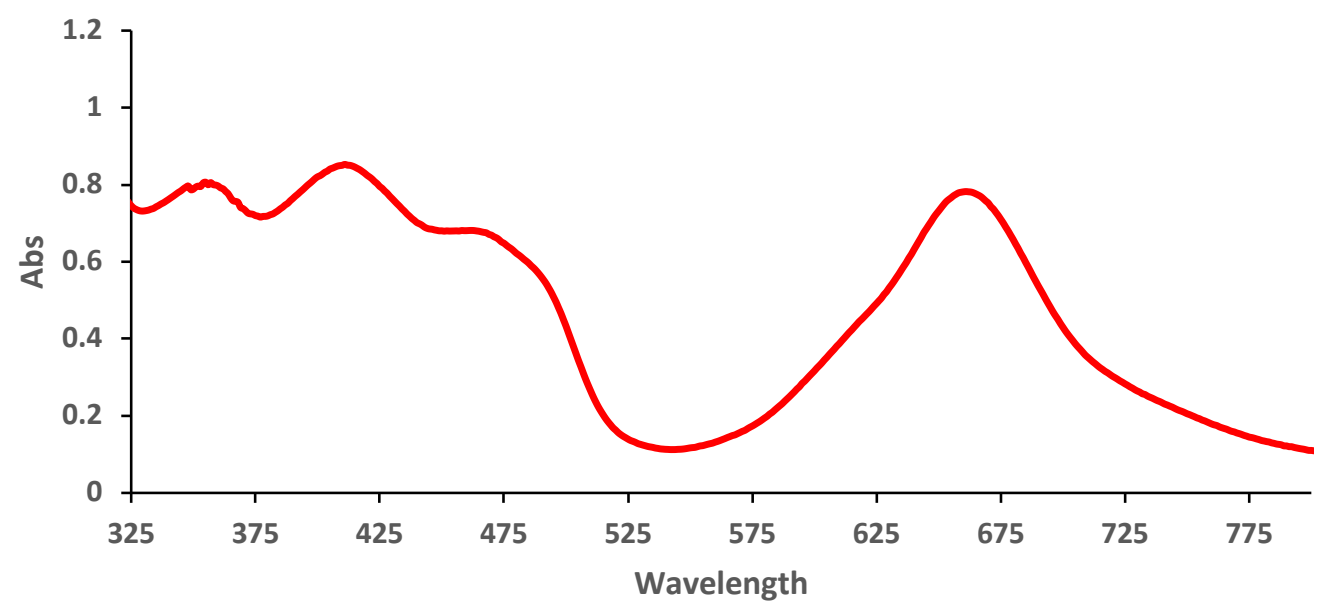

Figure A-32. UV-Vis Spectrum of nickel(II) complex 107a in $\mathrm{CH}_{2} \mathrm{Cl}_{2}$ 


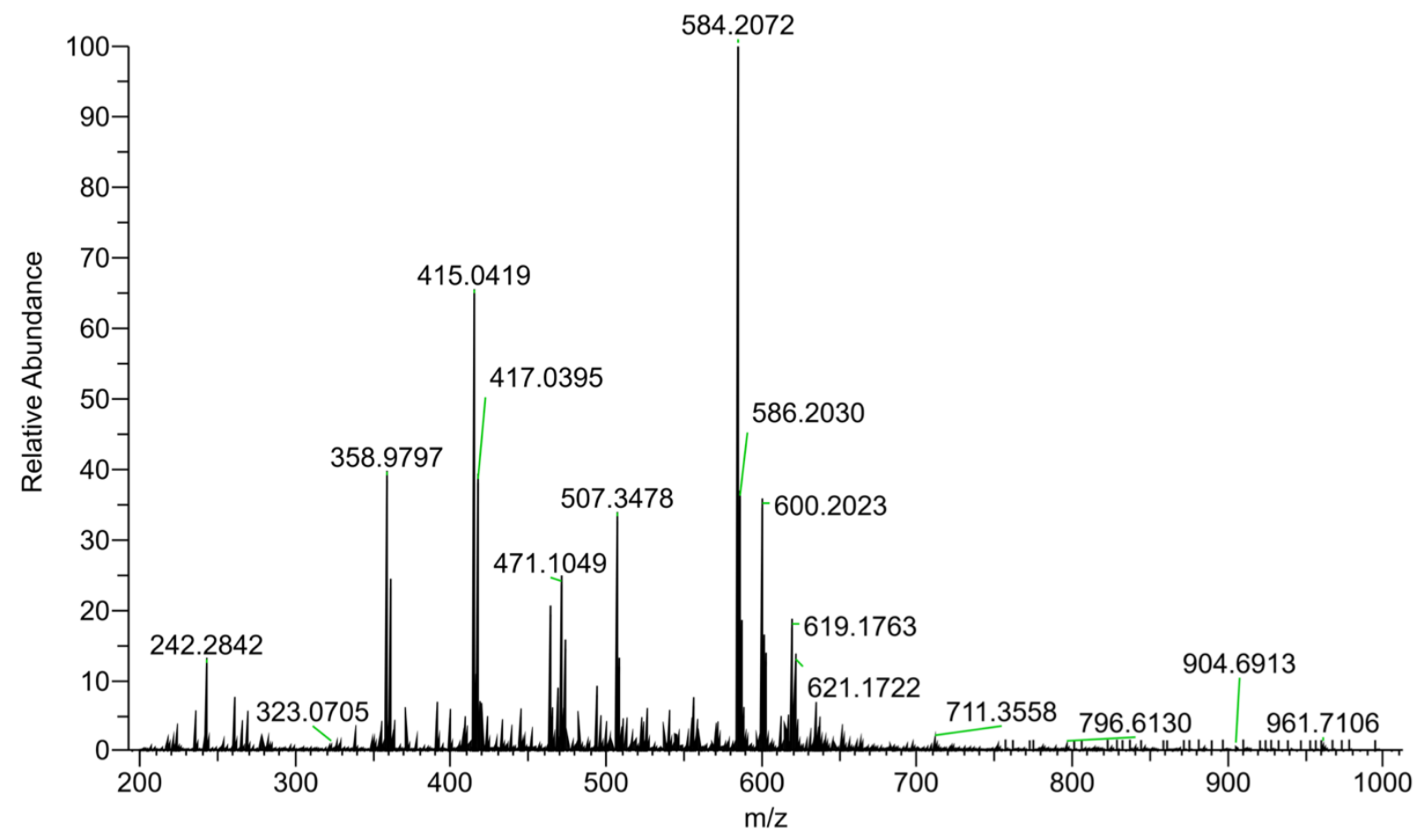

Figure A-33. ESI Mass spectrum of nickel (II) complex 107a in $\mathrm{CDCl}_{3}$ 


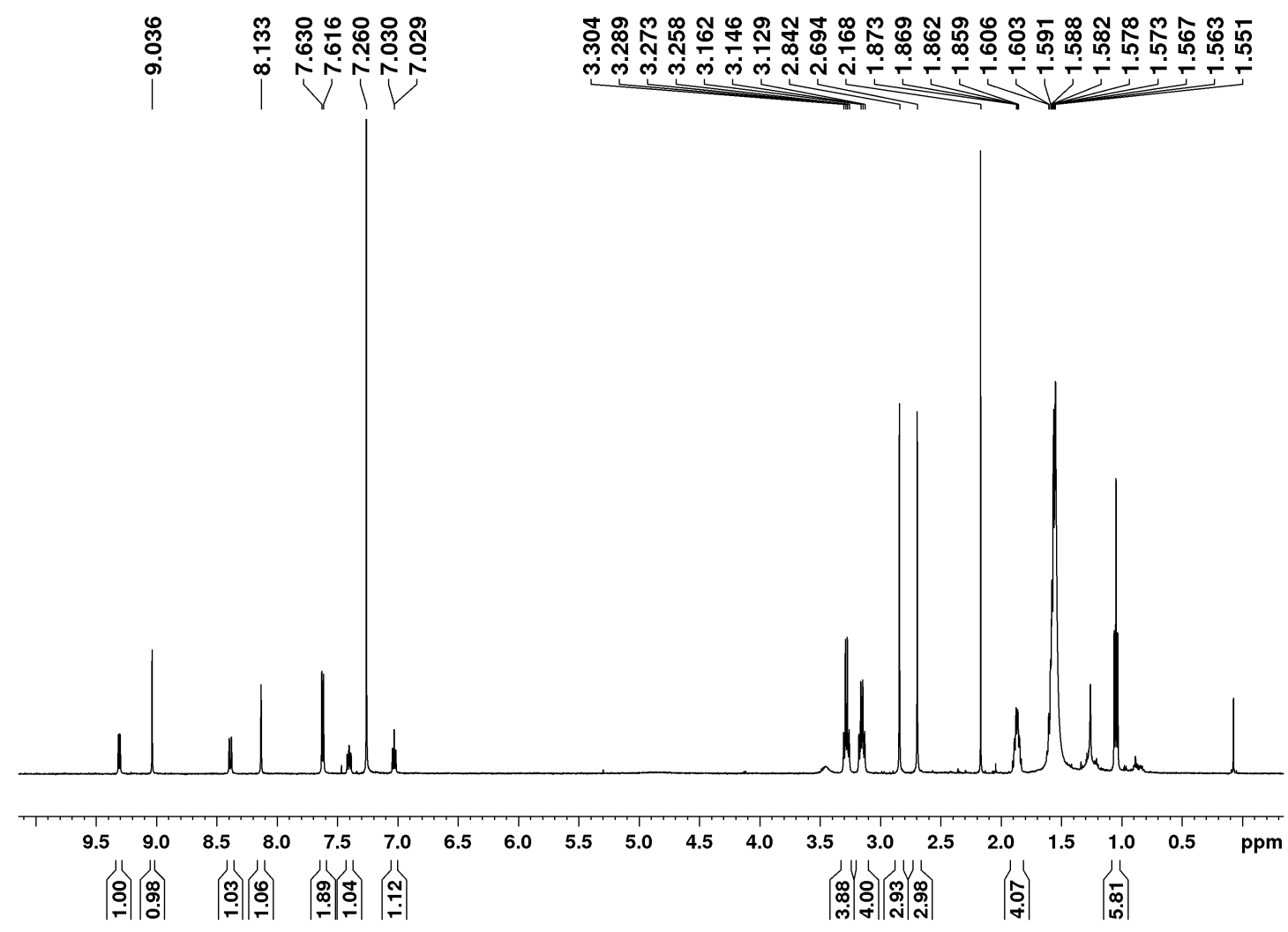

Figure A-34. $500 \mathrm{MHz}{ }^{1} \mathrm{H}$ NMR spectrum of oxyquinioliziniporphyrin 84b in $\mathrm{CDCl}_{3}$ 


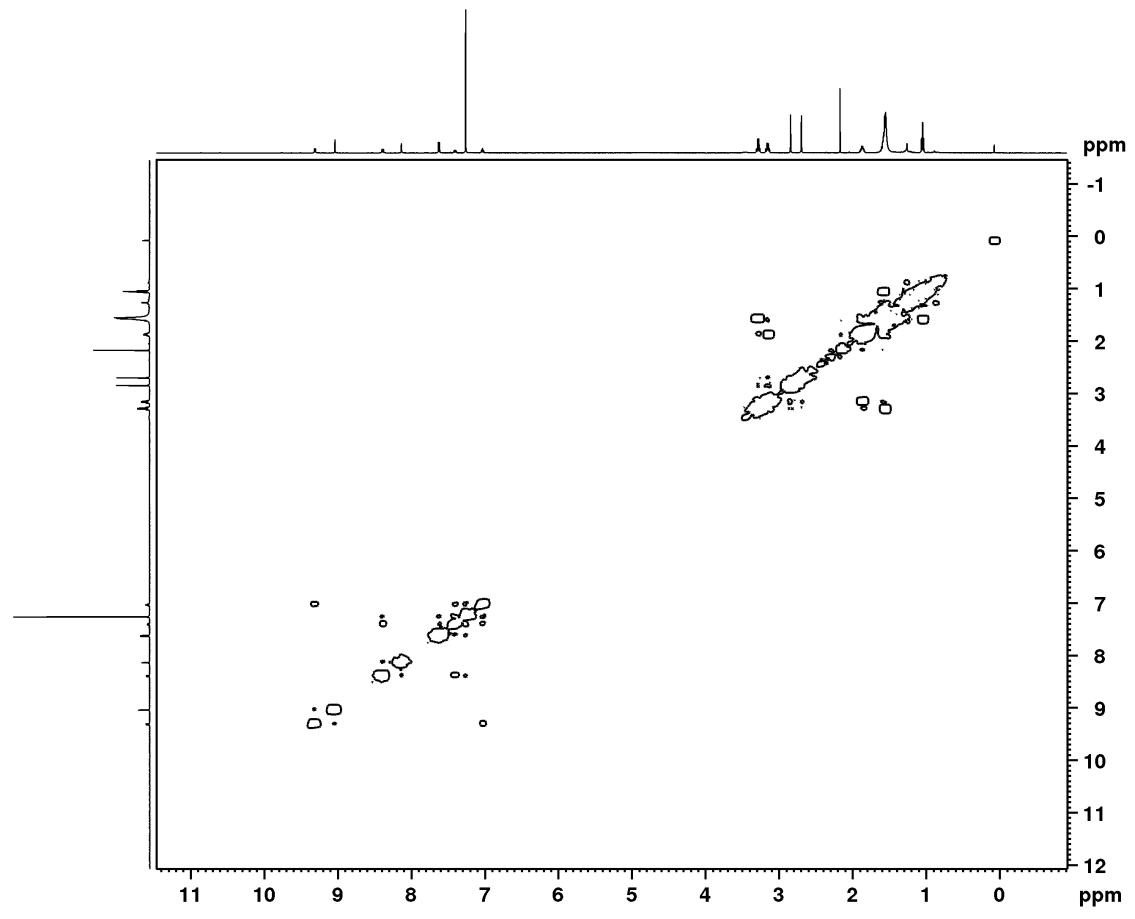

Figure A-35. ${ }^{1} \mathrm{H}-{ }^{1} \mathrm{H}$ COSY NMR spectrum of oxyquinoliziniporphyrin $\mathbf{8 4} \mathbf{b}$ in $\mathrm{CDCl}_{3}$ 


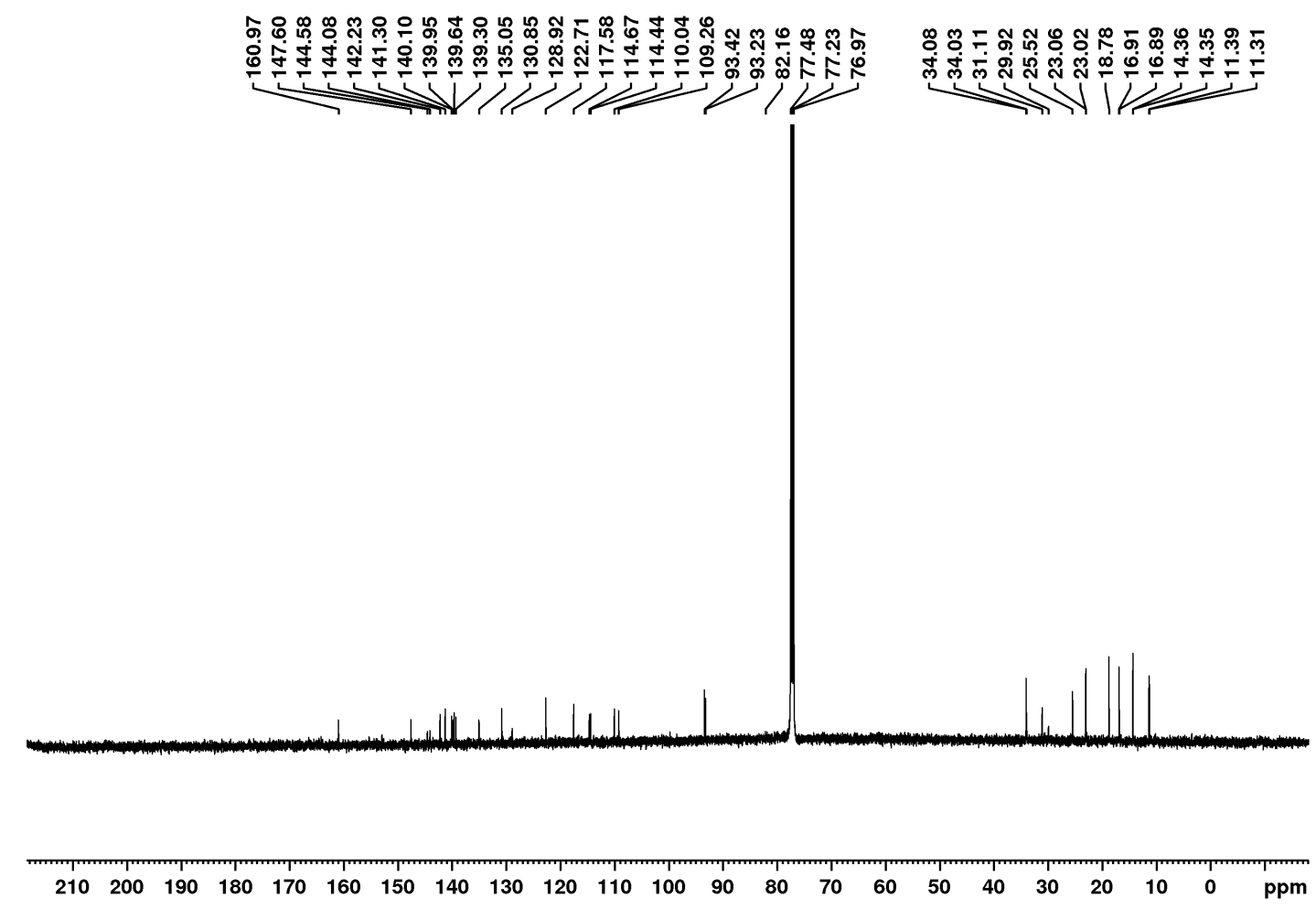

Figure A-36. $125 \mathrm{MHz}{ }^{13} \mathrm{C}$ NMR spectrum of oxyquinoliziniporphyrin $\mathbf{8 4 b}$ in $\mathrm{CDCl}_{3}$ 


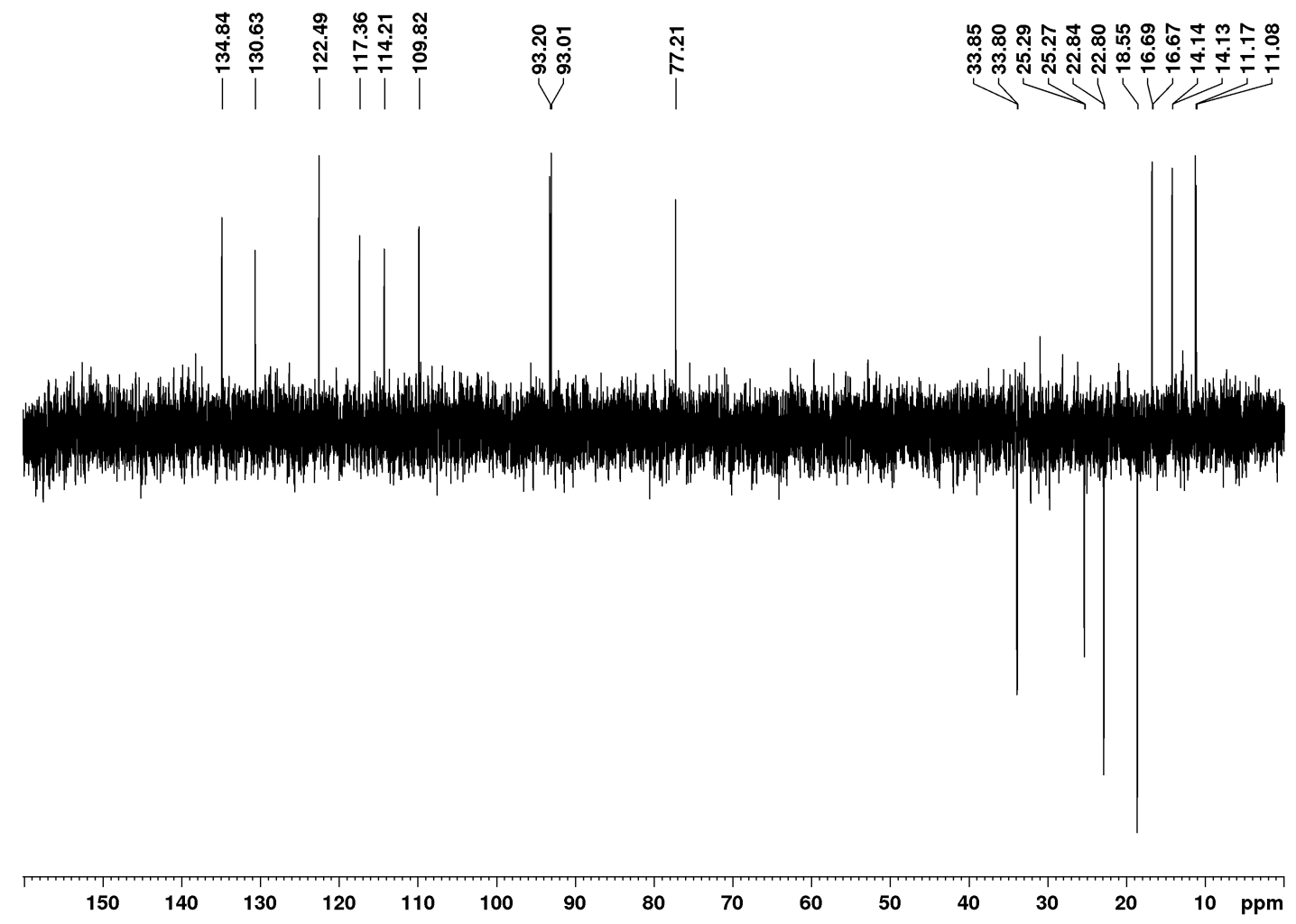

Figure A-37. DEPT-135 NMR spectrum of oxyquinoliziniporphyrin 84b in $\mathrm{CDCl}_{3}$ 


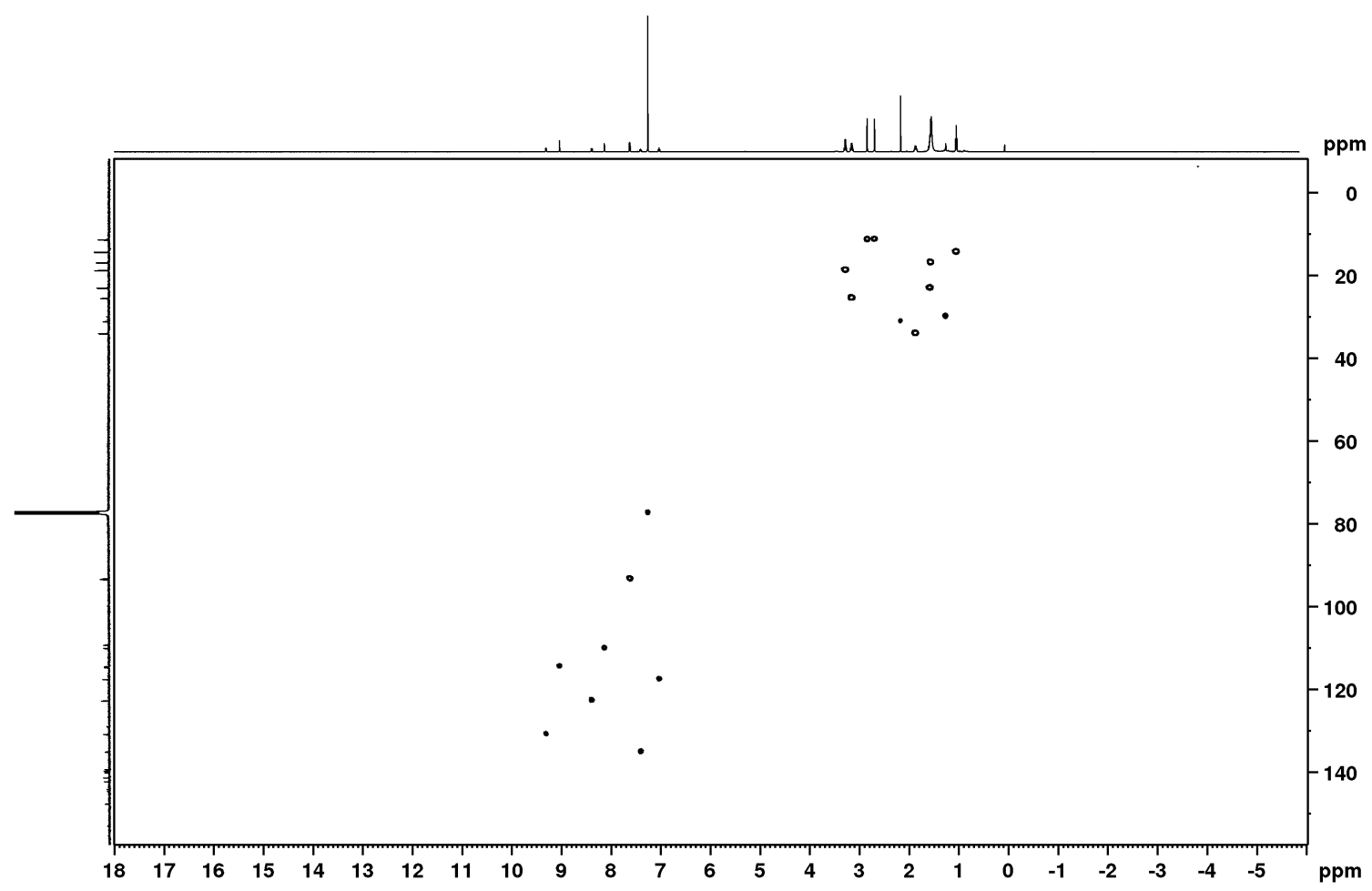

Figure A-38. HSQC NMR spectrum of oxyquinoliziniporphyrin 84b in $\mathrm{CDCl}_{3}$ 


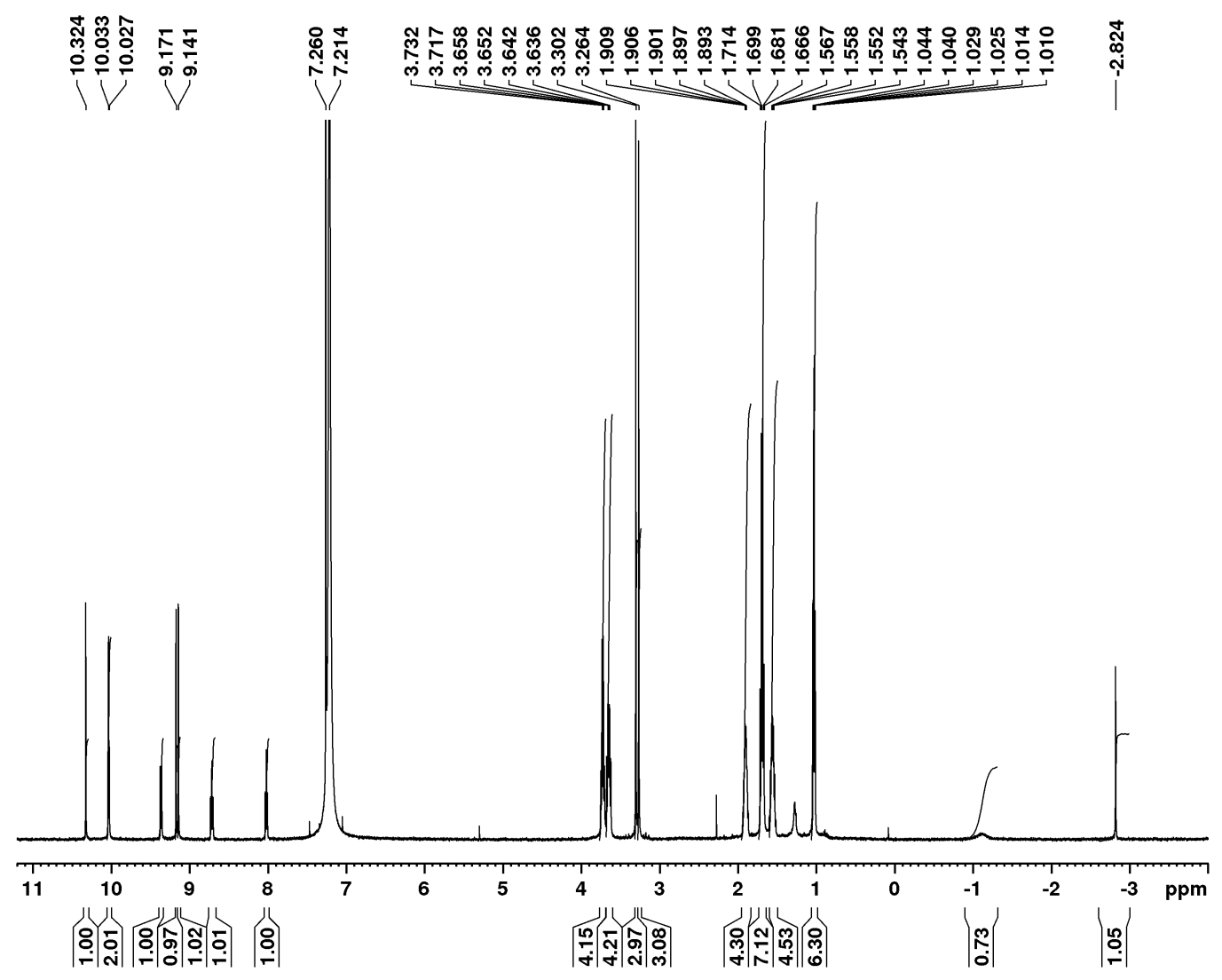

Figure A-39. $500 \mathrm{MHz}{ }^{1} \mathrm{H}$ NMR spectrum of oxyquinoliziniporphyrin 84b in $\mathrm{CDCl}_{3}$-TFA 


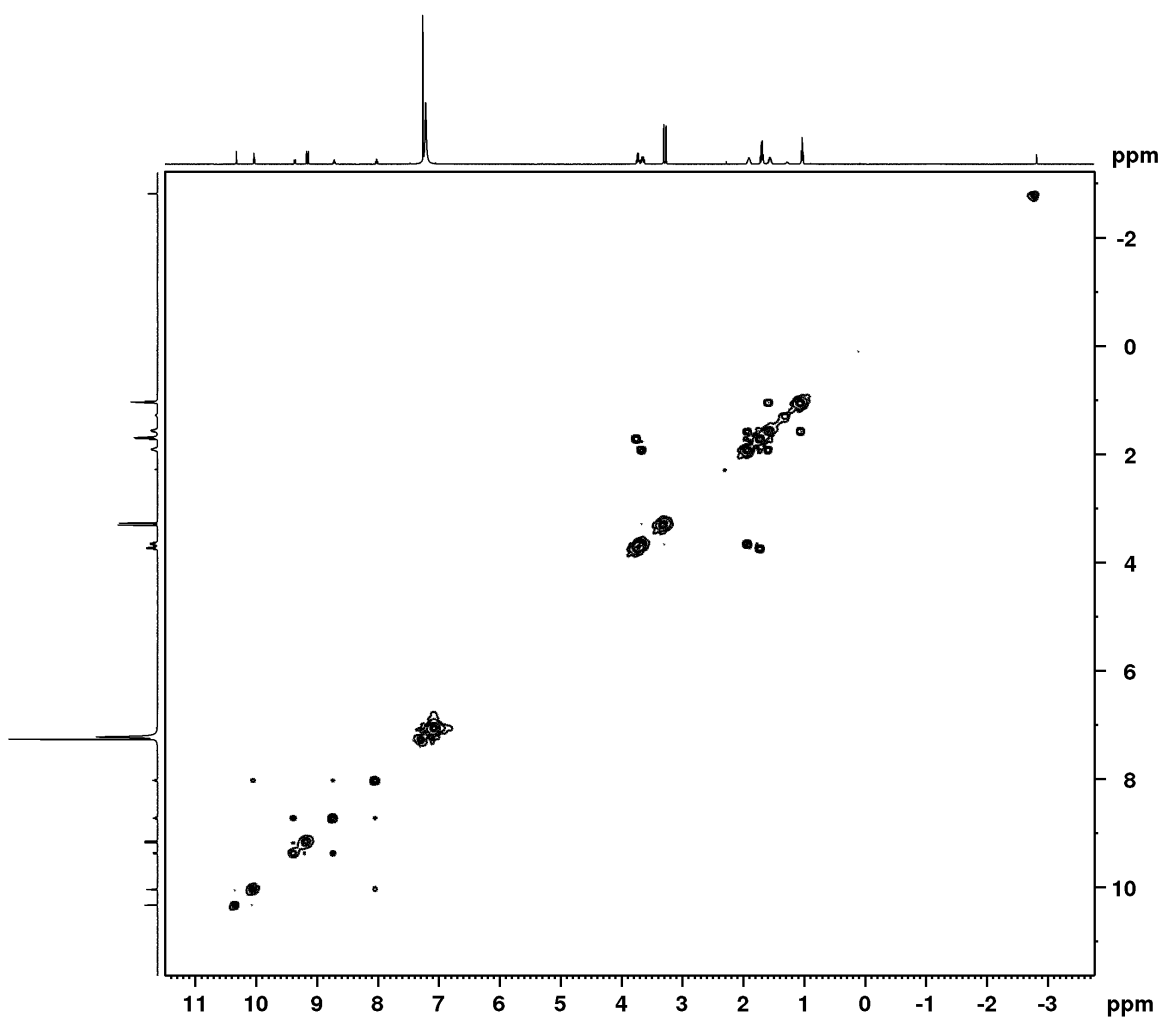

Figure A-40. ${ }^{1} \mathrm{H}-{ }^{1} \mathrm{H}$ COSY NMR spectrum of oxyquinoliziniporphyrin $84 \mathbf{b}$ in $\mathrm{CDCl}_{3}-\mathrm{TFA}$ 


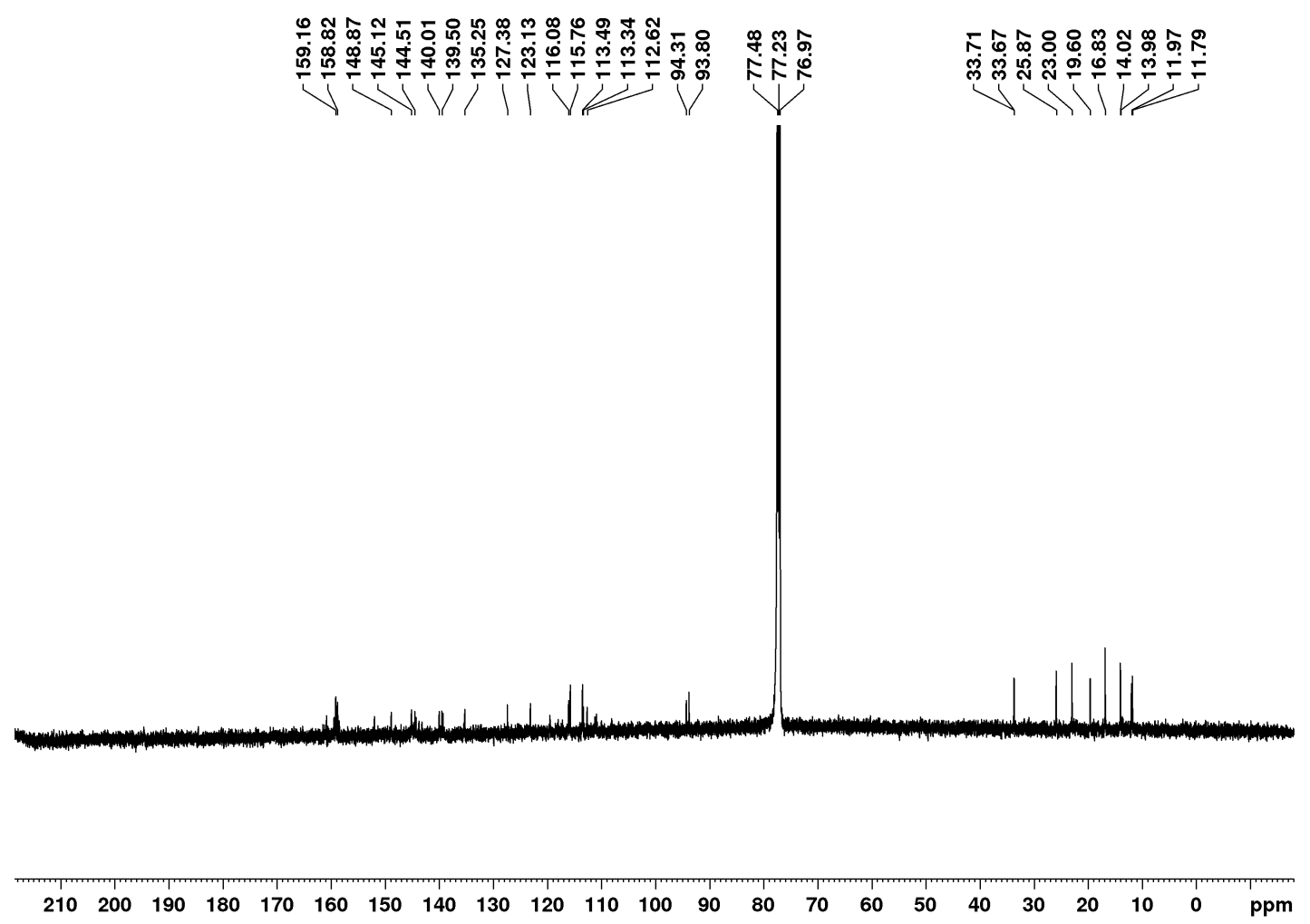

Figure A-41. $125 \mathrm{MHz}{ }^{13} \mathrm{C}$ NMR spectrum of oxyquinoliziniporphyrin $\mathbf{8 4 b}$ in $\mathrm{CDCl}_{3}-\mathrm{TFA}$ 


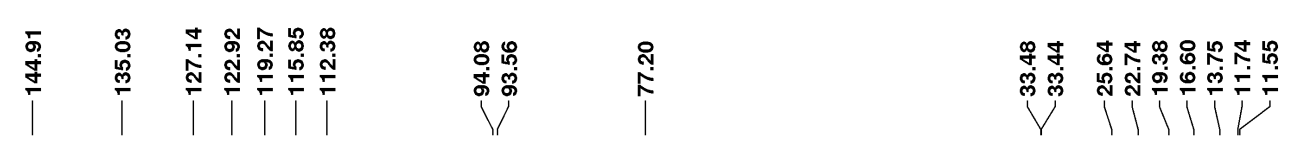

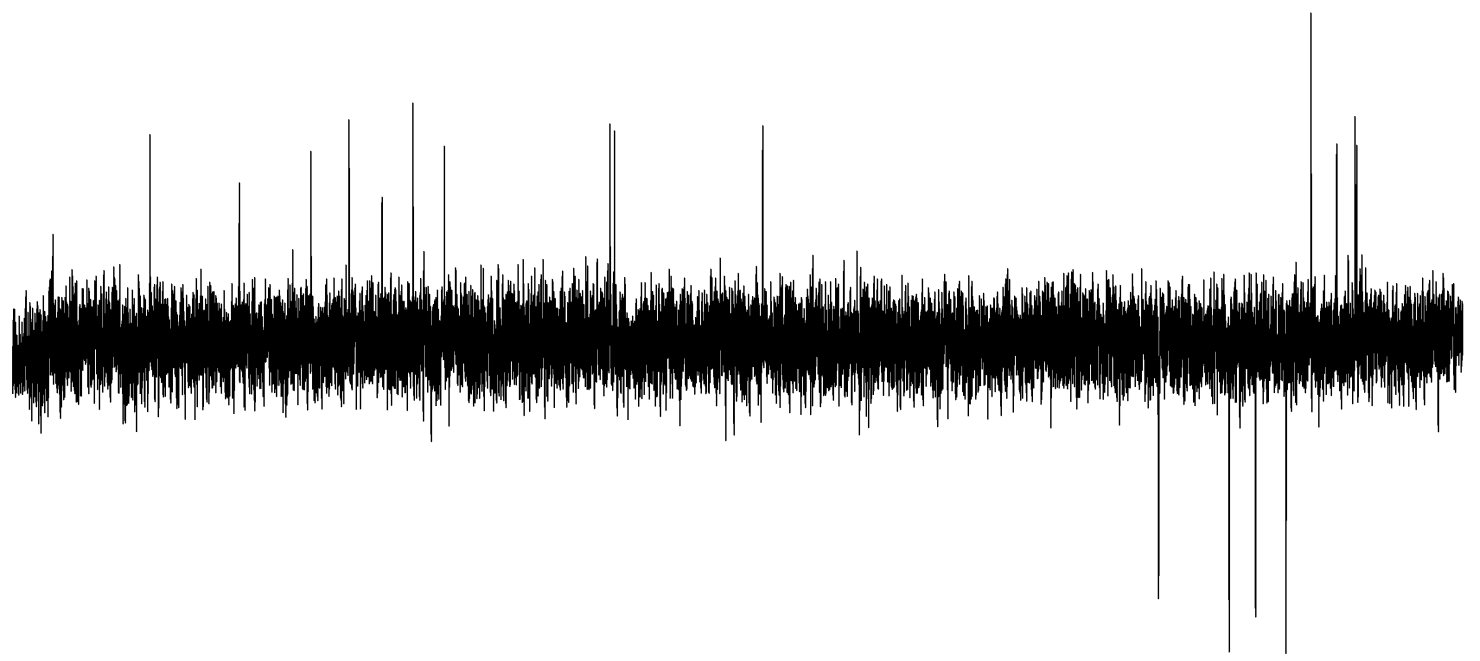

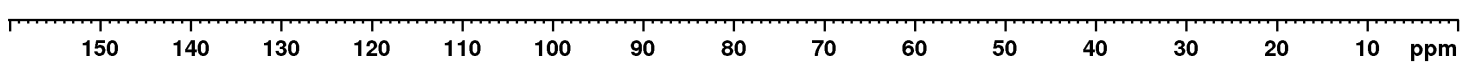

Figure A-42. DEPT-135 NMR spectrum of oxyquinoliziniporphyrin $\mathbf{8 4 b}$ in $\mathrm{CDCl}_{3}$-TFA 


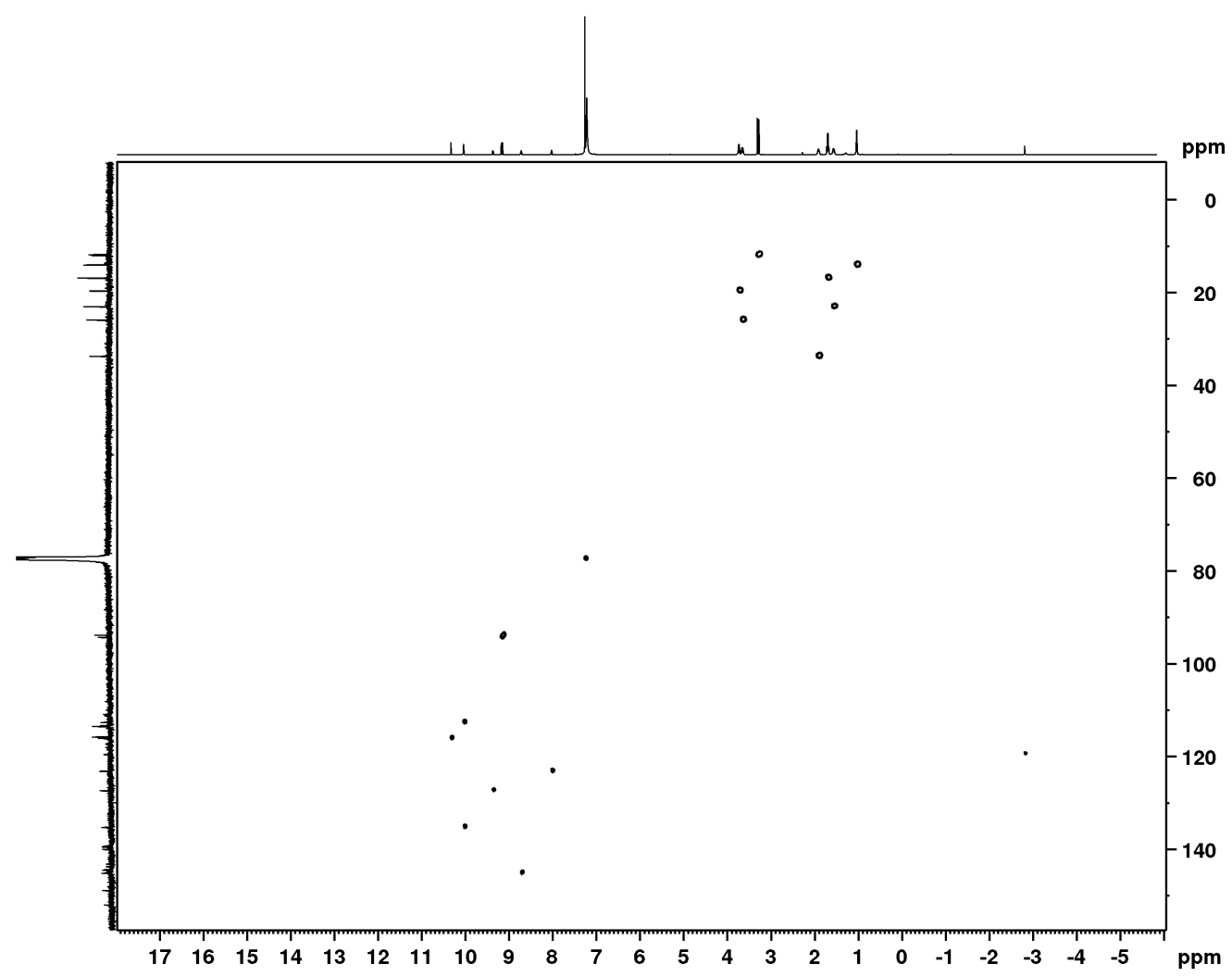

Figure A-43. HSQC NMR spectrum of oxyquinoliziniporphyrin 84b in $\mathrm{CDCl}_{3}$-TFA 


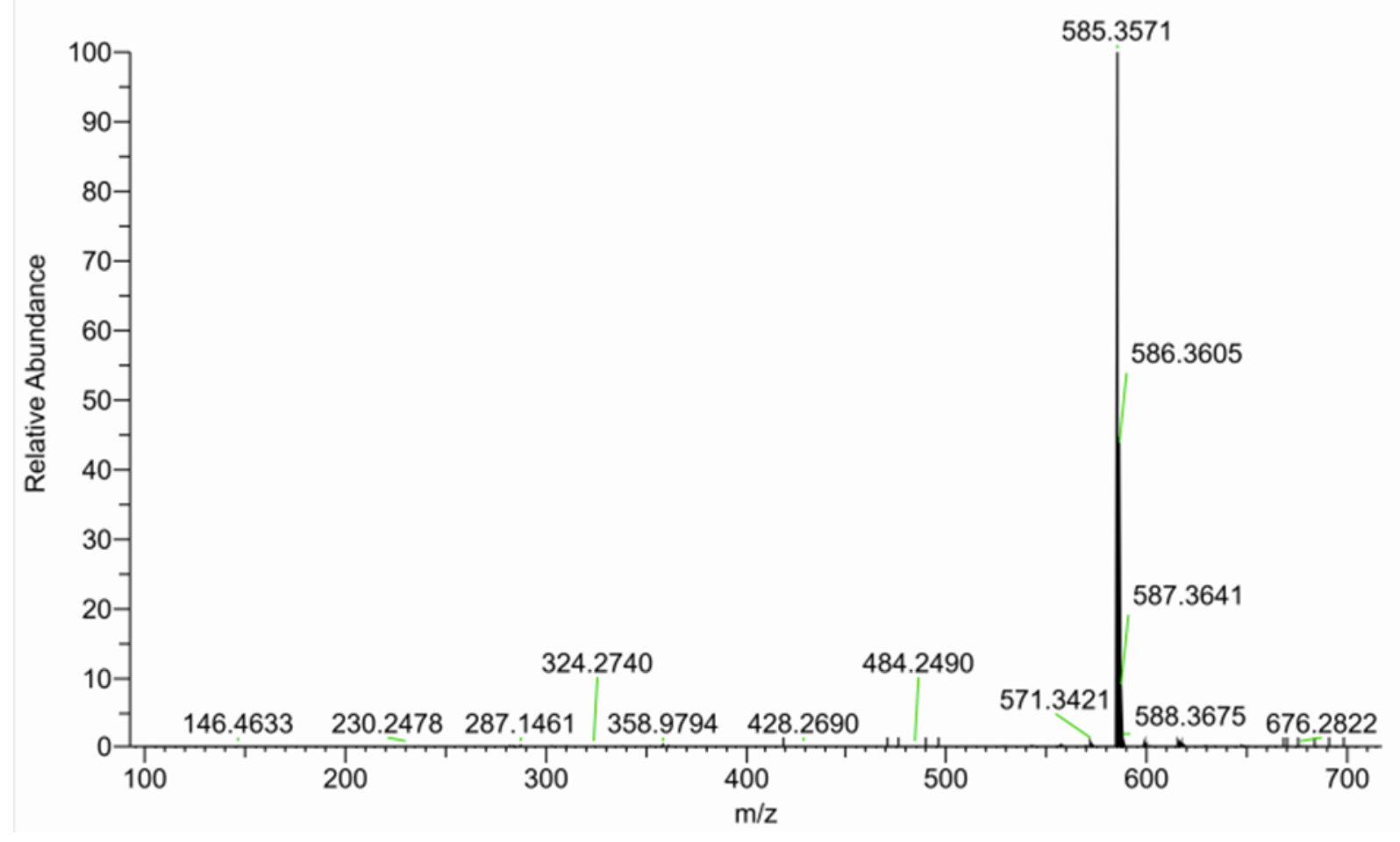

Figure A-44. ESI Mass Spectrum of oxyquinoliziniporphyrin 84b porph $\mathrm{CHCl}_{3}$

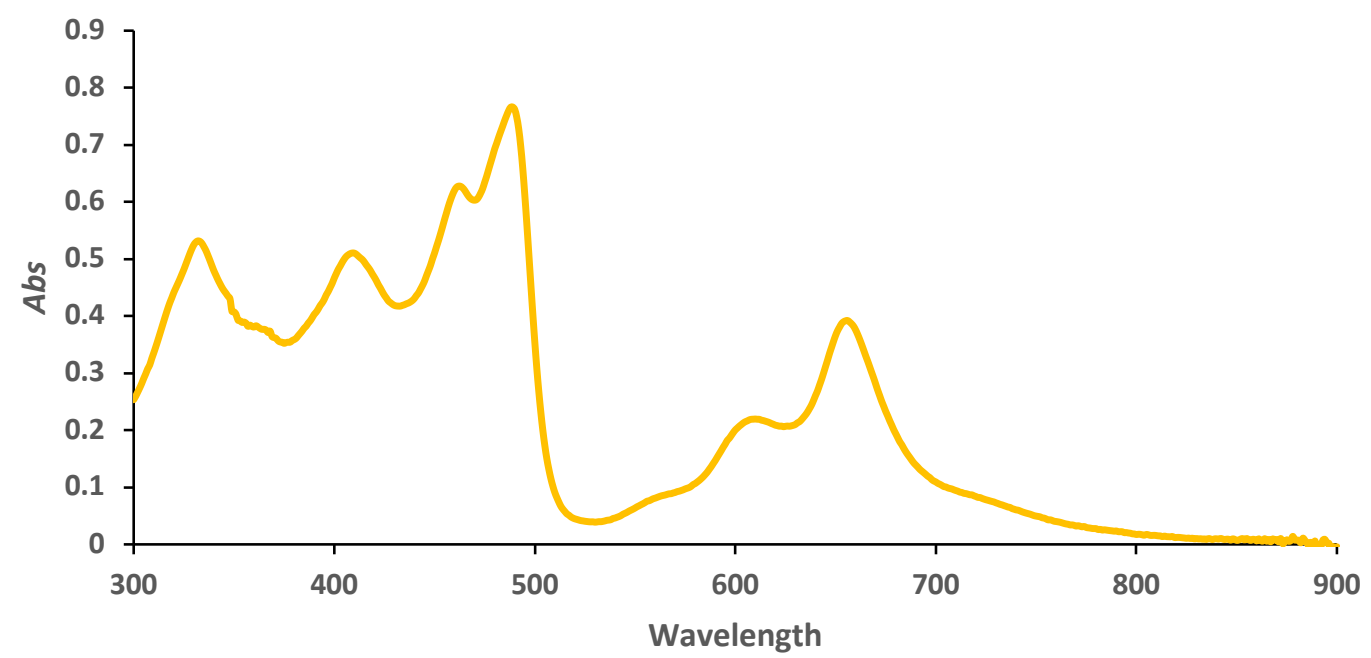

Figure A-45. UV-Vis spectrum of oxyquinoliziniporphyrin $\mathbf{8 4 b}$ in $1 \% \mathrm{TEA}-\mathrm{CH}_{2} \mathrm{Cl}_{2}$ 117 


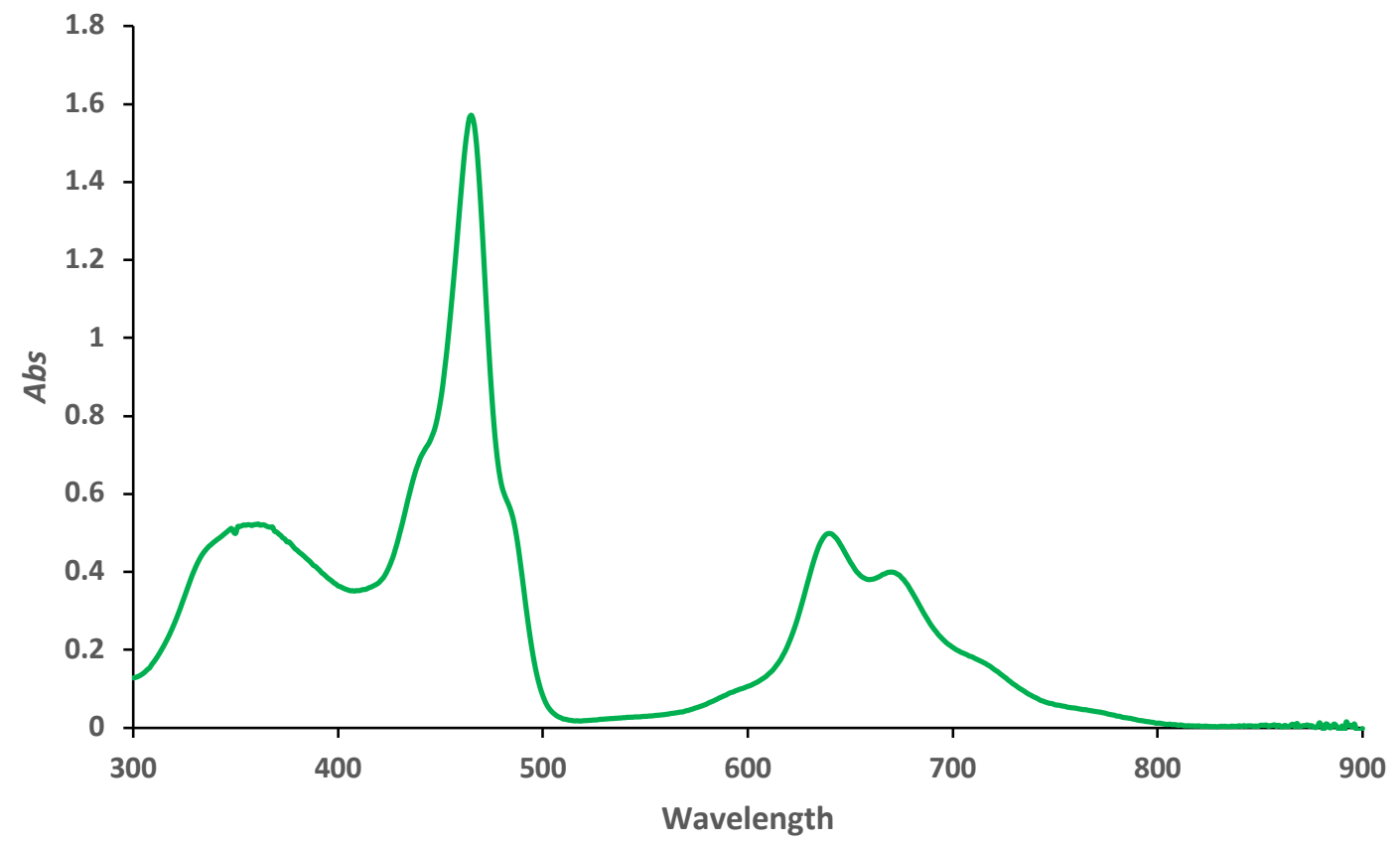

Figure A-46. UV-Vis spectrum of oxyquinoliziniporphyrin $\mathbf{8 4 \mathbf { b }}$ in 5 eq TFA- $\mathrm{CH}_{2} \mathrm{Cl}_{2}$

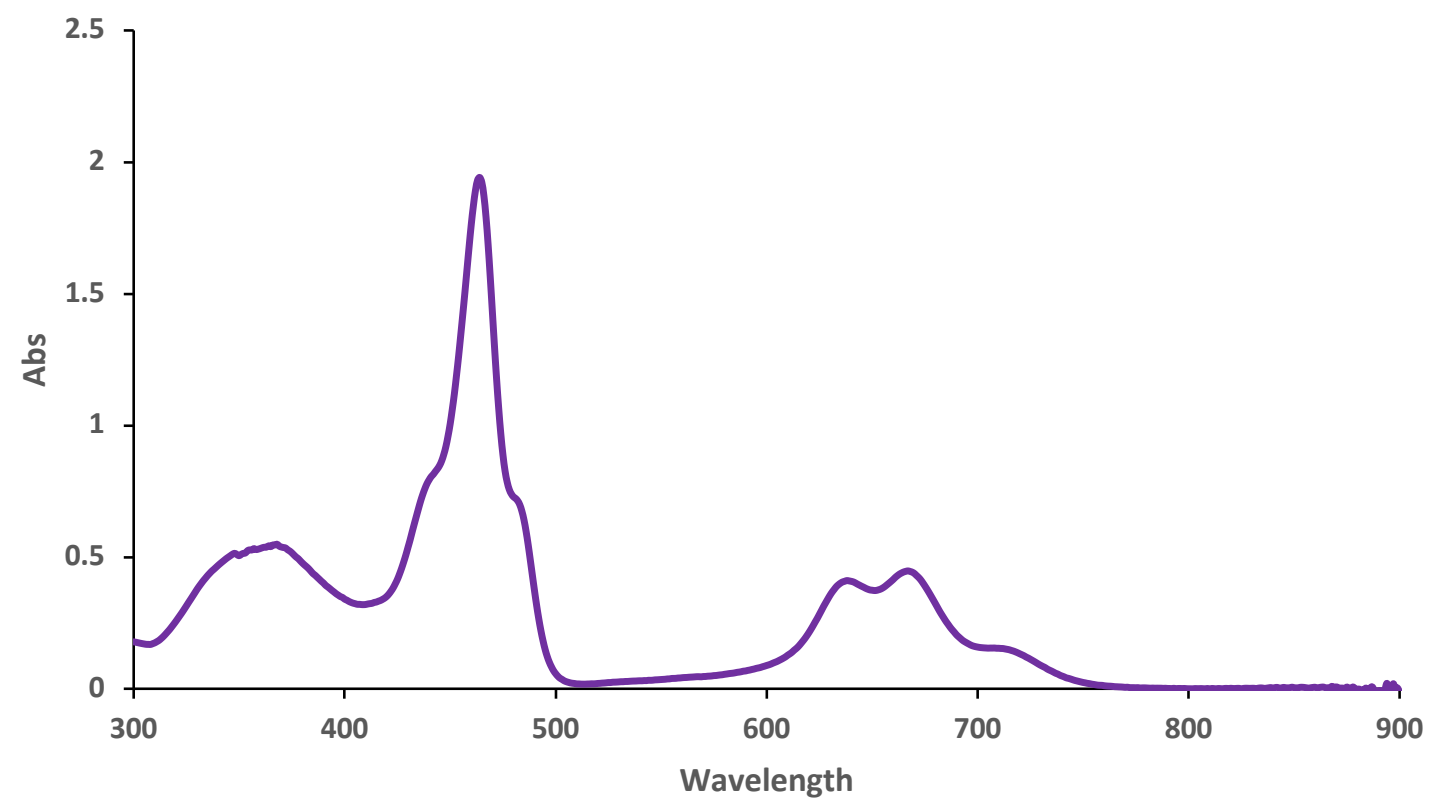

Figure A-47. UV-Vis spectrum of oxyquinoliziniporphyrin $\mathbf{8 4 \mathbf { b }}$ in $10 \% \mathrm{TFA}-\mathrm{CH}_{2} \mathrm{Cl}_{2}$ 


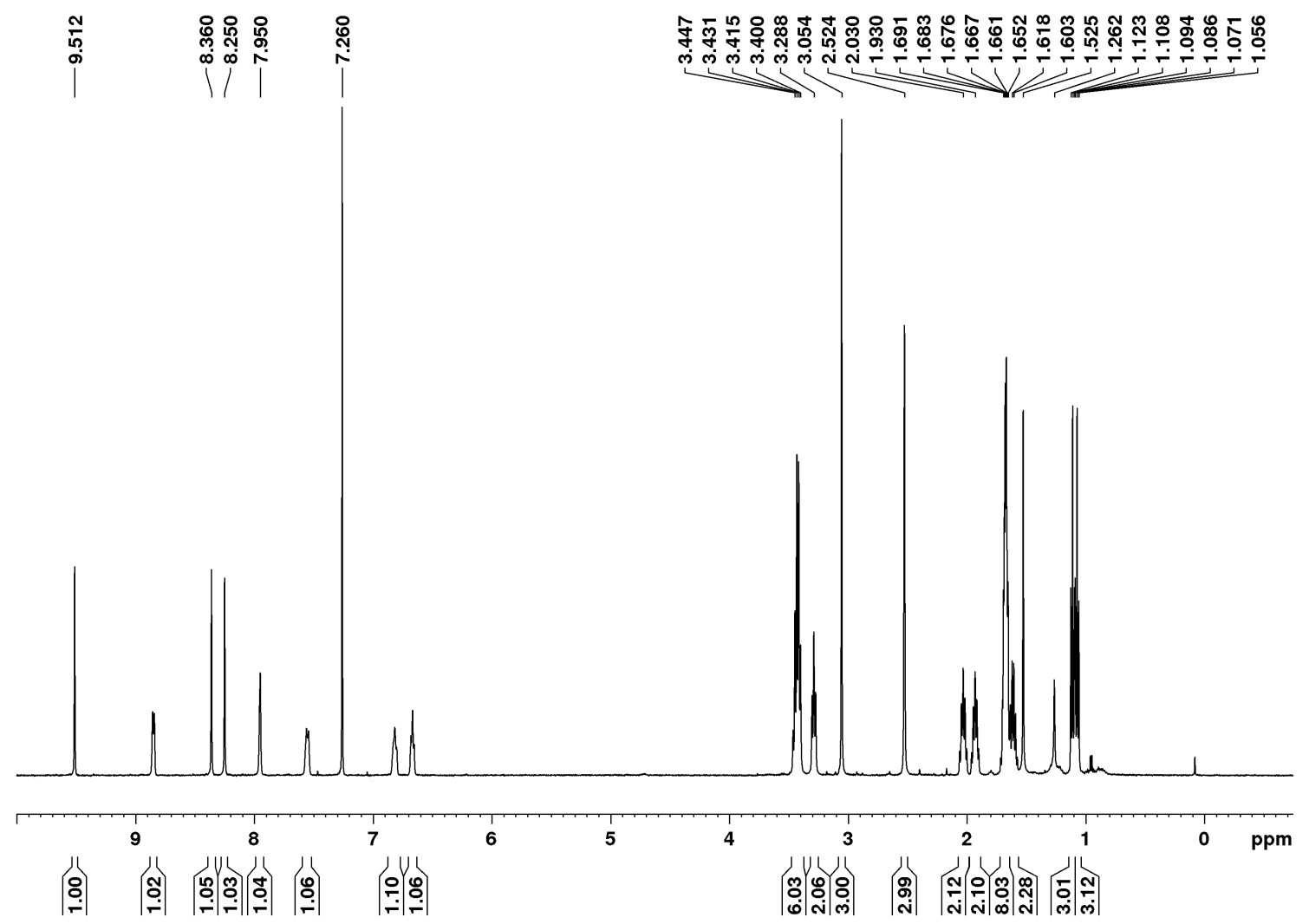

Figure A-48. $500 \mathrm{MHz}{ }^{1} \mathrm{HNMR}$ spectrum of palladium(II) complex $106 \mathbf{b}$ in $\mathrm{CDCl}_{3}$ 


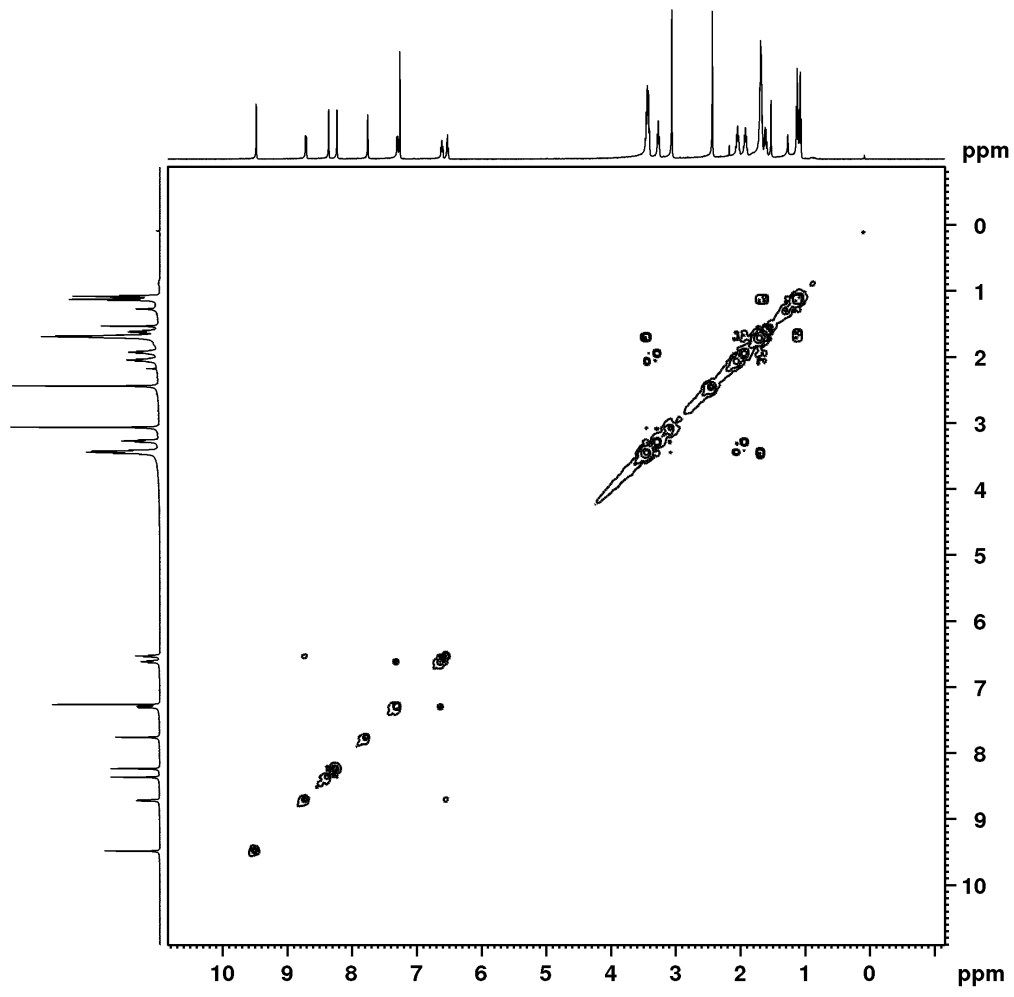

Figure A-49. ${ }^{1} \mathrm{H}-{ }^{1} \mathrm{H}$ COSY NMR spectrum of palladium(II) complex $\mathbf{1 0 6}$ in $\mathrm{CDCl}_{3}$ 


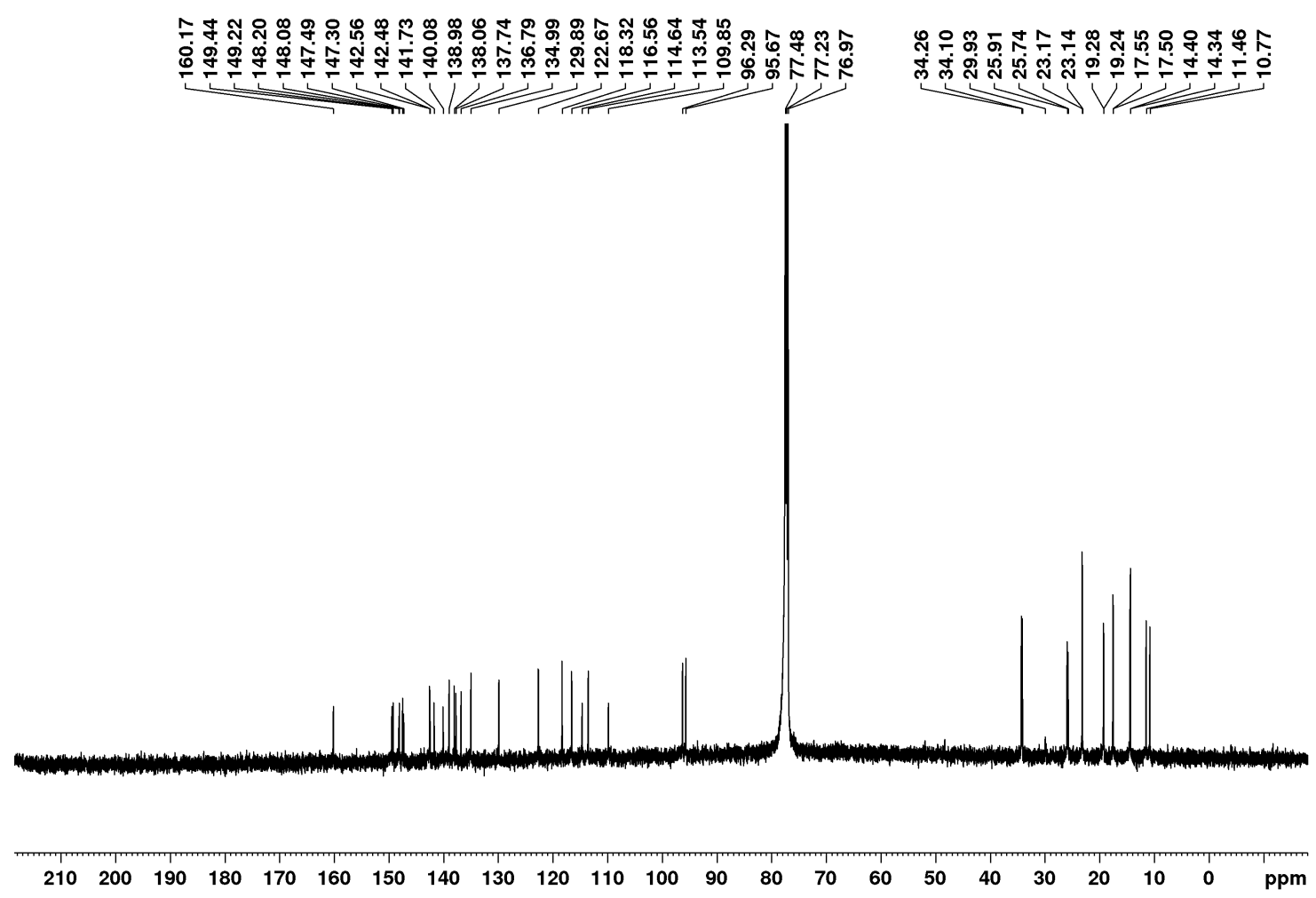

Figure A-50. $125 \mathrm{MHz}{ }^{13} \mathrm{C}$ NMR spectrum of palladium(II) complex $\mathbf{1 0 6}$ in $\mathrm{CDCl}_{3}$ 


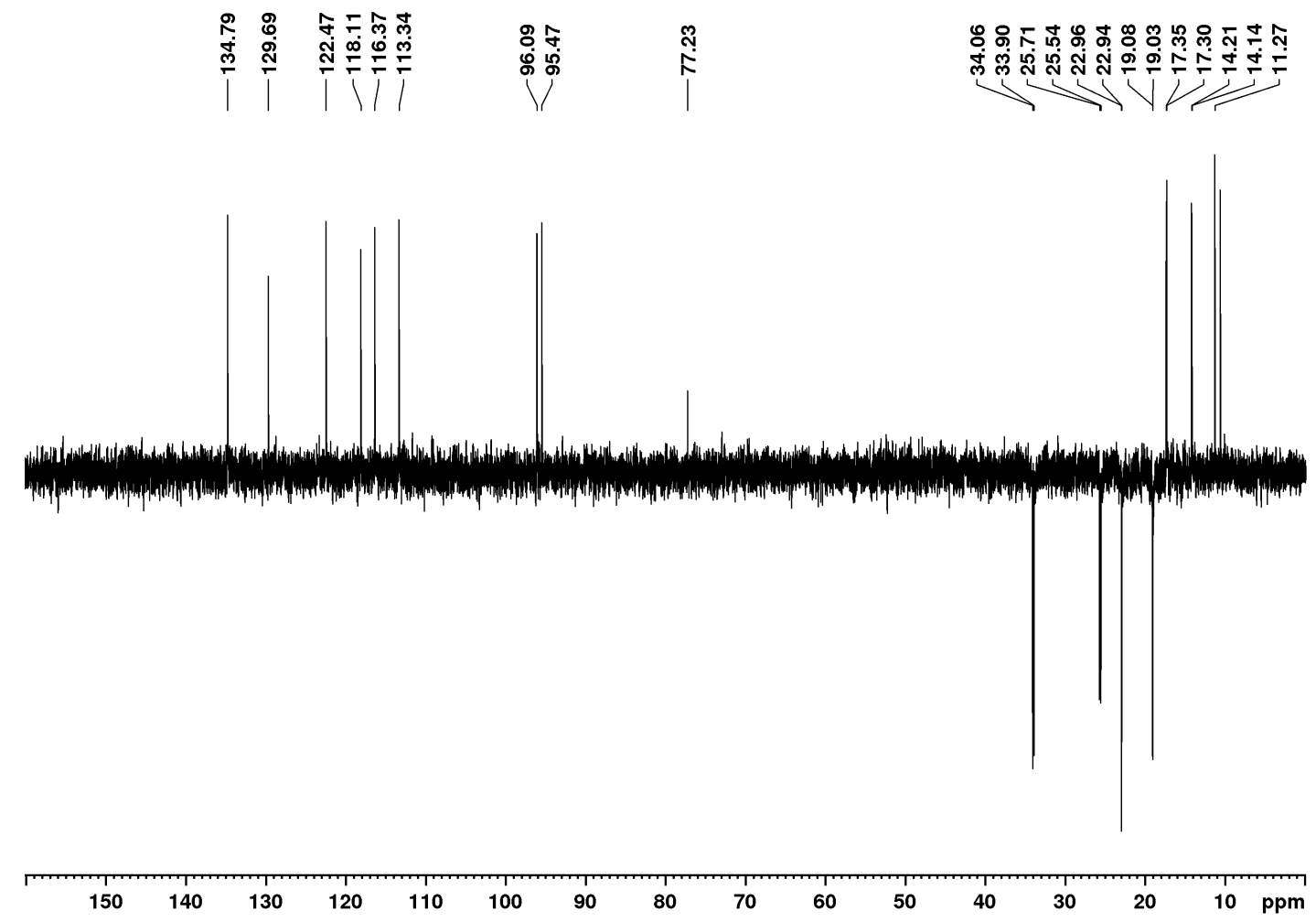

Figure A-51. DEPT 135 NMR spectrum of palladium(II) complex $\mathbf{1 0 6} \mathbf{b}$ in $\mathrm{CDCl}_{3}$ 


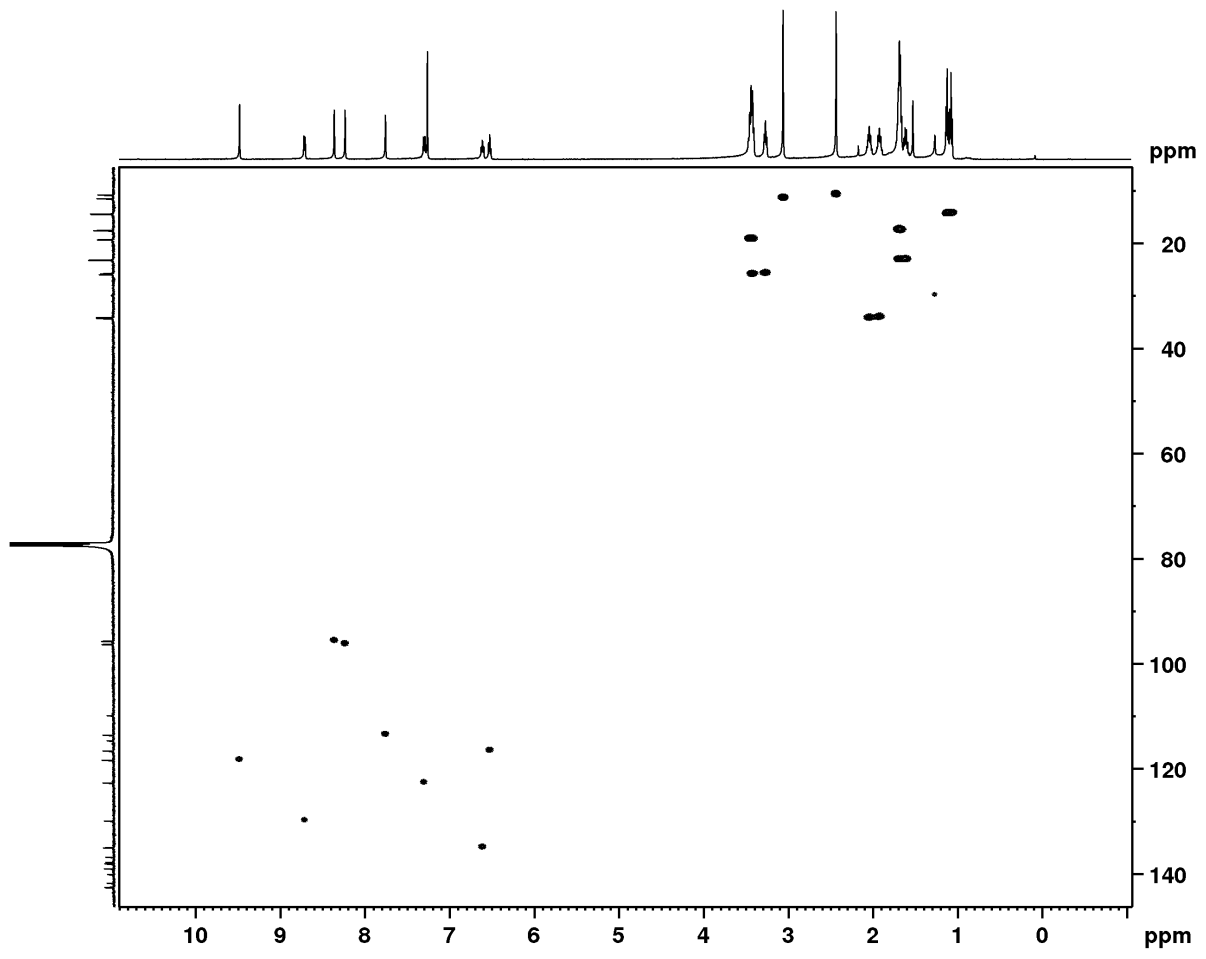

Figure A-52. HSQC NMR spectrum of palladium(II) complex $\mathbf{1 0 6}$ in $\mathrm{CDCl}_{3}$ 


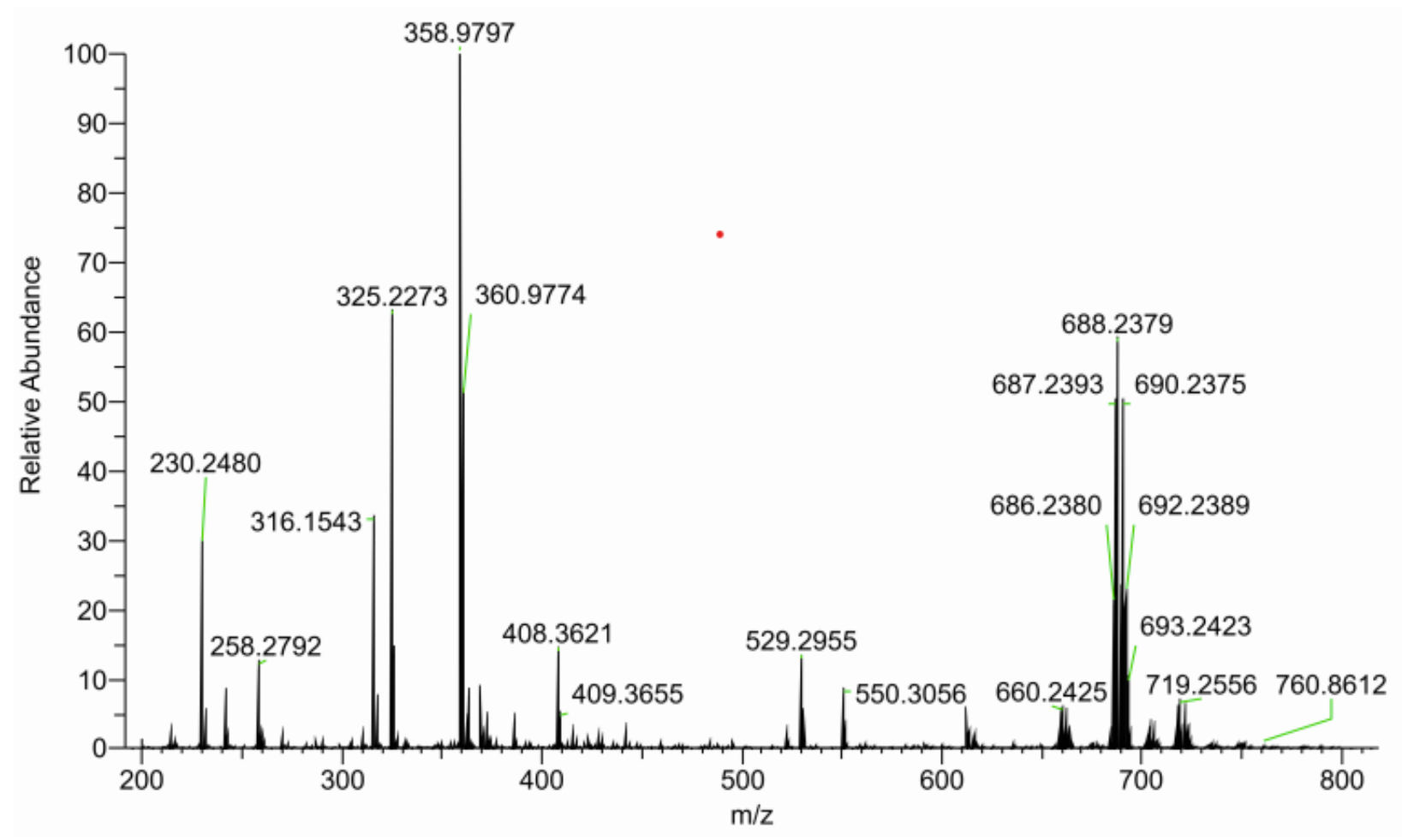

Figure A-53. ESI Mass spectrum of palladium(II) complex 106b in $\mathrm{CHCl}_{3}$

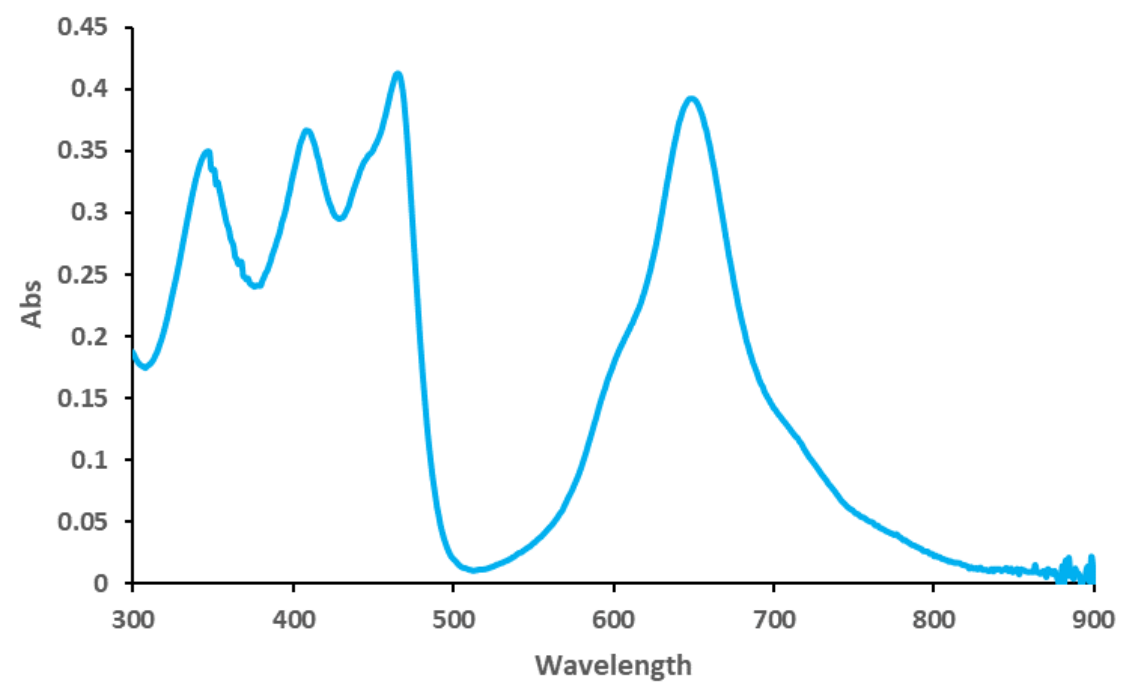

Figure A-54. UV-Vis spectrum of palladium(II) complex $\mathbf{1 0 6} \mathbf{b}$ in $\mathrm{CH}_{2} \mathrm{Cl}_{2}$ 


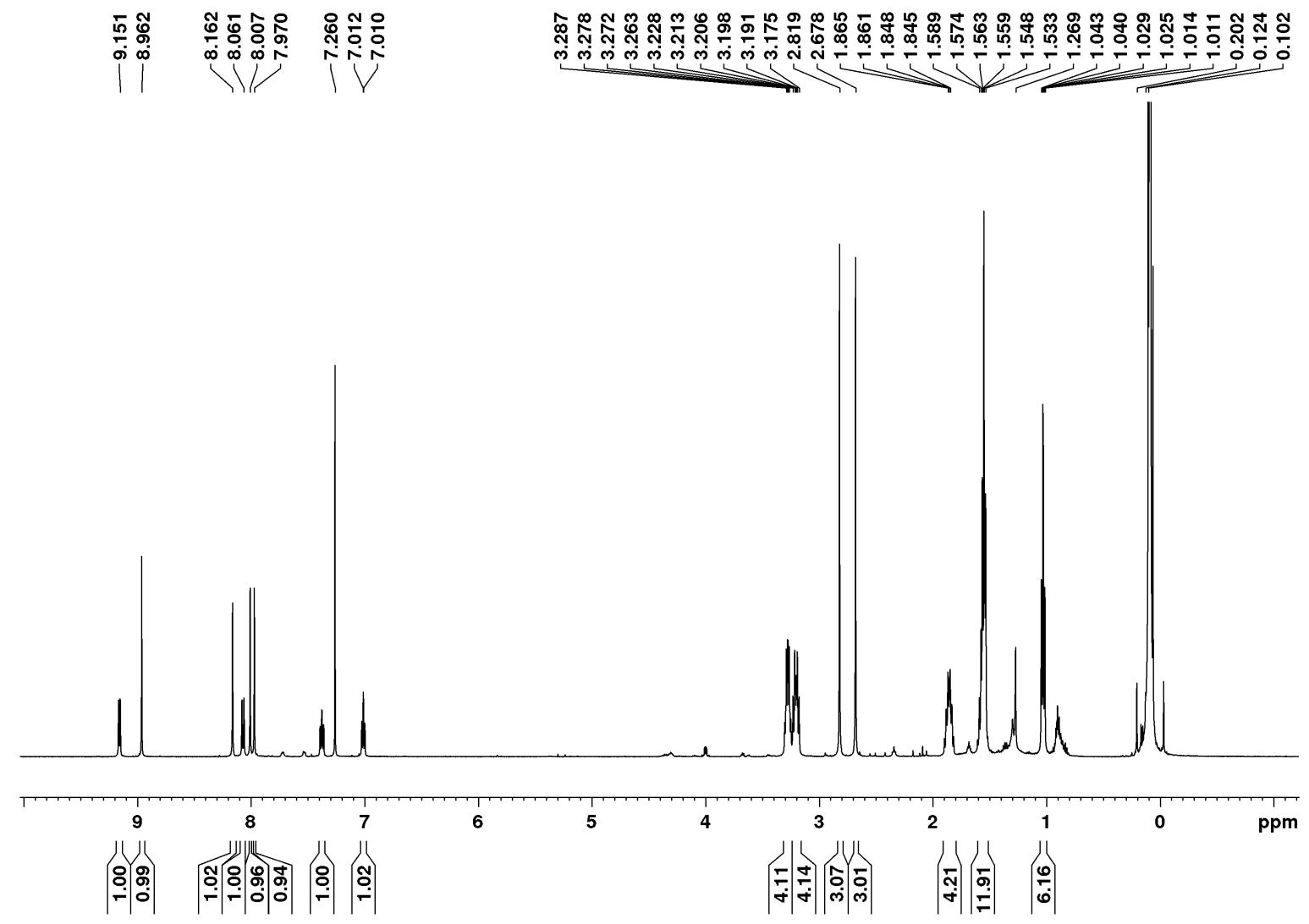

Figure A-55. $500 \mathrm{MHz}{ }^{1} \mathrm{HNMR}$ spectrum of nickel(II) complex 107b in $\mathrm{CDCl}_{3}$ 


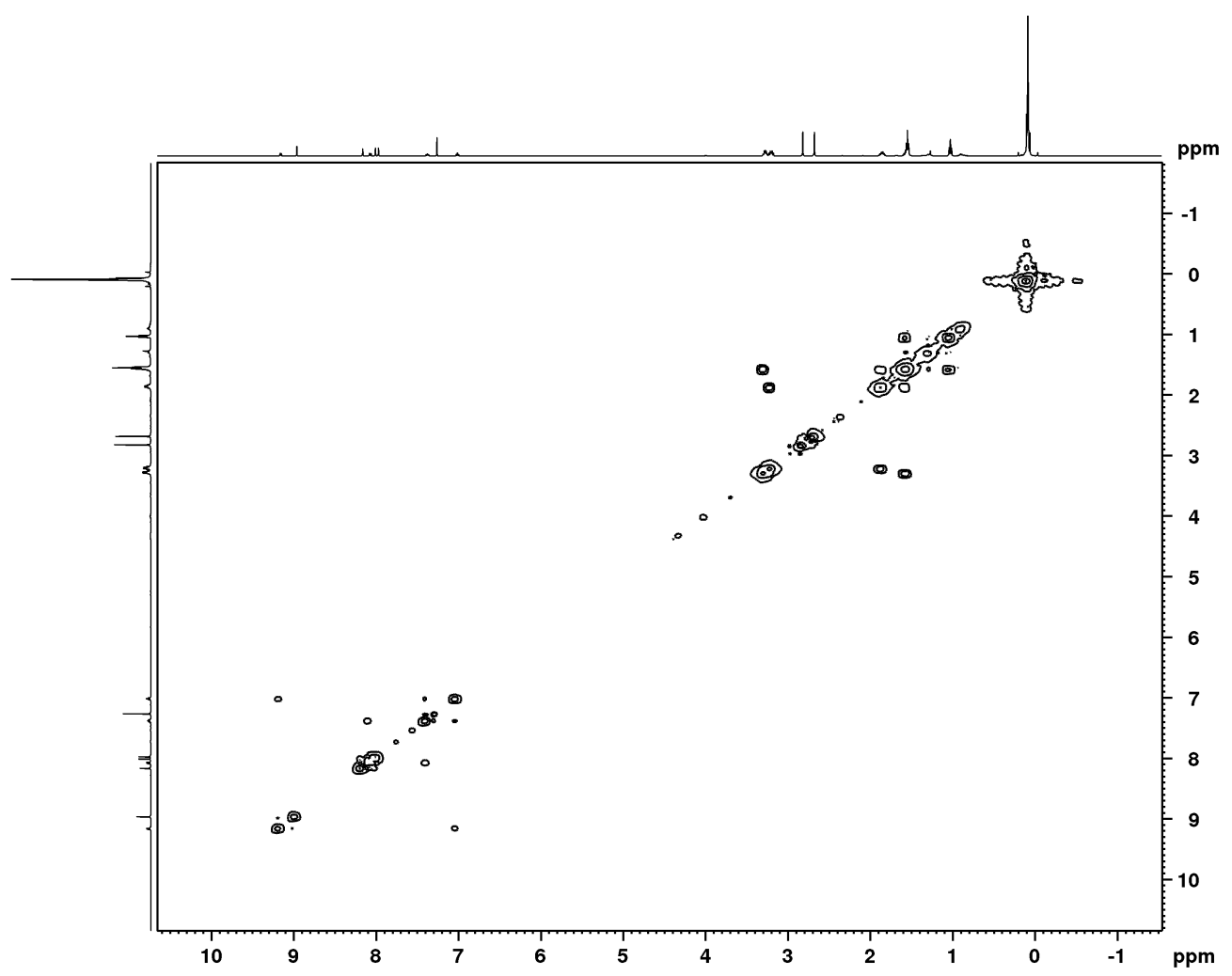

Figure A-56. ${ }^{1} \mathrm{H}-{ }^{1} \mathrm{H}$ COSY NMR spectrum of nickel(II) complex $107 \mathbf{b}$ in $\mathrm{CDCl}_{3}$ 


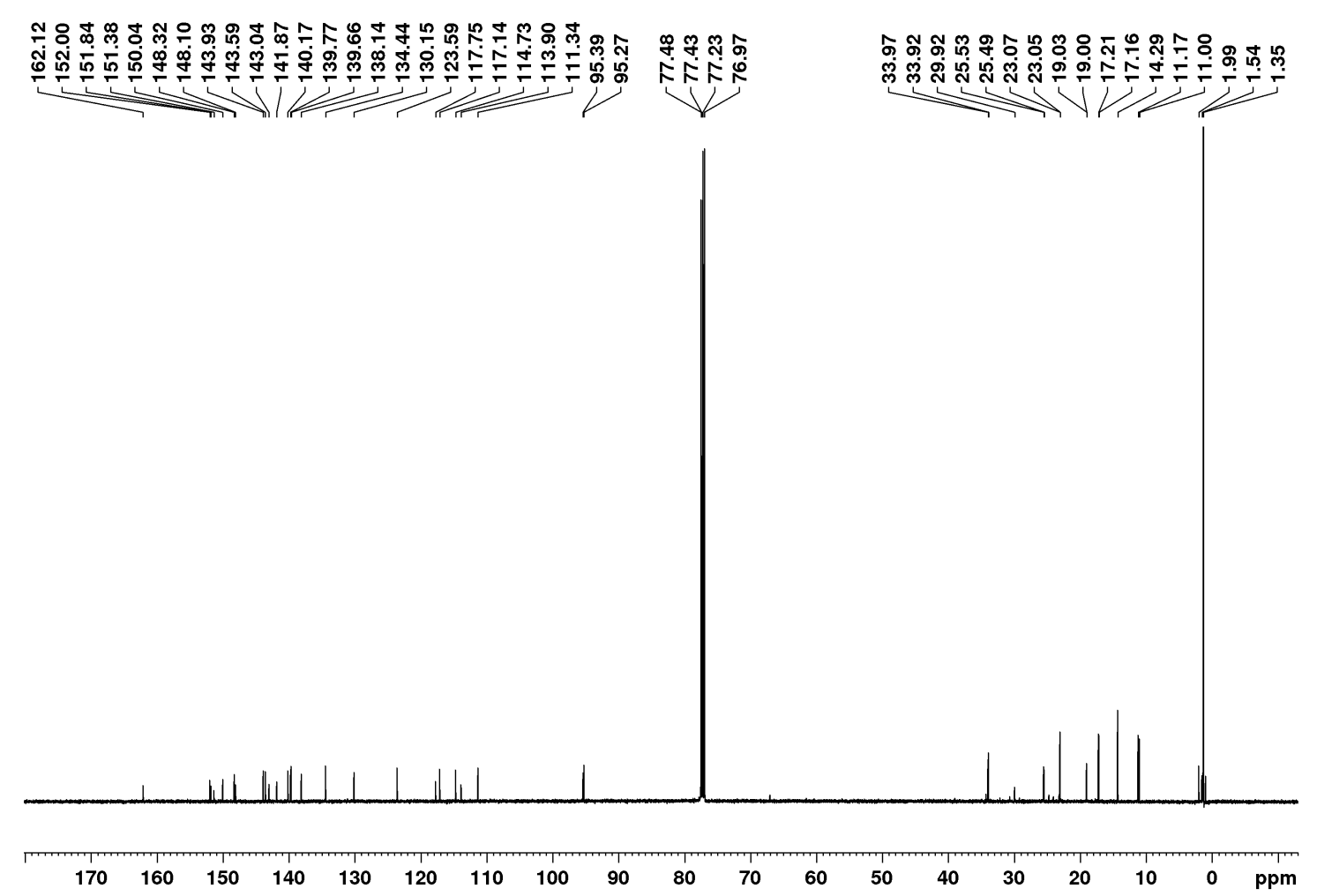

Figure A-57. $125 \mathrm{MHz}{ }^{13} \mathrm{C}$ NMR spectrum of nickel(II) complex 107b in $\mathrm{CDCl}_{3}$ 


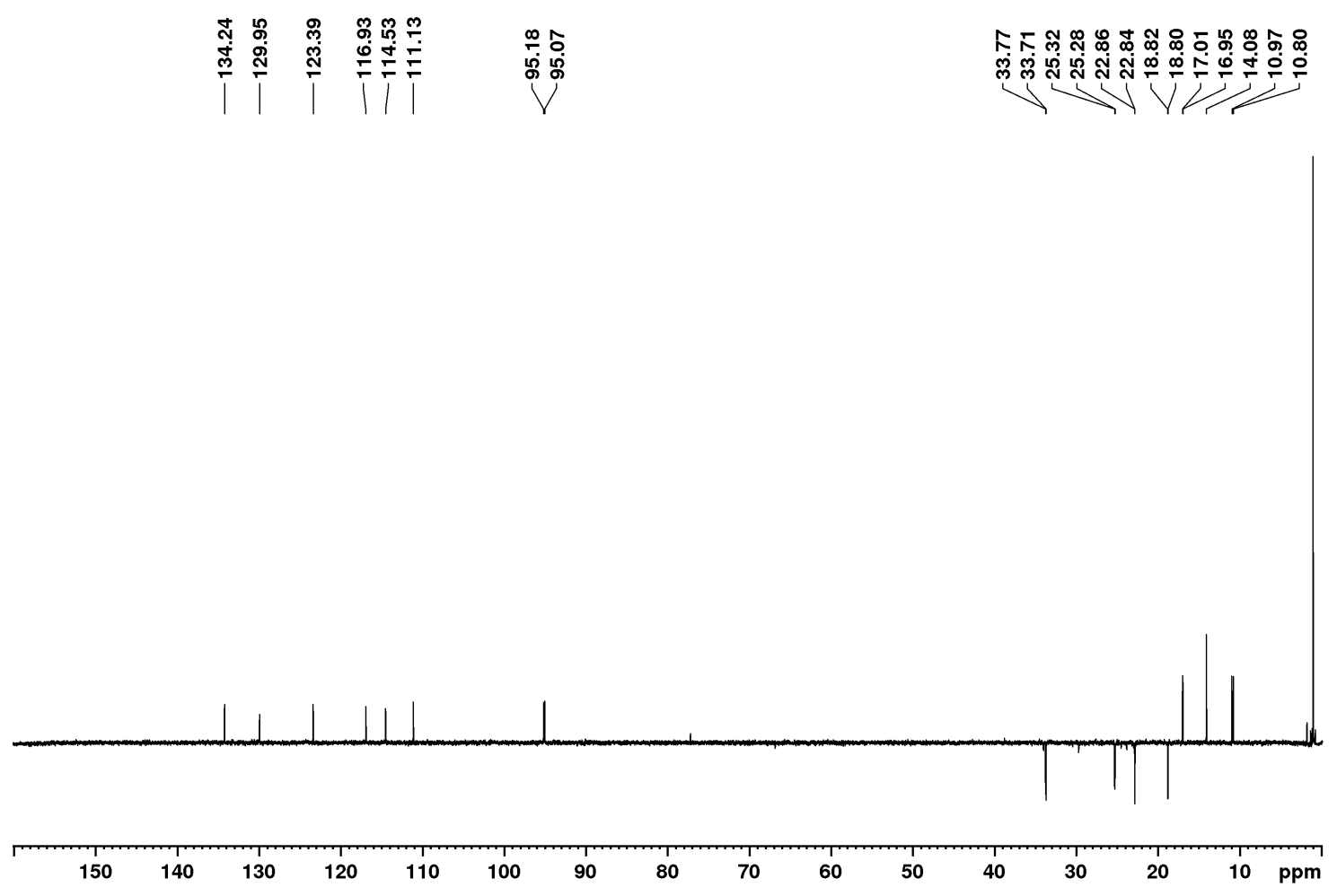

Figure A-58. DEPT $135 \mathrm{NMR}$ spectrum of nickel(II) complex $\mathbf{1 0 7}$ b in $\mathrm{CDCl}_{3}$ 


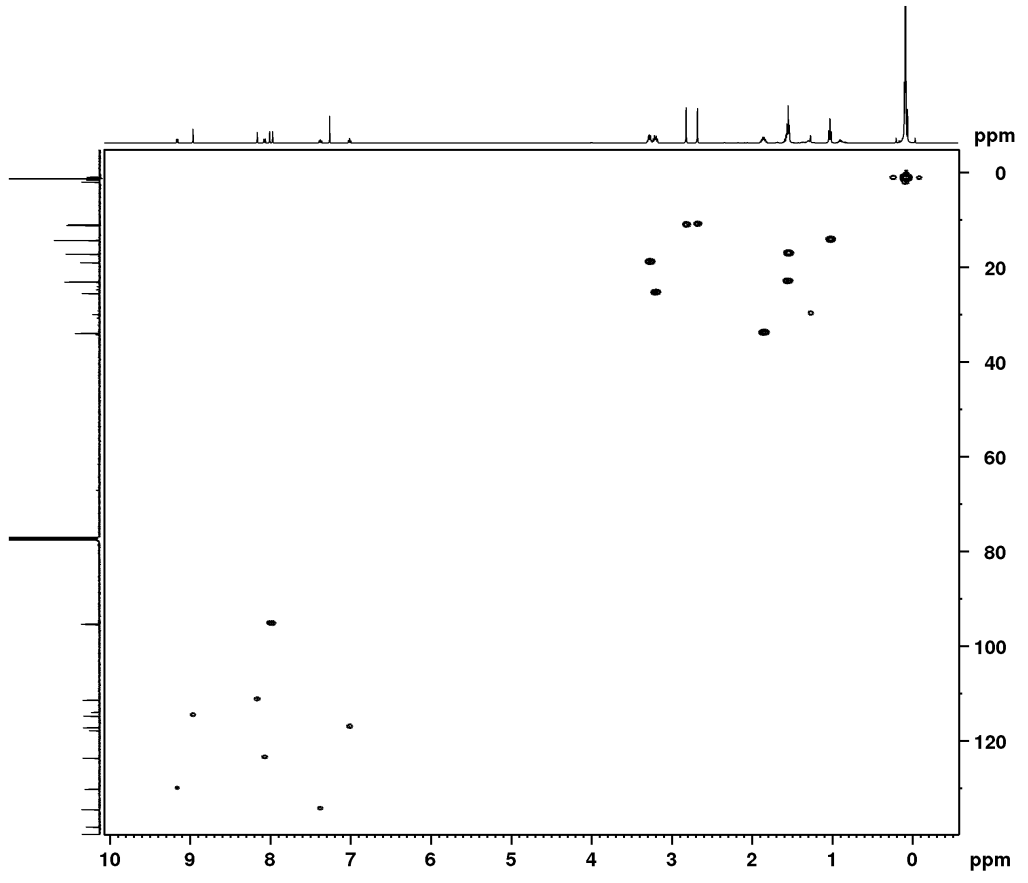

Figure A-59. HSQC NMR spectrum of nickel(II) complex $\mathbf{1 0 7 b}$ in $\mathrm{CDCl}_{3}$

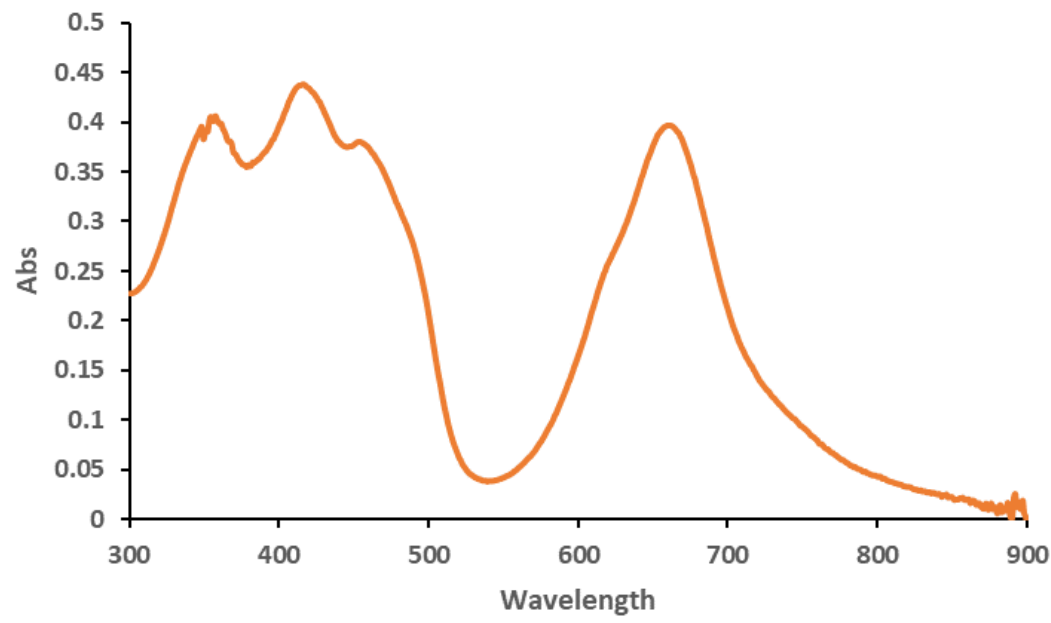

Figure A-60. UV-Vis spectrum of nickel(II) complex 107b in $\mathrm{CH}_{2} \mathrm{Cl}_{2}$ 


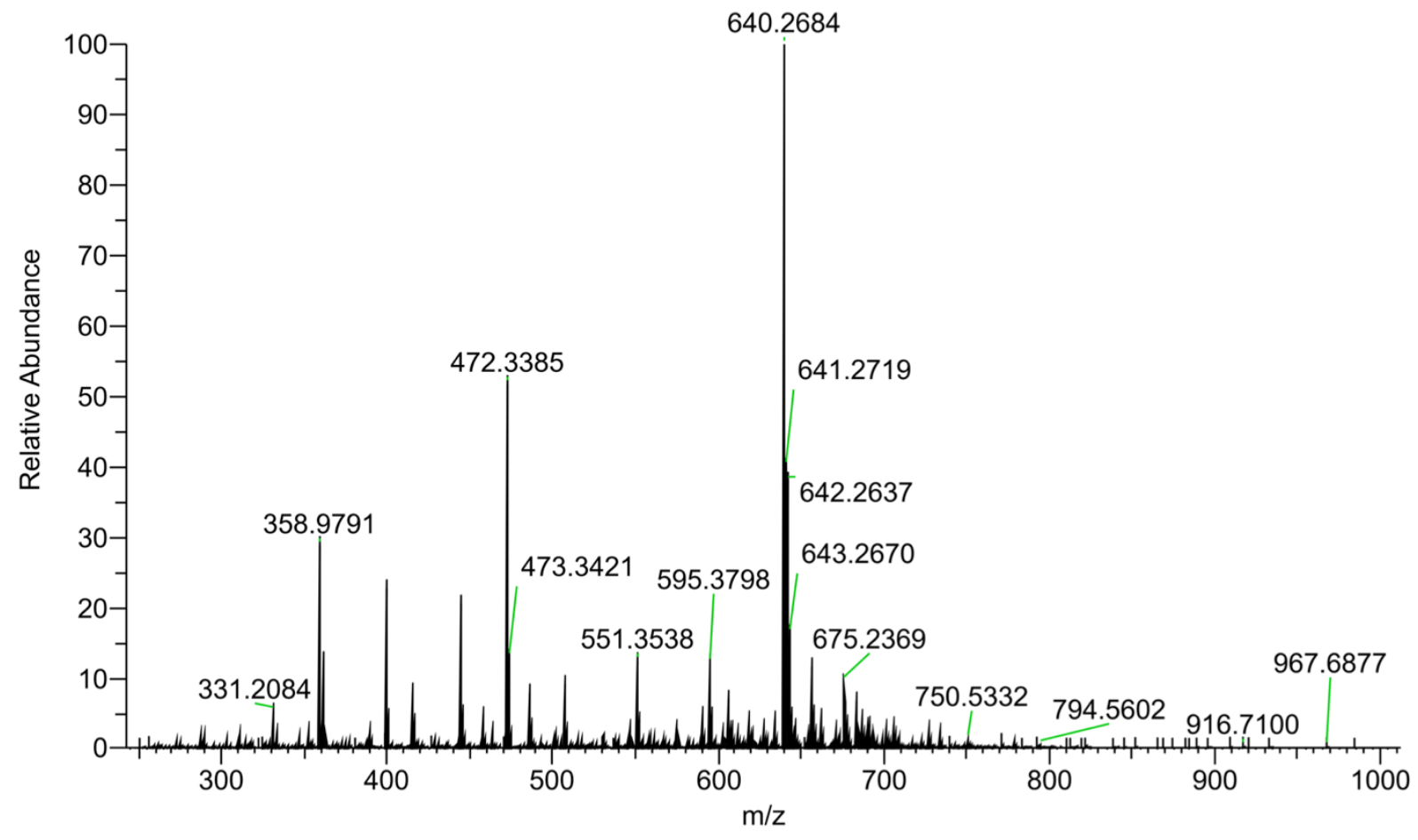

Figure A-61. ESI Mass spectrum of nickel(II) complex 107b 


\section{APPENDIX B: SELECTED SPECTROSCOPIC DATA FOR THE SYNTHESIS OF PYRIDOQUINOLIZINIPORPHYRIN}

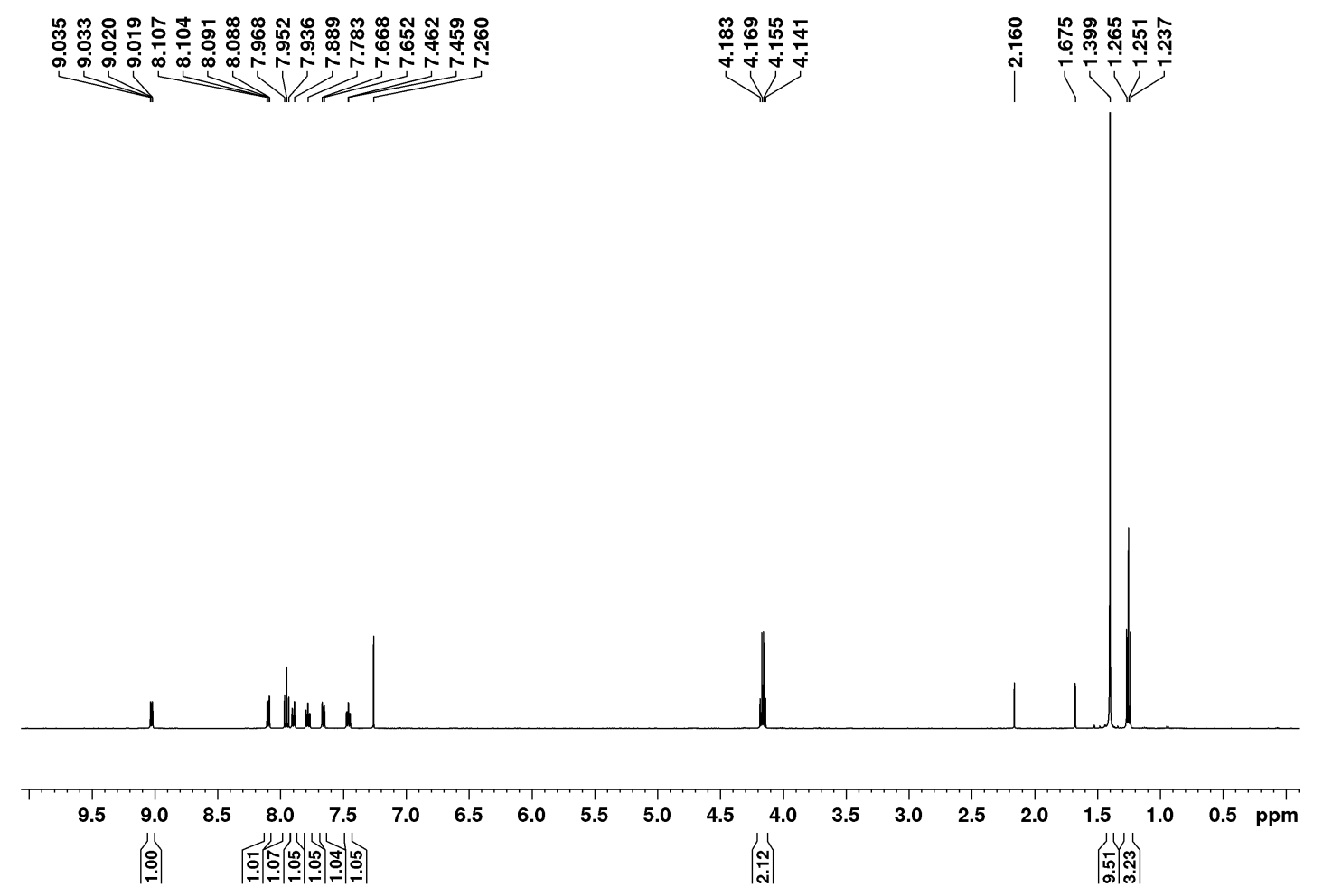

Figure B-1. $500 \mathrm{MHz}{ }^{1} \mathrm{H}$ NMR spectrum of tert-butyl ethyl 4H-quinolizin-4-ylidenemalonate (115) in $\mathrm{CDCl}_{3}$ 


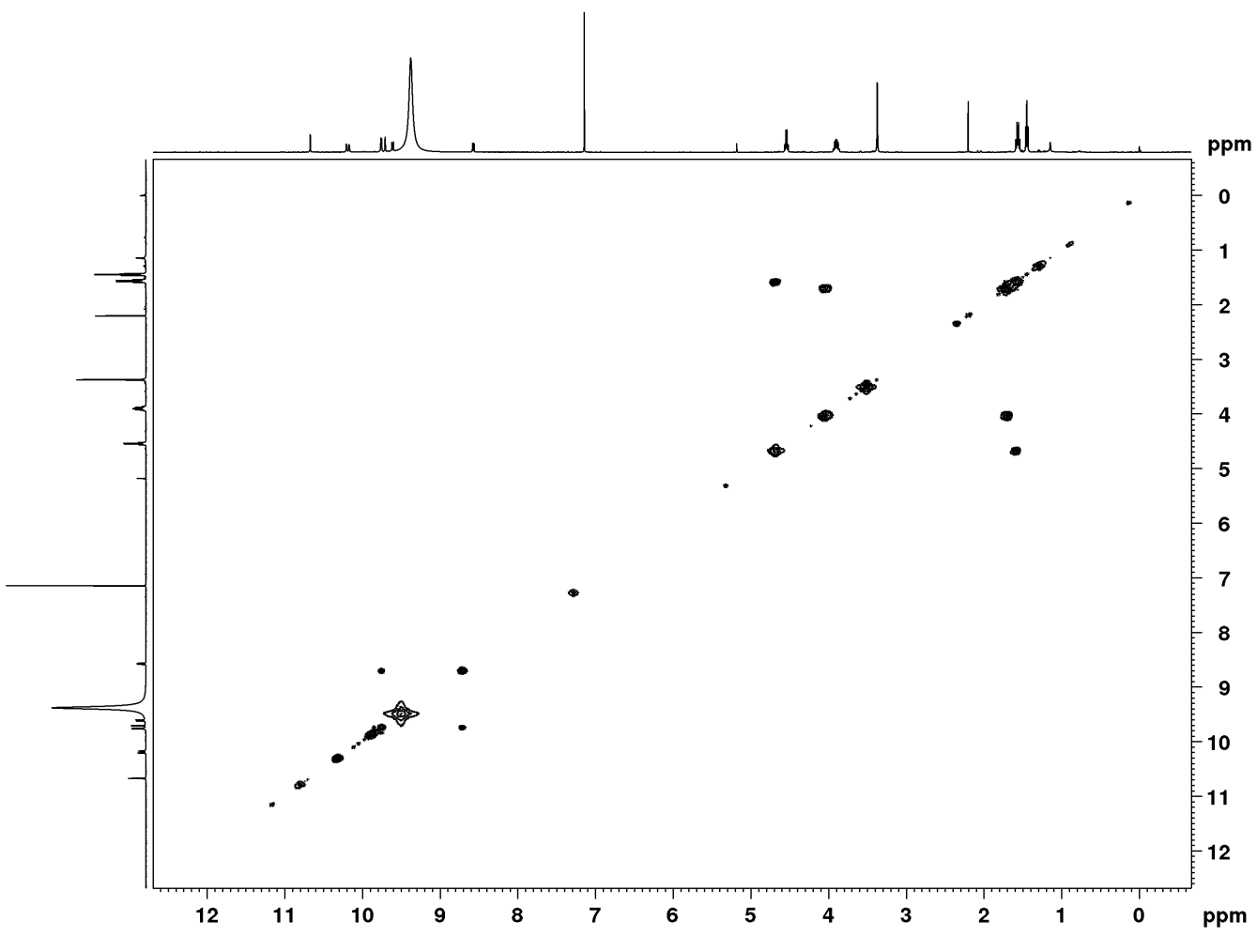

Figure B-2. ${ }^{1} \mathrm{H}-{ }^{1} \mathrm{H}$ COSY NMR spectrum of tert-butyl ethyl 4H-quinolizin-4-ylidenemalonate (115) in $\mathrm{CDCl}_{3}$ 


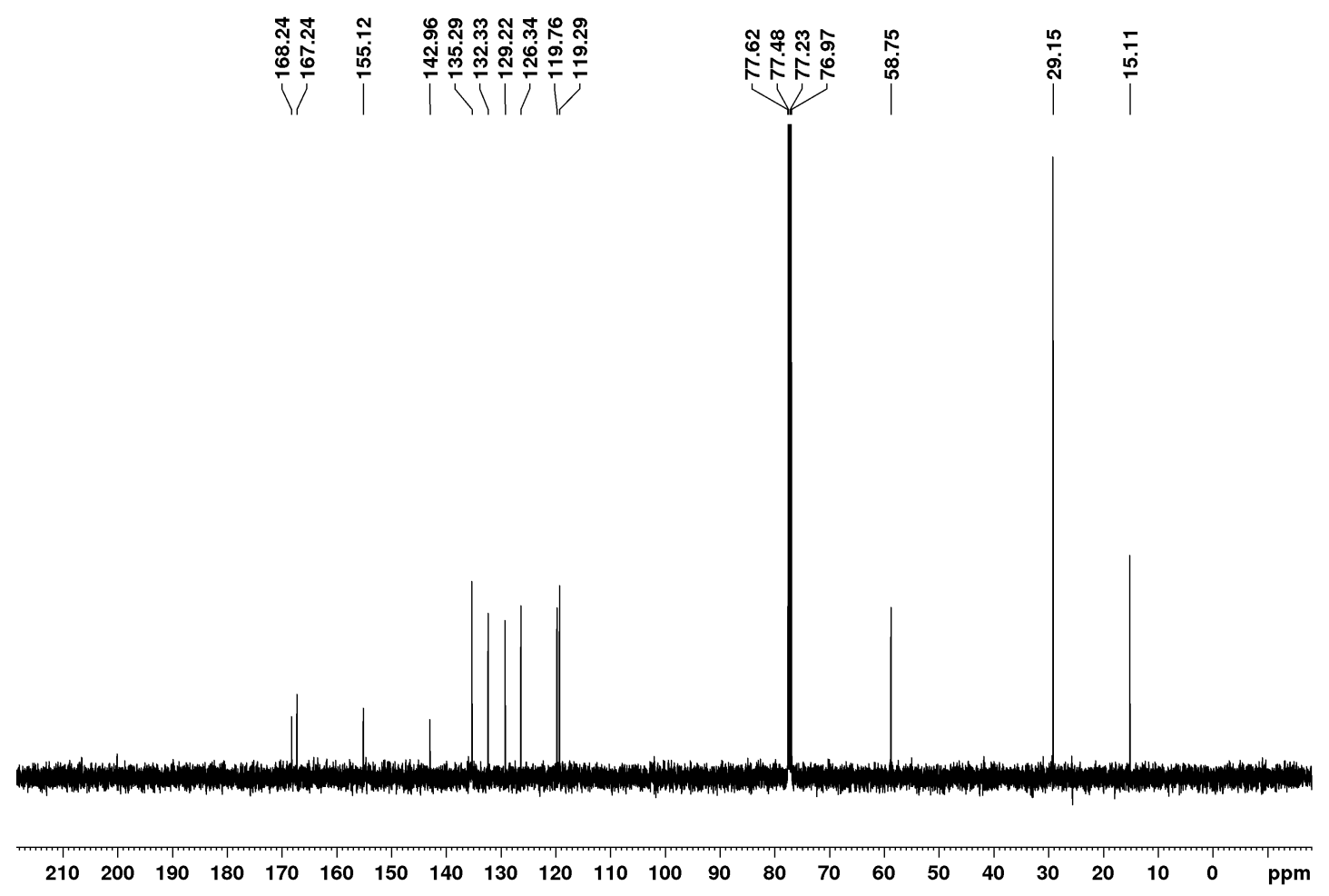

Figure B-3. $125 \mathrm{MHz}{ }^{13} \mathrm{C}$ NMR spectrum of tert-butyl ethyl $4 \mathrm{H}$-quinolizin-4-ylidenemalonate (115) in $\mathrm{CDCl}_{3}$ 


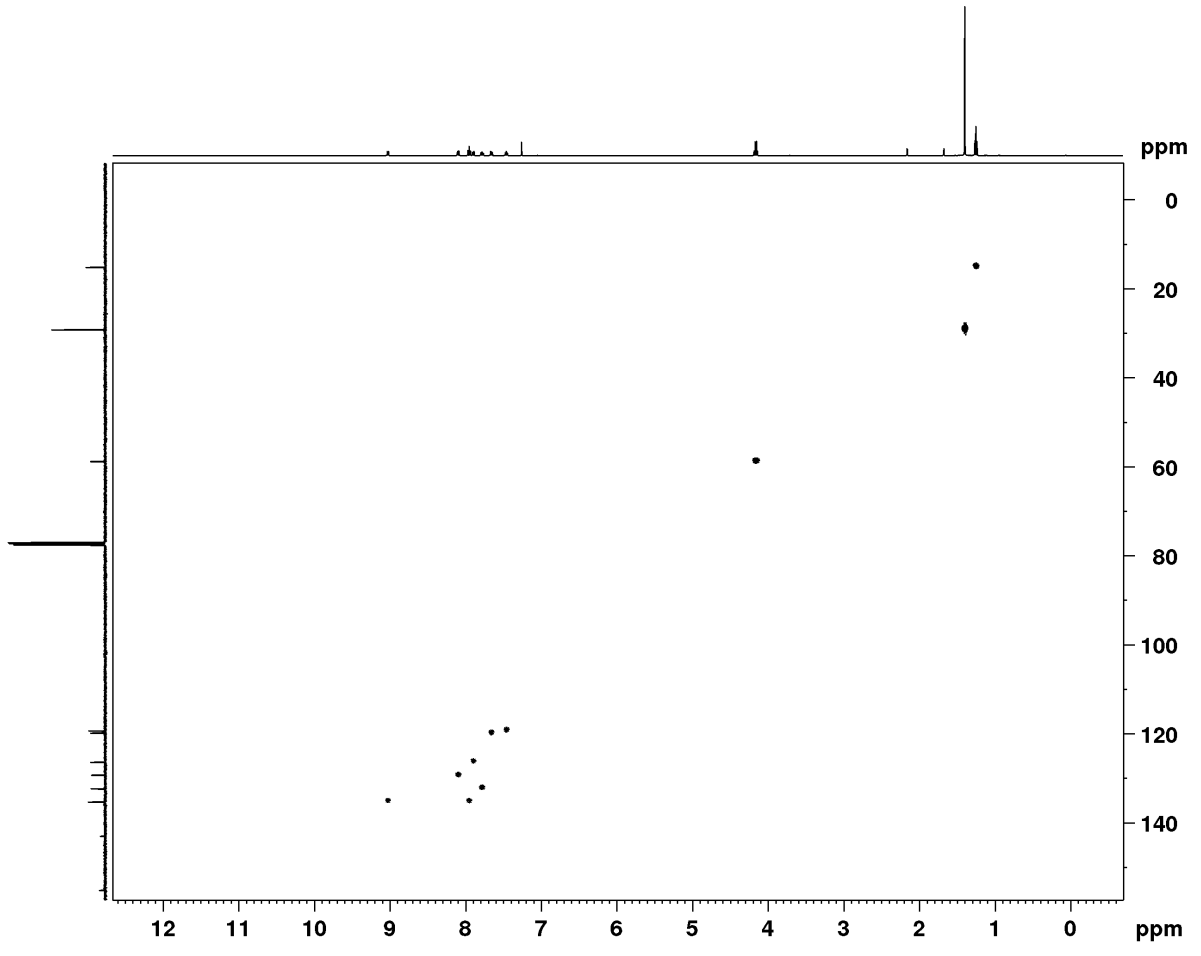

Figure B-4. HSQC NMR spectrum of tert-butyl ethyl 4H-quinolizin-4-ylidenemalonate (115) in $\mathrm{CDCl}_{3}$ 


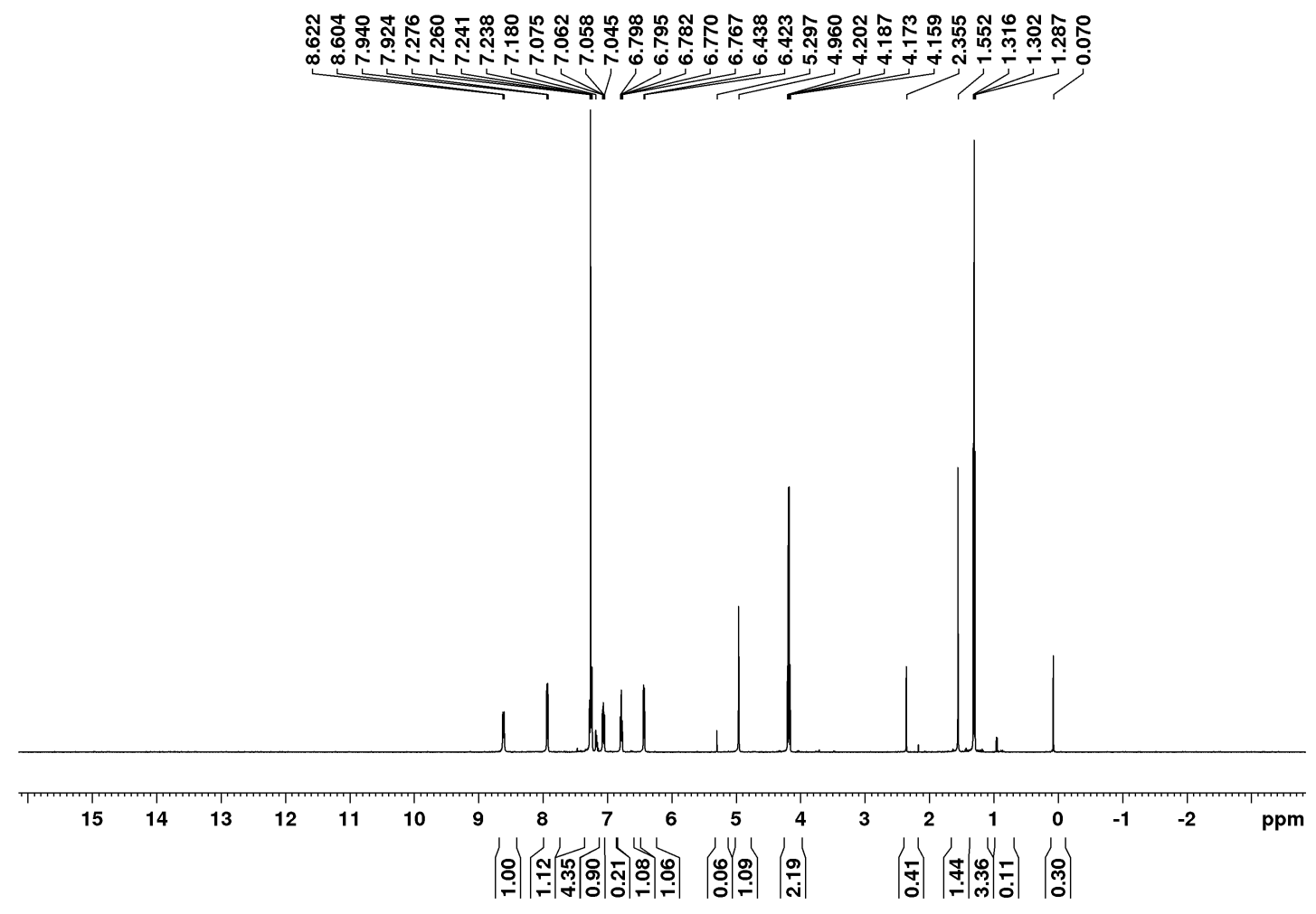

Figure B-5. $500 \mathrm{MHz}{ }^{1} \mathrm{H}$ NMR spectrum of ethyl 4H-quinolizin-4-ylidenemalonate (116) in $\mathrm{CDCl}_{3}$ 


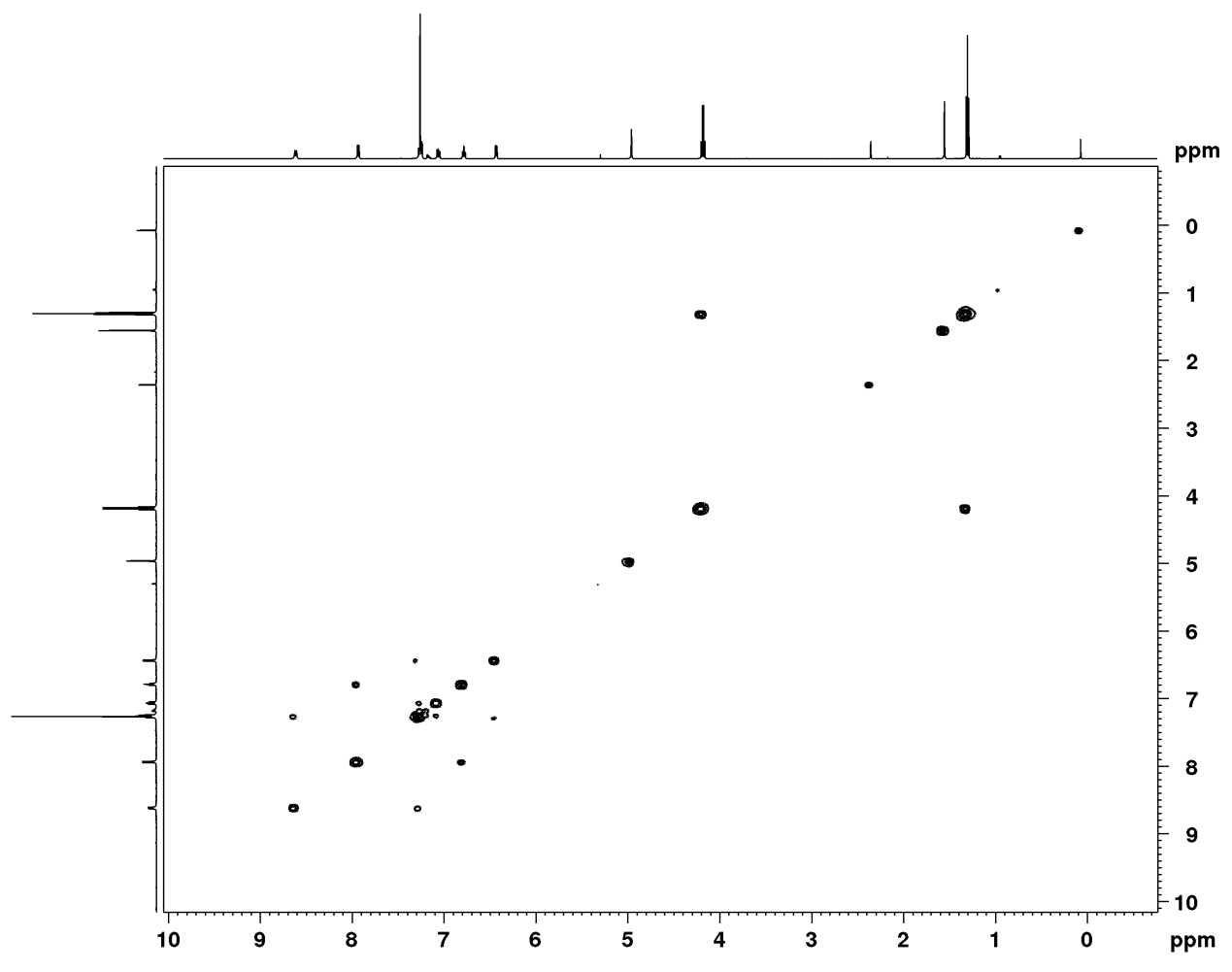

Figure B-6. ${ }^{1} \mathrm{H}-{ }^{1} \mathrm{H}$ COSY NMR spectrum of ethyl 4H-quinolizin-4-ylidenemalonate (116) in $\mathrm{CDCl}_{3}$ 


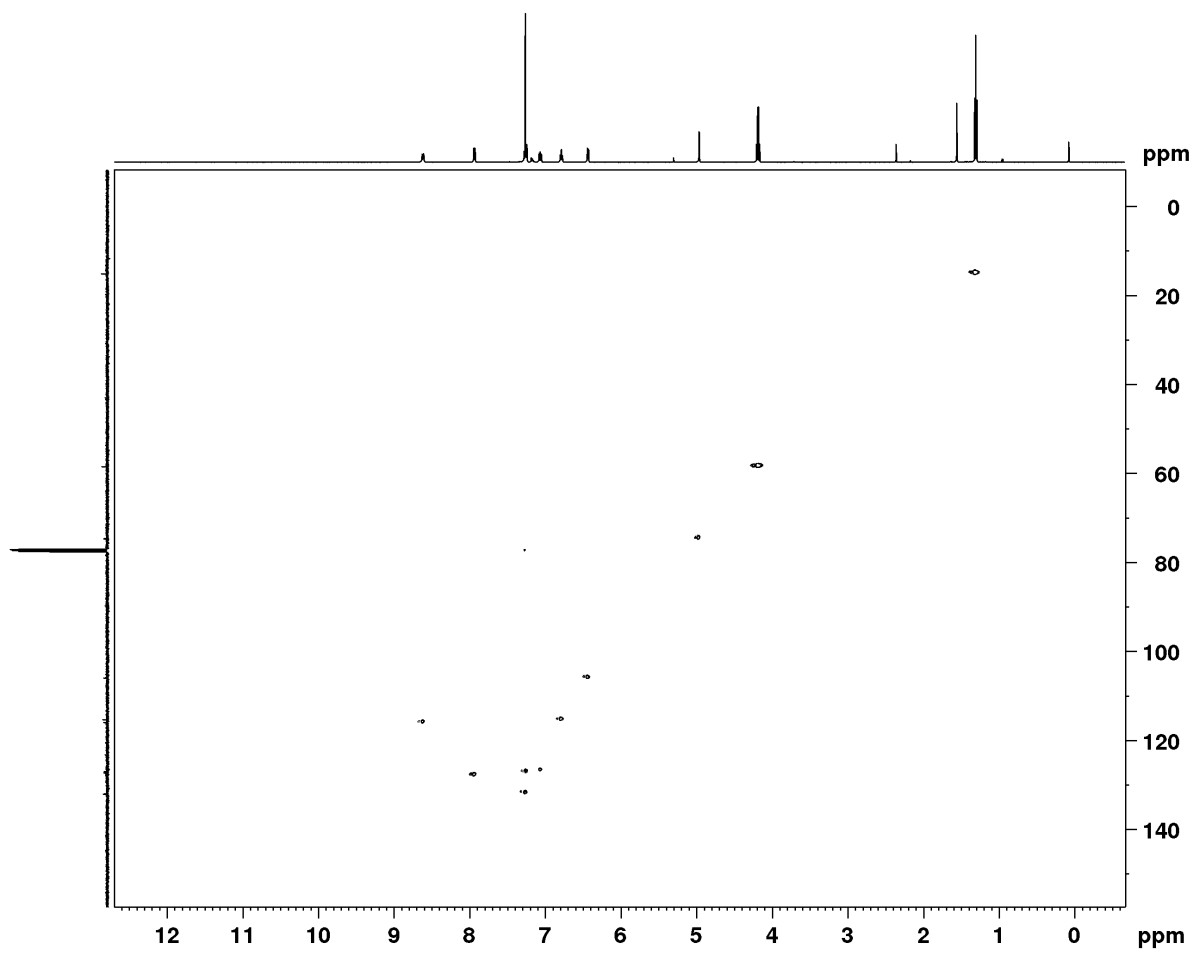

Figure B-7. HSQC NMR spectrum of ethyl 4H-quinolizin-4-ylidenemalonate (116) in $\mathrm{CDCl}_{3}$ 


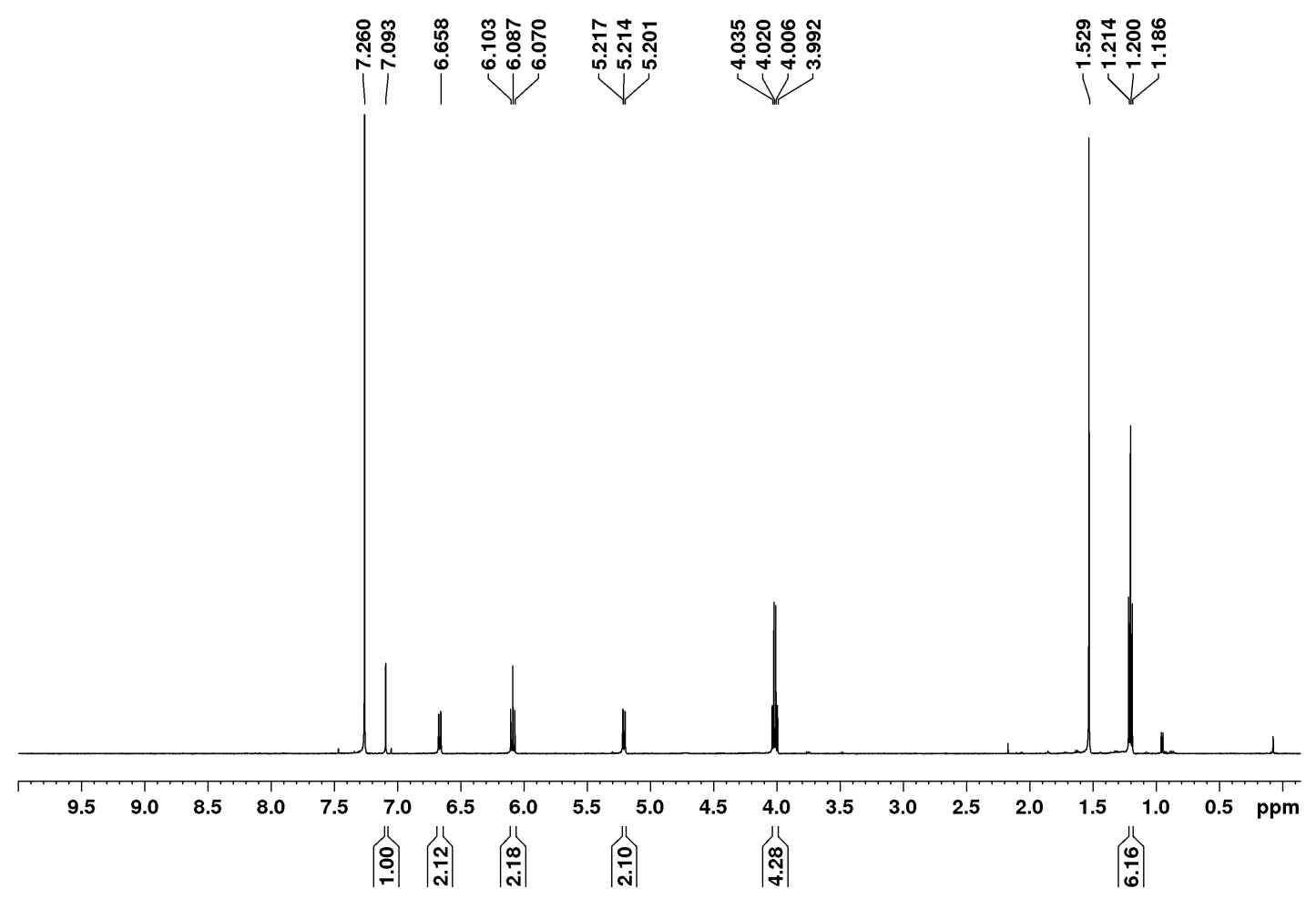

Figure B-8. $500 \mathrm{MHz}{ }^{1} \mathrm{H}$ NMR spectrum of diethyl pyrido[2,1,6-de]quinolizine-1,3dicarboxylate (117) in $\mathrm{CDCl}_{3}$. 